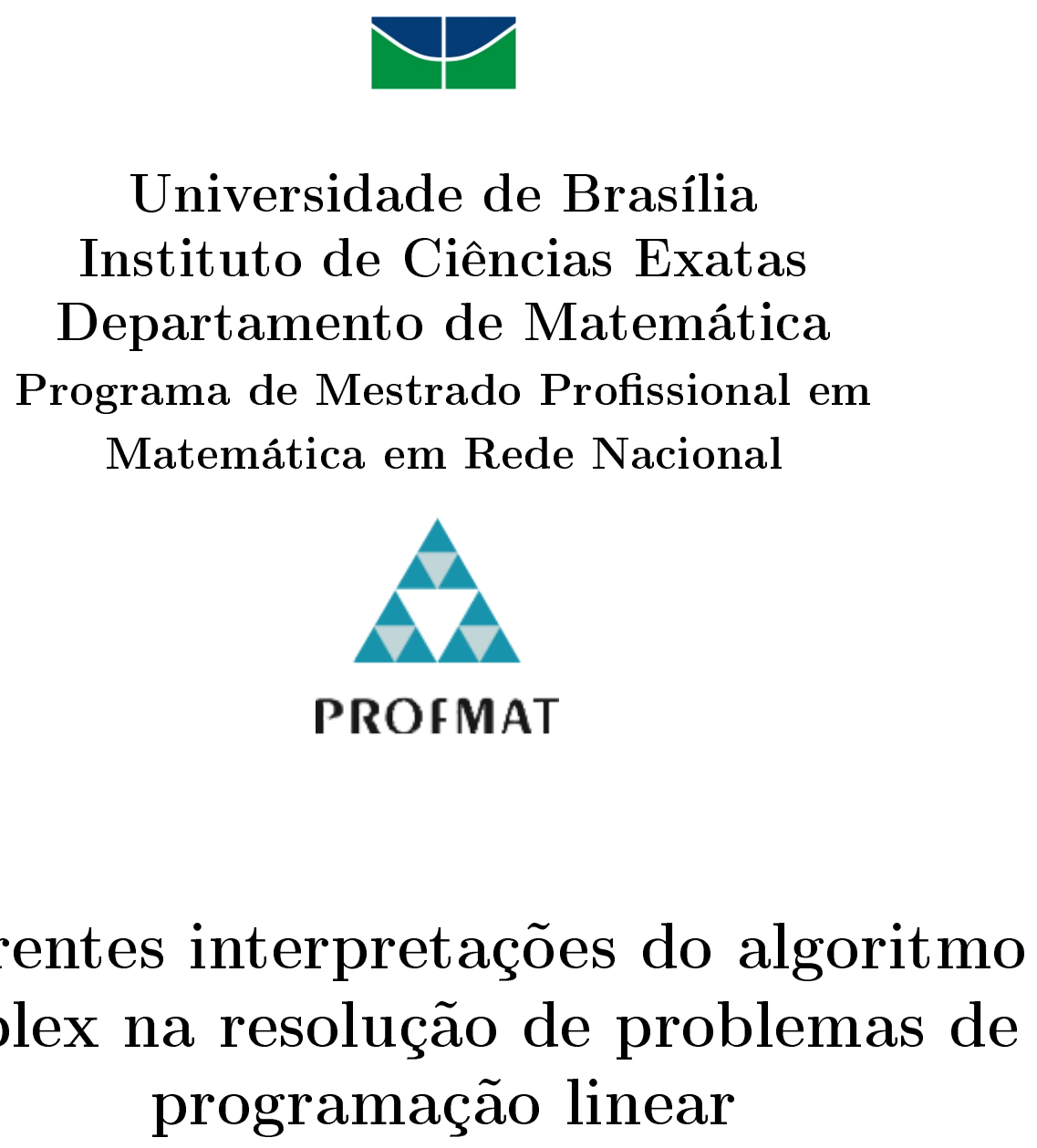
As diferentes interpretações do algoritmo simplex na resolução de problemas de programação linear

Marcelo Eustáquio Soares de Lima Júnior

Brasília 



\section{As diferentes interpretações do algoritmo simplex na resolução de problemas de programação linear}

Trabalho de Conclusão de Curso apresentado ao Departamento de Matemática da Universidade de Brasília, como parte dos requisitos para obtenção do grau de Mestre.

Orientador: Prof. Dr. Helder de Carvalho Matos

Brasília

2015 
Ficha catalográfica elaborada automaticamente, com os dados fornecidos pelo(a) autor(a)

Eustáquio Soares de Lima Júnior, Marcelo

As diferentes interpretações do algoritmo simplex na resolução de problemas de programação linear /

Marcelo Eustáquio Soares de Lima Júnior; orientador Helder Carvalho. -- Brasília, 2015.

$149 \mathrm{p}$.

Dissertação (Mestrado - Mestrado Profissional em Matemática) -- Universidade de Brasília, 2015.

1. Matemática. 2. Pesquisa Operacional. 3. Algoritmo Simplex. 4. Software Geogebra. 5. Ensino de Matemática. I. Carvalho, Helder, orient. II. Título. 
Universidade de Brasília

Instituto de Ciências Exatas

Departamento de Matemática

As diferentes interpretações do algoritmo simplex na resolução de problemas de programação linear.

por

\section{MARCELO EUSTÁQUIO SOARES DE LIMA JÚNIOR}

Dissertação apresentada ao Departamento de Matemática da Universidade de Brasília, como parte dos requisitos do "Programa" de Mestrado Profissional em Matemática em Rede Nacional - PROFMAT, para obtenção do grau de

\section{MESTRE}

Brasília, 08 de julho de 2015.

Comissão Examinadora:

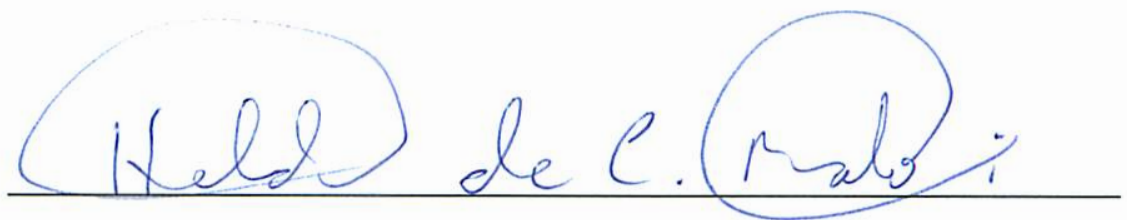

Prof. Dr. Helder de Carvalho Matos - MAT/UnB (Orientador)

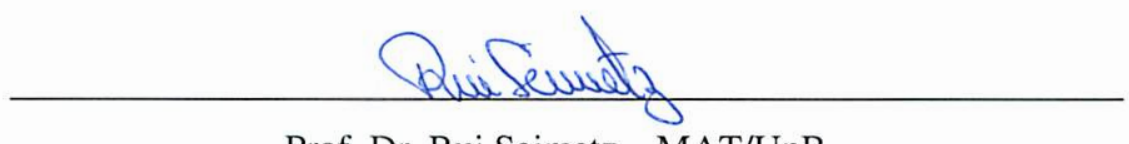

Prof. Dr. Rui Seimetz - MAT/UnB

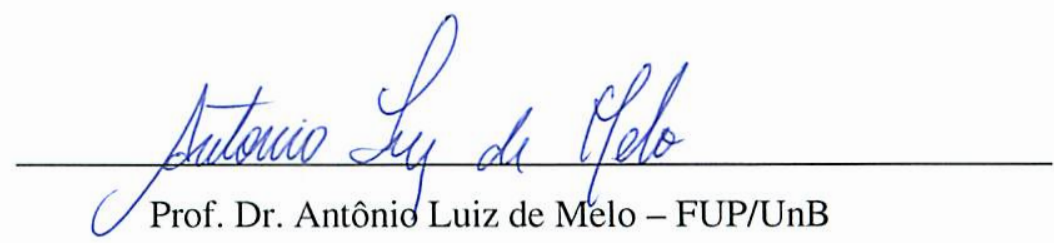


Todos os direitos reservados. É proibida a reprodução total ou parcial deste trabalho sem a autorização da universidade, do autor e do orientador.

Marcelo Eustáquio graduou-se em Ciência da Computação pela Universidade Federal de Minas Gerais. 


\section{Dedicatória}

Dedico este trabalho às minhas lindas e queridas filhas Gabriela e Carolina. 


\section{Agradecimentos}

Agradeço à minha família e todos que estiveram comigo nesta caminhada. 


\section{Resumo}

A principal ideia deste trabalho foi de aplicar o conteúdo Programação Linear no Ensino Médio de forma contextualizada e com a utilização dos sotwares Geogebra e o Excel. Neste trabalho abordamos a metodologia da resolução de problemas, partindo de exemplos que busquem a otimização através da programação linear. O experimento tem por objetivo principal descrever a abordagem utilizada na implementação realizada a partir desses problemas.

\section{Palavras-chave}

Programação Linear, Análise de Algoritmos, Sistemas Lineares, Modelagem Matemática, Software. 


\begin{abstract}
The main idea of this work was to apply the Linear Programming in secondary education content in context and with the use of Geogebra sotwares and Excel. This paper deals with the methodology of solving problems, starting with exempls involving optimization through linear programming. The experiment's main objective is to describe the approach used in the implementation carried out from these problems.
\end{abstract}

\title{
Keywords
}

Linear programming, algorithms analysis, linear systems, mathematical modelling, aoftware. 


\section{Lista de Figuras}

1 Ciclo PDCA: Plain, Do, Check e Act . . . . . . . . . . . . 20

2 Modelagem como tradução de ente do mundo real . . . . . . . . . . 25

3 Fases do processo de modelagem . . . . . . . . . . . . 26

4 Evolução da temperatura . . . . . . . . . . . . . . 28

5 Solução geométrica da situação problema . . . . . . . . . . . . . . . 29

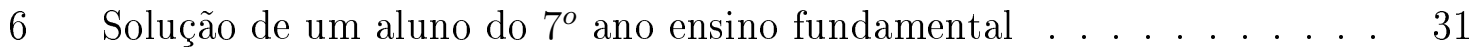

7 Solução de um aluno do $8^{\circ}$ ano do ensino fundamental $\quad \ldots . . . . . \quad 31$

8 Solução padrão de um aluno da $2^{a}$ série do ensino médio $\quad \ldots . . .32$

9 Noção de Algoritmo . . . . . . . . . . . . . . . . . . 36

10 Trocando o pneu furado do carro . . . . . . . . . . . . . 36

11 Viajar de ônibus . . . . . . . . . . . . . . 37

12 Desenvolvimento do Algoritmo de Euclides . . . . . . . . . . . . 38

13 Algoritmo "Força bruta" para cálculo do MDC . . . . . . . . . . . . . 39

14 Método de Euclides para cálculo do MDC . . . . . . . . . . . 40

15 Algoritmo: IRPF . . . . . . . . . . . . . . . 44

16 Simulador de Alíquota Efetiva da RFB . . . . . . . . . . . . . 45

17 Rendimentos tributáveis . . . . . . . . . . . . . . 45

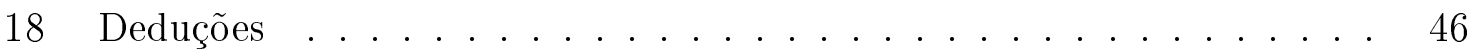

19 Rendimento base de cálculo . . . . . . . . . . . . . . . . 46

$20 \quad \operatorname{Imposto} \ldots \ldots \ldots \ldots \ldots \ldots \ldots \ldots$

21 Alíquota efetiva . . . . . . . . . . . . . . . . 47

22 Menu superior do site www.geogebra.org f . . . . . . . . . . . 48

23 Janela inicial do Geogebra Versão 5 . . . . . . . . . . . . . . . . . . 49

24 Controle deslizante . . . . . . . . . . . . . . . . . 51 
25 Área do quadrilátero ABCD . . . . . . . . . . . . . . . . 52

26 Reta que contém os pontos A e B . . . . . . . . . . . 53

27 Construção de retas paralelas e penpendiculares a uma reta dada . . . 54

28 Gráfico de uma função $f(x)=a x+b \ldots \ldots \ldots \ldots \ldots$

29 Reta que contém os pontos $P(2,3)$ e $Q=(4,-1) \ldots \ldots \ldots \ldots$

30 Coeficientes de $f(x)=a x+b \quad \ldots \ldots \ldots \ldots \ldots \ldots$

31 Gráfio do montante de uma aplicação financeira . . . . . . . . . . . 60

32 Opções associadas ao objeto Reta . . . . . . . . . . . . . . . 61

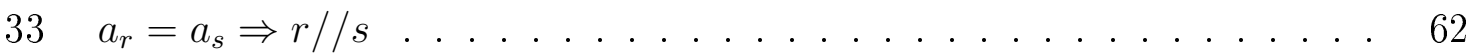

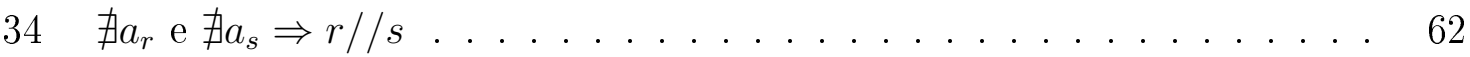

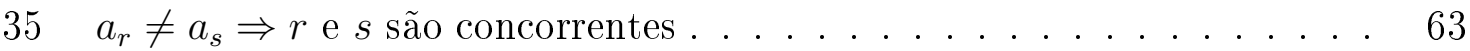

36 Interceptos da reta com os eixos coordenados . . . . . . . . . . 64

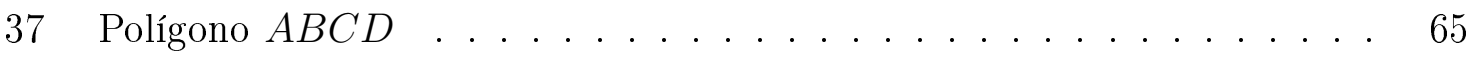

38 Resolução gráfica de inequações . . . . . . . . . . . . . . . 66

39 Estudo de sinal de $f(x)=x^{2}-6 x+8 \ldots \ldots \ldots \ldots \ldots \ldots$

40 Gráfico de $f(x)=x^{3}-6 x^{2}+11 x-60 \ldots \ldots \ldots \ldots 68$

41 Solução de $x^{3}-6 x^{2}+11 x-6<0 \ldots \ldots \ldots \ldots \ldots \ldots$

42 Semiplanos de origem vertical ou horizontal . . . . . . . . . . 70

43 Retângulo ABCD do exemplo $10 \ldots \ldots \ldots \ldots \ldots$

44 A reta $y=a x+b$ e os semiplanos por ela determinados . . . . . 73

45 Semiplano $2 x+3 y \geq 12 \ldots \ldots \ldots \ldots \ldots \ldots \ldots$

46 Solução de $2 x-4 y<6 \ldots \ldots \ldots \ldots \ldots \ldots \ldots \ldots$

47 Solução do sistema de inequações $\ldots \ldots \ldots \ldots \ldots \ldots$

48 Soluções particulares de $x+2 y=6 \ldots \ldots \ldots \ldots \ldots \ldots \ldots$

49 Sistema linear impossível de duas equações e duas incógnitas . . . . . 78 
50 Interpretação geométrica da solução do sistema possível e determinado

51 Solução do sistema linear de equações $2 x-3 y=19$ e $x+y=2 \quad \ldots \quad 80$

52 Classificação de um sistema . . . . . . . . . . . . . . . 80

53 Sistemas equivalentes . . . . . . . . . . . . . . . . 82

54 Interpretação geométrica de um sistema $3 \times 3 \ldots \ldots \ldots$

55 Idéias centrais do cálculo . . . . . . . . . . . . . . 88

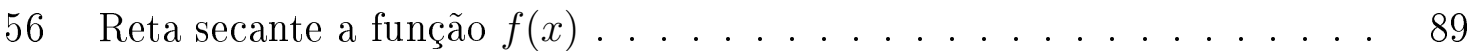

57 Reta tangente a função $f(x) \ldots \ldots \ldots$. . . . . . . . . . 90

58 Relação entre posição e deslocamento . . . . . . . . . . . . . . 91

59 Taxa de variação de $f(x)=x^{2}$ no Geogebra . . . . . . . . . . . 95

60 Função real de duas variáveis reais . . . . . . . . . . . . . . . 95

61 Gráfico de $f(x, y)=x^{2}+y^{2} \ldots \ldots \ldots \ldots$. . . . . . . . 96

62 Curvas de nível de $f(x, y)=x^{2}+y^{2} \ldots \ldots \ldots \ldots$. . . . . 97

63 Ângulo entre os vetores $\vec{u}$ e $\vec{v} \ldots \ldots . \ldots . \ldots . \ldots 100$

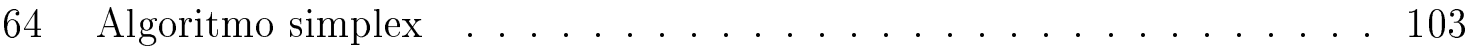

65 Região convexa . . . . . . . . . . . . . . 108

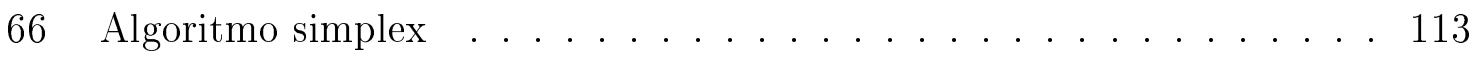

67 Restrições . . . . . . . . . . . . . . . . . . . 113

68 Interseção dos semiplanos . . . . . . . . . . . . . 117

69 Solução do sistema de inequações determinadas pelas restrições do PPL 118

70 Polígono $D A B C \ldots \ldots \ldots \ldots \ldots \ldots \ldots$

$71 \quad$ A gera o valor máximo de $f(x, y)=6 x+7 y \ldots \ldots . \ldots 120$

72 Empate na entrada de variáveis na base . . . . . . . . . . . 121

73 Degeneração . . . . . . . . . . . . . . . . . 122

74 Múltiplas soluções . . . . . . . . . . . . . . . . . 123 
75 Opções do Solver . . . . . . . . . . . . . . . . . . 126

76 Suplementos . . . . . . . . . . . . . . . . . . 127

77 Definindo células . . . . . . . . . . . . . . . . . . . . . . . . . . 129

78 Definindo restrições . . . . . . . . . . . . . . . . . . . 130

79 Parâmetros do solver . . . . . . . . . . . . . . . . 130

80 Adicionar Restrição . . . . . . . . . . . . . . . . . . . . . . 131

81 Resultado . . . . . . . . . . . . . . . . . . . . . . . 131

82 Exemplos de cestas de consumo . . . . . . . . . . . . . . . 134

83 Restrição Orçamentária . . . . . . . . . . . . . . . . . . . . . 135

84 Aumento na renda do consumidor . . . . . . . . . . . . . . 137

85 Mudança nos preços . . . . . . . . . . . . . . . . . 138

86 Representação gráfica das restrições do exemplo 30 . . . . . . . . . 140

87 Polígono viável do exemplo $30 \ldots \ldots$. . . . . . . . . . . . 141

88 Planilha do Excel com definição de variáveis e restrições . . . . . . . 142

89 Parâmetros do Solver . . . . . . . . . . . . . . . . . . . . . . . . 143

$90 \quad$ O valor máximo de $f$ é indicado na célula $D 6 \ldots \ldots \ldots \ldots \ldots$ 


\section{Lista de Tabelas}

1 Restrições de alimentos na dieta alimentar . . . . . . . . . . . . . . . 34

2 Comparação entre custos de execução dos algoritmos . . . . . . . . . 41

3 Tabela Progressiva para cálculo do IRPF de 2015 . . . . . . . . . . . . 42

4 Simulações de cálculo do IRRF . . . . . . . . . . . . . . . 43

$5 \quad$ Inclinação de $I$ para alguns valores de $h \quad \ldots \ldots . \ldots . \ldots 93$

6 Tableau inicial do exemplo $67 \ldots \ldots$. . . . . . . . . . . 114

7 Tableau após $1^{a}$ iteração . . . . . . . . . . . . . . . . . 114

8 Tableau após $2^{a}$ iteração . . . . . . . . . . . . . . 115

$9 \quad$ Tableau do problema $27 \ldots \ldots \ldots \ldots$

10 Solução do problema usando o Solver . . . . . . . . . . . . . . . . . 132

11 Valor das variáveis e da função objetivo em cada iteração . . . . . . . . 133 


\section{Sumário}

1 Introdução $\quad 19$

1.1 Resolução de situações-problema . . . . . . . . . . . . . . . 20

1.2 O ensino médio . . . . . . . . . . . . . . . . 22

1.3 Seções de desenvolvimento do trabalho . . . . . . . . . . . 23

2 Modelagem $\quad 25$

2.1 Introdução . . . . . . . . . . . . . . . . . . 25

2.2 Buscando outra solução para um problema proposto . . . . . . . . . 27

2.3 Fatores que contribuem para a modelagem matemática . . . . . . . . 29

2.4 Pesquisa Operacional . . . . . . . . . . . . . . . . . 32

2.4.1 O que é Programação Linear? . . . . . . . . . . . . . 33

2.4.2 Um exemplo introdutório . . . . . . . . . . . . . . 34

$\begin{array}{lll}3 & \text { Algoritmos } & 36\end{array}$

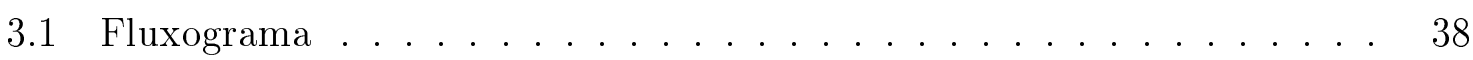

3.2 Comparando algoritmos . . . . . . . . . . . . . . 39

3.3 Um exemplo de atividade . . . . . . . . . . . . . . . . 42

3.3.1 Compreensão . . . . . . . . . . . . . . . . 42

3.3 .2 Matematização ..................... 43

3.3.3 Avaliação ......................... 45

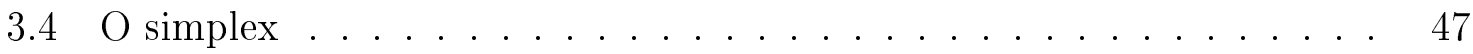

$\begin{array}{lll}4 \text { O Geogebra } & 48\end{array}$

4.1 Instalação . . . . . . . . . . . . . . . . . . . 48

4.2 A janela inicial do Geogebra . . . . . . . . . . . . . . . . 49 
4.3 Principais objetos do Geogebra . . . . . . . . . . . 50

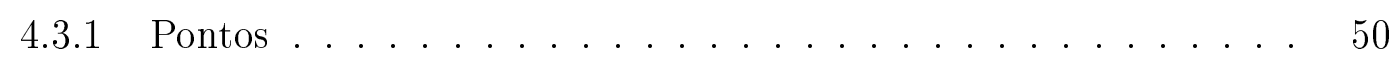

$4.3 .2 \operatorname{Retas} \ldots \ldots \ldots \ldots \ldots \ldots$

4.3.3 Seletor .......................... 50

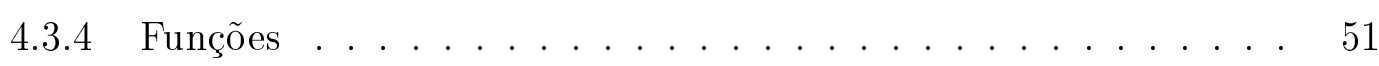

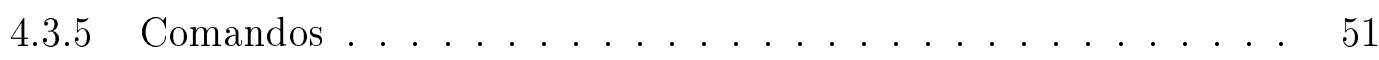

5 Fundamentos teóricos $\quad 55$

5.1 A equação da reta . . . . . . . . . . . . . . . 55

5.1 Posições relativas entre retas coplanares . . . . . . . . . 62

5.1 .2 Equação segmentária da reta . . . . . . . . . . . . 63

5.2 Inequações . . . . . . . . . . . . . . . . . . 65

5.2 .1 Inequações definidas em $\mathbb{R} \ldots \ldots . \ldots 67$

5.2 .2 Inequações definidas em $\mathbb{R}^{2} \ldots \ldots \ldots 70$

5.2.3 Semiplanos de origem oblíqua . . . . . . . . . . . . 72

5.3 Sistemas Lineares . . . . . . . . . . . . . . 76

5.3 .1 Equações lineares . . . . . . . . . . . . . . . 77

5.3 .2 Sistema linear . . . . . . . . . . . . . . 78

5.3 .3 Representação matricial . . . . . . . . . . . . . 81

5.3 .4 Escalonamento . . . . . . . . . . . . . 81

5.3.5 Análise de desempenho . . . . . . . . . . . 85

6 Noções de Cálculo $\quad 88$

6.1 Introdução . . . . . . . . . . . . . . . . . 88

6.2 Taxa de variação e derivada . . . . . . . . . . . . . 89

6.2.1 Interpretação cinemática . . . . . . . . . . . . . . . . . 91 
6.2.2 A derivada enquanto resultado de aproximações sucessivas . . . 92

6.3 Funções reais de duas variáveis reais . . . . . . . . . . . . . . . 95

6.4 Derivadas parciais e gradiente de uma função . . . . . . . . . . . 98

7 O Método Simplex 103

7.1 Introdução . . . . . . . . . . . . . . . . . . 103

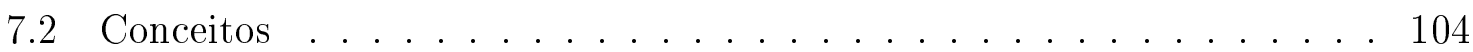

7.3 Teoremas fundamentais . . . . . . . . . . . . . . 107

$7.4 \mathrm{O}$ algoritmo simplex $\ldots \ldots \ldots \ldots \ldots$

7.4.1 Coeficiente de custo . . . . . . . . . . . . 110

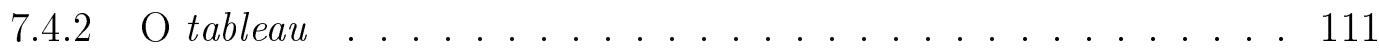

7.5 Método gráfico . . . . . . . . . . . . . . . 116

7.6 Casos excepcionais ....................... 120

7.6.1 Empate na entrada . . . . . . . . . . . 120

7.6 .2 Degeneração . . . . . . . . . . . . . . . . . . 121

7.6.3 Múltiplas soluções . . . . . . . . . . . . . . . . . 122

7.7 Complexidade computacional . . . . . . . . . . . . 124

7.7.1 Custo de execução do simplex . . . . . . . . . . . . . 124

7.8 Excel . . . . . . . . . . . . . . . . . . 125

7.8.1 Requisitos de hardware e software . . . . . . . . . . 125

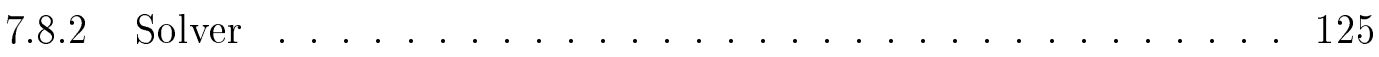

7.8.3 Instalação do Solver . . . . . . . . . . . . . . . 126

7.8.4 Definindo e resolvendo um problema . . . . . . . . . . . 127

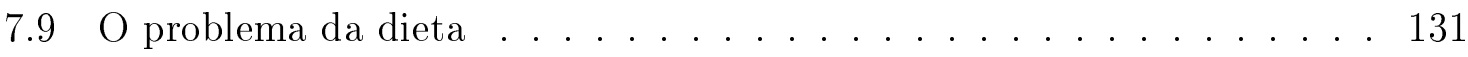

8 Teoria do Consumidor $\quad 134$ 
8.1 Introdução . . . . . . . . . . . . . . . . . . 134

8.2 Restrição Orçamentária . . . . . . . . . . . . . . . . . 135

8.3 Mudanças na reta orçamentária . . . . . . . . . . . . 136

8.3.1 Mudanças na renda . . . . . . . . . . . . . . . . 136

8.3.2 Mudanças nos preços . . . . . . . . . . . . . . 137

8.4 Uma situação problema . . . . . . . . . . . . . . . . . 137

8.4.1 Solução pelo método geométrico . . . . . . . . . . . . 139

8.4.2 Solução do problema proposto no exemplo 30 utilizando o Solver 141

8.4.3 Solução envolvendo método algébrico . . . . . . . . . . . . . 142 


\section{Introdução}

George Pólya, matemático húngaro que viveu entre 1887 e 1985, em sua obra "A arte de resolver problemas" [21], afirma que

" uma grande descoberta resolve um grande problema, mas há sempre uma pitada de descoberta na resolução de qualquer problema. O Problema pode ser modesto, mas se ele desafiar a curiosidade e puser em jogo as faculdades inventivas, quem o resolver por seus meios, experimenta o sentimento da autoconfiança e gozará o triunfo da descoberta".

Apontada por estudos e pesquisas em educação matemática, a resolução de problemas e, de modo mais geral, a resolução de situações-problema, vem se consolidando como estratégia de aprendizagem sólida no ensino de matemática com abordagem que possibilita acesso ao conhecimento construído pela sociedade, partindo do habitat do aluno e se desenvolvendo a partir do continuum de iterações desenvolvidas por ele com o meio que o cerca.

Enquanto metodologia de ensino, a resolução de situações-problemas consiste em apresentar ao aluno situações que estimulem a sua curiosidade e auxiliem na construção de conceitos matemáticos. Porém, seu uso nas aulas de matemática é ainda muito superficial e encontra muita resistência por parte dos professores, que consideram situação-problema como um simples problema, geralmente usado como exercício de fixação de conteúdos.

O conceito de situação-problema é mais amplo do que simplesmente problema por envolver aplicações concretas e diversos componentes da matemática e de outras áreas de conhecimento em sua resolução. Por meio de conceitos, técnicas e algoritmos matemáticos procura-se modelar uma situação real, organizando os dados em tabelas, traçando gráficos, elaborando equações ou funções, desenvolvendo cálculos e realizando análises dos resultados obtidos. Em geral, situações-problema são problemas que exigem pesquisa, levantamento de dados e podem ser apresentados na forma de projetos a serem desenvolvidos ou implementados usando conhecimentos e princípios de outras áreas de conhecimento.

Para o leitor interessado em mais conhecimentos acerca de situação-problema, recomendamos a referência [10]. 


\subsection{Resolução de situações-problema}

Para Polya [21], a resolução de um problema envolve desafio e descoberta, uma vez que não existe um método rígido ou algoritmo que possa ser aplicado para sempre obter a solução. Segundo Polya, existem estágios de pensamento que auxiliam o aluno neste processo e incluem a compreensão do problema, estabelecimento de um plano de ação, execução do plano e o retrospecto. Essas etapas assemelham-se à metodologia para desenvolvimento de processos, conhecida nas grandes organizações como Ciclo PDCA ou Ciclo de Deming, mostrado na Figura 1.

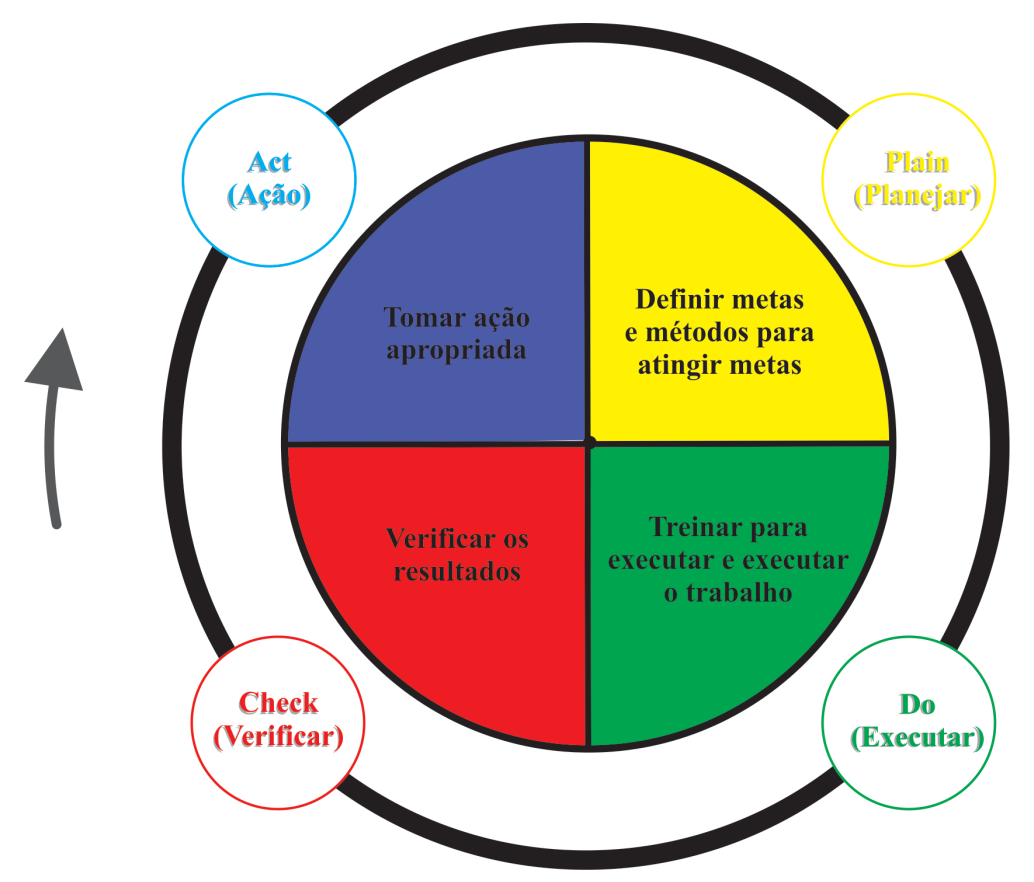

Figura 1: Ciclo PDCA: Plain, Do, Check e Act

Tal metodologia auxilia no diagnóstico, análise e prognóstico de problemas organizacionais, sendo extremamente útil para a solução de problemas. Poucos instrumentos se mostram tão efetivos para a busca do aperfeiçoamento quanto este método de melhoria contínua, tendo em vista que ele conduz a ações sistemáticas que proporcionam bons resultados na sobrevivência e colaboram para o crescimento das organizações.

A metodologia foi desenvolvida por Walter A. Shewhart [5] na década de 30 e consagrada por Willian Edwards Deming [5] [18] a partir da década de 50, quando foi empregada com sucesso nas empresas japonesas para incremento na qualidade de seus processos. O Ciclo PDCA tem como objetivo exercer o controle dos processos, podendo 
ser usado de forma contínua para seu gerenciamento em uma organização, por meio do estabelecimento de uma diretriz de controle (planejamento da qualidade), do monitoramento do nível de controle a partir de padrões pré-estabelecidos e da manutenção da diretriz atualizada, resguardando as necessidades do público alvo.

Sua utilização está intimamente ligada ao entendimento do conceito de processo, ou seja, de um conjunto de ações e atividades inter-relacionadas, que são executadas para alcançar um produto, resultado ou serviço predefinido. Cada processo é caracterizado por suas entradas, as ferramentas e técnicas que podem ser aplicadas e as saídas resultantes. PDCA é um acrônimo de P(plain), D(do), C(check) e A(act):

\section{- Plain:}

É a fase onde objetivos são estabelecidos, procedimentos necessários na resolução são planejados, dados para melhor compreender do que será desenvolvido são coletados e estratégias para melhor alcançar o resultado procurado são traçadas. Se necessário, são estudados casos particulares ou em pequena escala do problema a ser resolvido.

- Do:

Nessa fase ocorre a execução do plano desenvolvido na fase anterior. Por envolver aspectos operacionais da resolução do problema, compreende pesquisas e simulações e, no escopo da matemática, inclui procedimentos algébricos e aritméticos dos problemas.

\section{- Check:}

Momento que consiste em verificar se os resultados obtidos são compatíveis como fora proposto no problema, se pertencem ao seu domínio, atendendo suas restrições. Isto possibilita melhor compreensão do problema, reduzindo a distância entre o que foi exigido e o que foi desenvolvido.

- Act:

Por ser a última fase do ciclo, é responável por preparar a continuidade do processo, agindo sobre o que foi desenvolvido, buscando novos problemas ou modificando o problema resolvido para retornar a fase de planejamento, em novo ciclo que conta com aprendizado gerado pelo ciclo anterior. 
Uma das aplicações mais importantes do ciclo PDCA está em analisar e solucionar problemas, permitindo o controle de qualidade durante todas as fases d'o processo. Enquanto metodologia, o PDCA pode ser adotado como estratégia para auxiliar no processo de ensino, mas não deve ser visto como procedimento de escopo limitado a ser encerrado quando forem cumpridos certos critérios, mas sim como ciclo em constante desenvolvimento, onde novas iterações serão planejadas em função de sucesso obtido em iterações anteriores.

No capítulo 7 da referência [18], tem-se mais elementos acerca do Ciclo PDCA e métodos de controle de qualidade.

\subsection{O ensino médio}

A Lei $n^{\circ} 9.394$ de 20 de dezembro de 1996 estabelece as diretrizes e bases da educação nacional e propões princípios e objetivos que nortearão políticas do sistema educacional brasileiro. Ao longo de 92 artigos, são apresentadas definições e propostas características para cada um dos segmentos da educação básica brasileira. O artigo 35 atribui ao ensino médio a característica de terminalidade por ser a etapa final da educação bássica e apresenta suas finalidades:

Art. 35. O ensino médio, etapa final da educação básica, com duração mínima de três anos, terá como finalidades:

I. a consolidação e o aprofundamento dos conhecimentos adquiridos no ensino fundamental, possibilitando o prosseguimento de estudos;

II. a preparação básica para o trabalho e a cidadania do educando, para continuar aprendendo, de modo a ser capaz de se adaptar com flexibilidade a novas condições de ocupação ou aperfeiçoamento posteriores;

III. o aprimoramento do educando como pessoa humana, incluindo a formação ética e o desenvolvimento da autonomia intelectual e do pensamento crítico; e

IV. a compreensão dos fundamentos científico-tecnológicos dos processos produtivos, relacionando a teoria com a prática, no ensino de cada disciplina. 
Tais finalidades devem ser materializadas na construção de currículo que contemple a educação tecnológica básica, a compreensão do significado da ciência, o processo histórico de transformação da sociedade e da cultura tendo a língua portuguesa como instrumento de comunicação, acesso ao conhecimento e exercício da cidadania e metodologia de ensino e de avaliação que estimulem a iniciativa dos estudantes, elementos esses voltado para o desenvolvimento de competências básicas, com presença de elementos que remetem à interdisciplinaridade e contextualização, pertecentes a uma base nacional comum que propiciem formação geral e preparação básica para o mercado de trabalho.

Na sociedade atual, caracterizada pela escassez de recursos e constante busca pela otimização de processos, a Programação Linear tem se tornado um fator estratégico na busca dos melhores resultados por organizações de diferentes portes cujos objetivos, muitas vezes, resumem-se a minimizar tempo e gastos ou maximizar lucro e produção. Essas características evidenciam importantes aplicações de temas matemáticos como o estudo analítico da reta e sistemas lineares, criando associação teoria-prática e colaborando para a formação de novo perfil para o ensino médio, especialmente na vinculação ao mercado de trabalho e conhecimento de aspectos tecnológicos dos processos produtivos.

\subsection{Seções de desenvolvimento do trabalho}

O principal objetivo deste trabalho é apresentar uma proposta de ensino e aprendizagem de uma parte da matemática para o ensino médio, tendo como cenário a modelagem matemática e a programação linear, utilizando problemas reais observados no contexto econômico e produtivo do século XXI. Paralelamente, serão desenvolvidos recursos didáticos que auxiliem na fundamentação teórica e desenvolvimento algébrico do simplex, principal algoritmo para resolver problemas dessa natureza.

No capítulo 2 - Modelagem - serão delineados os conceitos de modelagem matemática e programação linear, que norteiam este trabalho. Discutir-se-ão estratégias na abordagem e modelagem desses problemas, bem como elencar fatores que interferem na capacidade de modelar ou na significância do modelo desenvolvido.

O capítulo 3 - Algoritmos - apresenta a noção de algoritmo e como pode ser empregado, na educação básica, na compreensão e resolução de problemas. Cocomitantemente serão propostos problemas simples com objetivo de desenvolver o encadeamento 
lógico de ações na construção de algoritmos bem como sua análise de complexidade.

O capítulo 4 - O Geogebra - destina-se a apresentar as funcionalidades do software necessários para desenvolvimento das atividades propostas nos capítulos 5, 6, 7 e 8 .

Nos capítulos 5 - Fundamentos Teóricos - e 6 - Fundamentos de Cálculo - serão desenvolvidos os aspectos teóricos que fundamentam a correção e eficiência do simplex, principal algoritmo adotado na resolução de problemas de programação linear. Apresentar-se-ão elementos que mostram a importância da associação de conceitos algébricos às suas respectivas versões geométricas, em especial nas seções que tratam de equação da reta, inequações de primeiro grau com duas incógnitas, resolução de sistemas lineares, noções de função e derivadas.

O capítulo 7 - Método Simplex - destina-se ao Algoritmo Simplex em suas versões mais conhecidas, cujo desenvolvimento é feito a partir de problemas definidos no $\mathbb{R}^{2}$, em virtude do aspecto geomético adotado na sua resolução. Para problemas definidos em dimensões superiores, o foco será na modelagem e resolução pelo método algébrico, com posterior verificação no Microsoft Excel.

Por fim, o capítulo 8 - Teoria do Consumidor - apresenta a modelagem de uma importante teoria da microeconomia que estabelece o comportamento do consumidor individual frente às decisões de consumo, na escolha dos melhores produtos dentro daquilo que eles podem adquirir. 


\section{Modelagem}

\subsection{Introdução}

Segundo o Novo Dicionário Aurélio da Língua Portuguesa, $4^{a}$ edição, 2009, define-se por modelo o objeto designado a ser reproduzido por imitação, uma representação em pequena escala de algo que se deseja executar em dimensões reais, um molde. Dessa definição, infere-se, em linhas gerais, que modelagem está relacionada á operação de representar um ente do mundo real por meio de um modelo, em processo de tradução do mundo real, mediante simplificações a partir de objetos previamente construídos, conforme representamos na figura 2.

Ente do mundo

real

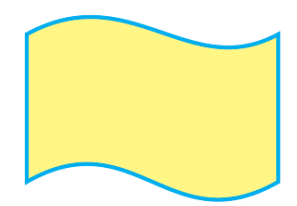

Modelo

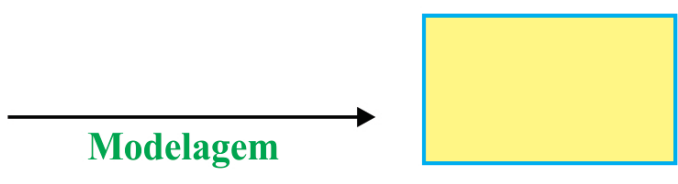

Figura 2: Modelagem como tradução de ente do mundo real

Nas ciências matemáticas, o processo de modelagem está associado à capacidade de transformar problemas reais em contextos cuja resolução seja de possível execução, a partir de habilidades e competências desenvolvidas, para posterior interpretação e mapeamento no mundo real.

No entanto, o processo pode sofrer ajustes em função da complexidade de problemas reais e da simplicidade de elementos matemáticos normalmente empregados na construção dos modelos. Na insuficiência de elementos necessários para a construção de um modelo, faz-se necessária a criação de novos elementos ou o estabelecimento de novas relações. Portanto, ao criar novos modelos, a sociedade colabora para o desenvolvimento da própria matemática uma vez que, segundo Ubiratan Dambrósio [2], "A modelagem matemática é matemática por excelência" por representar fatos e fenômenos observados no quotidiano, por meio de entidades e relacionamentos que podem ser socializados.

De forma geral, a construção de um modelo para a resolução de um problema 
resume-se ao cumprimento de um conjunto de estágios de cunho operacional onde são definidos objetivos, variáveis de decisão e controle e níveis de detalhamento, constituindo metodologia que muito se assemelha aos métodos gerenciais de melhoria contínua como o ciclo PDCA. Embora não apresentem limites bem definidos, evidenciam-se três fases no processo de modelagem: compreensão, matematização e avaliação, cujos marcos principais são apresentados na fiigura 3 .

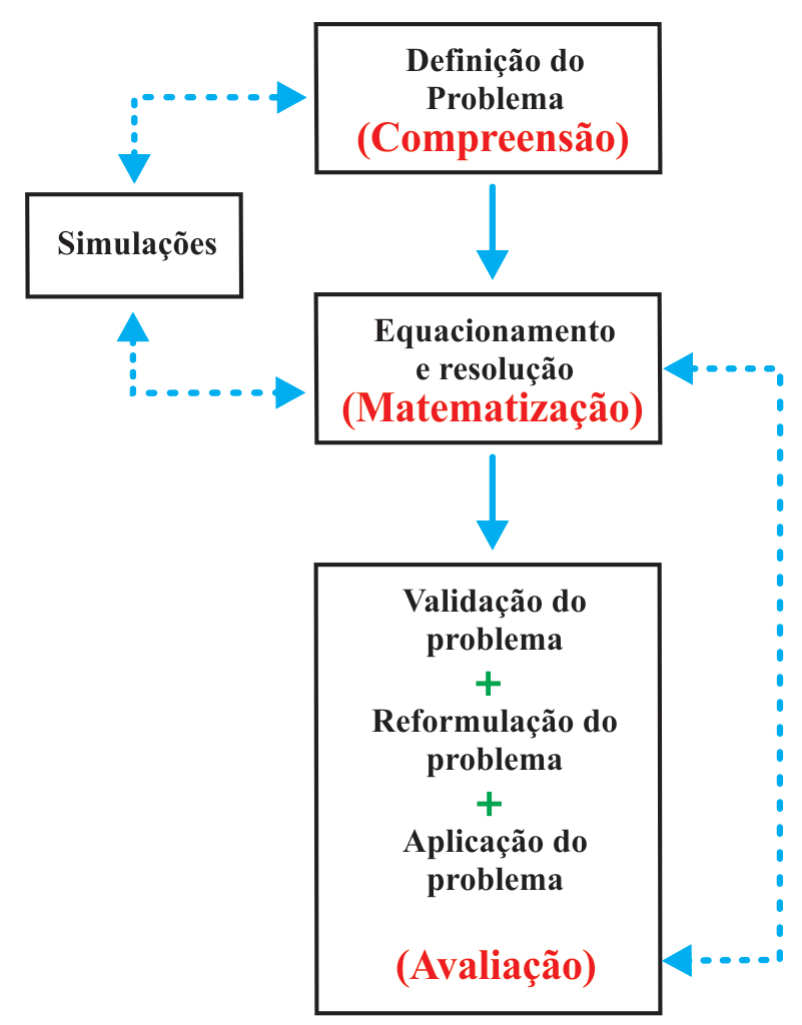

Figura 3: Fases do processo de modelagem

\section{Compreensão:}

A construção de um modelo é desencadeada pela plena apropriação e conhecimento do problema a ser modelado, acrescida da familiarização com ferramentas a serem utilizadas no processo, em ações que envolvem estudo, pesquisa e simulação. A dinâmica, nesse momento, consiste em aglutinar elementos que contribuam para a formalização matemática necessária na fase de matematização. 


\section{Matematização:}

É o momento no qual ocorre, de fato, a tradução da situação-problema para a linguagem matemática e consequente resolução. Habilidades como intuição e criatividade são essenciais para classificar informações, desconsiderando aquelas que forem irrelevantes, decidir que metas devem ser procuradas, selecionar variáveis relevantes e constantes relacionadas, usar notação matemática adequada ao cenário e descrever matematicamente a relação entre todos esses termos.

Ao final dessa etapa, uma resposta que atenda todas as restrições levantadas deve ser explicitada ou os elementos elencados devem ser suficientes para comprovar a sua inexistência.

\section{Avaliação:}

Uma vez determinada a solução do problema, faz-se necessária a validação desses resultados e do planejamento dos próximos passos a serem executados. Estratégias como reformulação do problema solucionado, elaboração de outro método de resolução para o mesmo problema ou ainda a busca de problemas com maior grau de complexidade podem ser utilizadas para preparar uma nova iteração do Ciclo de Deming. Havendo necessidade, caso a solução construída não seja adequada, as etapas anteriores devem ser revisitadas na busca da solução de eventuais inconsistências.

\subsection{Buscando outra solução para um problema proposto}

Uma possível implementação do estágio final da metodologia proposta consiste em, a partir do modelo elaborado para o problema proposto, elaborar outro modelo matemático, que não utilize das mesmas habilidades anteriormente empregadas, para resolver o mesmo problema. No novo cenário, restringem-se as ferramentas disponíveis e instiga o aluno a analisar o contexto por ótica diferente da que inicialmente costuma ver, como pode ser observado no item seguinte, proposto para alunos do $9^{\circ}$ ano do ensino fundamental, ao estudar o tema Função Afim.

O segmento de reta apresentado na figura 4 mostra a evolução da temperatura em região próxima a Porto Alegre, capital do Rio Grande do Sul, entre 5 e 11 horas. 


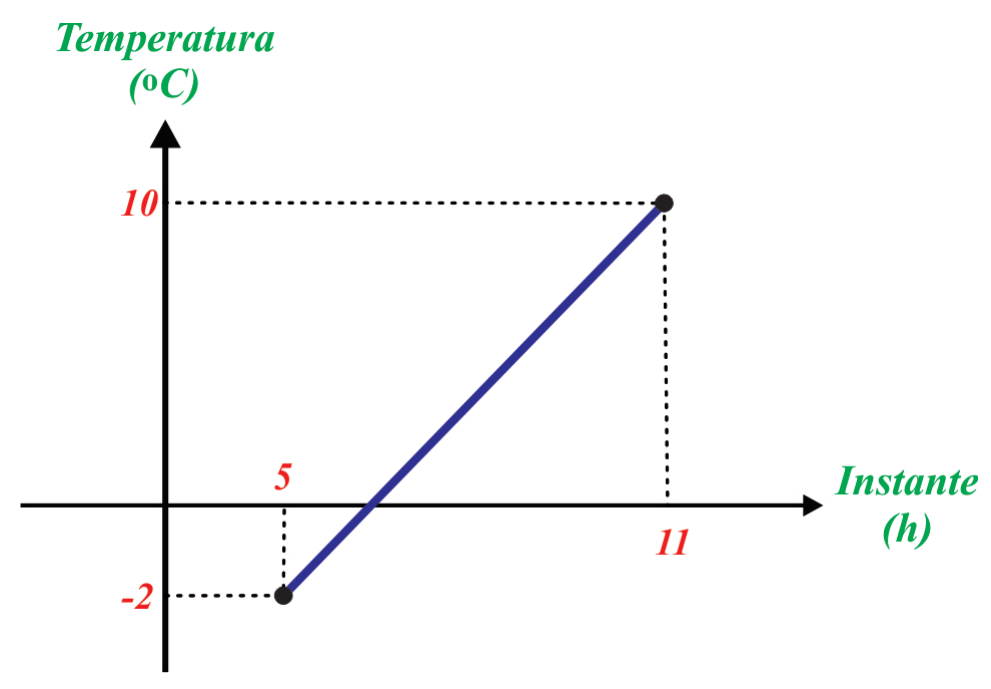

Figura 4: Evolução da temperatura

Calcular o instante em que a temperatura é nula.

De forma geral, o modelo proposto consiste em determinar a função afim, $f(t)=a t+b$, cujo gráfico contém o segmento de reta de extremos $(5,-2)$ e $(11,10)$ para, a seguir, determinar o momento em que o gráfico de $f$ intercepta o eixo horizontal. Assim, representando por $f(t)=a t+b$ a temperatura registrada nas proximidades da capital gaúcha no instante $t \in[5,11]$, escreve-se $f(5)=5 a+b=-2$ e $f(11)=11 a+b=10$. Subtraindo essas equações, obtem-se

$$
\begin{aligned}
f(11)-f(5) & =(11 a+b)-(5 a+b)=(10)-(-2) \\
& \Rightarrow 6 a=12 \\
& \Rightarrow a=2
\end{aligned}
$$

e, para o valor obtido de $a$, conclui-se que $b=-12$. Portanto, $f(t)=2 t-12$ e o instante no qual a temperatura se anula é a raiz da equação $f(t)=0$, ou seja, $t=6$ horas.

Resolvido o problema e encontrada a solução, a nova iteração do ciclo poderia ser desencadeada com a proposta de criação de novo modelo que não utilize habilidades contempladas no modelo apresentado. Ou seja, determinar o momento em que a tem- 
peratura se tornou igual a zero sem usar conceitos relacionados a Função Afim ou Equação da Reta e, um modelo que atende o novo questionamento proposto resumese em observar a proporcionalidade em figuras semelhantes, como se vê na figura 5.

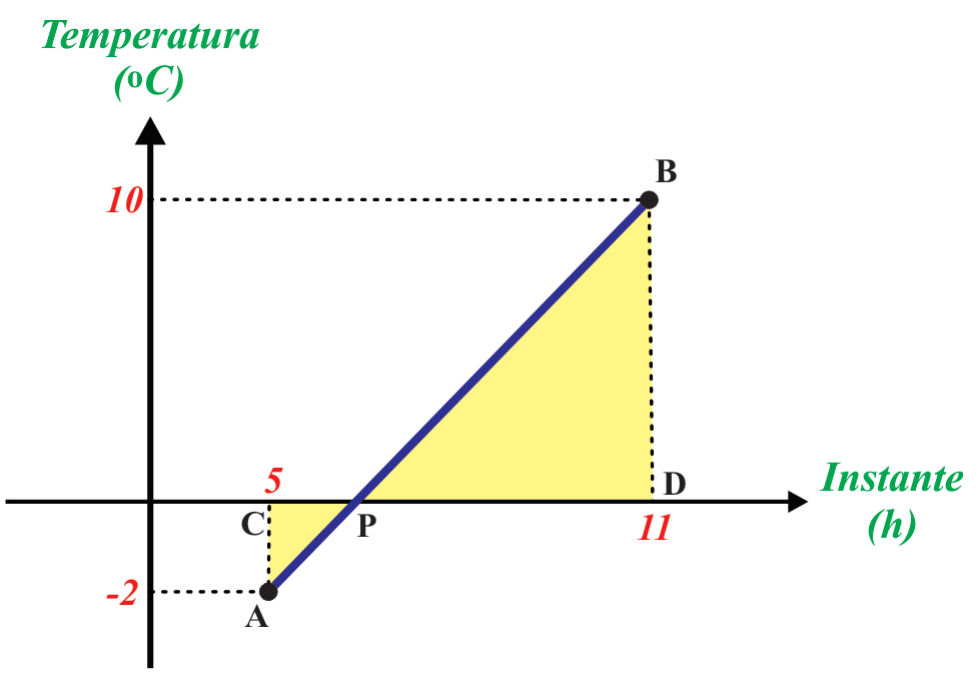

Figura 5: Solução geométrica da situação problema

Para tal, serão considerados os pontos $A=(5,-2), P=(x, 0), B=(11,10)$, $C=(5,0)$ e $D=(11,0)$, em que $x$ representará o instante em que a temperatura será nula. Por serem paralelos os segmentos $\overline{A C}$ e $\overline{B D}$, os triângulos $A P C$ e $P B D$ são semelhantes. Logo

$$
\frac{A C}{B D}=\frac{P C}{P D} \Rightarrow \frac{2}{10}=\frac{x-5}{11-x} \Rightarrow 5 x-25=11-x \Rightarrow x=6
$$

Novamente, no instante $t=6 h$, a temperatura registrada foi nula.

\subsection{Fatores que contribuem para a modelagem matemática}

A modelagem matemática origina-se em problemas do quotidiano cujas resoluções envolvem tradução do contexto apresentado para a linguagem matemática, para posterior verificação e validação a partir de dados reais. Consequentemente, um modelo construído reflete características de quem o elaborou, como interpretação da realidade na 
qual está imerso, habilidades cognitivas que desenvolveu, maturidade matemática adquirida e ferramentas matemáticas disponíveis no processo. Portanto, a capacidade de expressão do modelo é diretamente afetada pela visão de mundo de quem o desenvolve e como interpreta as relações entre os objetos nele contido, fatos confirmados com a aplicação de um teste diagnóstico aplicado para alunos das quatro séries finais do ensino fundamental e três séries do ensino médio.

Como parte do projeto pedagógico do Colégio Santo Agostinho, escola particular de Belo Horizonte, o teste diagnóstico de matemática é formado por 10 itens fechados e 2 abertos, elaborados pela equipe de professores dematemática da escola com o objetivo de explicitar conceitos ainda não assimilados propostos para séries anteriores. Um dos itens abertos, proposto para todas as séries que participaram do teste e respondido por aproximadamente 1000 alunos, foi elaborado para evidenciar diferentes soluções para o mesmo problema e está transcrito a seguir:

Em um restaurante há 20 mesas, todas ocupadas, algumas com 4 pessoas, e outras com apenas 2 pessoas, num total de 68 fregueses. Quantas mesas são ocupadas por 2 pessoas?

Em função da heterogeneidade da população submetida ao teste, formada por alunos com idade entre 11 e 17 anos, destacaram-se três modelos que permitiram incluir cada indivíduo em uma de três categorias em função da proficiência apresentada por ele: contato, sistematização ou aprofundamento.

Para o item em estudo, as soluções apresentadas evidenciaram algebrização do pensar matemático à medida que o indivíduo se aproxima das séries finais da educação básica, quando a álgebra apresenta, face à estrutura curricular, grande processo de sistematização e aprofundamento.

A ausência do uso da álgebra foi observado no grupo formado por alunos do $6^{\circ} \mathrm{e}$ $7^{\circ}$ anos do ensino fundamental, com idade média entre 11 e 12 anos, onde elementos algébricos não foram, em sua totalidade, apresentados e sistematizados. Nesse grupo, os indivíduos recorreram mais sistematicamente às quatro operações aritméticas básicas, adição, subtração, multiplicação e divisão, para resolver o problema. No entanto, foram raras as ocorrências de justificativas nas transições ou passagens escolhidas. Na figura 6 tem-se solução de um aluno do $7^{\circ}$ ano do ensino fundamental: 


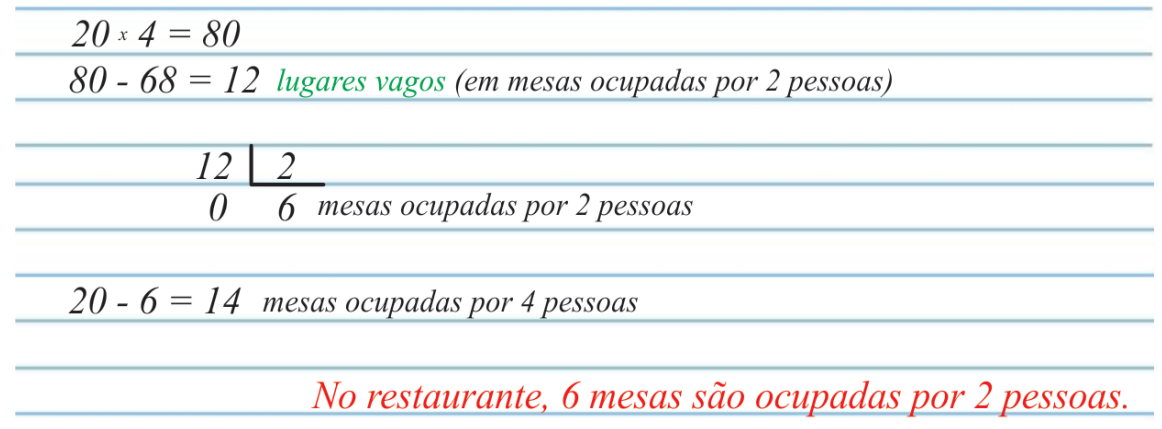

Figura 6: Solução de um aluno do $7^{\circ}$ ano ensino fundamental

O estudo da álgebra se desenvolve a partir do $7^{\circ}$ ano do ensino fundamental, com apresentação de conceitos como variável, incógnita, expressão algébrica, frações algébricas e equações, sendo abordada de forma mais sistemática nas séries seguintes, principalmente nos temas equações e sistemas de primeiro e segundo graus. À medida que foram analisadas as respostas de alunos do $8^{\circ}$ e do $9^{\circ}$ anos do ensino fundamental, percebeu-se mudança no padrão de solução adotado, que deixou de ser puramente aritmético com a incorporação de elementos algébricos como, de forma geral, equação linear de uma incógnita para alunos do $8^{\circ}$ ano e sistemas de duas equações com duas incógnitas para alunos do $9^{\circ}$ ano. Na figura 7 tem-se a resolução de um aluno do $8^{\circ}$ ano do ensino fundamental.

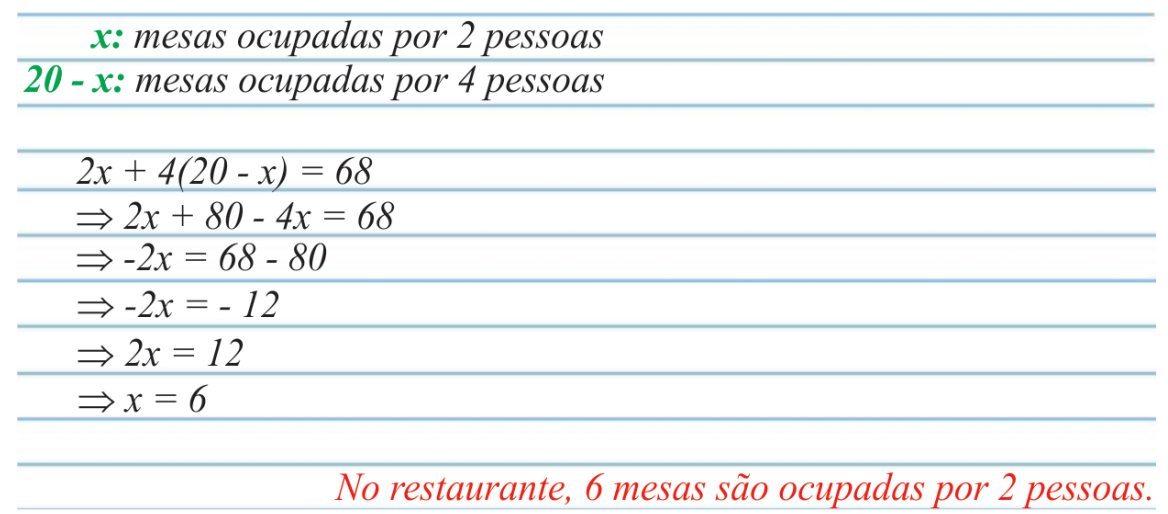

Figura 7: Solução de um aluno do $8^{\circ}$ ano do ensino fundamental

Por conter indivíduos que se encontram em processo de sistematização de elementos da álgebra, foram observadas soluções que utilizaram a álgebra como sistematização 
da aritmética. A partir de casos particulares, as expressões algébricas $x$ e $20-x$ foram obtidas como generalização das quantidades de mesas ocupadas por 2 e 4 pessoas, possibilitando conexão entre os diferentes elementos apresentados e contribuindo para verificação e validação mais eficientes do modelo desenvolvido, como pode ser observado na figura 8 .

\begin{tabular}{|c|c|}
\hline$x:$ mesas ocupadas pc & 2 pessoas \\
\hline y: mesas ocupadas po & pessoas \\
\hline $\int x+y=20$ & $-2 x-2 y=-40$ \\
\hline $2 x+4 y=68$ & $2 x+4 y=68+$ \\
\hline & $2 y=28 \Rightarrow y=14$ \\
\hline & $x+14=20 \Rightarrow x=6$ \\
\hline & staurante, 6 mesas são oct \\
\hline
\end{tabular}

Figura 8: Solução padrão de um aluno da $2^{a}$ série do ensino médio

\subsection{Pesquisa Operacional}

Segundo [11], a Pesquisa Operacional (PO) é uma área da matemática aplicada voltada para a resolução de problemas reais cujo foco é a a tomada de decisões, sendo adotada para avaliar linhas de ação alternativas e obter as soluções que melhor servem aos objetivos dos indivíduos ou organizações, sem descuidar, no entanto, dos elementos subjetivos e de enquadramento organizacional que caracterizam os problemas.

A PO surgiu durante a II Guerra Mundial como alternativa para lidar com problemas de natureza logistica, tática e de estratégia militar de grande dimensão e complexidade. Para apoiar os comandos operacionais na resolução desses problemas, foram então criados grupos multidisciplinares de matemáticos, físicos e engenheiros e cientistas sociais cujo objetivo consistia em aplicar o método científico aos problemas que lhes foram propostos. Desenvolveram então a ideia de criar modelos matemáticos, apoiados em dados e fatos, que lhes permitissem perceber os problemas em estudo e simular e avaliar o resultado hipotético de estratégias ou decisões alternativas.

O sucesso e credibilidade obtidos durante a guerra foram tão grandes que, terminado o conflito, esses grupos de cientistas e a sua nova metodologia de abordagem dos problemas se transferiram para as empresas que, com o "boom" econômico que 
se seguiu, se viram também confrontadas com problemas de decisão de grande complexidade. Em alguns países, em que prevaleceu a preocupação com os fundamentos teóricos, a Pesquisa Operacional se desenvolveu sob o nome de Ciência da Gestão ou Ciência da Decisão e em outros, em que predominou a ênfase nas aplicações, com o nome de Engenharia de Produção.

Seguiram-se grandes desenvolvimentos técnicos e metodológicos que hoje, com o apoio de sistemas computacionais de crescente capacidade, nos permitem trabalhar enormes volumes de dados sobre as atividades, não apenas das empresas, mas, também de instituições do setor público dentro e fora da área econômica. Em função do seu caráter multidisciplinar, a Pesquisa Operacional é uma disciplina científica de características horizontais com suas contribuições estendendo-se por praticamente todos os domínios da atividade humana, da Engenharia à Medicina, passando pela Economia e a Gestão Empresarial.

\subsubsection{O que é Programação Linear?}

No escopo da programação matemática, a programação linear é uma área da pesquisa operacional com grande aplicabilidade em apoio à decisão onde o termo "programação", tanto linear quanto matemática está relacionado ao planejamento de recursos escassos com objetivo de atender as condições operacionais que, por sua vez, são representadas por equações, inequações e funções lineares, elementos muito comuns na educação básica.

A apresentação de elementos de modelagem matemática e programação linear para alunos do ensino médio criaria oportunidade para aplicar conceitos como sistemas lineares e funções em problemas de apoio para tomada de decisão, muito comuns no planejamento logístico de frota e rotas, decisão em escolha de conjunto de produtos em manufatura, decisão de localização de facilidade ou instalação de fábricas ou centros de distribuição, dentre outros.

Ainda se justifica o uso da programação linear como ferramenta pedagógica para incentivar o uso de softwares no ensino da Matemática e como mecanismo de integração de diferentes segmentos do pensar matemático, como álgebra e geometria, o que colabora para a construção do significado geométrico do conjunto solução de uma equação, um sistema ou uma inequação. Para o estudo das funções, das equações, das desigualdades e da geometria analítica existe uma grande variedade de softwares de 
expressão, muitos enquadrados na filosofia do software livre.

\subsubsection{Um exemplo introdutório}

Antes de apresentar tratamento formal e elaborado sobre modelagem matemática em pesquisa operacional consideremos, como exemplo, o Problema da Dieta, cujo objetivo consiste em determinar, em uma dieta para redução calórica, as quantidades de certos alimentos que deverão ser ingeridos diariamente, de modo que determinados requisitos nutricionais sejam satisfeitos a custo mínimo.

Para tal, supondo que, por motivos justificáveis, uma certa dieta alimentar esteja restrita a leite desnatado, carne magra de boi, carne de peixe e uma salada de composição bem conhecida.

Tabela 1: Restrições de alimentos na dieta alimentar

\begin{tabular}{|c|c|c|c|c|c|}
\hline Vitamina & $\begin{array}{c}\text { Leite } \\
(\mathbf{l})\end{array}$ & $\begin{array}{c}\text { Carne } \\
(\mathbf{k g})\end{array}$ & $\begin{array}{c}\text { Peixe } \\
(\mathbf{k g})\end{array}$ & $\begin{array}{c}\text { Salada } \\
(\mathbf{1 0 0 g})\end{array}$ & $\begin{array}{c}\text { Quantidade } \\
\text { Mínima }\end{array}$ \\
\hline \hline $\mathrm{A}$ & $2 \mathrm{mg}$ & $2 \mathrm{mg}$ & $10 \mathrm{mg}$ & $20 \mathrm{mg}$ & $11 \mathrm{mg}$ \\
\hline $\mathrm{C}$ & $50 \mathrm{mg}$ & $20 \mathrm{mg}$ & $10 \mathrm{mg}$ & $30 \mathrm{mg}$ & $70 \mathrm{mg}$ \\
\hline $\mathrm{D}$ & $80 \mathrm{mg}$ & $70 \mathrm{mg}$ & $10 \mathrm{mg}$ & $80 \mathrm{mg}$ & $250 \mathrm{mg}$ \\
\hline Custo & $\mathrm{R} \$ 2,00$ & $\mathrm{R} \$ 4,00$ & $\mathrm{R} \$ 1,50$ & $\mathrm{R} \$ 3,00$ & - \\
\hline
\end{tabular}

Sabe-se ainda que os requisitos nutricionais serão expressos em termos de vitaminas A, C e D e controlados por suas quantidades mínimas (em miligramas), uma vez que são indispensáveis à preservação da saúde da pessoa que será submetida à dieta. A tabela Restrições de alimentos na dieta alimentar 1 resume a quantidade de cada vitamina em disponibilidade nos alimentos e sua necessidade diária para uma boa saúde de uma pessoa.

\section{Solução}

A primeira etapa na resolução de um problema consiste em sua compreensão. Neste momento, devem ser identificados os dados, as restrições e o objetivo, ou seja, o que está sendo solicitado. No Problema da Dieta, foi solicitada a quantidade de leite, de carne, de peixe e de salada na elaboração de uma dieta que atenda a certos requisitos nutricionais a custo mínimo. Para tal, representa-se por $x_{1}, x_{2}, x_{3}$ e $x_{4}$, respectiva- 
mente, a quantidade, em litros, de leite, em kg, de carne, em $\mathrm{kg}$, de peixe e em porções de $100 \mathrm{~g}$ de salada.

O objetivo proposto no problema, propor uma dieta que tenha custo mínimo, depende (está em função) da quantidade de leite $\left(x_{1}\right)$, da quantidade de carne $\left(x_{2}\right)$, da quantidade de peixe $\left(x_{3}\right)$ e da quantidade de salada $\left(x_{4}\right)$. Ou seja, o custo é função das variáveis $x_{1}, x_{2}, x_{3}$ e $x_{4}$. Por exemplo, caso sejam comprados 3 litros de leite, $2 \mathrm{~kg}$ de carne, $0,5 \mathrm{~kg}$ de peixe e $400 \mathrm{~g}$ de salada seriam gastos $3 \times R \$ 2,00+2 \times$ $R \$ 4,00+0,5 \times R \$ 1,50+4 \times R \$ 3,00=R \$ 26,75$. Generalizando, $C\left(x_{1}, x_{2}, x_{3}, x_{4}\right)=$ $2 x_{1}+4 x_{2}+1,5 x_{3}+3 x_{4}$ ou simplesmente $C=2 x_{1}+4 x_{2}+1,5 x_{3}+3 x_{4}$, função chamada de função objetivo.

No entanto, as variáveis sofrem restrições em função dos requisitos mínimos de vitaminas A, C e D a serem ingeridos diariamente. Usando raciocínio similar ao que fora usado para a função objetivo, para a vitamina A, cujo consumo deve ser, no mínimo, 11 mg, obtém-se a desigualdade $2 x_{1}+2 x_{2}+10 x_{3}+20 x_{4} \geq 11$. Analogamente, são obtidas restrições quando consideradas a quantidades mínimas das vitaminas $\mathrm{C}$ e $\mathrm{D}$, que geram as desigualdades $50 x_{1}+20 x_{2}+10 x_{3}+30 x_{4} \geq 70$ e $80 x_{1}+70 x_{2}+10 x_{3}+80 x_{4} \geq 250$.

Tanto a função objetivo quanto as restrições observadas são lineares, o que nos permite classificar o problema como problema de programação linear. Por fim, como se tratam de quantidades a serem adquiridas, não existe sentido em escrever, por exemplo, $x_{3}=-2$. Escreve-se, consequentemente, $x_{1}, x_{2}, x_{3}, x_{4} \geq 0$ ou ainda $x_{i} \in \mathbb{R}_{+}$, $i \in\{1,2,3,4\}$. Observando que o objetivo do problema é a otimização do custo diário, o modelo elaborado pode ser sintetizado com a seguinte formulação:

$$
\begin{array}{ll}
\text { Minimizar } & C\left(x_{1}, x_{2}, x_{3}, x_{4}\right)=2 x_{1}+4 x_{2}+1,5 x_{3}+3 x_{4} \\
\text { Sujeito a } & \left\{\begin{array}{l}
2 x_{1}+2 x_{2}+10 x_{3}+20 x_{4} \geq 11 \\
50 x_{1}+20 x_{2}+10 x_{3}+30 x_{4} \geq 70 \\
80 x_{1}+70 x_{2}+10 x_{3}+80 x_{4} \geq 250 \\
x_{1}, x_{2}, x_{3}, x_{4} \geq 0
\end{array}\right.
\end{array}
$$

Após apresentar os elementos necessários para a compreensão do algoritmo simplex no capítulo 7, resolveremos o Problema da Dieta. 


\section{Algoritmos}

Embora o termo algoritmo há muito seja associado à Ciência da Computação e ao desenvolvimento de sistemas informatizados, muitas são suas implicações no quotidiano e, especialmente, no ensino de matemática. Segundo Cormen [6], um algoritmo é um procedimento utilizado na transformação de um conjunto denominado entrada em outro chamado saída, ou seja, uma sequência de operações ou instruções implementadas em ordem pré-determinada com intuito de transformar entrada em saída, como pode ser observado na Figura 9.

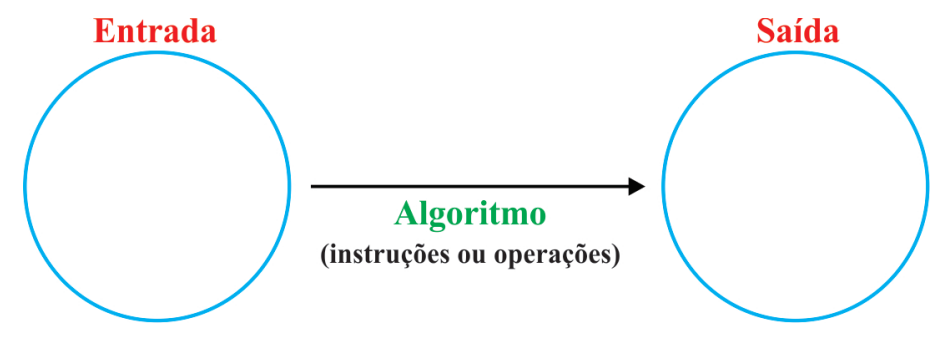

Figura 9: Noção de Algoritmo

Em função do sequenciamento de operações, os algoritmos são ferramentas lógicas empregadas na resolução de problemas bem especificados e sem ambiguidade, cujo enunciado apresenta relacionamento entre entradas e saídas e o desenvolvimento se dá pelo cumprimento de premissas básicas, organizadas de forma ordenada dentro de uma sequência finita de passos, como é observado no algoritmo abaixo, o qual denominaremos Trocar pneu furado do carro, detalhado na Figura 10.

Trocar pneu furado do carro

1. Desligar o carro

2. Pegar as ferramentas (macaco e chave de roda)

3. Pegar o estepe

4. Levantar carro com o auxílio do macaco

5. Desenroscar os quatro parafusos do pneu furado

6. Retirar pneu furado

7. Colocar o estepe

8. Colocar e enroscar os quatro parafusos

9. Baixar o carro com o macaco

10. Guardar ferramentas e estepe

Figura 10: Trocando o pneu furado do carro 
À medida que problemas mais complexos são apresentados, instruções para prover leitura e processamento de dados, avaliar expressões algébricas, relacionais e lógicas, tomar decisões com bases nos resultados das expressões avaliadas ou repetir um conjunto de ações de acordo com uma condição são acrescentadas às instruções que tem seu desenvolvimento direto e sem depender de pré-condições variáveis.

Entrar no ônibus e pagar a passagem

1. Ir até a parada

2. enquanto o ônibus não chega faça

3. esperar o ônibus

4. fim-enquanto

5. subir no ônibus

6. pegar bilhete

7. se não há passagem então

8. pegar dinheiro

9. fim-se

10. pagar ao cobrador

11. troco $\leftarrow$ dinheiro - passagem

12. $\ldots$

Figura 11: Viajar de ônibus

O algoritmo "Entrar no ônibus e pagar a passagem", detalhado na Figura 11, é formado por estruturas repetitivas, onde conjunto de instruções é desenvolvido enquanto é atendida uma condição previamente indicada, como é observada na Figura 11, entre as linhas 2 e 4, em que a ação "esperar ônibus" se repetirá enquanto a condição "ônibus não chega" permanecer verdadeira. Assim que essa proposição se tornar falsa, na chegada do ônibus, o algoritmo deixará de repetir a ação "esperar ônibus", e executará a linha 5. Nas linhas de 7 a 9, é possível observar um exemplo da execução (ou não-execução) de uma ação com base na avaliação de uma expressão em uma estrutura condicional. Nesse trecho, o algorítmo avaliará se a expressão "não há passagem" é verdadeira e, em caso positivo, executará a ação "pegar dinheiro". Caso a expressão "não tenho passagem" seja falsa, isto é, a pessoa tem passagem, o algoritmo ignorará a ação "pegar dinheiro" e executará a linha 10.

Embora não façam parte do escopo desta dissertação, elementos como modularização, tipos abstratos de dados, grafos, além da análise detalhada de algoritmos desenvolvidos para representar situações quotidianas como as retrataddas nas Figuras 10 e 11 podem ser obtidas na referência [6]. 


\subsection{Fluxograma}

Um fluxograma consiste na apresentação do algoritmo em formato gráfico onde ações, estados ou transições são representados por entes geométricos. O início e o fim do algoritmo são delimitados por elipses, as ações a serem executadas por retângulos ou paralelogramos e as estruturas condicionais por losangos no qual são ligadas as duas possibilidades de proseguimento do algoritmo, uma caso a condição seja verdadeira e outra caso seja falsa.

Exemplo 1. O máximo divisor comum de dois números a e b onde pelo menos um é diferente de zero, denotado por mdc( $(a, b)$ ou simplesmente $(a, b)$, é o maior número inteiro positivo que divide simultaneamente a e $b$.

No cálculo do maior dividor comum entre os números $a$ e $b$ serão definidas como entradas os valores de $a$ e $b$ e, como saída, o maior número inteiro positivo que os divide. O algoritmo lato sensu consiste no detalhamento de todos os passos que permitem obter as saídas desejadas para as entradas apresentadas, como se vê na Figura 12, onde está detalhado o Algoritmo de Euclides.

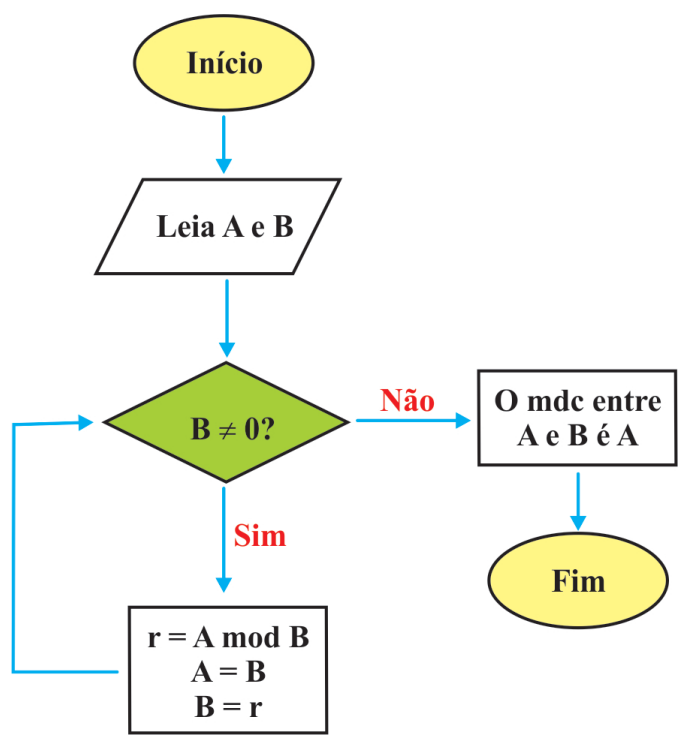

Figura 12: Desenvolvimento do Algoritmo de Euclides

Imediatamente após ser iniciado, o Algoritmo Euclides apresenta instrução, no paralelogramo com os dizeres Leia $A$ e $B$, para definição dos valores para $A$ e $B$, onde, sem perda de generalidade, será considerado que $A>B$. A seguir, no losango, é verificada a proposição lógica $B \neq 0$ : caso seja verdadeira, as três instruções presentes 
no retângulo após a seta indicada com do texto Sim são desenvolvidas, isto é, $r=A$ $\bmod B, A=B$ e $B=r$ e o fluxo é direcionado, novamente, para a estutura condicional. Caso a proposição seja falsa, conclui-se que o $m d c$ entre os números apresentados como entrada é indicado por $A$.

O uso de fluxogramas auxilia no desenvolvimento de habilidades como encadeamento lógico de fatos segundo condições prévias, possibilitando visão global dos procedimentos utilizados na resolução de um problema e são úteis para consolidar conceitos logicamente relacionados.

\subsection{Comparando algoritmos}

Diferentes algoritmos podem ser empregados na resolução do mesmo problema assim como podemos utilizar diferentes métodos para resolver uma equação polinomial de segundo grau, um sistema de equações lineares ou um problema de programação linear. No entanto, a escolha errada do algoritmo pode ocasionar desperdício de ativos como tempo de execução ou cálculos feitos na realização de uma tarefa proposta.

Esse aspecto será observado na comparação dos custos de execução, no pior caso, dos algoritmos Força bruta e Euclides, usados para determinar o maior divisor comum (mdc) entre os números $a$ e $b$ dados, onde $a \geq b$, em função do valor atribuído para $b$ :

\section{Força bruta:}

A idéia básica é buscar, entre todos os números inteiros positivos entre 1 e $\min (a, b)$, o maior inteiro que divide simultaneamente $a$ e $b$. Para tal, iniciase $d$ com $\min (a, b)$ e testa-se todos os seus antecessores, até encontrar um que divida os dois valores apresentados como entrada, conforme indica a Figura 13.

$$
\begin{aligned}
& \text { Força bruta }(\mathbf{a}, \mathbf{b})>\text { supomos que }(\mathbf{a} \neq \mathbf{0} \text { ou } \mathbf{b} \neq \mathbf{0}) \text { e } \mathbf{a} \geq \mathbf{b} \\
& \text { 1. Se } \mathbf{b}=\mathbf{0} \text {, então devolva } \mathbf{a} \\
& \text { 2. Se } \mathbf{a}=\mathbf{0} \text {, então devolva } \mathbf{b} \\
& \text { 3. } \mathbf{d} \leftarrow \mathbf{b} \\
& \text { 4. Enquanto } \mathbf{d} \backslash \mathbf{a} \text { ou } \mathbf{d} \backslash \mathbf{b} \text { faça } \\
& \text { 5. } \mathbf{d} \leftarrow \mathbf{d} \text { - } \mathbf{1} \\
& \text { 6. devolva } \mathbf{d}
\end{aligned}
$$

Figura 13: Algoritmo "Força bruta" para cálculo do MDC

No pior caso, quando $a$ e $b$ são primos entre si, as linhas 1, 2, 3 e 6 são executadas 1 vez cada enquanto as linhas 4 e 5 são executadas $b$ vezes cada. Considerando que o 
tempo de execução de cada linha seja sempre constante, o custo total da execução do algoritmo Força bruta será $C_{1}(b)=4+2 b$. Tal comportamento demonstra que, para $b$ suficientemente grande, o custo tem relação aproximadamente proporcional quando comparado com o valor da entrada $b$, ou seja,

$$
\lim _{b \rightarrow \infty} \frac{C_{1}(b)}{b}=\lim _{b \rightarrow \infty} \frac{2 b+4}{b}=2
$$

\section{Algoritmo de Euclides:}

O algoritmo de Euclides ou método das divisões sucessivas já figurava nos volumes VII e X da célebre e importante obra de Euclides - os Elementos - por volta do ano 300 a.C, e ainda guarda muita semelhança com o que é praticado atualmente nas escolas. Sua correção baseia-se no fato de que, sendo $a \geq 0$ e $b>0$, para cada $d>0$, é válido que $d \mid a$ e $d \mid b$ se, e somente se, $d \mid b$ e $d \mid a(\bmod b)$. Recursivamente, é representado por $m d c(a, b)=m d c(b, a(\bmod b))$, como pode ser observado na Figura 14.

Euclide (a, b) $>$ supomos que (a $\neq 0$ ou $b \neq 0)$ e $a \geq b$

1. Se $\mathbf{b}=\mathbf{0}$

2. então devolva a

3. senão devolva Euclides $(\mathbf{b}, \mathbf{a}(\bmod \mathbf{b}))$

Figura 14: Método de Euclides para cálculo do MDC

Para o pior caso, o custo de execução do Algoritmo de Euclides é proporcional ao número de vezes em que a linha 3 é executada. Assim, supondo-se que o algoritmo efetue $k$ vezes a linha 3 e que na primeira iteração $a \geq b>0$, definiremos

$$
(a, b)=\left(a_{0}, b_{0}\right),\left(a_{1}, b_{1}\right),\left(a_{2}, b_{2}\right), \cdots,\left(a_{k}, b_{k}\right)=((a, b), 0)
$$

como valores dos parâmetros no início de cada iteração. Por definição, é estabelecida a relação de recorrência:

$$
\begin{aligned}
a_{i+1} & =b_{i} \\
b_{i+1} & =a_{i}\left(\bmod b_{i}\right), i \in\{1,2,3, \ldots, k\}
\end{aligned}
$$


Como $p(\bmod q)<\frac{p}{2}$ para números inteiros não negativos $p$ e $q$, escrevemos:

$$
\begin{aligned}
& i=1 \Rightarrow b_{2}=a_{1}\left(\bmod _{1}\right)=b_{0}\left(\bmod _{1}\right)<\frac{b_{0}}{2} \leq \frac{b}{2^{1}} \\
& i=3 \Rightarrow b_{4}=a_{3}\left(\bmod _{3}\right)=b_{2}\left(\bmod _{3}\right)<\frac{b_{2}}{2} \leq \frac{b}{2^{2}} \\
& i=5 \Rightarrow b_{6}=a_{5}\left(\bmod _{5}\right)=b_{4}\left(\bmod _{5}\right)<\frac{b_{4}}{2} \leq \frac{b}{2^{3}} \\
& i=7 \Rightarrow b_{8}=a_{7}\left(\bmod _{7}\right)=b_{6}\left(\bmod _{7}\right)<\frac{b_{6}}{2} \leq \frac{b}{2^{4}}
\end{aligned}
$$

Como o segundo parâmetro é reduzido a menos da sua metade a cada 2 iterações do algoritmo, existe $n \in \mathbb{N}$ tal que $2^{n} \leq b<2^{n+1}$. Da primeira desigualdade, vem que $n \leq \log _{2} b$ e, portanto, concluimos que $n<\log _{2} b+1$. Portanto, no pior caso, o custo de execução do Algoritmo de Euclides, $C_{2}(b)=\log _{2} b+1$, tem comportamento logarítmico.

Estabelecidas funções que associam o custo de execução dos algoritmos ao parâmetro de entrada $b$, é possível perceber a diferença entre as taxas de crescimento por elas apresentadas. Para tal, basta considerar apenas termos da sequência

$$
\left(2^{m}\right)_{m \in\{0,1,2,3, \ldots\}}
$$

para $b$ na construção da tabela Comparação entre custos de execução que permite perceber que $C_{1}(b) \gg C_{2}(b)$, fato que pode ser confirmado a partir da sequência monótona crescente $f(b)=\frac{2 b+4}{\log _{2} b+1}$. A Tabela 2 mostra os custos de execução dos algoritmos Força Bruta e de Euclides, representados respectivamente por $C_{1}$ e $C_{2}$.

Tabela 2: Comparação entre custos de execução dos algoritmos

\begin{tabular}{|c|c|c|c|c|c|c|c|}
\hline $\mathbf{b}$ & $\mathbf{1}$ & $\mathbf{2}$ & $\mathbf{4}$ & $\mathbf{8}$ & $\mathbf{1 6}$ & $\ldots$ & $\mathbf{2}^{\mathbf{m}}$ \\
\hline \hline $\mathrm{C}_{1}(\mathrm{~b})=2 \mathrm{~b}+4$ & 6 & 8 & 12 & 20 & 36 & $\ldots$ & $2 \cdot 2^{\mathrm{m}}+4$ \\
\hline $\mathrm{C}_{2}(\mathrm{~b})=1+\log _{2} \mathrm{~b}$ & 1 & 2 & 3 & 4 & 5 & $\ldots$ & $\mathrm{m}+1$ \\
\hline
\end{tabular}




\subsection{Um exemplo de atividade}

Um dos principais tributos brasileiros, o Imposto de Renda Retido na Fonte (IRRF) é gerado pelo pagamento de salário, vencimento ou demais remunerações decorrentes de vínculo empregatício, recebidos por pessoa física residente no Brasil e retido em decorrência de trabalhos ou seviços prestados no exercício de empregos, cargos e funções. Esses e outros fatores serão abordados na construção de um algoritmo para se determinar o valor do imposto a ser retido do salário do trabalhador mediante estudo e verificação no site da Receita Federal do Brasil [3], seguindo etapas do processo de modelagem propostas no Capítulo 2 - Modelagem.

\subsubsection{Compreensão}

O resultado procurado consiste na construção de um algoritmo (fluxograma) que, a partir do rendimento bruto de um trabalhador e deduções que lhe são de direito, possibilite determinar o valor a ser retido a título de IRRF do salário desse trabalhador. O procedimento é público e utiliza normatização presente no site da Receita Federal do Brasil [3], onde são definidos conceitos como Rendimento Bruto, Rendimento Base de Cálculo, Alíquota e Parcela a Deduzir, todos fundamentais no cálculo do IRRF, bem como sua Tabela Progressiva, conforme Tabela 3.

Tabela 3: Tabela Progressiva para cálculo do IRPF de 2015

\begin{tabular}{|c|c|c|}
\hline Base de Cálculo & Alíquota & Parcela a Deduzir \\
\hline Até $1.903,98$ & - & - \\
\hline De 1.903 .99 até $2.826,65$ & 7,5 & 142,80 \\
\hline De $2.826,66$ até $3.751,05$ & 15,0 & 354,80 \\
\hline De $3.751,06$ até $4.664,68$ & 22,5 & 636,13 \\
\hline Acima de $4.664,68$ & 27,5 & 869,36 \\
\hline
\end{tabular}

Segundo a mesma tabela, o IRRF é calculado tomando por referência o Rendimento Base, definido pela diferença entre seu vencimento bruto e deduções como: valores pagos a título de pensão alimentícia; a quantia, por dependente, de $\mathrm{R} \$ 189,59$; as contribuições pagas ao INSS de qualquer ente federativo; as contribuições pagas para previdência complementar; e demais parcelas indenizatórias como auxílio alimentação e auxílio transporte. Então, um trabalhador sem dependentes cujo rendimento bruto seja $R \$ 2.000,00$ dos quais $R \$ 220,00$ são recolhidos a título de INSS, terá, como 
rendimento base a importância $R \$ 2.000,00-R \$ 220,00=R \$ 1.780,00$ e, conforme a tabela progressiva será incluído na faixa dos que estão isentos do pagamento de imposto. Analogamente, o rendimento base de outro trabalhador, que recebe mensalmente $\mathrm{R} \$ 5.400,00$, recolhe $\mathrm{R} \$ 594,00$ para a previdência social e possui três dependentes, será $R \$ 5.400,00-R \$ 594,00-3 \cdot R \$ 189,59=R \$ 4.237,23$ e pertencerá à faixa da tabela cuja alíquota é $22,5 \%$.

A alíquota e a parcela a ser deduzida serão escolhidas de acordo com o rendimento base conforme tabela progressiva. No exemplo do trabalhador cujo rendimento base foi $R \$ 4.237,23$, o IRRF no mês em questão será

$$
\frac{22,5}{100} \cdot R \$ 4.237,23-R \$ 636,13=R \$ 317,25
$$

Outras particularidades podem ser úteis na compreensão do processo de cálculo do IRRF que emprega alíquotas diferentes e parcelas a deduzir também diferentes, conforme valor auferido para o rendimento base.

\subsubsection{Matematização}

A tradução da situação-problema para a linguagem matemática e consequente construção do algoritmo será obtida como generalização de um procedimento a partir de alguns de seus casos particulares, cujos resultados serão consolidados na forma de uma tabela. A Tabela 4 mostra algumas simulações a serem desenvolvidas para a matematização do problema proposto.

Tabela 4: Simulações de cálculo do IRRF

\begin{tabular}{|c|c|c|c|c|c|c|}
\hline $\begin{array}{c}\text { Rendimento } \\
\text { Bruto }\end{array}$ & $\begin{array}{c}\text { Núme ro de } \\
\text { Dependentes }\end{array}$ & $\begin{array}{c}\text { Contribuições } \\
\text { Previdenciárias }\end{array}$ & $\begin{array}{c}\text { Rendimento } \\
\text { Base }\end{array}$ & Alíquota (\%) & $\begin{array}{c}\text { Parcela a } \\
\text { deduzir }\end{array}$ & $\begin{array}{c}\text { Impos to de } \\
\text { Renda }\end{array}$ \\
\hline \hline $\mathrm{R} \$ 2.000,00$ & 0 & $\mathrm{R} \$ 220,00$ & $\mathrm{R} \$ 1.780,00$ & 0 & $\mathrm{R} \$ 0,00$ & $\mathrm{R} \$ 0,00$ \\
\hline $\mathrm{R} \$ 5.400,00$ & 3 & $\mathrm{R} \$ 594,00$ & $\mathrm{R} \$ 4.237,23$ & 22,5 & $\mathrm{R} \$ 636,13$ & $\mathrm{R} \$ 317,25$ \\
\hline $\mathrm{R} \$ 3.000,00$ & 1 & $\mathrm{R} \$ 330,00$ & $\mathrm{R} \$ 2.480,41$ & 7,5 & $\mathrm{R} \$ 142,80$ & $\mathrm{R} \$ 43,23$ \\
\hline
\end{tabular}

As expressões aritméticas empregadas devem ser apresentadas na tabela para posterior uso no cálculo do Rendimento Base, denotado por $x$, definido pela diferença entre o Rendimento Bruto, $R_{\text {bruto }}$ e o somatório de todas deduções, $d(i)$ a serem consideradas, ou seja,

$$
x=R_{\text {bruto }}-\sum d(i)
$$


A seguir, em função da alíquota $a$ e da parcela a deduzir $p$, determina-se o correspondente imposto de renda retido na fonte $I R R F=\frac{a}{100} \cdot x-p$. Notação alternativa consiste no uso de função definida por diferentes sentenças:

$$
\operatorname{IRRF}(x)=\left\{\begin{array}{lc}
0, & x \leq 1.903,98 \\
0,075 x-142,80, & 1.903,99 \leq x \leq 2.826,65 \\
0,150 x-354,80, & 2.826,66 \leq x \leq 3.751,05 \\
0,225 x-636,13, & 3.751,06 \leq x \leq 4.664,67 \\
0,275 x-869,36, & x \geq 4.664,68
\end{array}\right.
$$

A sentença a ser empregada no cálculo do IRRF para trabalhadores com diferentes rendimentos base, no fluxograma, pode ser representada pelo uso da estrutura condicional (losango) e posterior desenvolvimento algébrico, conforme a Figura 15.

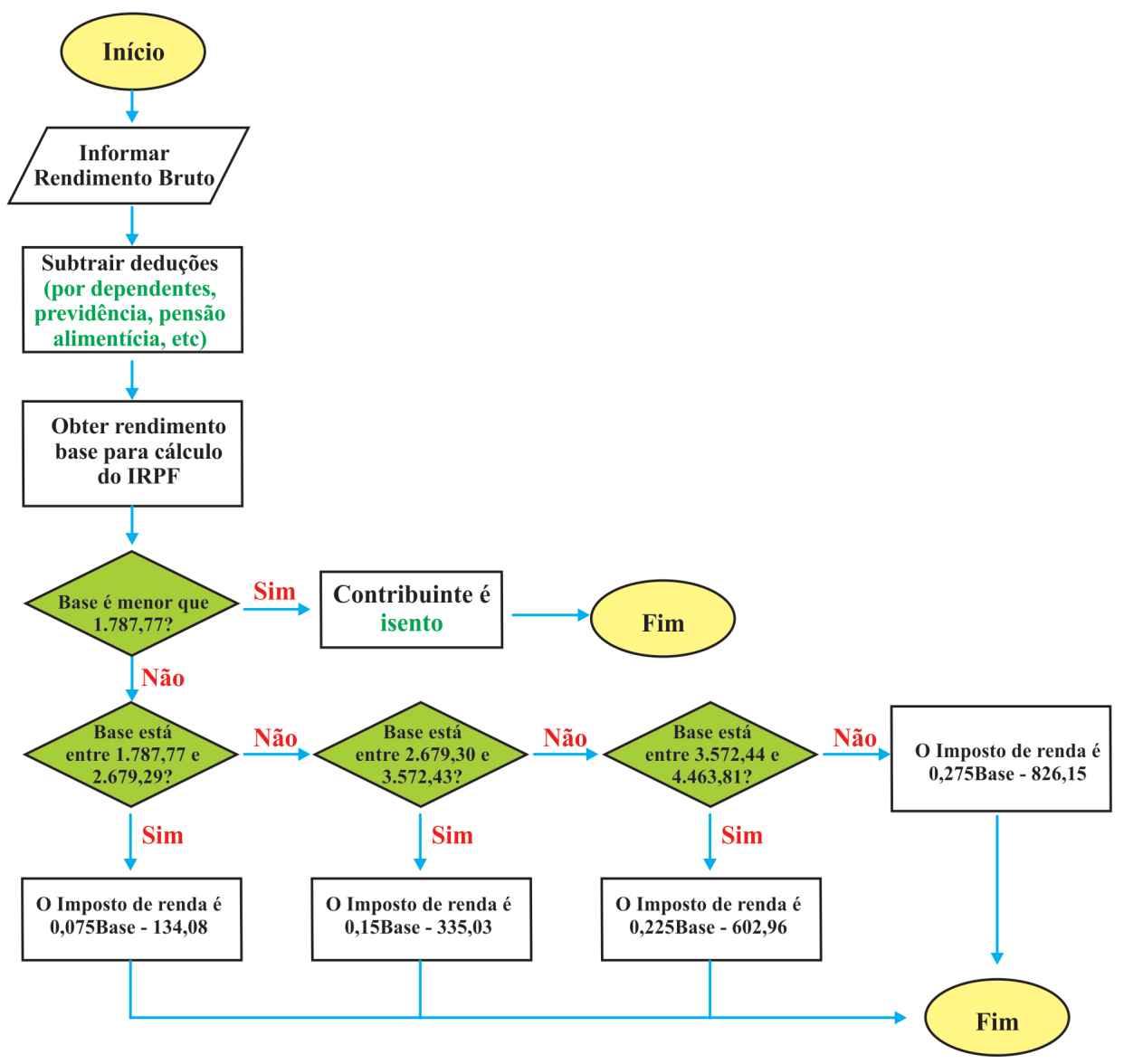

Figura 15: Algoritmo: IRPF 


\subsubsection{Avaliação}

Após matematização e construção do algoritmo, na forma de fluxograma, que detalha todas as etapas do cálculo do IRRF, sua correção e adequabilidade serão verificadas a partir de comparação com resultados obtidos por ferramenta desenvolvida pela Receita Federal do Brasil. O Simulador de Alíquota Efetiva, disponibilizado no site da Receita Federal [4], apresenta como modalidades o cálculo sobre a renda mensal e sobre a renda anual. Escolhendo a primeira opção, é apresentado formulário cujo cabeçalho fora transcrito na Figura 16.

\section{Simulação de Alíquota Efetiva

IMPOSTO SOBRE A RENDA MENSAL - Valores em Reais

Figura 16: Simulador de Alíquota Efetiva da RFB

O uso da ferramenta é intuitivo e consiste no preenchimento de formulário com informações relativas aos elementos que compõem o cálculo do IRRF, conforme é detalhado a seguir:

1. O campo 1. Rendimentos tributáveis deve ser preenchido com o rendimento bruto do trabalhador. Caso o trabalhador tenha mais do que uma fonte de renda, os valores devem ser somados e lançados na Figura 17.

1. Rendimentos tributáveis

0,00

Figura 17: Rendimentos tributáveis

2. Em 2. Deduções, todas as deduções devem ser inseridas nos respectivos campos. As principais deduções são relacionadas à previdência social, número de 
dependentes e pensão alimentícia. As demais deduções devem ser somadas e lançadas no campo 2.4 Outras deduções, como se vê na Figura 18.

\section{Deduções}

2.1 Previdência Oficial

2.2 Dependentes (quantidade)

O valor da dedução é R\$ 189,59 mensais, por dependente.

2.3 Pensão alimentícia

2.4 Outras deduções

0,00

0,00

Previdência Privada, Funpresp, FAPI e parcela isenta de aposentadoria, reserva remunerada, reforma e pensão para declarante com 65 anos ou mais, caso não tenha sido deduzida dos rendimentos tributáveis. CarnêLeão: Livro Caixa.

\subsection{Total de Deduções}

Figura 18: Deduções

3. O valor base de cálculo, exibido na Figura 19 determinado pela diferença entre os campos (1) e (2.5), é mostrado em 3. Base de cálculo e determinará a escolha da alíquota e parcela a deduzir correspondentes, conforme tabela progressiva para cálculo do IRRF. Todas as deduções devem ser inseridas nos respectivos campos.

\section{Base de cálculo (1 - 2.5)}

Figura 19: Rendimento base de cálculo

4. O IRRF é apresentado na Figura 20, no campo 4. Imposto, onde consta também o demonstrativo de sua apuração, isto é, a participação de cada faixa no valor do imposto a ser retido do salário do trabalhador. Por exemplo, caso um trabalhador tenha rendimentos que o inclua na $3^{a}$ faixa, o simulador mostrará que as duas primeiras faixas (onde estão os isentos do pagamento do imposto e os que pagam $7,5 \%$ de alíquota) são relevantes no cálculo do imposto. 


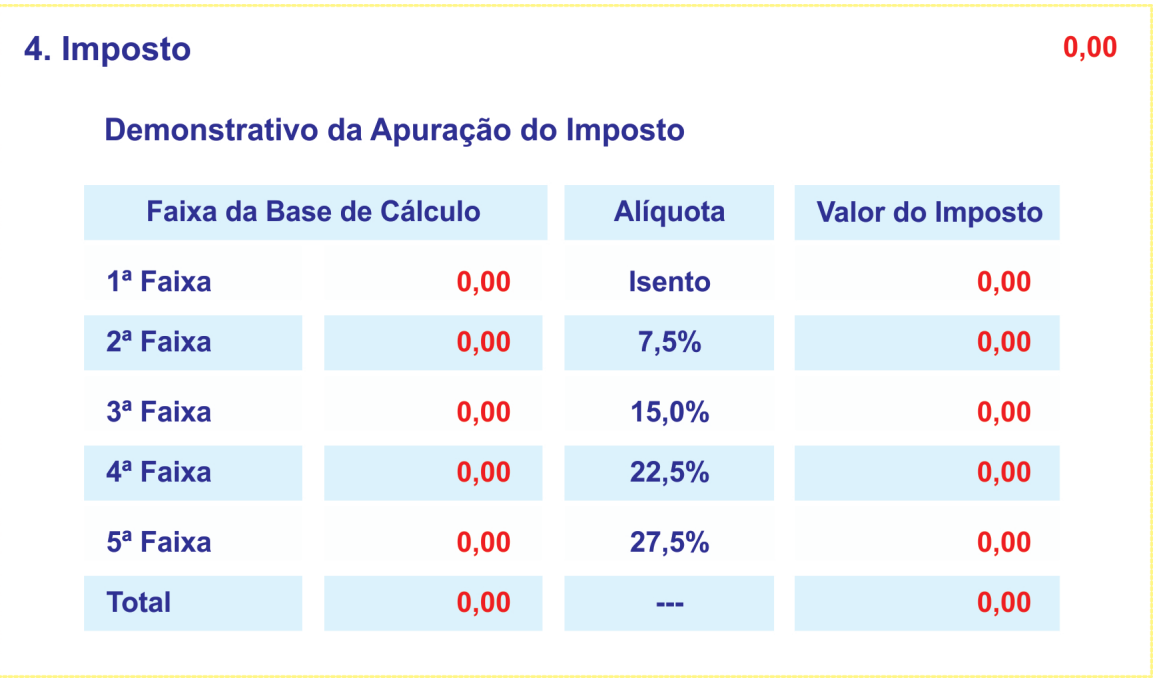

Figura 20: Imposto

5. Por fim, o último campo, 5. Alíquota efetiva, presente na Figura 21, contém o percentual dos rendimentos tributáveis correspondente ao IRRF.

\section{Alíquota efetiva --- \% 0,00 Percentual do imposto pago sobre os rendimentos tributáveis.}

Figura 21: Alíquota efetiva

\subsection{O simplex}

Por ser um algoritmo, o simplex é formado por sequenciamento lógico de operações a serem executadas na resolução de problemas de programação linear e será apresentado no Capítulo 7, pautado em fundamentação teórica presente nos Capítulos 5 (Elementos Teóricos) e 6 (Noções de Cálculo). 


\section{O Geogebra}

O GeoGebra é um aplicativo de geometria dinâmica que possibilita a integração entre conceitos da geometria e da álgebra em uma única GUI (Graphical User Interface). Sua distribuição é livre, nos termos da GNU (General Public License), e é escrito em linguagem Java, o que lhe confere flexibilidade e utilização em diferentes plataformas. Porém, é necessário que no computador esteja instalado uma JVM (Java Virtual Machine) específica para a plataforma ou sistema operacional em uso.

O software permite realizar construções geométricas com a utilização de elementos primitivos da geometria como pontos e retas, assim como inserir equações e funções e também alterar características desses objetos dinamicamente. Características como essas permitem ao GeoGebra manipular números, pontos, vetores, derivadas e integrais de funções como variáveis. Para tal, o programa reúne as ferramentas tradicionais de geometria com outras mais adequadas à álgebra e ao cálculo.

\subsection{Instalação}

Para instalar o Geogebra, devemos acessar o site www.geogebra.org e, no menu superior do mesmo, mostrado na figura 22, clicar sobre o item Downloads.

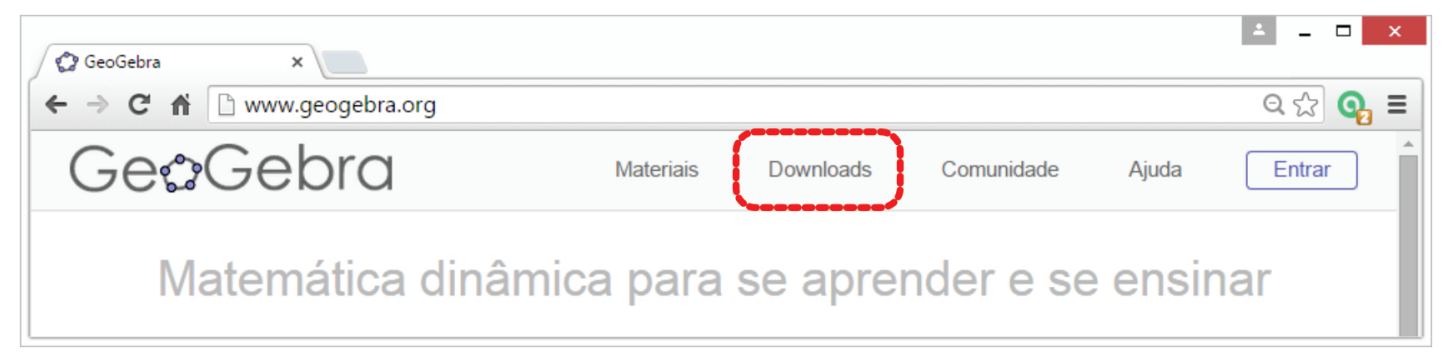

Figura 22: Menu superior do site www.geogebra.org

Na página apresentada a seguir, são apresentadas versões do Geogebra para diferentes arquiteturas de hardware como tablets, desktops e smartphones. Deve ser escolher a versão de acordo com o sistema operacional em uso e seguir processo de instalação a partir de orientações do próprio Geogebra. No sistema operacional Windows, após encerramento do software, o mesmo pode ser inicializado a partir de atalho presente no menu iniciar em procedimmennto similar ao empregado nas demais versões. 


\subsection{A janela inicial do Geogebra}

Ao iniciar nova instância do aplicativo, é apresentada janela composta de cinco regiões conforme se vê na figura 23 .

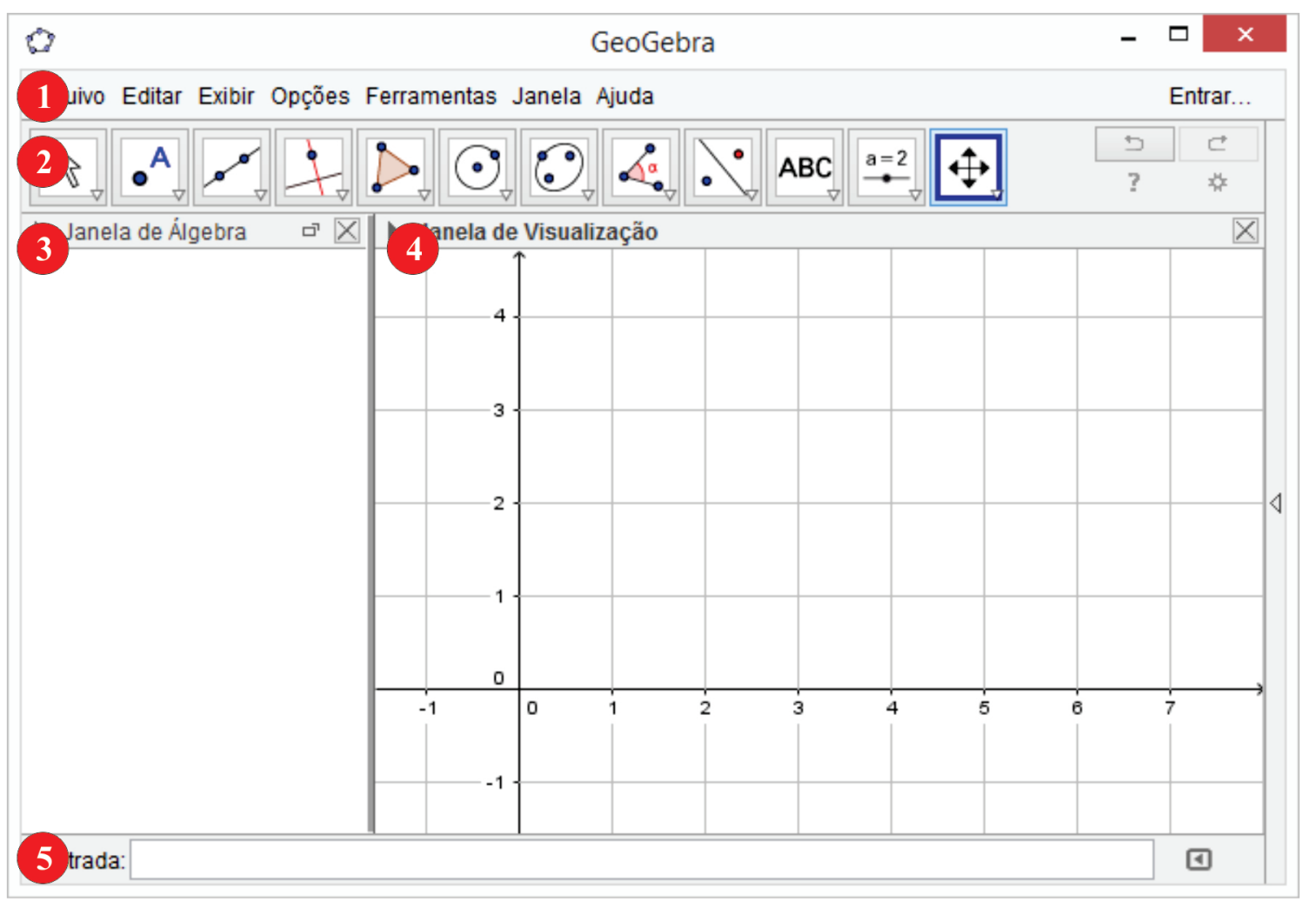

Figura 23: Janela inicial do Geogebra Versão 5

Essas regiões concentram as funcionalidades implementadas pelo Geogebra e são:

1. Barra de menus: contém opções que permitem ao usuário, dentre outras funcionalidades, gravar ou imprimir arquivo do Geogebra criado ou criar nova ferramenta.

2. Barra de ferramentas: é um conjunto de doze grupos de operações oferecidas pelo Gogebra que permitem criar novos objetos matemáticos como pontos, retas ou circunferências e realizar operações com eles.

3. Janela de Álgebra: é a região utilizada para apresentar características de dos elementos contidos no painel de visualização. Por exemplo, caso seja definido 
um objeto representado por uma circunferência de centro $O=(1,3)$ e raio 5 , na Janela de álgebra será mostrada suaequação, ou seja, $(x-1)^{2}+(y-3)^{2}=25$.

4. Janela de visualização: painel onde é apresentada a representação gráfica de cada objeto previamente definido.

5. Entrada: é um campo onde podemos definir um objeto a partir de sua equação. Por exemplo, ao digitar, no campo de entrada, $f(x)=x^{2}$ e pressionar a tecla Enter, será mostrado na Janela de Visualização uma parábola e na Janela de Álgebra, sua formulação algébrica.

\subsection{Principais objetos do Geogebra}

\subsubsection{Pontos}

No Geogebra, os pontos são representados a partir de letras maiúsculas do alfabeto latino. Para crar instância de um ponto, utilizamos suas coordenadas separadas por vírgula caso a forma adotada seja cartesianas como em $P=(2,3)$. Em coordenadas polares, as coordenadas são separadas por ponto e vírgula como em $P=\left(2 ; 30^{\circ}\right)$.

\subsubsection{Retas}

Uma reta pode ser construída na janela de visualização digitando-se diretamente, em Entrada, a equação que a define. Caso exista a necessidade de nomeá-la, deve-se usar uma letra minúscula do alfabeto latino. Caso, em Entrada, seja digitado $r: x-y=0$, será construída a reta $x-y=0$ e a ela será atribuído o nome $r$.

\subsubsection{Seletor}

É a representação gráfica de um número livre ou, de forma geral, de uma variável que assume valores em intervalo previamente definido e pode ser criado a partir da ferramenta Controle deslizante ou do comando de mesmo nome. Na figura 24 é mostrada a janela Controle Deslizante do Geogebra, acessada a partir da Barra de Ferramentas, na qual é definido um número denominado $k$ no intervalo fechado $[-5,5]$ com incrementos de 0.1 . 


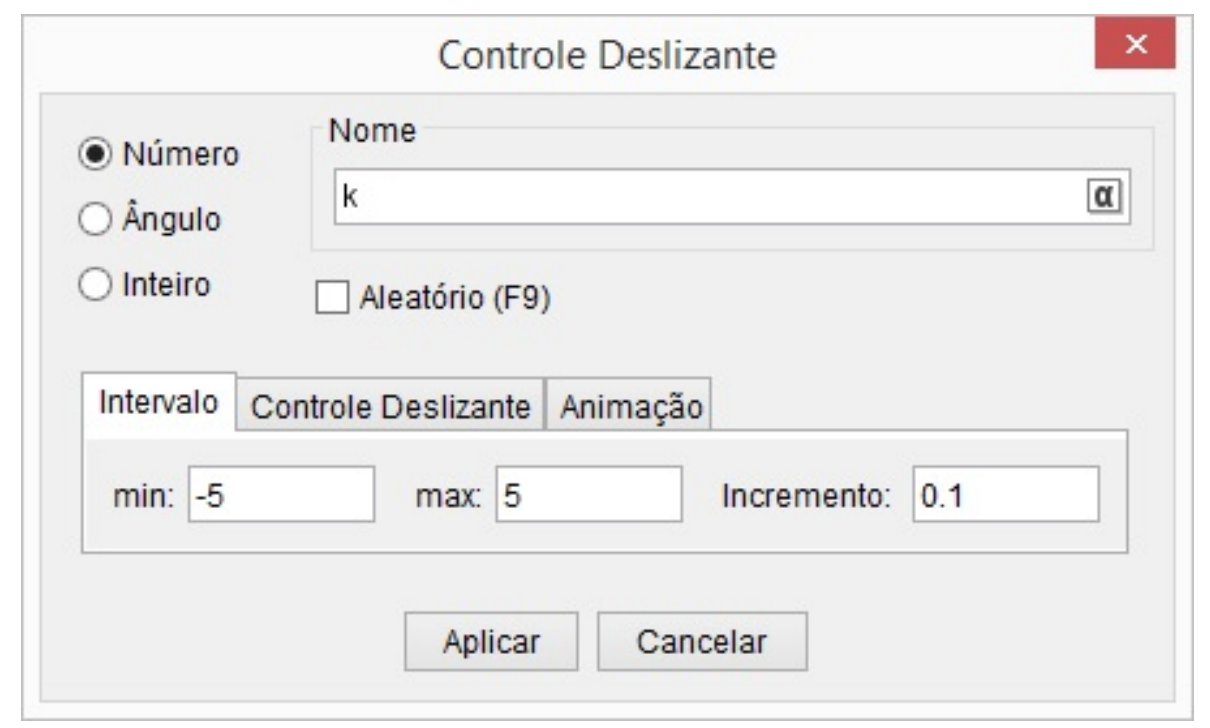

Figura 24: Controle deslizante

\subsubsection{Funções}

A definição de uma função, no Geogebra, segue nomenclatura amplamente divulgada na matemática. Para definir e construir o gráfico da função $f(x)=x^{2}$ definida para todo $x \in \mathbb{R}$ deve-se, no campo Entrada, digitar $f(x)=x^{2}$.

\subsubsection{Comandos}

A seguir, listamos os comandos do Geogebra que serão necessários para plena compreensão das atividades propostas nos capítulos 5, 6, 7 e 8 .

- Polígono [Ponto A, Ponto B, ... ]: Cria polígono cujos vértices são determinados a partir de lista de pontos indicados como parâmetro. Por exemplo, digitando-se, em Entrada, p: Polígono[(0,0), (0,4), (3,0)] e pressionando a tecla Enter, será construído o triângulo que contém tais vértices e a ele será atribuído o nome $p$.

- Área[ $<$ Polígono $>$ ]: Calcula a área do polígono indicado como parâmetro, indicando o resultado na Janela de Álgebra.

Exemplo 2. Calcular a área do polígono $A B C D$, de vértices $A=(1,1), B=(1,4)$, $C=(4,4)$ e $A=(4,1)$. 


\section{Solução}

1. Na Janela de Visualização, clicar com o botão direito do mouse e marcar a opção Malha para exibir a malha quadriculada;

2. Em Entrada, digitar $A=(1,1)$ e pressionar a tecla Enter;

3. Em Entrada, digitar $B=(1,4)$ e pressionar a tecla Enter;

4. Em Entrada, digitar $C=(4,4)$ e pressionar a tecla Enter;

5. Em Entrada, digitar $D=(4,1)$ e pressionar a tecla Enter;

6. Em Entrada, digitar p: Polígono[A, B, C, D] e pressionar Enter para definir o polígono que contém os referidos pontos e a ele associar o nome $p$.

7. Em Entrada, digitar Área[p] e pressionar Enter apresentar o valor da área do polígono $p$. Na figura 25, a área está associada à varivel e, cujo valor é 9 .

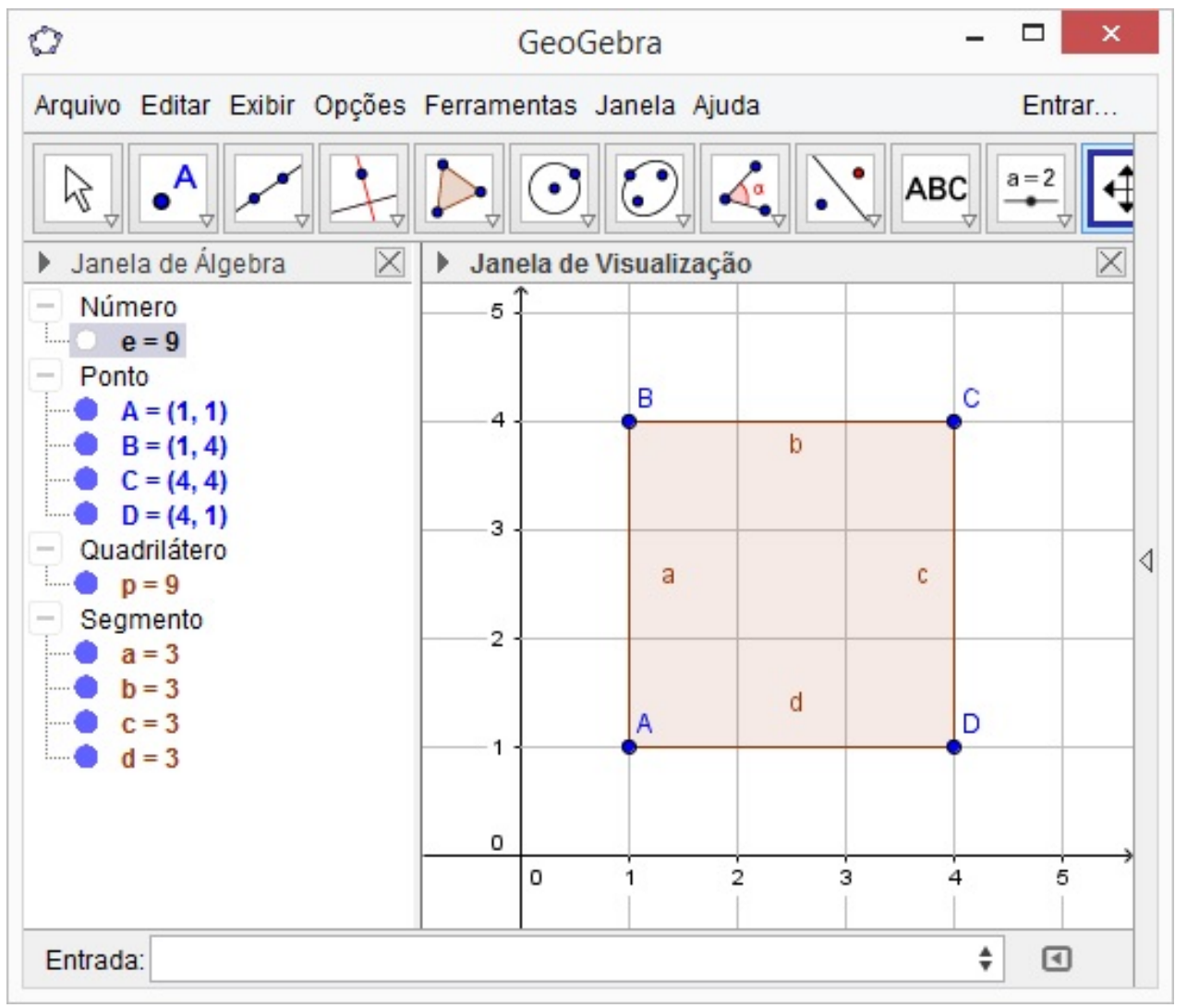

Figura 25: Área do quadrilátero ABCD 
- Perímetro[ $<$ Polígono $>$ ]: Calcula o perímetro do polígono indicado como parâmetro, indicando o resultado na Janela de Álgebra.

- Distância [Ponto A, Ponto B]: determina a distância entre os pontos $A$ e $B$, indicados como parâmetro. Por exemplo, o resultado do processamento do comando distância[(2, 3), (4, 7)], apresentado na Janela de Visualização, é 5.

- Interseção [reta r, reta s]: determina o ponto de interseção entre as retas $r$ e $s$. Este comando é particularmente útil para determinar solução de sistemas lineares de duas equações e duas incógnitas, como será detalhado em 5.3.2 Sistemas Lineares.

- Reta [Ponto A, Ponto B]: determina a equação da reta que contém os pontos $A$ e $B$, representando-a graficamente na Janela de Visualização. A reta $r$, representada na figura 26, foi construído a partir do comando $r$ : Reta [A, B].

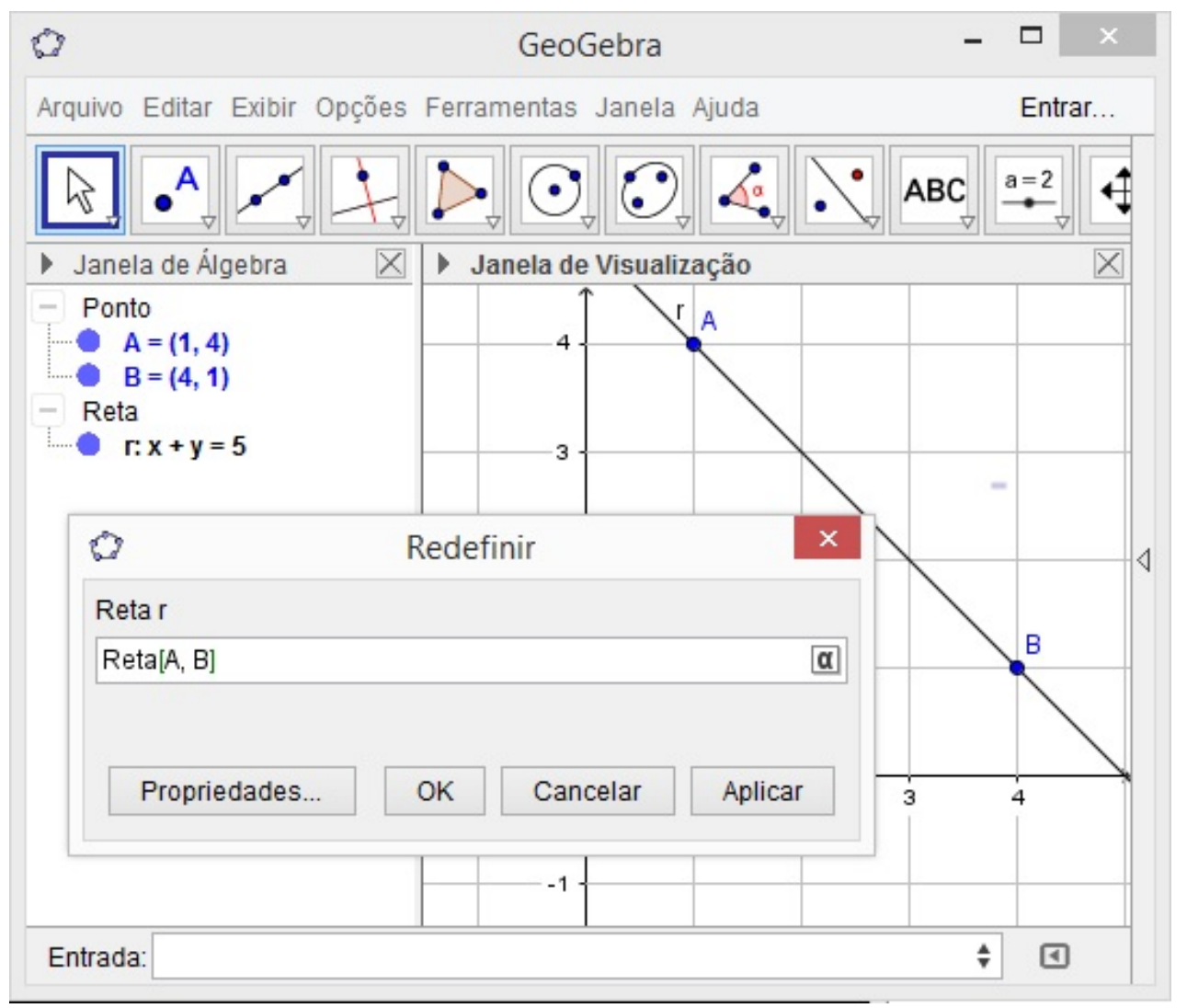

Figura 26: Reta que contém os pontos A e B 
- Reta [Ponto $\mathbf{P}$, reta $\mathbf{r}$ ]: determina a equação da reta paralela à reta $r$ que contém o ponto $P$ e representa, graficamente, o resultado na Janela de Visualização. Por exemplo, o resultado da execução de $\operatorname{Reta}[(0,0), 2 x+3 y=9]$ é $2 x+3 y=0$.

- Perpendicular [Ponto P, reta $\mathbf{r}$ ]: determina a equação da reta perpendicular à reta $r$ que contém o ponto $P$ e representa, graficamente, o resultado na Janela de Visualização. Por exemplo, o resultado da execução de Perpendicular[(0, 0), $2 x+3 y=9]$ é $-3 x+2 y=0$.

Exemplo 3. Na figura 27, as retas s et foram obtidas a partir do uso dos comandos s: Reta[O, r] e s: Perpendicular $[O, r]$, respectivamente onde $r: 2 x+3 y=9$ e $O=(0,0)$.

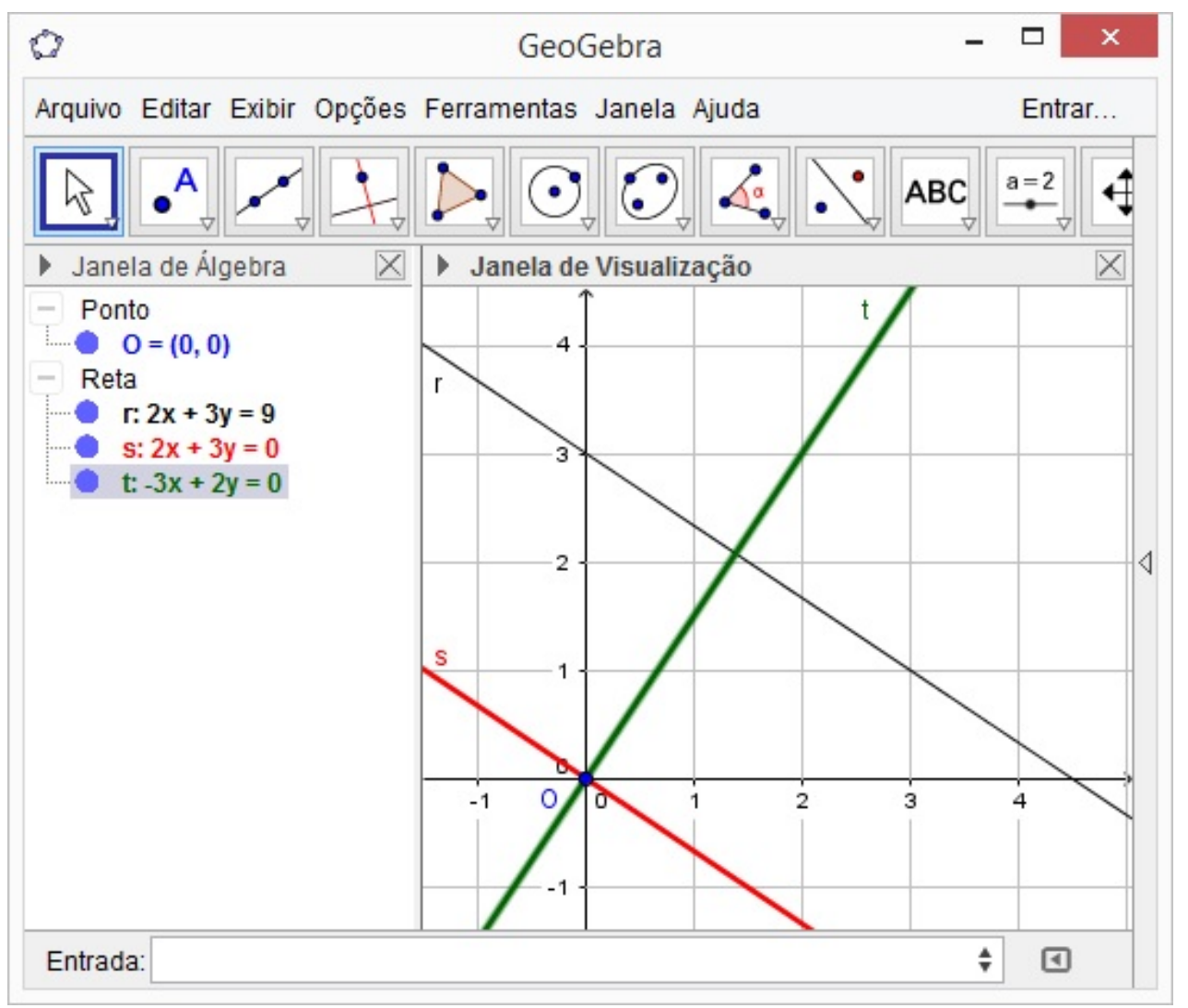

Figura 27: Construção de retas paralelas e penpendiculares a uma reta dada 


\section{Fundamentos teóricos}

O Simplex é um algoritmo que se utiliza de ferramenta baseada na Álgebra Linear para determinar, por um método iterativo, a solução ótima de um Problema de Programação Linear (PPL). Sua concepção básica é simples e, mesmo assim, é considerado eficiente.

Neste capítulo, serão apresentados fundamentos teóricos necessários para a utilização do Simplex bem como justificativas para compreensão de detalhes de cada etapa de sua aplicação, acrescidas de exemplos de abordagem dos temas relacionados com auxílio do software Geogebra. Para mais detalhes, recomendamos a obra de Manoel Paiva [20].

\subsection{A equação da reta}

A programação linear é uma técnica que propõe otimizar (maximizar ou minimizar) o valor de uma função linear, respeitando um conjunto de restrições (equações ou inequações) lineares. Detalhes do algoritmo abordado neste trabalho utilizam a premissa de que, no $\mathbb{R}^{2}$, a representação gráfica de uma equação do tipo $A x+B y=C$ ou $y=a x+b$ é uma reta.

Definição 1. Uma função $f: \mathbb{R} \longrightarrow \mathbb{R}$ é denominada afim se existem constantes reais a e $b$ tais que $f(x)=a x+b$ para todo $x \in \mathbb{R}$. Os coeficientes a e b são denominados, respectivamente, coeficiente angular e coeficiente linear.

A função identidade $f(x)=x$, a função linear $f(x)=a x$ e suas translações $f(x)-y^{\prime}=a\left(x-x^{\prime}\right)$ são exemplos de funções afins. Casos concretos e aplicados podem ser apresentados, por exemplo, no estudo da matemática financeira ou da cinemática.

Teorema 1. O coeficiente angular ou taxa de variação da função $f: \mathbb{R} \longrightarrow \mathbb{R}$ definida por $f(x)=a x+b$ que contém os pontos $P_{1}=\left(x_{1}, y_{1}\right)$ e $P_{2}=\left(x_{2}, y_{2}\right)$ é

$$
a=\frac{y_{2}-y_{1}}{x_{2}-x_{1}}
$$

Demonstração. Por serem $P_{1}=\left(x_{1}, y_{1}\right)$ e $P_{2}=\left(x_{2}, y_{2}\right)$ pontos de $f$, temos que $f\left(x_{1}\right)=a x_{1}+b=y_{1}$ e $f\left(x_{2}\right)=a x_{2}+b=y_{2}$. Subtraindo essas equações, 
$f\left(x_{2}\right)-f\left(x_{1}\right)$, obtém-se

$$
\left(a x_{2}+b\right)-\left(a x_{1}+b\right)=y_{2}-y_{1} \Rightarrow a\left(x_{2}-x_{1}\right)=y_{2}-y_{1} \Rightarrow a=\frac{y_{2}-y_{1}}{x_{2}-x_{1}}
$$

Teorema 2. O gráfico de $f: \mathbb{R} \longrightarrow \mathbb{R}$ definida por $f(x)=a x+b$ é uma reta.

Demonstração. Sejam $P_{1}, P_{2}$ e $P_{3}$ pontos de abscissas $x_{1}, x_{2}$ e $x_{3}$ pertencentes ao gráfico de $f(x)=a x+b$, conforme a figura 28 .

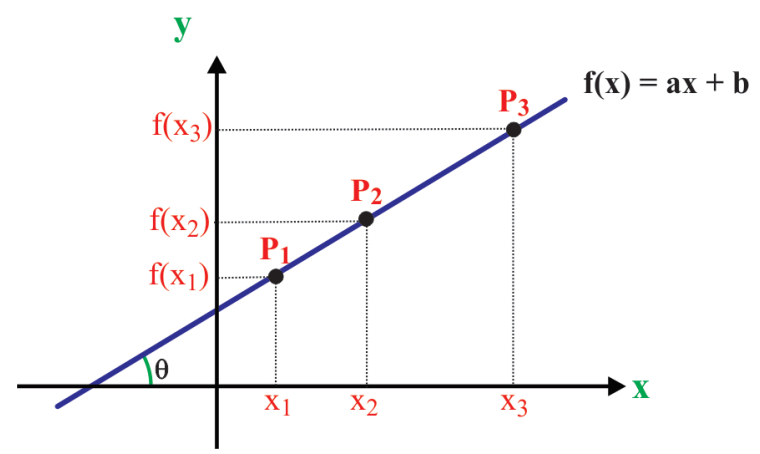

Figura 28: Gráfico de uma função $f(x)=a x+b$

Provar que o gráfico de $f$ é uma reta consiste em mostrar que quaisquer três de seus pontos são colineares, fato que será comprovado ao concluir que as inclinações de $\overline{P_{1} P_{2}}$ e $\overline{P_{1} P_{3}}$ apresentam o mesmo valor.

Portanto,

$$
\begin{aligned}
a_{P_{1} P_{2}} & =\frac{f\left(x_{2}\right)-f\left(x_{1}\right)}{x_{2}-x_{1}} \\
& =\frac{\left(a x_{2}+b\right)-\left(a x_{1}+b\right)}{x_{2}-x_{1}} \\
& =\frac{a x_{2}-a x_{1}}{x_{2}-x_{1}}=\frac{a\left(x_{2}-x_{1}\right)}{x_{2}-x_{1}} \\
& =\frac{a\left(x_{3}-x_{1}\right)}{x_{3}-x_{1}} \\
& =\frac{a x_{3}+b-a x_{1}-b}{x_{3}-x_{1}} \\
& =\frac{f\left(x_{3}\right)-f\left(x_{1}\right)}{x_{3}-x_{1}} \\
& =a_{P_{1} P_{3}}
\end{aligned}
$$


O conceito de coeficiente angular, fundamental para mostrar que o gráfico de $f(x)=a x+b$ é uma reta, deve ser usado na demonstração de teoremas ou resolução de problemas como, por exemplo, da determinação da equação de uma reta dados dois de seus pontos.

Exemplo 4. Determinar a equação da reta que contém $P_{1}=\left(x_{1}, y_{1}\right)$ e $P_{2}=\left(x_{2}, y_{2}\right)$.

\section{Solução}

Seja $P=(x, y) \in \overline{P_{1} P_{2}}$. Determina-se a equação da reta que contém $P_{1}=\left(x_{1}, y_{1}\right)$ e $P_{2}=\left(x_{2}, y_{2}\right)$ ao estabelecer a colinearidade entre $P, P_{1}$ e $P_{2}$, ou seja,

$$
\begin{aligned}
a_{P P_{1}}=a_{P P_{2}} & \Rightarrow \frac{y-y_{1}}{x-x_{1}}=\frac{y-y_{2}}{x-x_{2}} \\
& \Rightarrow\left(y-y_{1}\right)\left(x-x_{2}\right)=\left(y-y_{2}\right)\left(x-x_{1}\right) \\
& \Rightarrow x y-x_{2} y-y_{1} x+x_{2} y_{1}=x y-x_{1} y-y_{2} x+x_{1} y_{2} \\
& \Rightarrow\left(x_{1}-x_{2}\right) y-\left(y_{1}-y_{2}\right) x=x_{1} y_{2}-x_{2} y_{1} \\
& \Rightarrow\left(y_{1}-y_{2}\right) x-\left(x_{1}-x_{2}\right) y+x_{1} y_{2}-x_{2} y_{1}=0
\end{aligned}
$$

Considerando $y_{1}-y_{2}=A, x_{2}-x_{1}=B$ e $x_{1} y_{2}-x_{2} y_{1}=C$, a equação reduz-se a $A x+B y+C=0$, conhecida como Equação Geral da Reta. Porém, explicitando y em termos das coordenadas de $P_{1}$ e $P_{2}$, obtém-se a Equação Reduzida da Reta

$$
y=\frac{y_{2}-y_{1}}{x_{2}-x_{1}} x+\frac{x_{2} y_{1}-x_{1} y_{2}}{x_{2}-x_{1}}
$$

onde $\frac{x_{2} y_{1}-x_{1} y_{2}}{x_{2}-x_{1}}=b$ é o coeficiente linear de $\overline{P_{1} P_{2}}$.

Paralelamente ao desenvolvimento algébrico, o Geogebra pode ser utilizado como ferramenta dinâmica para verificar se um problema foi desenvolvido corretamente, como será ilustrado no exemplo seguinte, onde é determinada a equação de reta a partir de dois pontos dados e uso do comando Reta.

Exemplo 5. Determinar a equação da reta que passa por $P=(2,3)$ e $Q=(4,-1)$. 


\section{Solução}

Algebricamente, o procedimento consiste em empregar a condição de alinhamento de três pontos utilizando, para tal, os pontos $P=(2,3), Q=(4,-1)$ e $T=(x, y)$ :

$$
\begin{aligned}
a_{P T}=a_{Q T} & \Rightarrow \frac{y-3}{x-2}=\frac{y+1}{x-4} \\
& \Rightarrow(y-3)(x-4)=(y+1)(x-2) \\
& \Rightarrow y x-4 y-3 x+12=y x-2 y+x-2 \\
& \Rightarrow-2 y-4 x+14=0 \\
& \Rightarrow 2 x+y=7 \\
& \Rightarrow y=7-2 x
\end{aligned}
$$

O resultado é confirmado, no Geogebra, a partir do desenvolvimento dos seguintes passos:

1. Clicar com o botão direito do mouse sobre um dos eixos coordenados, na Janela de Visualização e escolher a opção Malha.

2. Em Entrada, digitar $P=(2,3)$ e pressionar a tecla Enter para marcar, na Janela de Visualização, o ponto $P=(2,3)$;

3. Em Entrada, digitar $Q=(4,-1)$ e pressionar a tecla Enter para marcar, na Janela de Visualização, o ponto $Q=(4,-1)$;

4. Em Entrada, digitar $r: \operatorname{Reta}[P, Q]$ e pressionar Enter para criar o objeto reta a partir dos pontos $P$ e $Q$;

A instrução $r: \operatorname{Reta}[P, Q]$ construirá, na Janela de Visualização do Geogebra, a reta $r$ que contém os pontos $P$ e $Q$, definidos anteriormente e mostrará, na Janela de Âlgebra, a equação da reta procurada. A figura 29 mostra o resultado da construção da reta que contém os pontos $P$ e $Q$ a partir do Geogebra. 


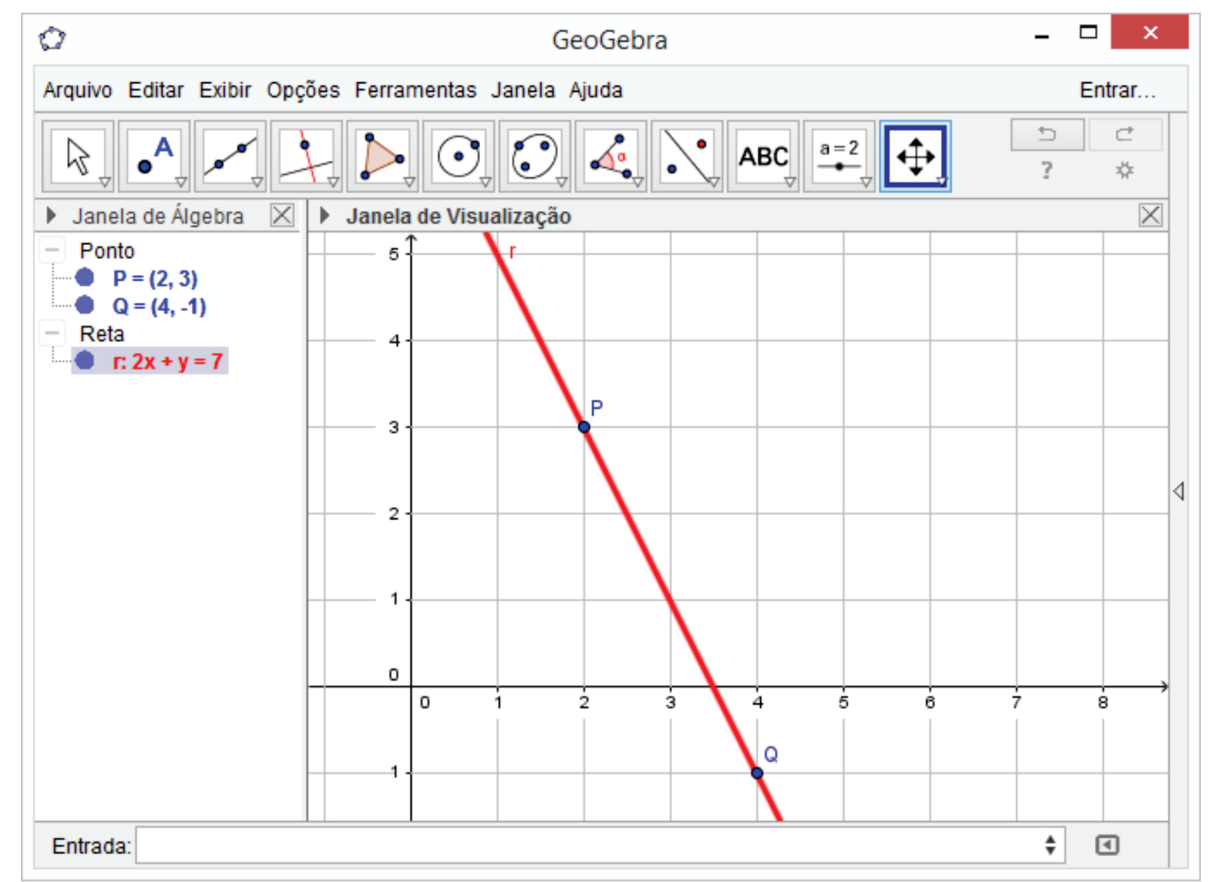

Figura 29: Reta que contém os pontos $P(2,3)$ e $Q=(4,-1)$

Os coeficientes $a$ e $b$ apresentam significados geométricos singulares: enquanto o coeficiente $b$ caracteriza-se por definir ponto de interseção entre o gráfico de $f$ e o eixo das ordenadas, o coeficiente $a$, ou inclinação da reta, é equivalente à tangente do ângulo formado pela reta, gráfico de $f(x)=a x+b$, e pelo semieixo horizontal positivo, e possibilita classificar a função como crescente, decrescente ou constante, caso a seja, respectivamente, positivo, negativo ou igual a zero, como se vê na figura 30 .

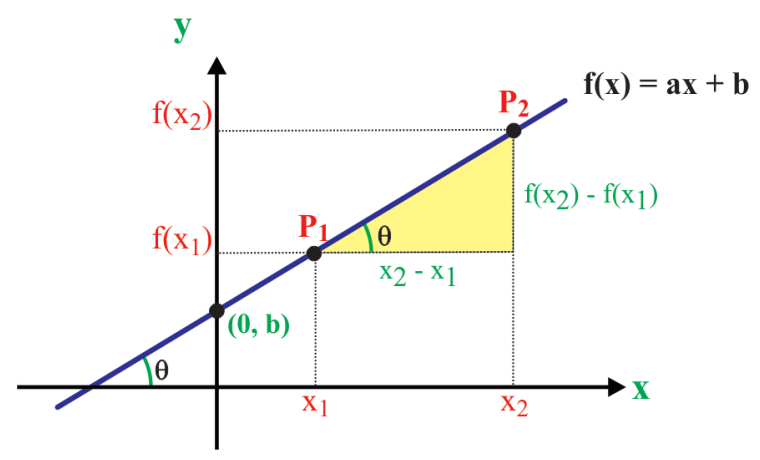

Figura 30: Coeficientes de $f(x)=a x+b$ 


$$
a=\operatorname{tg} \theta=\frac{\triangle y}{\triangle x}=\frac{y_{2}-y_{1}}{x_{2}-x_{1}}
$$

Exemplo 6. O montante resultante da aplicação da quantia de $C$ reais, à taxa de $i$ por unidade de tempo de juros simples durante período de $t$ unidades de tempo é $M(t)=$ $C(1+i t)$, cuja representação gráfica consiste de semirreta crescente que intercepta o eixo das ordenadas no ponto $(0, C)$ como está detalhado na figura 31.

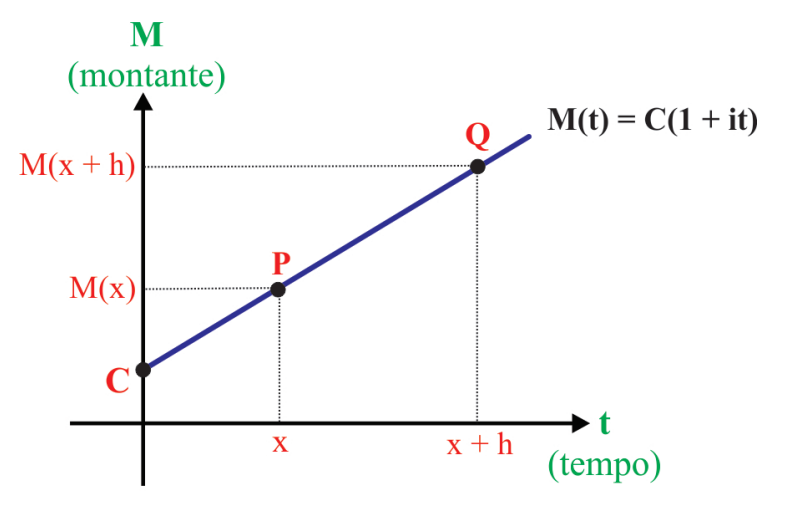

Figura 31: Gráfio do montante de uma aplicação financeira

O estudo das equações do tipo $A x+B y+C=0$ não deve ser apresentado sem a devida vinculação com sua representação gráfica, mesmo no ensino fundamental, quando são desenvolvidos os primeiros elementos algébricos. A equivalência entre termos como "equação de primeiro grau com duas incógnitas" e "equação da reta" é colocada em segundo plano em decorrência do processo de algebrização da matemática ainda muito presente no ensino fundamental. Nesse contexto, o Geogebra se apresenta como ferramenta que colabora com a construção da bijeção entre equação de uma reta, em qualquer uma das suas representações, e sua representação cartesiana.

Exemplo 7. Escrever, na forma reduzida, a equação da reta cuja forma geral é $6 x+2 y-7=0$.

\section{Solução}

O desenvolvimento algébrico consiste em explicitar a variável y em um dos lados da igualdade, como é observado em $6 x+2 y-7=0 \Rightarrow 2 y=-6 x+7 \Rightarrow y=-3 x+\frac{7}{2}$ 
Determinada a forma reduzida da equação apresentada, o resultado será comprovado com o Geogebra, após cumprimento dos seguintes passos:

1. Clicar com o botão direito do mouse sobre um dos eixos coordenados, na Janela de Visualização e escolher a opção Malha. Embora não seja essencial na resolução do problema, a malha quadriculada colabora com a identificação de elementos quantitativos da reta a ser construída.

2. Em Entrada, digitar $6 x+2 y-7=0$ e pressionar Enter. Como decorrência dessa ação, na Janela de Visualização, é construída a representação cartesiana da reta $6 x+2 y-7=0$;

3. Na Janela de Álgebra, clicar com botão direito do mouse sobre a equação da reta e, no menu de contexto apresentado, escolher a opção Equação $y=a x+b$. As ações apresentadas permitem reverter a equação para a forma apresentada originalmente. As opções apresentadas pelo Geogebra são ilustradas na figura 32 .

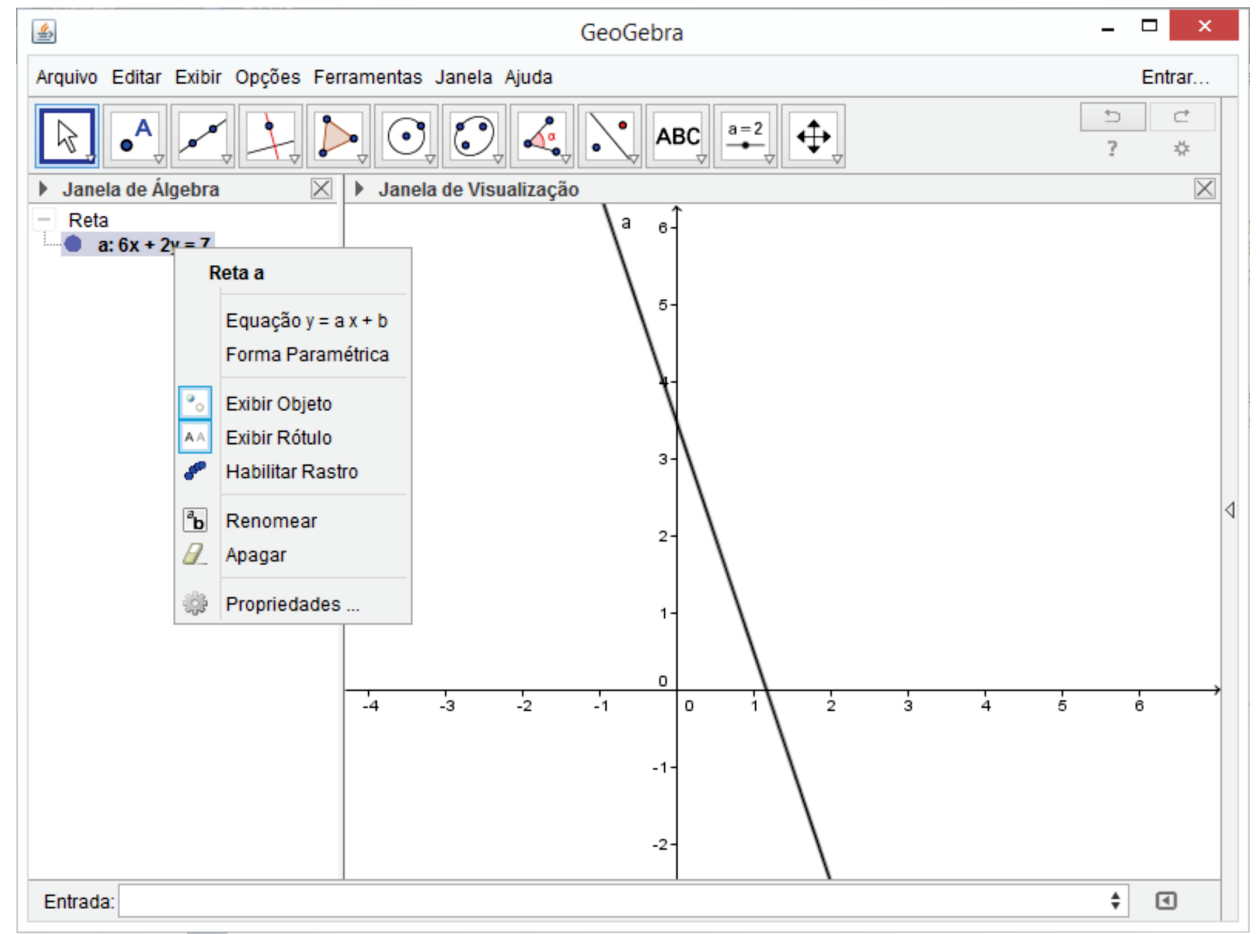

Figura 32: Opções associadas ao objeto Reta 


\subsubsection{Posições relativas entre retas coplanares}

No sistema de coordenadas cartesianas, duas retas, $r$ e $s$, de inclinações $a_{r}$ e $a_{s}$, respectivamente, podem ser paralelas distintas, paralelas coincidentes ou concorrentes, conforme é apresentado a seguir:

I. As retas $r$ e $s$, de equações $A x+B y=C$ e $D x+E y=F$, respectivamente, são paralelas se, e somente se, apresentam os mesmos coeficientes angulares ou se não existem seus coeficientes angulares.

Teorema 3. Se r e s sãa paralelas, então $\frac{A}{D}=\frac{B}{E}$.

Demonstração. As formas reduzidas de $r$ e $s$ são, respectivamente, $y=-\frac{A}{B} x+\frac{C}{B}$ e $y=-\frac{D}{E} x+\frac{F}{E}$. Então $-\frac{A}{B}=-\frac{D}{E} \Rightarrow \frac{A}{D}=\frac{B}{E}$. Caso $\frac{A}{D}=\frac{B}{E}=\frac{C}{F}, r$ e $s$ são coincidentes. Essas situações são ilustradas nas figuras 33 e 34
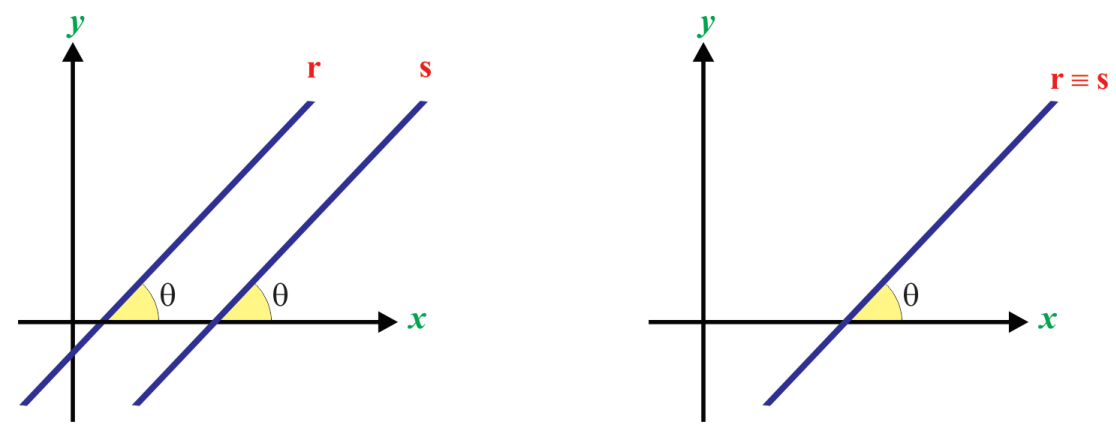

Figura 33: $a_{r}=a_{s} \Rightarrow r / / s$
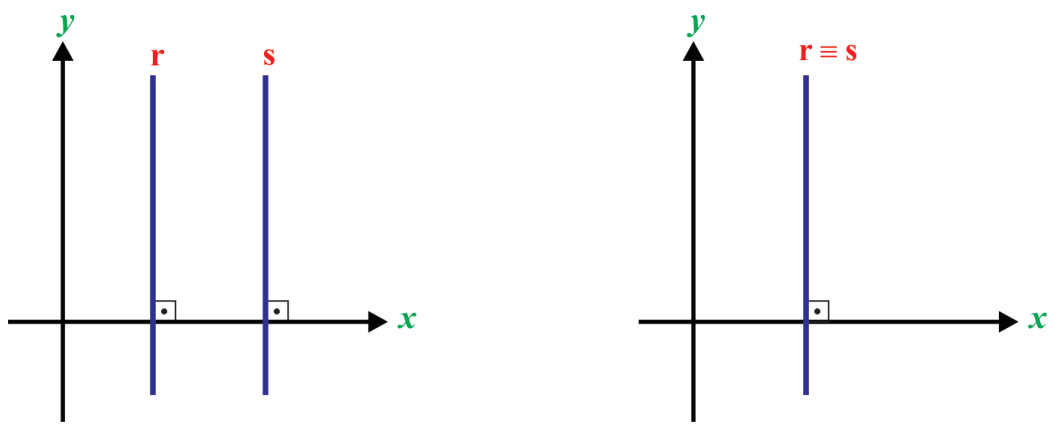

Figura 34: $\nexists a_{r}$ e $\nexists a_{s} \Rightarrow r / / s$ 
II. As retas $r$ e $s$, de equações $A x+B y=C$ e $D x+E y=F$, respectivamente, são concorrentes se, e somente se apresentam coeficientes angulares diferentes ou se existe o coeficiente angular de uma delas e não existe o da outra.

Teorema 4. Sejam $r$ e s retas de equações $A x+B y=C$ e $D x+E y=F$, respectivamente. Se r e s são concorrentes, então $\frac{A}{D} \neq \frac{B}{E}$.

Demonstração. As inclinações das retas $r$ e $s$ são, respectivamente, $\frac{-A}{B}$ e $\frac{-D}{E}$. Para que sejam retas concorrentes, basta que tenham inclinações diferentes, ou seja, $\frac{-A}{B} \neq \frac{-D}{E}$, ou seja, $\frac{A}{D} \neq \frac{B}{E}$.

Na figura 35 tem-se os gráficos de retas concorrentes.
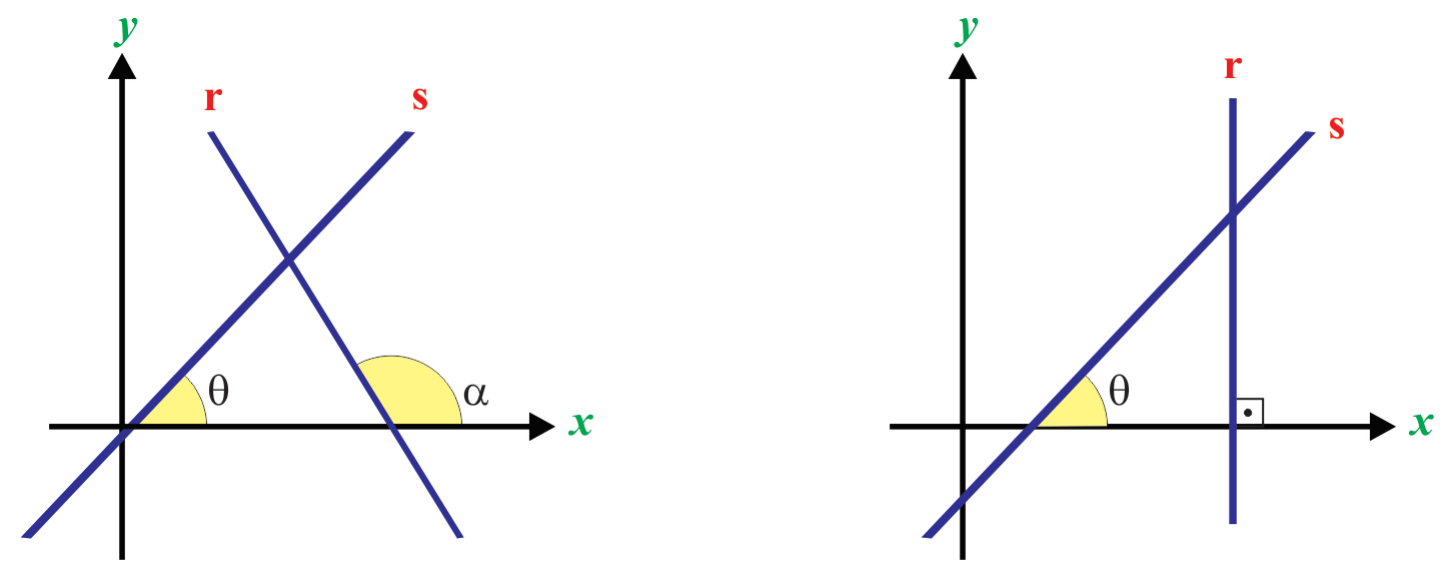

Figura 35: $a_{r} \neq a_{s} \Rightarrow r$ e $s$ são concorrentes

As retas $2 x+3 y=12$ e $8 x+12 y=5$ são paralelas enquanto $x+y=12 \mathrm{e}$ $2 x+3 y=9$ são concorrentes - fatos que podem ser facilmente comprovados no Geogebra digitando-se, no Campo de Entrada, cada uma das equações indicadas. Se fossem retas coincidentes, suas equações corresponderiam a um só lugar geométrico.

\subsubsection{Equação segmentária da reta}

A equação segmentária apresenta, em sua formulação, dois elementos posicionais importantes: os interceptos da reta com os eixos coordenados, os quais definidos por $Q=(0, q)$ e $P=(p, 0)$, conforme é observado na figura 36 . 


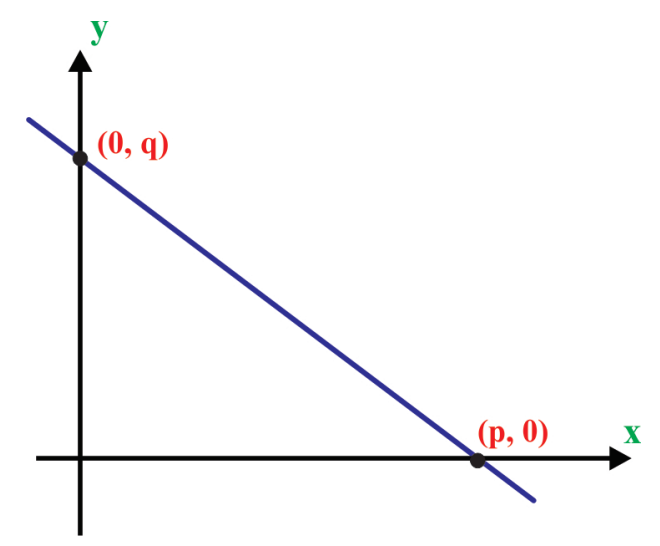

Figura 36: Interceptos da reta com os eixos coordenados

Considerando $T=(x, y)$ como ponto da reta que contém $P$ e $Q$, e adotando a condição de alinhamento de três pontos, escreve-se:

$$
\begin{aligned}
a_{T Q}=\frac{y-q}{x-0} & =\frac{y-0}{x-p}=a_{T P} \\
& \Rightarrow x y=x y-q x-p y+p q \\
& \Rightarrow q x+p y=p q
\end{aligned}
$$

A forma segmentária da reta é obtida dividindo-se a equação obtida por $p q$, cujos denominadores evidenciam os interceptos da reta com os eixos coordenados:

$$
\frac{x}{p}+\frac{y}{q}=1
$$

Exemplo 8. Calcular a área da região delimitada pelas retas $\frac{x}{2}+\frac{y}{3}=1, \frac{x}{5}+\frac{y}{8}=1$ e pelos eixos coordenados.

\section{Solução}

1. Clicar com o botão direito do mouse sobre um dos eixos coordenados, na Janela de Visualização e escolher a opção Malha.

2. Em Entrada, digitar $x / 2+y / 3=1$ e pressionar Enter.

3. Em Entrada, digitar $x / 5+y / 8=1$ e pressionar Enter.

4. Em Entrada, digitar $A=$ Intersecao $[a, x=0]$ e pressionar Enter. 
5. Em Entrada, digitar $B=$ Intersecao $[b, x=0]$ e pressionar Enter.

6. Em Entrada, digitar $C=$ Intersecao $[b, y=0]$ e pressionar Enter.

7. Em Entrada, digitar $D=$ Intersecao $[a, y=0]$ e pressionar Enter.

8. Em Entrada, digitar $P=\operatorname{Poligono}[A, B, C, D]$ e pressionar Enter.

Conforme se vê na figura 37, a área de P, exibida na Janela de Álgebra e indicada pelo nome do polígono, é 17.

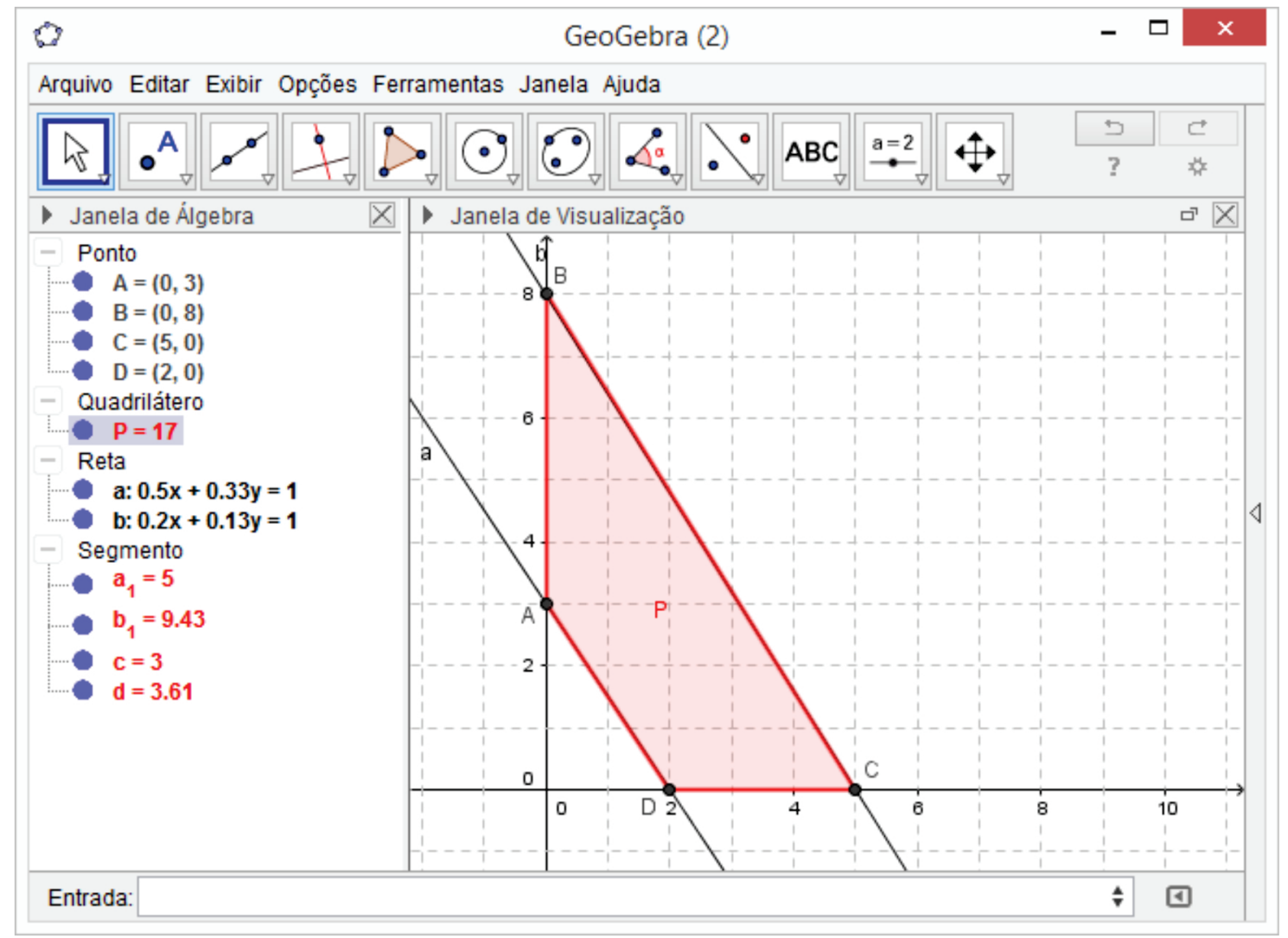

Figura 37: Polígono $A B C D$

\subsection{Inequações}

Nesta seção, apresentaremos o tema inequações, especialmente às definidas no $\mathbb{R}^{2}$ por ser importante elemento para bom entendimento do algoritmo simplex, particularmente em sua versão geométrica. 
Definição 2. Sejam $f, g: D \subset \mathbb{R} \rightarrow \mathbb{R}$ duas funções reais definidas em sunconjunto não vazio de $\mathbb{R}$. Define-se por inequação na incónita $x$ a qualquer uma das sentenças abertas $f(x)>g(x), f(x)<g(x), f(x) \geq g(x)$ ou $f(x) \leq g(x)$. O número real $x_{0} e^{\prime}$ solução da inequação $f(x)>g(x)$ se, e somente se $f\left(x_{0}\right)>g\left(x_{0}\right)$ for verdadeira.

Resolver uma inequação $f(x)<g(x)$, em $D$, consiste em determinar todos os números reais $x_{0} \in D$ para os quais a sentença $f\left(x_{0}\right)<g\left(x_{0}\right)$ é verdadeira. Algebricamente, o procedimento de resolução de inequações de uma variável resume-se a obter expressões equivalentes simplificadas, como podemos observar no exemplo seguinte:

$$
\begin{aligned}
4 x-3 & >3 x+6 \\
& \Rightarrow 4 x-3+(-3 x+3)>3 x+6+(-3 x+3) \\
& \Rightarrow 4 x-3 x-3+3>3 x-3 x+6+3 \\
& \Rightarrow x>9
\end{aligned}
$$

Geometricamente, o conjunto solução da inequação é formado por todo $x \in \mathbb{R}$ para que $f(x)=4 x-3$ tenham ordenada maior do que a ordenada do $g(x)=3 x+6$, fato que se concretiza em $\{x \in \mathbb{R}: x>9\}$ e representado na figura 38 .

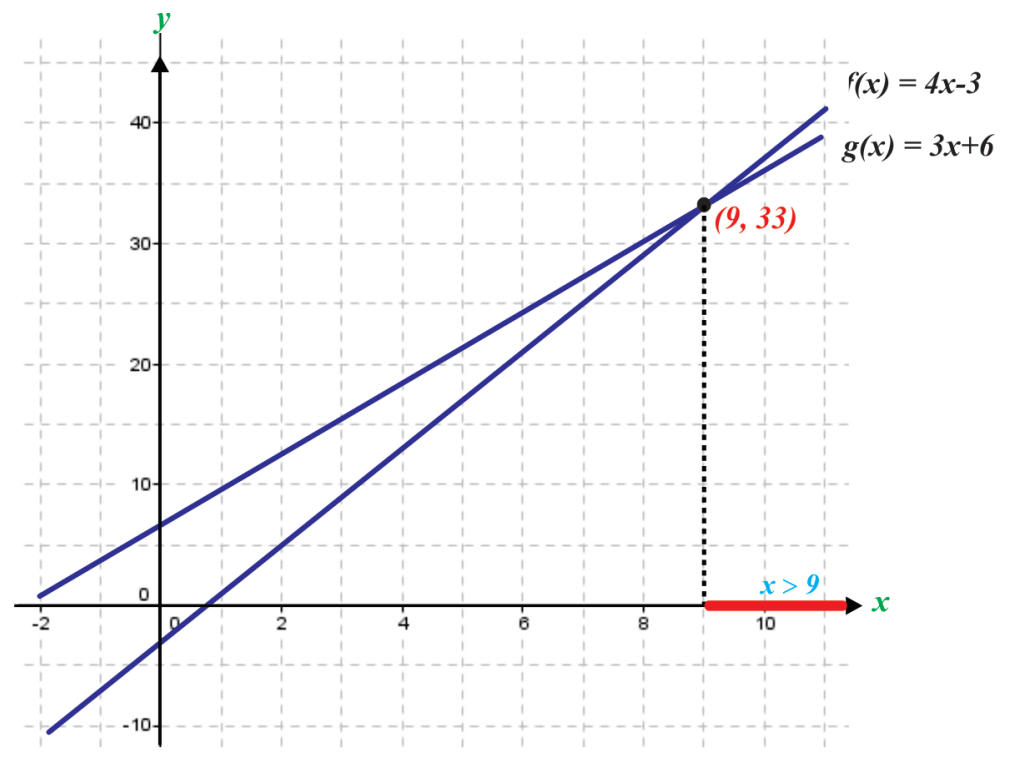

Figura 38: Resolução gráfica de inequações 


\subsubsection{Inequações definidas em $\mathbb{R}$}

O estudo de inequações de uma variável definidas em $\mathbb{R}$ com uma incógnita está bem sistematizado nas principais referências bibliográficas do ensino médio, [9], [13] e [20], com predominância de aspectos algébricos sobre geométricos e uso de regras fundamentadas em coeficienes e elementos específicos das principais funções como as polinomiais de $1^{o}$ e $2^{o}$ graus, exponenciais, logaritmicas, trigonométricas e modulares.

O recurso gráfico deve ser evocado ao resolver desigualdades como $x^{2}-6 x+8 \geq 0$, ocasião em que é construído o gráfico da função quadrática $f(x)=x^{2}-6 x+8$ para posterior estudo de sinal. Na figura 39, a solução de $x^{2}-6 x+8 \geq 0$ está associada às regiões indicadas com o sinal de + .

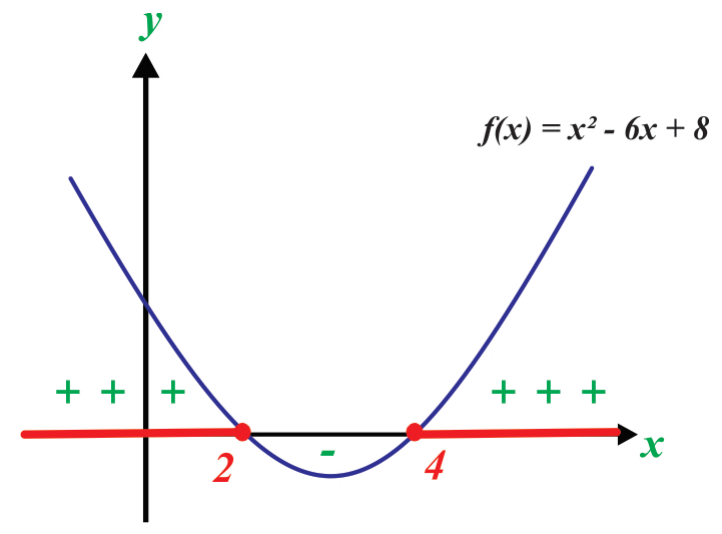

Figura 39: Estudo de sinal de $f(x)=x^{2}-6 x+8$

Nesse contexto, o Geogebra surge como ferramenta para auxiliar na sistematização do estudo de sinal de uma função por possibilitar a construção de gráficos de diferentes tipos de função como, por exemplo, uma função polinomial de $3^{\circ}$ grau.

Exemplo 9. Determinar o conjunto solução da inequação $x^{3}-6 x^{2}+11 x-6<0$.

\section{Solução}

Adotando abordagem geométrica na resolução da desigualdade proposta, o conjunto solução de $x^{3}-6 x^{2}+11 x-6<0$ será determinado a partir do estudo de sinal de $f(x)=x^{3}-6 x^{2}+11 x-6$, cujo gráfico será construído no Geogebra. 
1. Clicar com o botão direito do mouse sobre a Janela de Visualização e marcar a opção Malha para exibir a malha quadriculada sobre o sistema de coordenadas cartesianas.

2. Em Entrada, digitar $f(x)=x^{3}-6 x^{2}+11 x-60$ e pressionar Enter para exibição do gráfico de $f$, como se vê na figura 40. Caso haja necessidade, recomenda-se o ajuste quanto a visualização da figura gerada usando as ferramentas Ampliar e Reduzir.

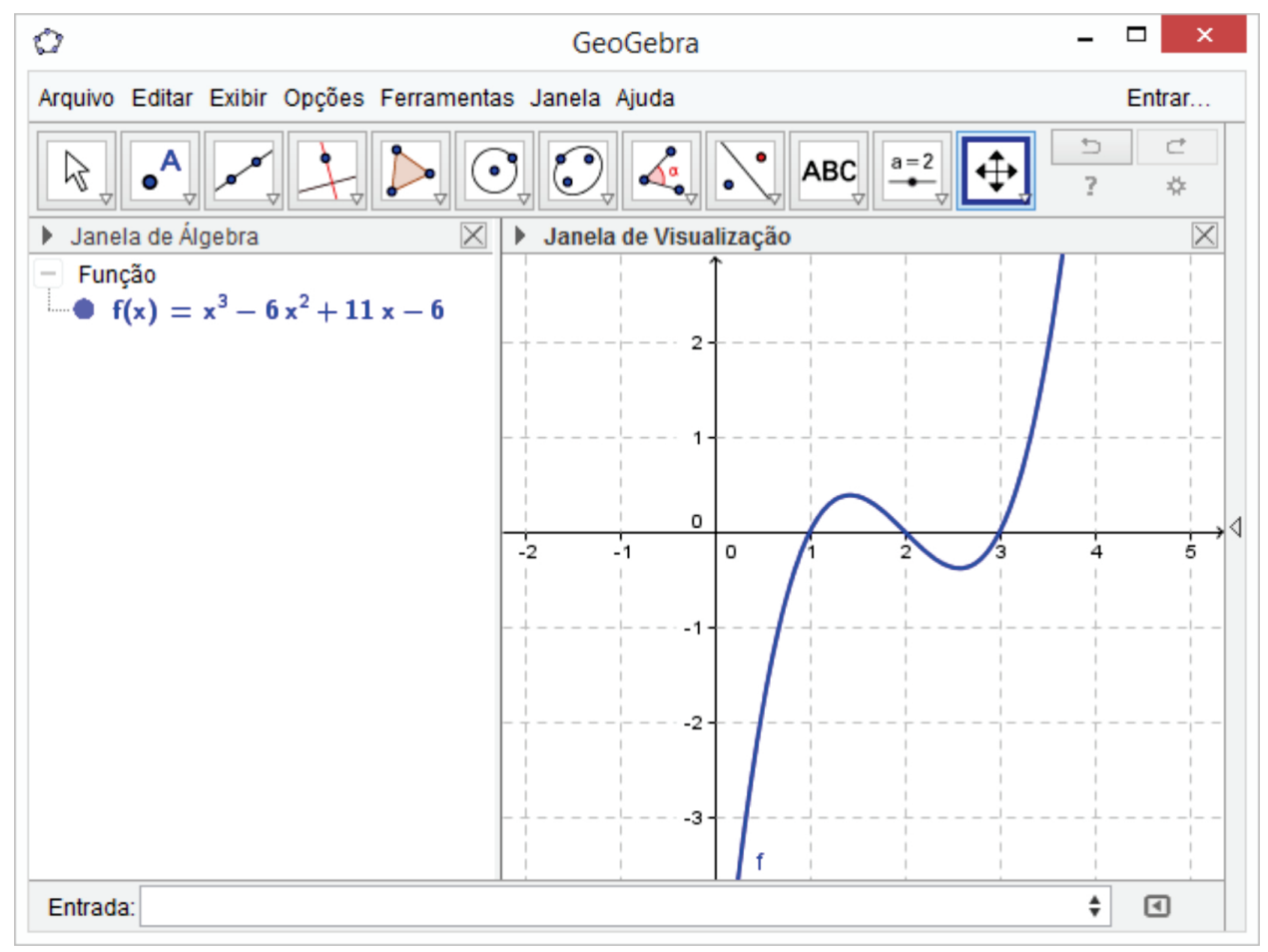

Figura 40: Gráfico de $f(x)=x^{3}-6 x^{2}+11 x-60$

3. O conjunto solução da desigualdade proposta é $\{x \in \mathbb{R}: f(x)<0\}$, isto é, $\{x \in \mathbb{R}: x<1$ ou $2<x<3\}$.

As ferramentas Controle Deslizante e Habilitar Rastro podem ser usadas para enfatizar o conjunto solução da inequação proposta. Para tal, devem ser desenvolvidos os seguintes passos:

4. Criar Controle Deslizante de nome $t$, definido no intervalo -6 (min) e $6(\max )$ e 0.1 de incremento. O controle criado será exibido como Número na Janela 
de Âlgebra;

5. Em Entrada, digitar $P=S e[f(t)<0,(t, 0)]$. Esse comando criará o ponto $P=(x, 0)$, para os quais $f(x)<0$, isto é, todos os pontos para os quais $f$ tem ordenada negativa.

6. Na Janela de Álgebra, clicar com o botão direito do mouse sobre $P$ e marcar a opção Habilitar Rastro. Caso seja necessário, a cor do objeto $P$ pode ser alterada para destacar o conjunto solução da desigualdade.

7. Escolher a ferramenta Mover, clicar sobre o Controle Deslizante $t$ e arastá-lo por toda a sua extensão. Essas ações destacam, sobre o eixo horizontal, pontos que compõem o conjunto solução da desigualdade proposta. O resultado dessas ações é mostrado na figura 41.

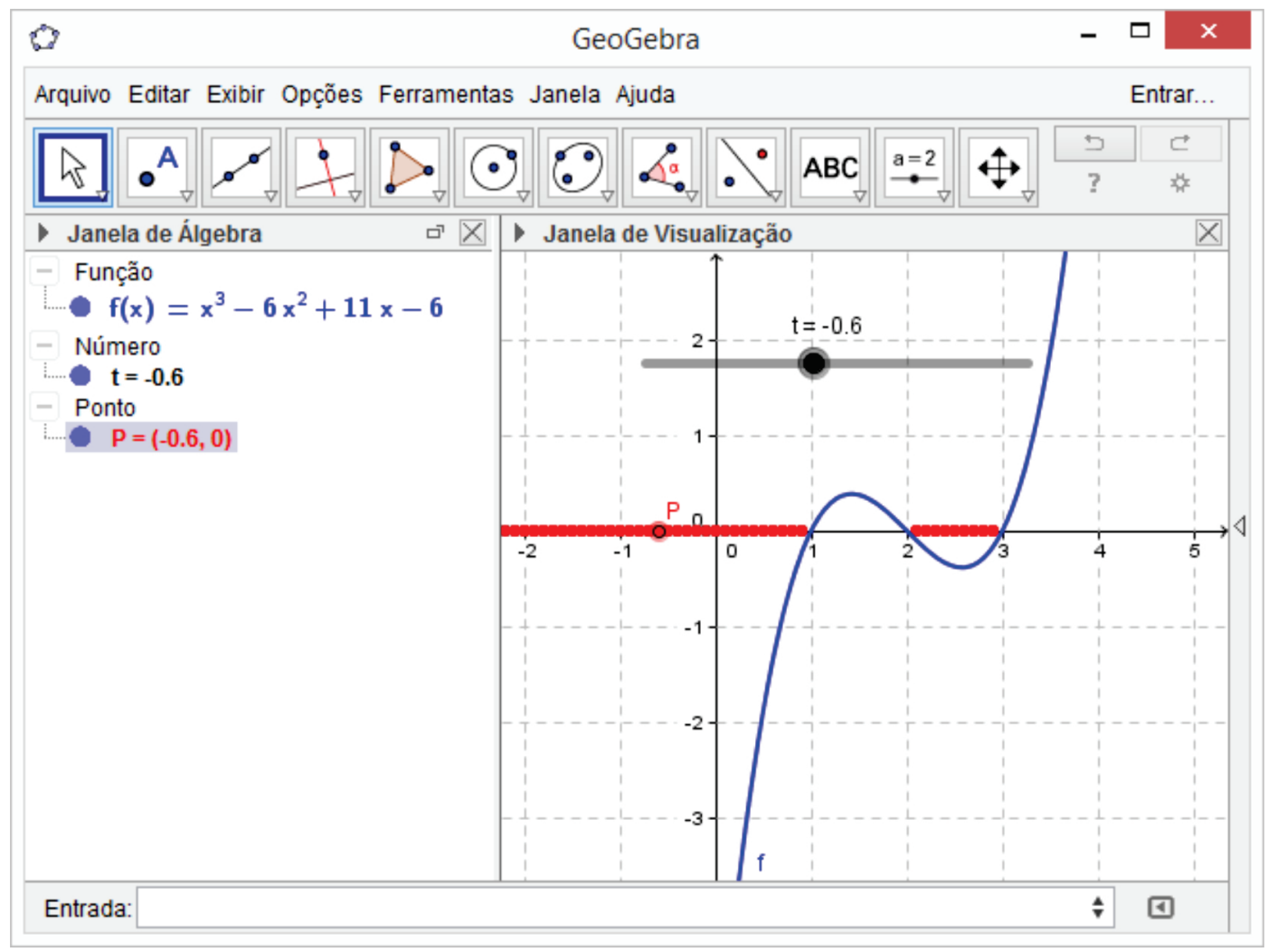

Figura 41: Solução de $x^{3}-6 x^{2}+11 x-6<0$ 


\subsubsection{Inequações definidas em $\mathbb{R}^{2}$}

Definição 3. Sejam $f, g: D \subset \mathbb{R}^{2} \rightarrow \mathbb{R}$ duas funções reais definidas em $D$. Define-se por inequação definida em $\mathbb{R}^{2}$ a qualquer uma das sentenças abertas $f(x, y)>g(x, y)$, $f(x, y)<g(x, y), f(x, y) \geq g(x, y)$ ou $f(x, y) \leq g(x, y)$. O par ordenado $\left(x_{0}, y_{0}\right) \in \mathbb{R}^{2}$ é solução da inequação, sem perda de generalidade, $f(x, y)>g(x, y)$ se, e somente se, $f\left(x_{0}, y_{0}\right)>g\left(x_{0}, y_{0}\right)$ for verdadeira.

É exemplo de inequação definida em $\mathbb{R}^{2}$ a desigualdade $x+y \geq 4$ cujo conjunto solução é formado por todos os pares $\left(x_{0}, y_{0}\right) \in \mathbb{R}^{2}$ tais que $x_{0}+y_{0} \geq 4$, dos quais citamse $(1,3)$ e $(4,1)$ uma vez que $1+3 \geq 4$ e $4+1 \geq 4$, respectivamente. Informalmente, desigualdades lineares definidas no $\mathbb{R}^{2}$ como, sem perda de generalidade, $A x+B y>C$ apresentam como solução um dos semiplanos cuja origem é $A x+B y=C$.

Em geral, a reta vertical $x=k$ é origem dos semiplanos fechados $x \geq k$ e $x \leq k$, e dos semiplanos abertos $x>k$ e $x<k$. Analogamente, a reta horizontal $y=k$ é origem dos semiplanos fechados $y \geq k$ e $y \leq k$, e dos semiplanos abertos $y>k$ e $y<k$. Na representaçõ de cada semiplano, deve ser considerado a posição do ponto em relação à origem, como em $x>k$, formado por pontos situados à direita de $x=k$ ou em $y<k$ cujos pontos estão abaixo de $y=x$. Na figura 42 estão representados semiplanos com origens paralelas aos eixos coordenados.

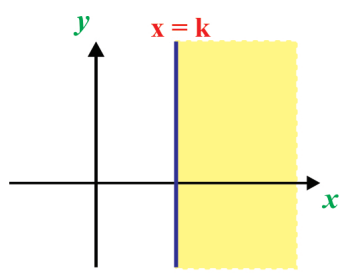

Representação gráfica de $\mathrm{x} \geq \mathrm{k}$

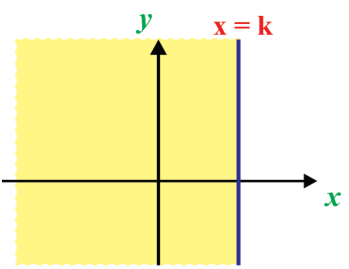

Representação gráfica de $\mathrm{x} \leq \mathrm{k}$

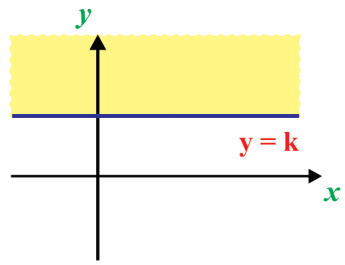

Representação gráfica de $\mathrm{y} \geq \mathrm{k}$

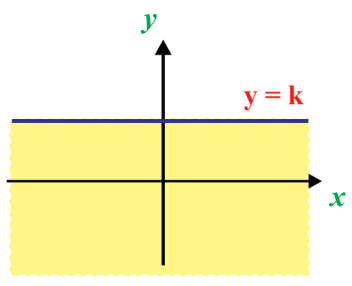

Representação gráfica de $\mathrm{y} \leq \mathrm{k}$

Figura 42: Semiplanos de origem vertical ou horizontal

São muitas as possibilidades de abordagem do estudo de semiplanos, especialmente como mecanismo de contextualização no escopo da própria matemática, como será apresentado no exemplo seguinte, inicialmente proposto para a $1^{a}$ série do ensino médio.

Exemplo 10. Calcular a área e o perímetro da região plana determinada por

$$
\left\{(x, y) \in \mathbb{R}^{2}: 1 \leq x \leq 5\right\} \text { e }\left\{(x, y) \in \mathbb{R}^{2}: 2 \leq y \leq 8\right\}
$$




\section{Solução}

A região plana, algebricamente representada pelo produto cartesiano

$$
\{x \in \mathbb{R}: 1 \leq x \leq 5\} \times\{y \in \mathbb{R}: 2 \leq y \leq 8\}
$$

é um retângulo limitado pelas retas verticais $x=1$ e $x=5$ e pelas retas horizontais $y=2$ e $y=8$, cujos lados medem $5-1=4$ e $8-2=6$. Portanto, a área e o perímetro da região $\left\{(x, y) \in \mathbb{R}^{2}: 1 \leq x \leq 5\right\} \cap\left\{(x, y) \in \mathbb{R}^{2}: 2 \leq y \leq 8\right\}$ são, respectivamente, $4 \times 6=24$ e $4+6+4+6=20$.

A seguir, detalhamos a solução do problema proposto no Geogebra:

1. Clicar com o botão direito do mouse sobre a Janela de Visualização e marcar a opção Malha para exibir a malha quadriculada sobre o sistema de coordenadas cartesianas;

2. Em Entrada, digitar $1<=x<=5$ e pressionar Enter para exibir a interseção dos semiplanos $1 \leq x$ e $x \leq 5$;

3. Em Entrada, digitar $2<=y<=8$ e pressionar Enter para exibir a região limitada pelas retas $y=2$ e $y=8$;

A região cujo perímetro e área se deseja determinar consiste na sobreposição ou interseção dos conjuntos indicados nos passos (2) e (3) e se apresenta como o retângulo de vértices $(1,2),(1,8),(5,8)$ e $(5,2)$ que designaremos por $A, B, C$ e $D$.

4. Em Entrada, digitar $A=(1,2)$ e pressionar Enter;

5. Em Entrada, digitar $B=(1,8)$ e pressionar Enter;

6. Em Entrada, digitar $C=(5,8)$ e pressionar Enter;

7. Em Entrada, digitar $D=(5,2)$ e pressionar Enter;

8. Em Entrada, digitar $P=$ Poligono $[A, B, C, D]$ e pressionar Enter para construir o retângulo $A B C D$, associado ao identificador $P$ 
9. Para explicitar a área de P, em Entrada, digita-se o comando Área = Área[P] e pressiona-se Enter. Analogamente, o perímetro é obtido a partir do comando Perímetro $=$ Perímetro $[\mathbf{P}]$. Os resultados serão exibidos na Janela de Álgebra, como pode ser observado na figura 43.

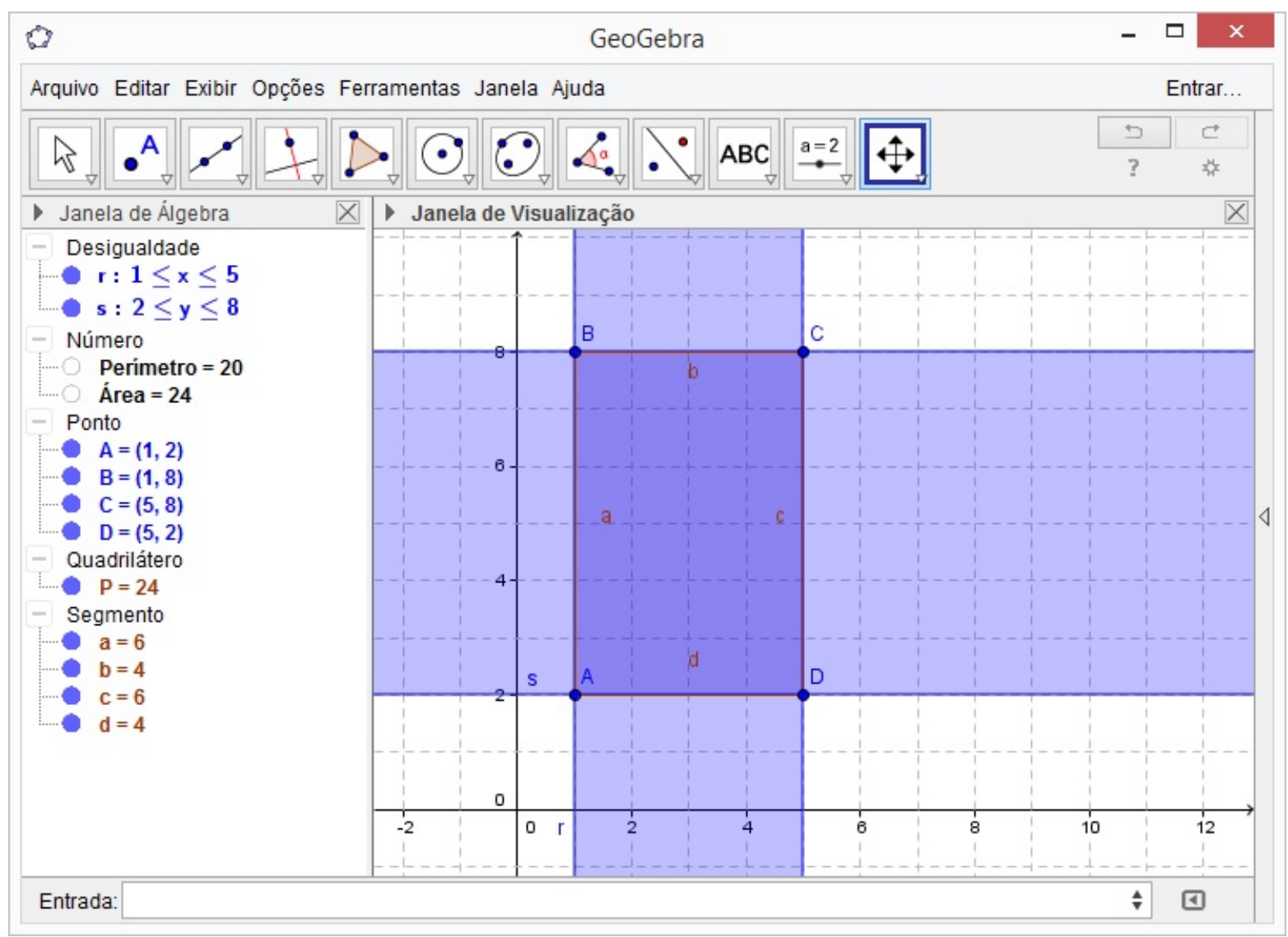

Figura 43: Retângulo ABCD do exemplo 10

\subsubsection{Semiplanos de origem oblíqua}

A resolução de uma inequação do tipo $A x+B y \leq C$ ou $A x+B y \geq C$, que envolve a identificação do semiplano gerado pela reta $A x+B y=C$, contém o conjunto de pontos $(x, y)$ satisfazendo a desigualdade proposta. Para tal, explicita-se $y$ e escolhe-se uma das opções a seguir:

I. Se $y>-\frac{A}{B} x+\frac{C}{A}$, o conjunto solução será o semiplano formado por todos os pontos localizados acima da reta $y=-\frac{A}{B} x+\frac{C}{A}$; ou 
II. Caso $y<-\frac{A}{B} x+\frac{C}{A}$, a solução será o semiplano formado por todos os pontos localizados abaixo de $y=-\frac{A}{B} x+\frac{C}{A}$.

A representação gráfica dos semiplanos de origem $y=a x+b$ é apresentada na figura 45.

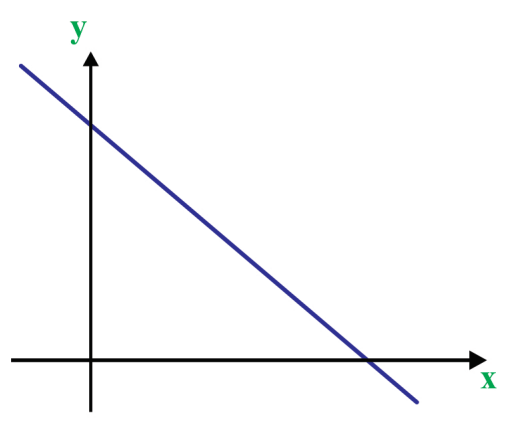

$\mathbf{y}=\mathbf{a x}+\mathbf{b}$

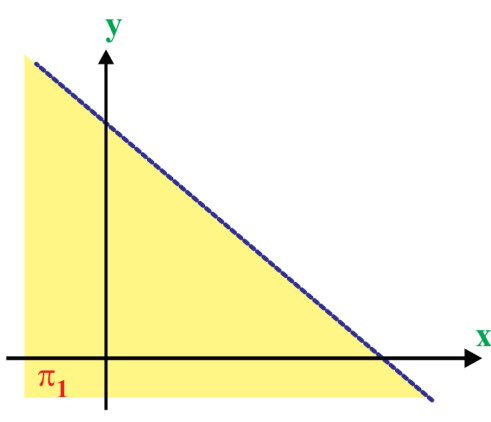

$\mathbf{y}<\mathbf{a x}+\mathbf{b}$

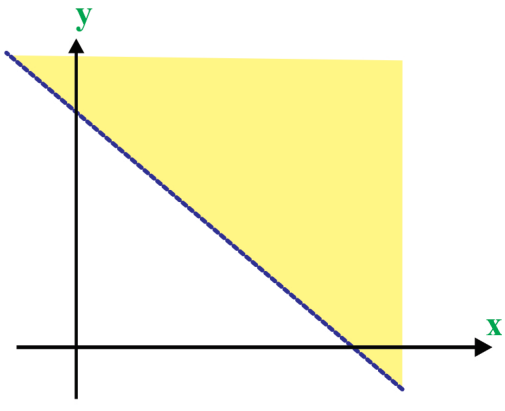

$\mathbf{y}>\mathbf{a x}+\mathbf{b}$

Figura 44: A reta $y=a x+b$ e os semiplanos por ela determinados

Exemplo 11. Representar, graficamente, a solução da desigualdade $2 x+3 y \geq 12$.

\section{Solução}

O subespaço de $\mathbb{R}^{2}$ ao qual a desigualdade $2 x+3 y \geq 12$ está associado é um semiplano de origem $2 x+3 y=12$, reta que intercepta os eixos coordenados em $(6,0)$ e $(0,4)$. Tomando, por exemplo, a origem $(0,0)$, conclui-se que a mesma não satisfaz a desigualdade proposta e possibilita que se conclua que a solução da desigualdade proposta é formada por todos os pontos localizados acima de $2 x+3 y=12$, fato confirmado com o Geogebra em dois passos:

1. Exibir malha quadriculada clicando, com o botão direito do mouse, sobre a Janela de Visualização e marcar a opção Malha.

2. Em Entrada, digitar $2 x+3 y>=12$ e pressionar a tecla Enter.

O resultado é mostrado na Janela de Visualização do Geogebra, como se vê na figura 45. 


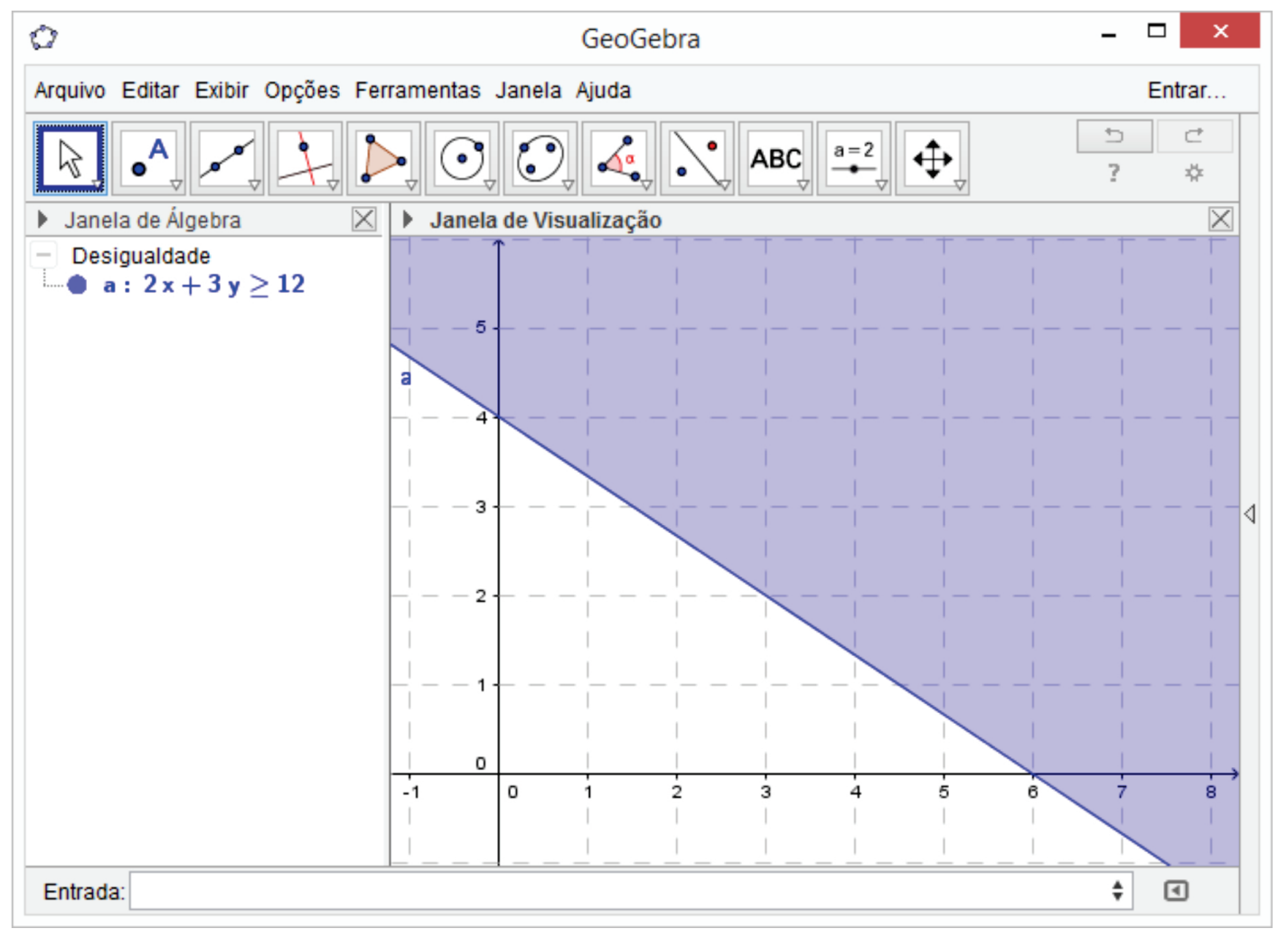

Figura 45: Semiplano $2 x+3 y \geq 12$

Exemplo 12. Determine o conjunto solução da inequação $2 x-4 y<6$

\section{Solução}

Explicitando-se $y$ no primeiro lado da desigualdade, obtem-se $y>\frac{1}{2} x-\frac{3}{2}$, fato que permite inferir o conjunto solução de $2 x-4 y<6$ como o semiplano formado por todos os pontos acima da reta $2 x-4 y=6$, fato confirmado, em poucos passos, pelo Geogebra.

1. Exibir malha quadriculada;

2. Em Entrada, digitar $2 x-4 y<6$ e pressionar Enter;

O resultado é mostrado na figura 46.

Uma das soluções de $2 x-4 y<6$, segundo sua representação gráfica, é o ponto $O=(0,0)$, fato confirmado algebricamente ao substituí-lo no primeiro lado da desigualdade e observar que a proposição obtida é verdadeira. 


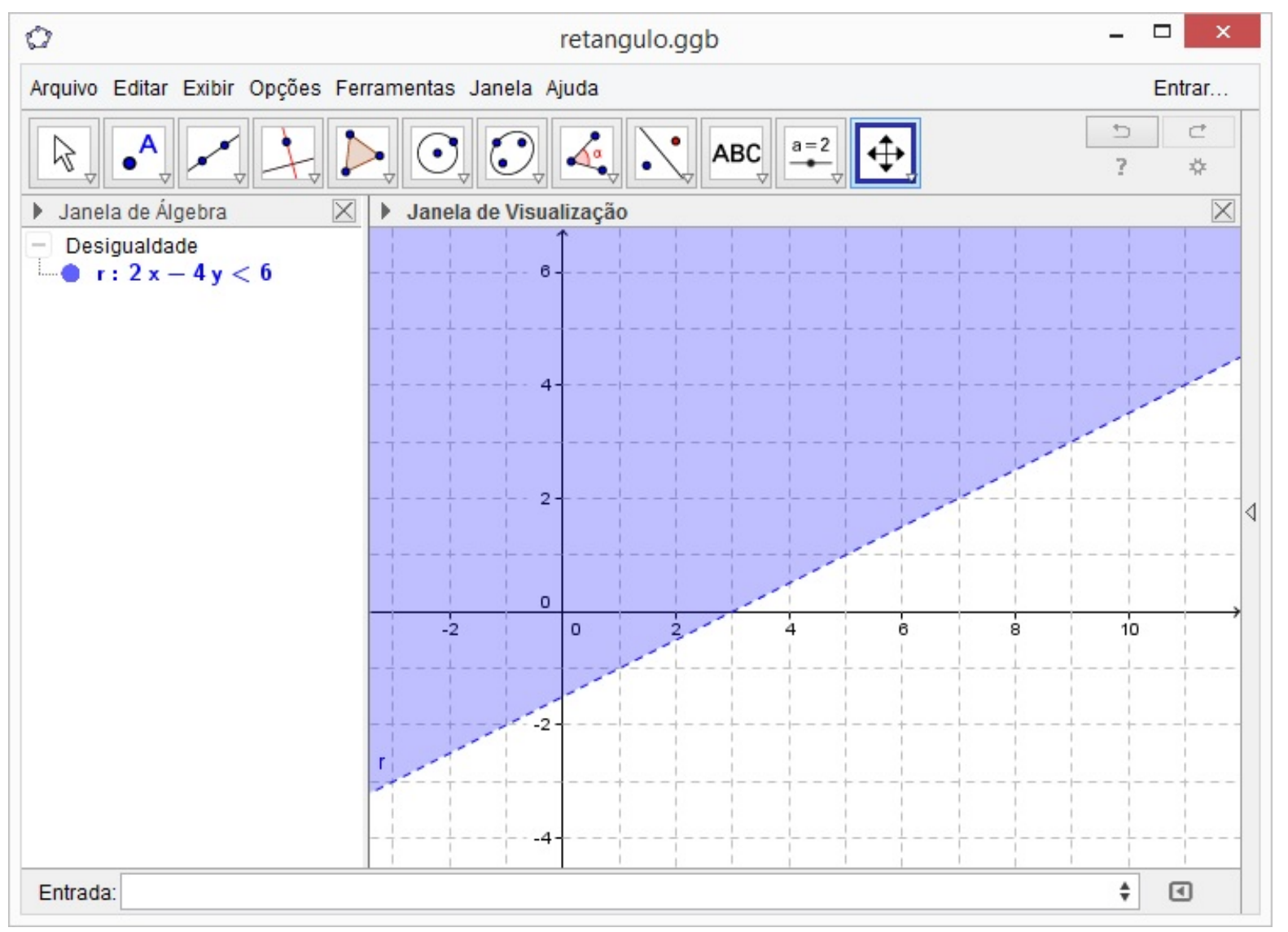

Figura 46: Solução de $2 x-4 y<6$

Exemplo 13. Representar, graficamente, o conjuto de todos os pares $(x, y) \in \mathbb{R}^{2}$ tais que $2 x+y \leq 8$ e $x-2 y>-1$.

Inequações de primeiro grau com duas incógnitas, quando representadas no espaço bidimensional $\mathbb{R}^{2}$ geram semiplano e esse fato será observado nesta atividade, que consiste em resolver, graficamente, o sistema de inequações

$$
S=\left\{\begin{array}{c}
2 x+y \leq 8 \\
x-2 y>-1
\end{array}\right.
$$

Um desenvolvimento para o problema proposto é apresentado a seguir:

1. Exibir eixos e malhas;

2. Em Entrada, escrever $p: 2 x+y<=8$ e pressionar Enter; 
3. Em Entrada, digitar $q: x-2 y>-1$ e pressionar Enter;

A região sombreada com tom mais escuro está contida em cada um dos semiplanos do sistema proposto e, portanto, determina a interseção entre eles, como pode ser observado na figura 47

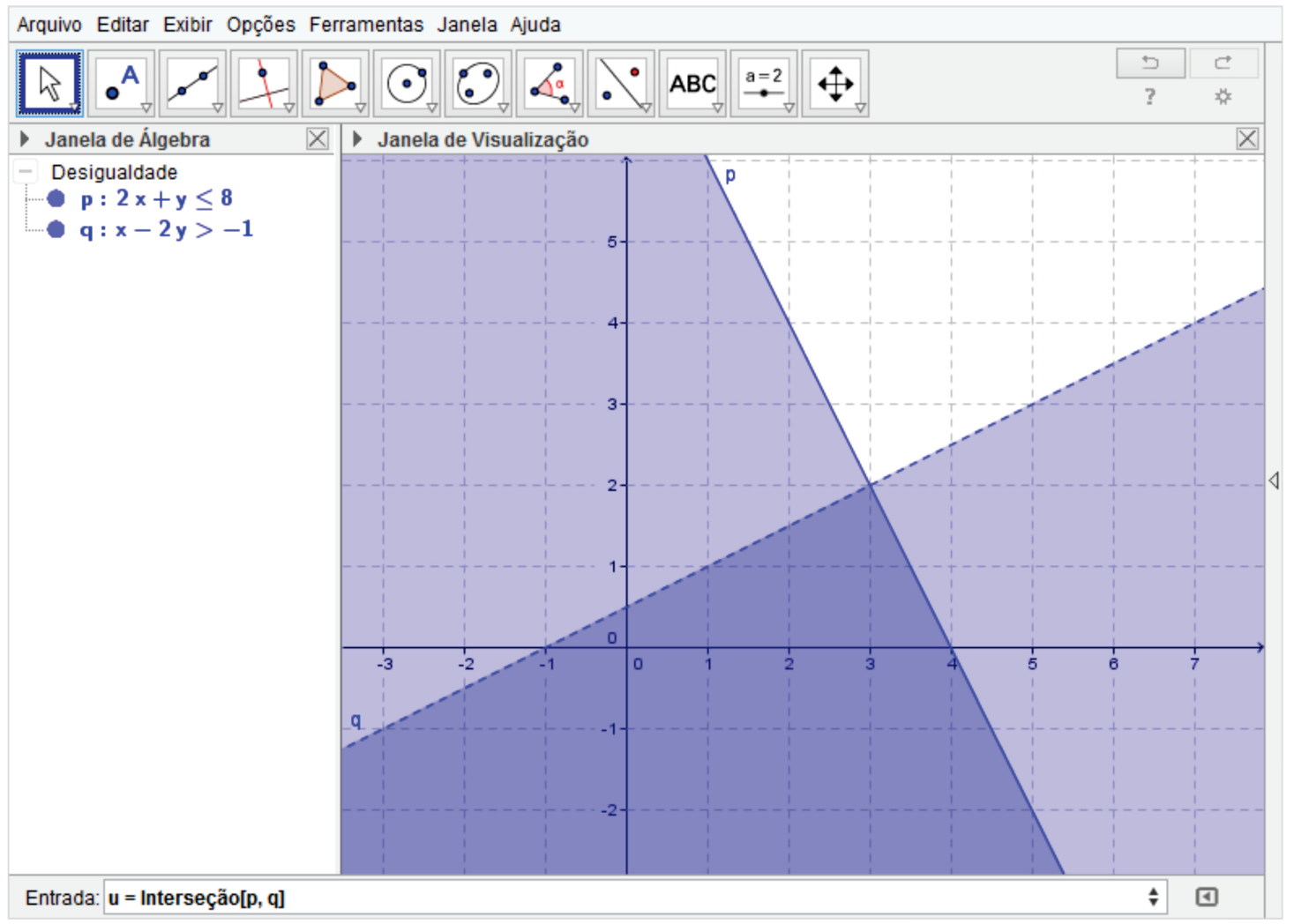

Figura 47: Solução do sistema de inequações

\subsection{Sistemas Lineares}

Por fim, nesta seção, apresentaremos o tema Sistemas Lineares, importante para a compreensão da versão algébrica do simplex e de fundamental relevância para a educação básica. 


\subsubsection{Equações lineares}

Definição 4. Uma equação com n incógnitas é linear se possui a forma

$$
\sum_{i=1}^{n} a_{i} x_{i}=a_{1} x_{1}+a_{2} x_{2}+\ldots+a_{n} x_{n}=b
$$

onde as incógnitas $x_{1}, x_{2}, \ldots, x_{n}$ apresentam expoentes unitários e, tanto coeficientes $a_{1}, a_{2}, \ldots, a_{n}$ como termo independente $b$ pertencem ao dominio dos números reais. Uma solução para a equação linear acima é uma $n$-upla $\left(r_{1}, r_{2}, \ldots, r_{n}\right) \in \mathbb{R}^{n}$ para o qual $a_{1} r_{1}+a_{2} r_{2}+\ldots+a_{n} r_{n}=b$.

A solução de $2 x=6$ é $S=\{3\}$, enquanto $0 x=5$ não tem nenhuma solução pois não existe nenhum número real que multiplicado por 0 resulte em 5 . Por outro lado, a equação $x+2 y=6$ apresenta infinitas soluções das quais exemplificamos $(2,2),(0,3)$ e $(4,1)$, como pode ser observado na figura 48.

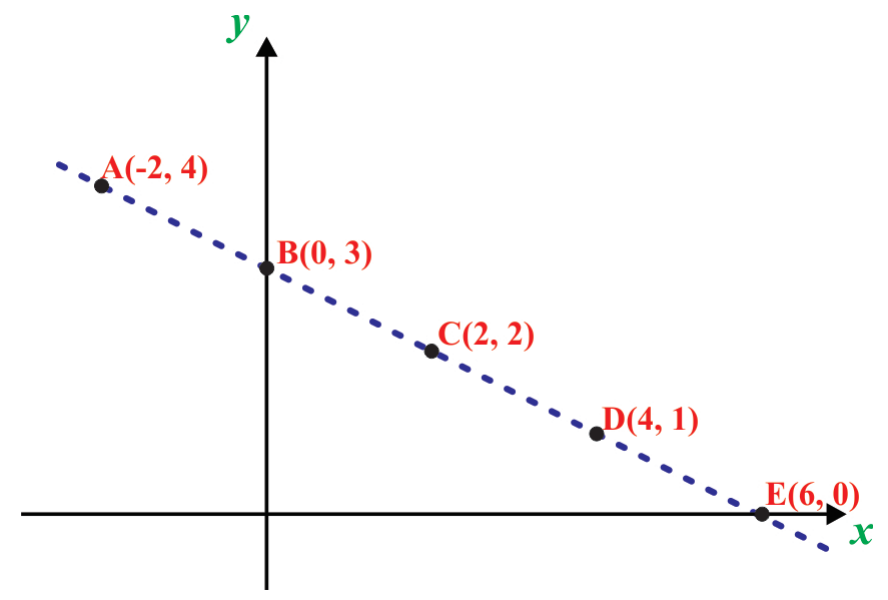

Figura 48: Soluções particulares de $x+2 y=6$

Por apresentar infinitos elementos, o conjunto $S$, solução de $x+2 y=6$, é representado a partir da parametrização obtido ao atribuir $y=t$ e determinar, em função de $t$, o valor correspondente para $x: x+2 \cdot t=6 \Rightarrow x=6-2 t$. Portanto, $S=\{(6-2 t, t): t \in \mathbb{R}\}$. 


\subsubsection{Sistema linear}

Definição 5. Define-se por sistema linear $m \times n$ o conjunto $S$ formado por $m$ equações lineares e de $n$ incógnitas cada.

$$
S=\left\{\begin{array}{c}
a_{11} x_{1}+a_{12} x_{2}+\ldots+a_{1 n} x_{n}=b_{1} \\
a_{21} x_{1}+a_{22} x_{2}+\ldots+a_{2 n} x_{n}=b_{2} \\
\vdots \\
a_{m 1} x_{1}+a_{m 2} x_{2}+\ldots+a_{m n} x_{n}=b_{m}
\end{array}\right.
$$

onde, para cada $i, j \in \mathbb{N}$, $a_{i j}$ são coeficientes reais, $x_{i} \in \mathbb{R}$ são as incógnitas e $b_{i} \in \mathbb{R}$ são os termos independentes.

A solução do sistema de equações lineares $m \times n$ é toda n-upla $R=\left(r_{1}, r_{2}, \cdots, r_{n}\right)$ que faz com que todas as equações do sistema tornem-se proposições verdadeiras. Caso não exista n-upla $R$ que satisfaça todas as equações do sistema, o mesmo é classificado como impossível. A figura 49 mostra um exemplo de sistema linear impossível de duas equações e duas incógnitas.

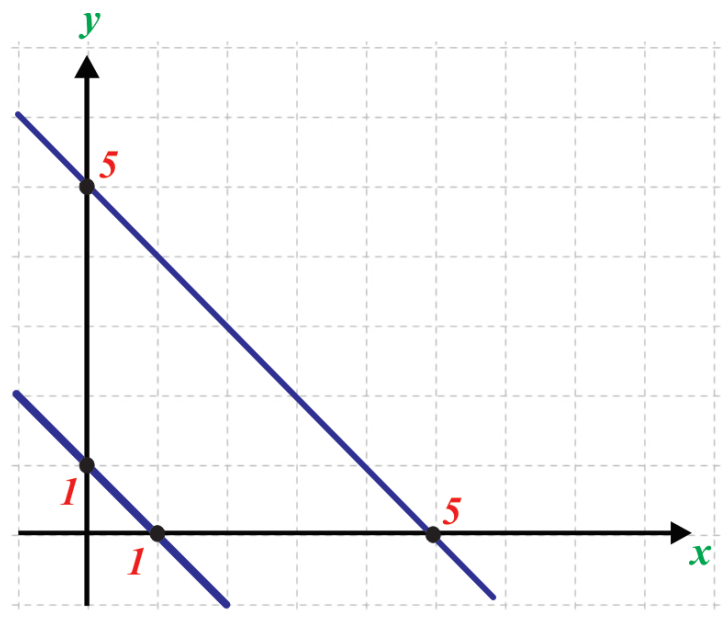

Figura 49: Sistema linear impossível de duas equações e duas incógnitas

É classificado como sistema linear possível o sistema linear que possui pelo menos uma solução como pode ser observado no sistema formado pelas equações $5 x+4 y=18$ e $4 x+2 y=12$, cuja representação gráfica resume-se ao par de retas que concorrem no ponto $(2,2)$, solução do sistema, como se vê na figura 50 . 


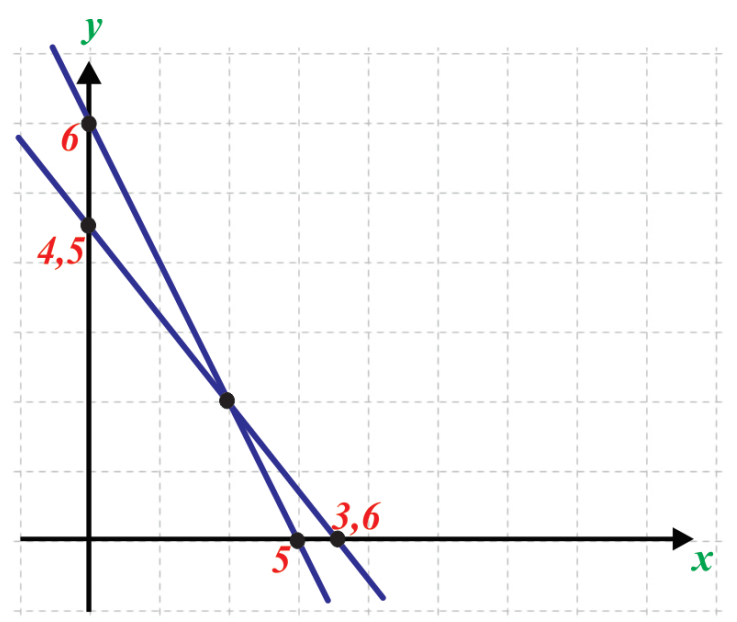

Figura 50: Interpretação geométrica da solução do sistema possível e determinado

Caso um sistema linear tenha infinitas soluções, sua classificação será possível e indeterminado, possui como representação gráfica um par de retas coincidentes e conjunto solução representado de forma parametrizada.

Exemplo 14. Determinar, a partir do Geogebra, o conjunto solução do sistema cujas equações são $2 x-3 y=19$ e $x+y=2$.

\section{Solução}

O desenvolvimento aqui proposto consiste no sequenciamento de ações previamente definidas utilizando elementos nomeados segundo preceitos tradicionalmente adotados pela nomenclatura matemática como, por exemplo, letras maiúsculas e minúsculas do nosso alfabeto para pontos e retas, respectivamente.

1. Em Entrada, digitar $r: 2 x-3 y=19$ e pressionar Enter;

2. Em Entrada, digitar $s: x+y=2$ e pressionar Enter;

3. Em Entrada, digitar $\mathrm{P}=$ Interseção[r, s] e pressionar Enter;

Na Janela de Álgebra, será mostrado o ponto $P=(5,-3)$ como solução do sistema proposto, fato confirmado geometricamente na Janela de Visualização ao apresentar $P$ como ponto de interseção entre $r$ e $s$, como pode ser observado na figura 51. 


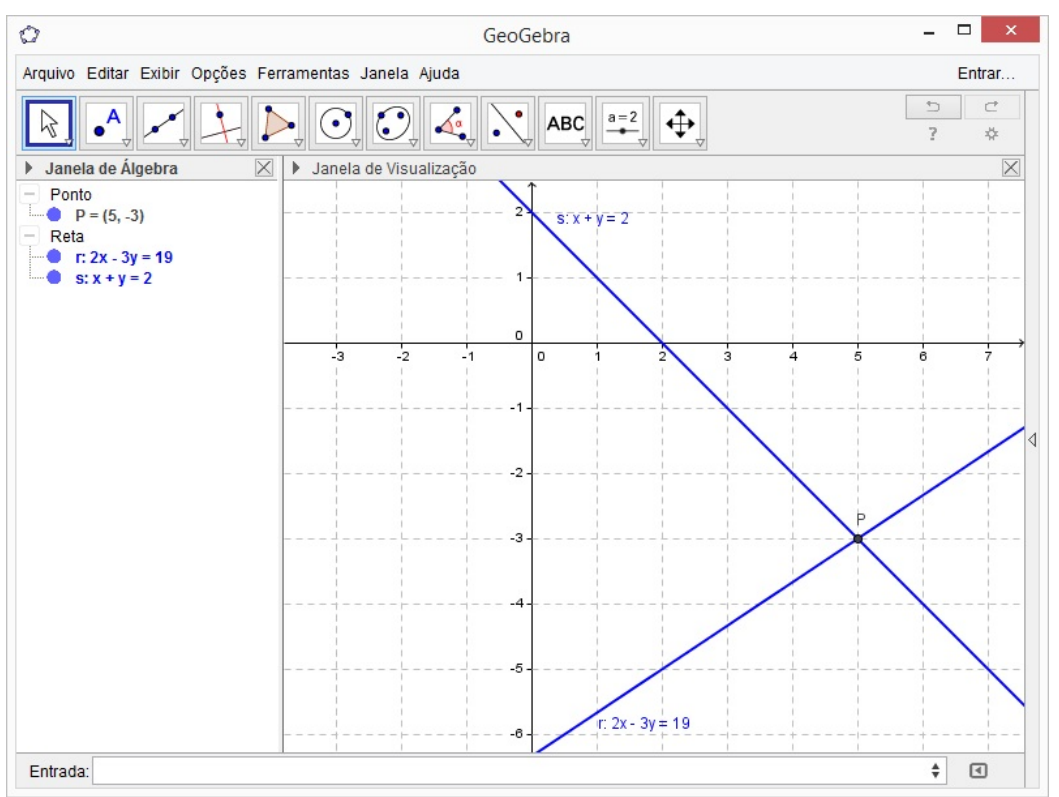

Figura 51: Solução do sistema linear de equações $2 x-3 y=19$ e $x+y=2$

Portanto, em função da quantidade de soluções de um sistema linear, classificamolo como impossível, possível determinado ou possível indeterminado caso não tenha solução, tenha apenas uma solução ou a quantidade de soluções seja infinita, respectivamente. A figura 52 presenta fluxograma de classificação de um sistema linear a partir da quantidade de soluções.

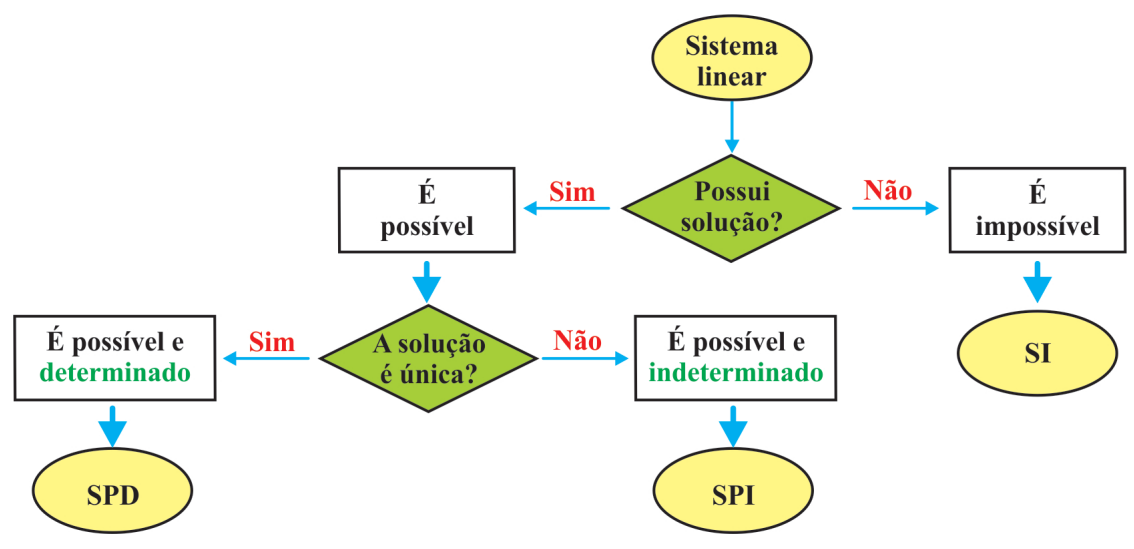

Figura 52: Classificação de um sistema 


\subsubsection{Representação matricial}

Dado um sistema linear $S$ definido por $m$ equações de no máximo $n$ incógnitas cada, podemos associar a ele a equação matricial $A_{m \times n} \cdot x_{n \times 1}=B_{m \times 1}$ como é observado em

$$
\left[\begin{array}{cccc}
a_{11} & a_{12} & \ldots & a_{1 n} \\
a_{21} & a_{22} & \ldots & a_{2 n} \\
\ldots & \ldots & \ldots & \ldots \\
a_{m 1} & a_{m 2} & \ldots & a_{m n}
\end{array}\right] \cdot\left[\begin{array}{c}
x_{1} \\
x_{2} \\
\ldots \\
x_{n}
\end{array}\right]=\left[\begin{array}{c}
b_{1} \\
b_{2} \\
\ldots \\
b_{m}
\end{array}\right]
$$

onde $A=\left[a_{i j}\right]_{m \times n}$ é a matriz dos coeficientes, $x=\left[x_{i}\right]_{n}$ é o vetor das incógnitas e $b=\left[b_{i}\right]_{m}$ o vetor dos termos independentes. Dizemos que $r=\left(r_{1}, r_{2}, \cdots, r_{n}\right) \in \mathbb{R}^{n}$ é solução do sistema linear $A \cdot x=b$ se, e somente se, $A \cdot r=b$. Ou seja, se $r$ satisfaz todas as equações do sistema.

\subsubsection{Escalonamento}

O Método de Gauss-Seidel ou Escalonamento, principal método utilizado para resolver sistemas lineares, resume-se em transformar a matriz de coeficientes em uma matriz triangular superior pelo uso de operações elementares para posterior retrosubstituições que possibilitem determinar o conjunto solução do sistema. Tais operações se caracterizam por, quando aplicadas às equações de um sistema linear, não alterarem seu conjunto solução. As principais operações que atendem tais preceitos são:

1. Ao trocar posições de duas equações do sistema, seu conjunto solução permanece inalterado.

$$
\left\{\begin{array} { l } 
{ a _ { 1 1 } x + a _ { 1 2 } y = b _ { 1 } } \\
{ a _ { 2 1 } x + a _ { 2 2 } y = b _ { 2 } }
\end{array} \Leftrightarrow \left\{\begin{array}{c}
a_{21} x+a_{22} y=b_{2} \\
a_{s} x+a_{12} y=b_{1}
\end{array}\right.\right.
$$

2. Ao multiplicar ambos os membros de uma das equações por um número real $k$ não nulo, o conjunto solução do sistema permanece inalterado.

$$
\left\{\begin{array} { c } 
{ a _ { 1 1 } x + a _ { 1 2 } y = b _ { 1 } } \\
{ a _ { 2 1 } x + a _ { 2 2 } y = b _ { 2 } }
\end{array} \Leftrightarrow \left\{\begin{array}{c}
k a_{11} x+k a_{12} y=k b_{1} \\
a_{21} x+a_{22} y=b_{2}
\end{array}\right.\right.
$$

3. Ao substituir, em um sistema, uma equação por uma combinação linear de suas 
equações, sua solução permanece inalterada.

$$
\left\{\begin{array} { l } 
{ a _ { 1 1 } x + a _ { 1 2 } y = b _ { 1 } } \\
{ a _ { 2 1 } x + a _ { 2 2 } y = b _ { 2 } }
\end{array} \Leftrightarrow \left\{\begin{array}{l}
a_{11} x+a_{12} y=b_{1} \\
p a_{11} x+q a_{21} x+p a_{12}+q a_{22} y=p b_{1}+q b_{2}
\end{array}\right.\right.
$$

Definição 6. Dois sistemas lineares são equivalentes se tem o mesmo conjunto solução.

Por exemplo, os sistemas

$$
S_{1}:\left\{\begin{array}{l}
x+3 y=5 \\
2 x-y=3
\end{array} \quad \text { e } \quad S_{2}:\left\{\begin{array}{c}
x-2 y=0 \\
x+y=3
\end{array}\right.\right.
$$

são equivalentes uma vez que possuem o mesmo conjunto solução, $S=\{(2,1)\}$ e, sendo equivalentes, as equações do sistema $S_{2}$ podem ser obtidas a partir de $S_{1}$ utilizando-se, para tal, operações elementares. Como exemplo, a equação $x-y=0$, de $S_{2}$, pode é obtida a partir de $3 E_{1}-5 E 2$, ode $E_{1}$ e $E_{2}$ sao, respectivamente, $x+3 y=5$ e $2 x-y=3$, equações de $S_{1}$.

Na figura 53 se vê dois, graficamente, dois sistemas equivalentes.
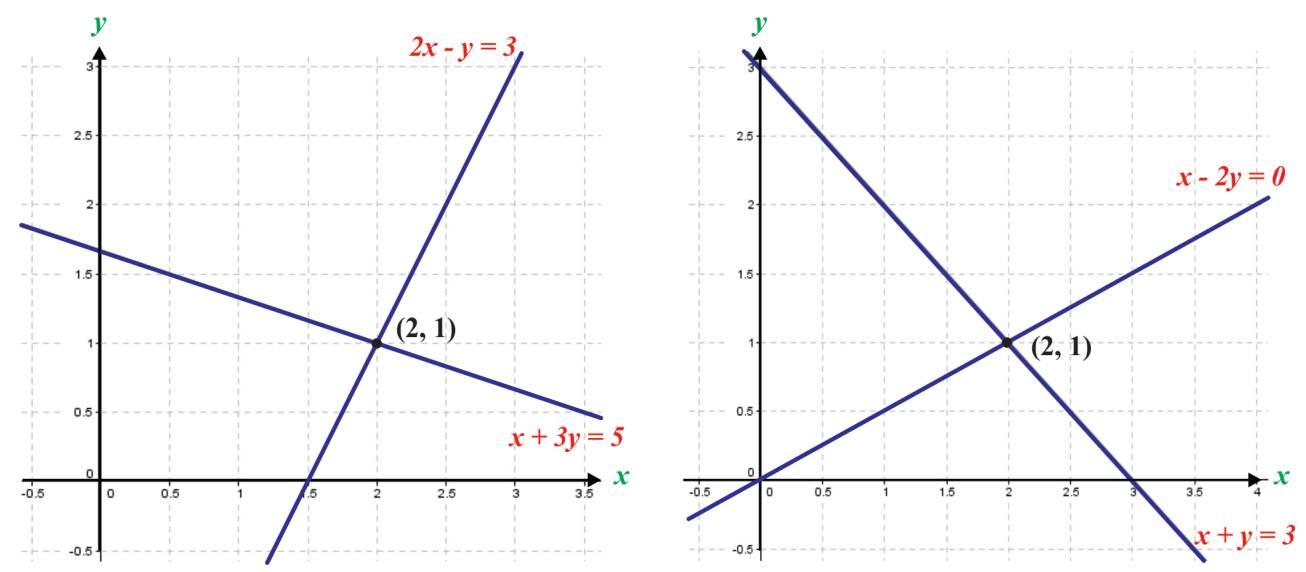

Figura 53: Sistemas equivalentes

Diante do exposto, afirma-se que o processo de escalonamento de um sistema $S$ consiste na construção de um sistema equivalente a $S$ utilizando-se, para tal, as operações elementares de forma que, no novo sistema, as equações apresentam incógnitas dispostas numa mesma ordem, cada equação possui pelo menos um coeficiente não nulo, os coeficientes nulos estão à esquerda dos não nulos e o número de coeficientes 
nulos aumenta de uma equação para a equação seguinte.

Exemplo 15. Utilizar o método do escalonamento para resolver o sistema

$$
\left\{\begin{array}{c}
4 x-2 y+z=-1 \\
2 x+y-z=5 \\
4 x-3 y+z=-3
\end{array}\right.
$$

\section{Solução}

O método é inicializado representando o sistema como equação matricial, considerando $A_{3 \times 3}$ como a matriz de coeficientes, $x_{3 \times 1}$ o vetor de incógnitas e $b_{3 \times 1}$ o vetor de termos independentes. À esquerda da matriz dos coeficientes, as linhas da matriz foram nomeadas como $L_{1}, L_{2}$ e $L_{3}$.

$$
\begin{aligned}
& L_{1} \\
& L_{2} \\
& L_{3}
\end{aligned}\left[\begin{array}{ccc}
4 & -2 & 1 \\
2 & 1 & -1 \\
4 & -3 & 1
\end{array}\right] \cdot\left[\begin{array}{l}
x \\
y \\
z
\end{array}\right]=\left[\begin{array}{c}
-1 \\
5 \\
-3
\end{array}\right]
$$

Para anular os coeficientes $a_{21}$ e $a_{31}$ da matriz dos coeficientes, serão utilizadas operações elementares que gerarão as linhas $L_{4}$ e $L_{5}$ para substituir $L_{2}$ e $L_{3}$, respectivamente, conforme indicado a seguir:

$$
\begin{array}{r}
L_{1} \\
L_{4}=-2 L_{2}+L_{1} \\
L_{5}=L_{1}-L_{3}
\end{array} \quad\left[\begin{array}{ccc}
4 & -2 & 1 \\
0 & -4 & 3 \\
0 & 1 & 0
\end{array}\right] \cdot\left[\begin{array}{l}
x \\
y \\
z
\end{array}\right]=\left[\begin{array}{c}
-1 \\
-11 \\
2
\end{array}\right]
$$

Embora seja possível iniciar a sequência de retrosubstituições, continuaremos com a aplicação do método até encontrar uma matriz de coeficientes triangular. Para tal, reescrevem-se $L_{1}$ e $L_{4}$ e substitui-se $L_{5}$ pela combinação linear de $L_{4}$ e $L_{5}$, gerando $L_{6}$.

$$
\begin{array}{r}
L_{1} \\
L_{4} \\
L_{6}=4 L_{5}+L_{4}
\end{array}\left[\begin{array}{ccc}
4 & -2 & 1 \\
0 & -4 & 3 \\
0 & 0 & 3
\end{array}\right] \cdot\left[\begin{array}{l}
x \\
y \\
z
\end{array}\right]=\left[\begin{array}{c}
-1 \\
-11 \\
-3
\end{array}\right]
$$


De $L_{6} \cdot(x, y, z)^{T}=-3$ vem que $3 z=-3$, ou seja, $z=-1$. Analogamente, $L_{4} \cdot(x, y, z)^{T}=-11$ possibilita que se determine $y$, pois $-4 y+3 z=-11 \Rightarrow-4 y-3=$ $-11 \Rightarrow-4 y=-8$, ou seja, $y=2$. Para $L_{1} \cdot(x, y, z)^{T}=-1$, vem que $4 x-2 y+z=$ $-1 \Rightarrow 4 x-4-1=-1 \Rightarrow x=1$.

Portanto, o conjunto solução é $S=\{(1,2,-1)\}$

No espaço tridimensional $\mathbb{R}^{3}$, equações lineares determinam planos e resolver o sistema proposto consiste em determinar o ponto em que os planos $4 x-2 y+z=-1$, $2 x+y-z=5$ e $4 x-3 y+z=-3$ se interceptam, procedimento que, no Geogebra, é desenvolvido cumprindo-se os seguintes passos:

1. Na barra de menus, clicar em Exibir e escolher a opção Janela de Visualização 3D. O mesmo resultado será obtido pressionando-se, simultaneamente, as teclas Ctrl + Shift +3 ;

2. Para exibir a malha quadriculada no plano $x O y, z=0$, clicar com o botão direito do mouse sobre a Janela de Visualização 3D e, no menu de contexto apresentado, escolher a opção Malha;

3. Em Entrada, digitar $a: 4 x-2 y+z=-1$ e pressionar Enter para representar, graficamente, o plano $4 x-2 y+z=-1$ e a ele atribuir o nome $a$;

4. Em Entrada, digitar $b: 2 x+y-z=5$ e pressionar Enter;

5. Em Entrada, digitar $c: 4 x-3 y+z=-3$ e pressionar Enter;

6. Em Entrada, digitar $\mathbf{r}=$ Interseção[a, b] para associar à reta $r$ a interseção entre $a$ e $b$;

7. Em Entrada, digitar $\mathbf{P}=$ Interseção[c, $\mathbf{r}]$ para determinar o ponto onde a reta $r$ intercepta o plano $c$;

O procedimento adotado se deve à limitação do comando Interseção do Geogebra que opera somente com dois parâmetros de entrada e tem correção garantida em virtude da precedência das operações da álgebra booleana, traduzida, segundo linguagem de conjuntos, por

$$
A \cap B \cap C=(A \cap B) \cap C
$$


onde $A \cap B=r$.

8. Na Janela de Visualização, a solução do sistema é representada pelo ponto $P=(1,2,-1)$, como está representado na figura 54 .

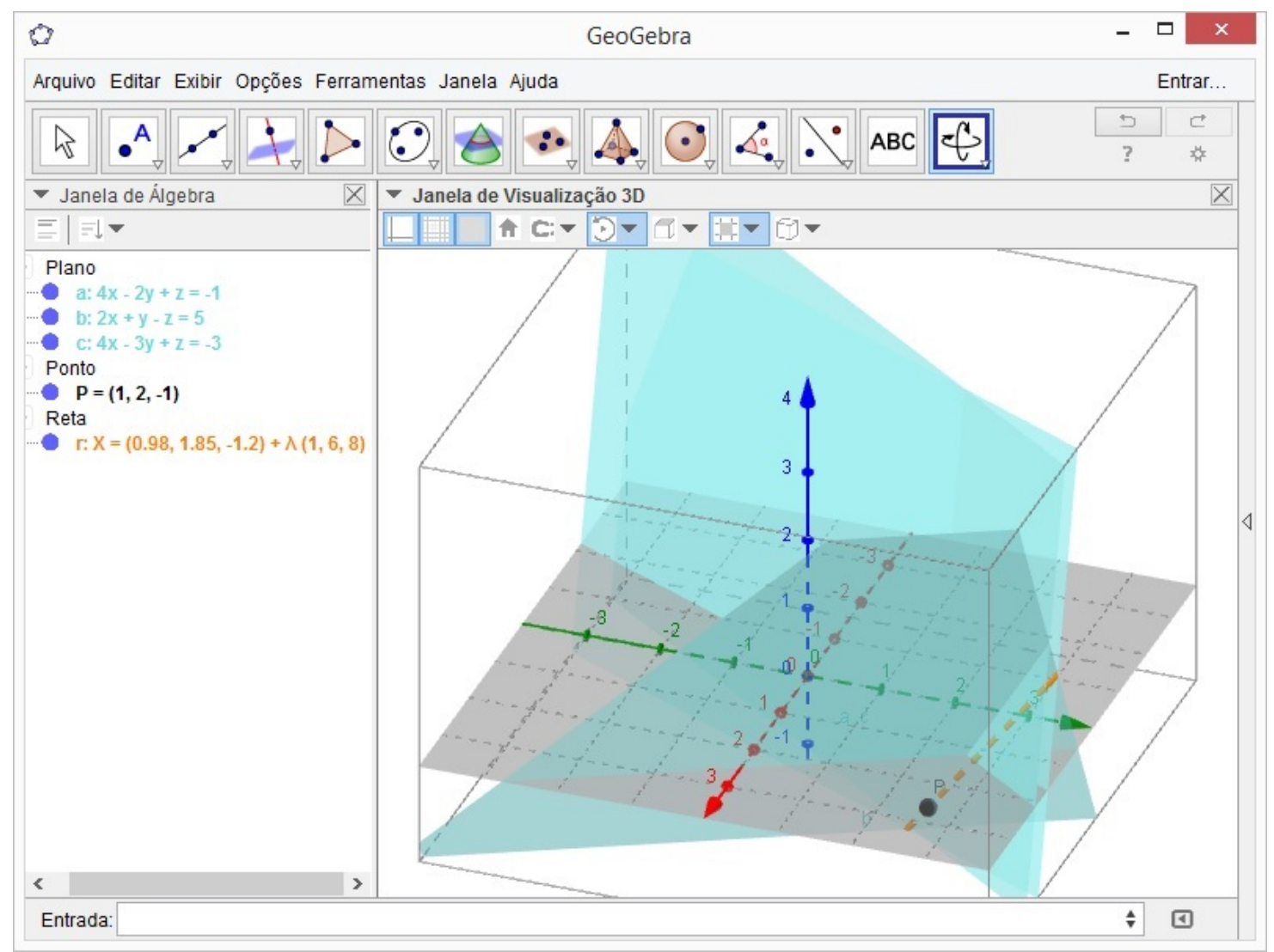

Figura 54: Interpretação geométrica de um sistema $3 \times 3$

\subsubsection{Análise de desempenho}

O estudo de sistemas lineares no ensino médio deve ter como principal método de resolução o escalonamento por ser evolução natural do método da adição, presente na matriz curricular do ensino fundamental e por não ser exaustivo, como o método da substituição, à priori, pode ser. Corroboram com essa tese as Orientações Curriculares do Ensino Médio ao afirmar que

"a resolução de sistemas $2 \times 2$ ou $3 \times 3$ deve ser feita via operações elementares (o processo de escalonamento), com discussão das diferentes 
situações (sistemas com uma única solução, com infinitas soluções e sem solução). Quanto à resolução de sistemas de equação $3 \times 3$, a regra de Cramer deve ser abandonada, pois é um procedimento custoso (no geral, apresentado sem demonstração, e, portanto de pouco significado para o aluno), que só permite resolver os sistemas quadrados com solução única. Dessa forma, fica também dispensado o estudo de determinantes."

Para confirmar o alto custo de execução do Método de Cramer, quando comparado com o Método do Escalonamento, seguem comparações entre as eficiências desses algoritmos:

1. O alto custo de execução do Método de Cramer se deve à sua estrutura recursiva uma vez que envolve cálculo de determinantes de matrizes quadradas. Um sistema $n \times n$, resolvido pelo Método de Cramer, envolve cálculo de $n+1$ determinantes de ordem $n$ e seu custo de execução, $C=C(n)$, pode ser expresso por $C(n)=$ $(n+1) D(n)$ onde $D(n)$ é o custo, em termos de operações aritméticas, do cálculo do determinante de uma matriz de ordem $n$. Segundo método dos cofatores para cálculo de determinantes, estabelece-se que $D(n)=n \cdot D(n-1)$ onde $D(1)=1$. Então

$$
\begin{aligned}
T(n) & =(n+1) \times D(n) \\
& =(n+1) \times(n+n \times D(n-1)) \\
& =(n+1) \times(n+n \times((n-1)+(n-1) \times D(n-2))) \\
& =\vdots \\
& =(n+1) \times(n+n \times(n-1+(n-1) \times(\cdots(3+3 \times(2)) \cdots))) \\
& =(n+1) \cdot n+(n+1) \cdot n \cdot(n-1)+(n+1) \cdot n \cdot(n-1) \cdot(n-2)+\ldots \\
& =(n+1) ! \times\left[\frac{1}{(n-1) !}+\frac{1}{(n-2) !}+\cdots+\frac{1}{2 !}+\frac{1}{1 !}\right] \\
& >(n+1) !
\end{aligned}
$$

2. Na fase de triangulação, para cada coeficiente a ser anulado, serão necessários duas multiplicações e uma substração. Logo, o número de operações aritméticas 
é

$$
\begin{aligned}
O(n) & =3 \cdot[(n+1)(n-1)+n(n-2)+\cdots+3 \cdot 1] \\
& =3 \sum_{i=1}^{n-1}(i+2) \cdot i=3 \sum_{i=1}^{n-1} i^{2}+6 \sum_{i=1}^{n-1} i \\
& =3 \frac{1}{6}(n-1) n(2 n-1)+6 \cdot \frac{1}{2} n(n-1) \\
& =\frac{2 n^{3}+3 n^{2}-5 n}{2}
\end{aligned}
$$

Nas substituições sucessivas, serão $n$ divisões enquanto subtrações e multiplicações totalizam, cada uma,

$$
1+2+3+\cdots+(n-1)=\frac{n(n-1)}{2}
$$

Portanto, para o escalonamento, o total do operações aritméticas no pior caso, em função de $n$, será

$$
T(n)=\frac{2 n^{3}+3 n^{2}-5 n}{2}+n+2 \frac{n(n-1)}{2}=\frac{2 n^{3}+5 n^{2}-5 n}{2}
$$

e sua complexidade será cúbica.

Por apresentar complexidade cúbica, para $n$ suficientemente grande, o custo de execução, em números de operações aritméticas, do Método de Cramer tende a ser maior que o custo previsto para o Método do Escalonamento. 


\section{Noções de Cálculo}

Adotando fundamentação teórica presente nas referências [15] e [16], o presente capítulo apresentará os principais elementos do cálculo associados ao processo de otimização de funções definidas em $\mathbb{R}^{n}$ como taxa de variação, derivada e gradiente e como tais noções podem, intuitivamente, ser exploradas na educação básica.

\subsection{Introdução}

O Cálculo pode ser dividido, segundo Simmons [22], a partir da natureza de suas idéias centrais, em Cálculo Diferencial e Cálculo Integral, cada uma com sua problematização particular e notação própria. Quase todas as aplicações do Cálculo estão relacionadas a dois problemas geométricos de compreensão relativamente simples e referentes ao gráfico de uma função $y=f(x)$ e estão apresentados na figura 55 .

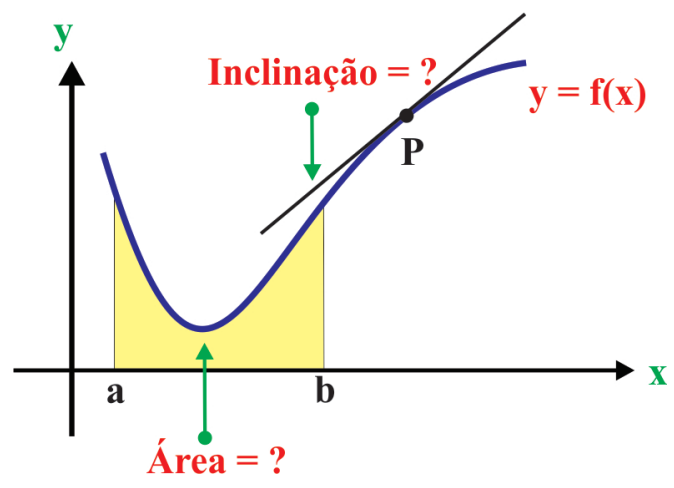

Figura 55: Idéias centrais do cálculo

Enquanto a idéia central do cálculo diferencial consiste em determinar a inclinação da reta tangente ao gráfico de uma função em um ponto dado, no cálculo integral, o problema a ser resolvido está relacionado à área da região limitada pelo gráfico da função, pelo eixo das abscissas e pelas retas $\mathrm{x}=\mathrm{a}$ e $\mathrm{x}=\mathrm{b}$. A priori, esses problemas apresentam alcance bem limitado, restrito à geometria. Porém, o alto grau de aplicabilidade de seus principais conceitos, derivada e integral, em diferentes segmentos do conhecimento humano como física, economia, logistica, biologia e na própria matemática colaborou, e continua contribuindo, para o seu aprimoramento enquanto ciência. 


\subsection{Taxa de variação e derivada}

Ao cálculo diferencial incumbe-se o estudo da taxa com a qual as grandezas variam noção que colaborou para a formalização do conceito de taxa de variação.

Definição 7. Seja $f$ uma função real definida em um subintervalo não vazio $I$ de $\mathbb{R}$. A taxa de variação de $f$ no intervalo aberto $I=(x, x+h)$ é

$$
m_{I}=\frac{\triangle f}{\triangle x}=\frac{f(x+h)-f(x)}{h}
$$

Geometricamente, tal razão corresponde à inclinação da reta secante à função $f$ nos pontos $(x, f(x))$ e $(x+h, f(x+h))$, como se vê na figura 56 .

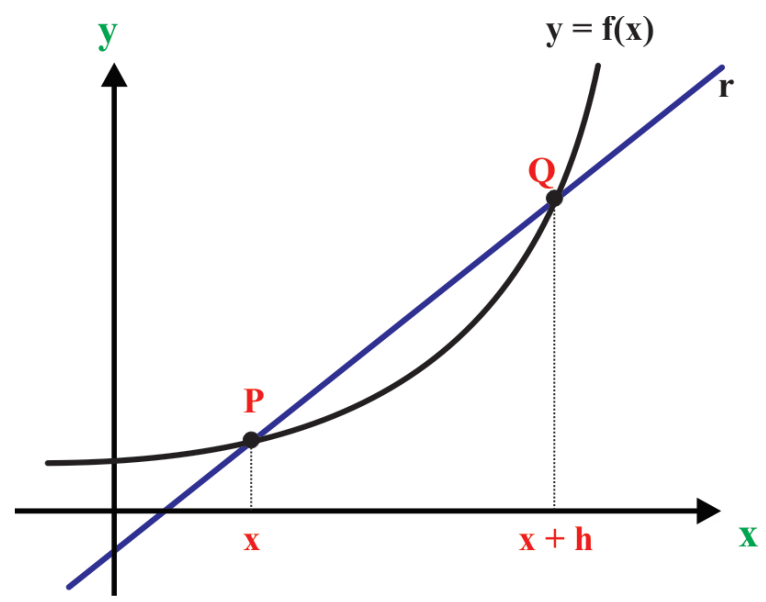

Figura 56: Reta secante a função $f(x)$

A apresentação do conceito de taxa de variação para a primeira série do ensino médio possibilita retomada de conceitos importantes da álgebra do ensino fundamental como cálculo algébrico, produtos notáveis e frações algébricas, como pode ser observado no cálculo da taxa de variação de $f(x)=x^{2}$ no intervalo $I=(x, x+h)$ :

$$
\begin{aligned}
m_{I} & =\frac{f(x+h)-f(x)}{h}=\frac{(x+h)^{2}-x^{2}}{(x+h)-x} \\
& =\frac{x^{2}+2 h x+h^{2}-x^{2}}{h}=\frac{2 h x+h^{2}}{h}=\frac{h(2 x+h)}{h}=2 x+h
\end{aligned}
$$


Fixando $(x, f(x))$ e considerando valores suficientemente próximos de 0 para $h$, $(x+h, f(x+h))$ se aproxima de $(x, f(x))$ e $I=(x, x+h)$ tende a ter comprimento nulo. Nessa situação, a reta tangente à curva no ponto de abscissa $x$ tem inclinação definida como limite das inclinações das retas secantes à medida que o comprimento de $I$ tende a zero.

Definição 8. A derivada da função $y=f(x)$ no ponto $P$ pode ser definida pelo limite das inclinações das retas secantes $P Q$, à medida em que $Q \rightarrow P$, ou seja

$$
f^{\prime}(x)=\lim _{h \rightarrow 0} m_{P Q}=\lim _{h \rightarrow 0} \frac{f(x+h)-f(x)}{h}
$$

Depreende-se então que a inclinação da reta tangente à função $y=f(x)$ no ponto $\left(x_{0}, f\left(x_{0}\right)\right)$ é $f^{\prime}\left(x_{0}\right)$ e seu valor está associado à taxa de crescimento da função nesse ponto. Assim, quanto maior for $f^{\prime}\left(x_{0}\right)$, maior será a taxa com que $f$ cresce nas proximidades de $\left(x_{0}, f\left(x_{0}\right)\right)$. Analogamente, à medida que $f^{\prime}\left(x_{0}\right)$ se aproxima de 0 , a taxa de variação se aproxima de zero e a função apresenta comportamento momentâneo de estabilidade. Na figura 57 tem-se esboçøda reta tangente ao gráfico de $y=f(x)$ no ponto $P=(x, x+h)$.

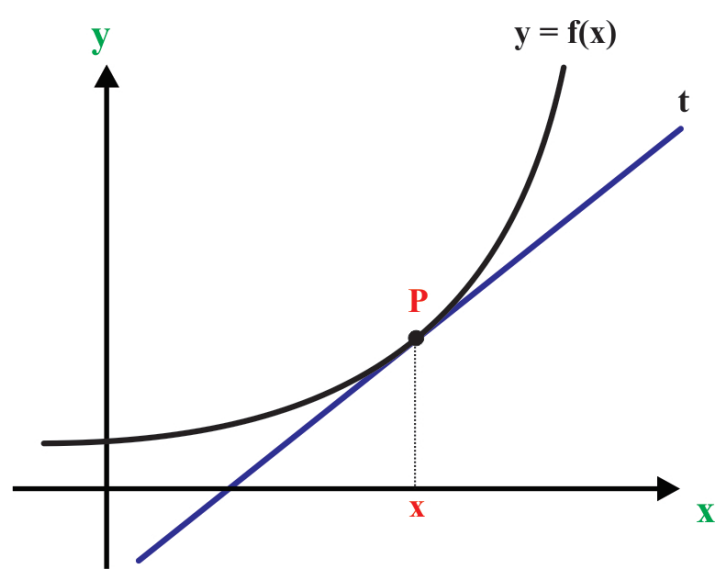

Figura 57: Reta tangente a função $f(x)$

Para $f(x)=x^{3}$, definida para todo $x \in \mathbb{R}$, a derivada $f^{\prime}(x)$ é determinada, segundo definição, por: 


$$
\begin{aligned}
f^{\prime}(x) & =\lim _{h \rightarrow 0} \frac{f(x+h)-f(x)}{h} \\
& =\lim _{h \rightarrow 0} \frac{(x+h)^{3}-(x)^{3}}{h} \\
& =\lim _{h \rightarrow 0} \frac{x^{3}+3 x^{2} h+3 x h^{2}+h^{3}-x^{3}}{h} \\
& =\lim _{h \rightarrow 0} \frac{3 x^{2} h+3 x h^{2}+h^{3}}{h} \\
& =\lim _{h \rightarrow 0} 3 x^{2}+3 x h+h^{2} \\
& =3 x^{2}
\end{aligned}
$$

Embora não pertença ao programa de matemática para o ensino médio desde a década de 1990, o conceito de derivada encontra aplicação imediata na matemática, em situações de otimização de funções contínuas e na cinemática, na formalização dos conceitos de velocidade média e velocidade instantânea.

\subsubsection{Interpretação cinemática}

Uma partícula $P$, descrevendo trajetória $l$ em relação ao referencial $O$, não necessariamente retilínea, tem sua posição determinada, em cada instante, por $x=x(t)$, também denominada equação horária do movimento. A figura 58 associa a posição de $P$ da partícula ao intante $t$ de sua trajetótia.

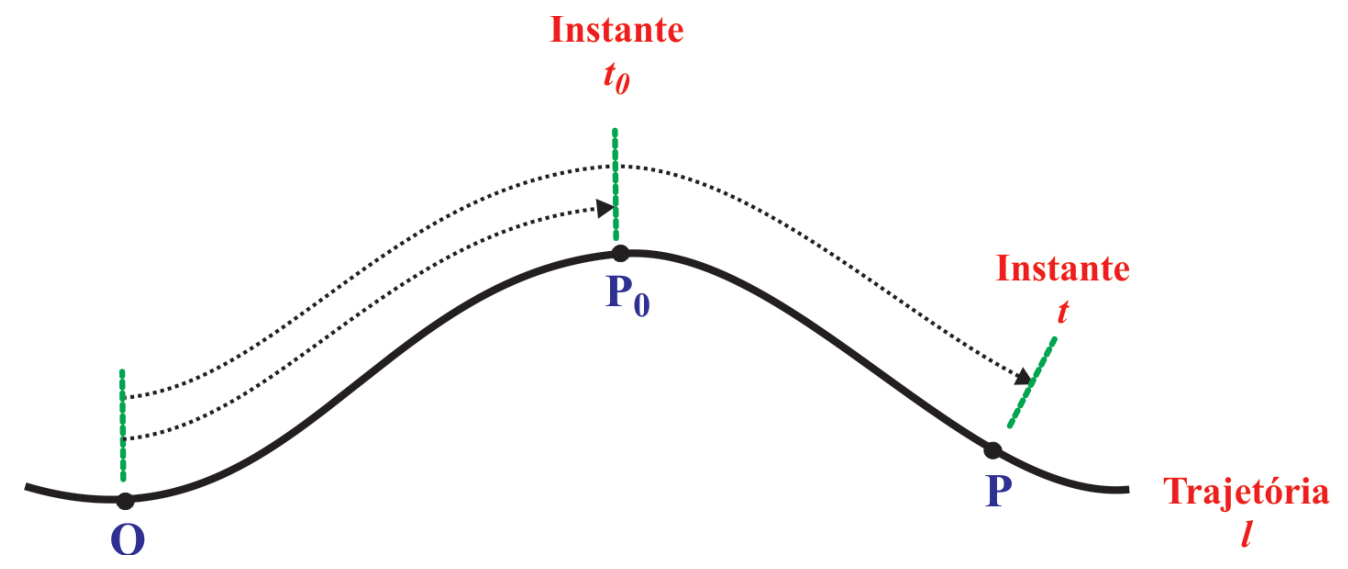

Figura 58: Relação entre posição e deslocamento 
Dado um instante $t_{0}$ e supondo que no instante $t \neq t_{0}$, a velocidade escalar média da partícula entre $t$ e $t_{0}$ é dada pela taxa de variação do deslocamento dessa partícula no intervalo $\left(t_{0}, t\right)$ :

$$
v_{m}=\frac{x(t)-x\left(t_{0}\right)}{t-t_{0}}=\frac{\triangle x}{\triangle t}
$$

À medida que $t \rightarrow t_{0}$, a taxa de variação da posição em relação ao tempo passa a retratar a velocidade da partícula no instante $t_{0}$, fazendo surgir o conceito de velocidade instantânea escalar, definida como o limite a que tende a velocidade escalar média $v_{m}=\frac{\Delta x}{\Delta t}$ quando $\triangle t \rightarrow 0$ e se configura como aplicação do conceito de derivada, sendo representado por

$$
v=\lim _{\triangle t \rightarrow 0} v_{m}=\lim _{\triangle t \rightarrow 0} \frac{\triangle s}{\triangle t}
$$

Exemplo 16. Seja $x=x(t)$ a posição de uma particula em movimento retilíneo uniformemente variável. Se $x(x)=x_{0}+v_{0} t+\frac{1}{2} a t^{2}$, sua velocidade será $v(t)=v_{0}+a t$.

Demonstração. Por definição, a velocidade $v=v(t)$ de uma partícula é determinada por sua derivada em relação a $t$. Então,

$$
\begin{aligned}
v(t)=x^{\prime}(t) & =\lim _{h \rightarrow 0} \frac{x(t+h)-x(t)}{h} \\
& =\lim _{h \rightarrow 0} \frac{\left[x_{0}+v_{0}(t+h)+\frac{1}{2} a(t+h)^{2}\right]-\left[x_{0}+v_{0} t+\frac{1}{2} a t^{2}\right]}{h} \\
& =\lim _{h \rightarrow 0} \frac{\left.x_{0}+v_{0} t+v_{0} h+\frac{1}{2} a t^{2}+a t h+\frac{1}{2} a h^{2}-x_{0}-v_{0} t-\frac{1}{2} a t^{2}\right]}{h} \\
& =\lim _{h \rightarrow 0} \frac{v_{0} h+a t h+\frac{1}{2} a h^{2}}{h} \\
& =\lim _{h \rightarrow 0}\left(v_{0}+a t+\frac{1}{2} a h\right) \\
& =v_{0}+a t
\end{aligned}
$$

\subsubsection{A derivada enquanto resultado de aproximações sucessivas}

A noção proposta para derivada de uma função $f$, definida como limite das inclinações das retas secantes à curva nos pontos $(x, f(x))$ e $(x+h, f(x+h))$ na medida que esses pontos figuram suficientemente próximos, associa o importante conceito do cálculo diferencial à série de arredondamentos de $\frac{f\left(x_{0}+h\right)-f\left(x_{0}\right)}{h}$, no qual $h \rightarrow 0$. Esse aspecto é 
confirmado ao determinar, segundo aproximações de $f$, tomadas no compacto $[x, x+h]$, o valor de $f^{\prime}\left(x_{0}\right)$ onde $x_{0} \in(x, x+h)$.

Exemplo 17. Calcular a derivada de $f(x)=x^{2}$ no ponto de abscissa 3.

\section{Solução}

A derivada de $f$ no ponto de abscissa 3 está associada, geometricamente, à inlinação da reta tangente ao gráfico de $f$ em $(3, f(3))$ e será determinada a partir de retas secantes ao gráfico de $f$ em intervalos do tipo $I=[3,3+h]$ e utilizando definição de taxa de variação nesse intervalo:

$$
f^{\prime}(3)=\lim _{h \rightarrow 0} \frac{f(3+h)-f(3)}{h}
$$

A série de arredondamentos será iniciada considerando $h=1$, ocasião onde é determinada a inclinação da reta secante ao gráfico de $f$ nos pontos $(3, f(3))$ e $(4, f(4))$. Logo, a taxa de variação de $f$ em $I=[3,4]$ é

$$
m_{I}=\frac{f(4)-f(3)}{4-3}=\frac{4^{2}-3^{2}}{4-3}=7
$$

A seguir, na tabela 5, é mostrado que quanto mais próximo de 0 que $h$ for, a inclinação de $I$ se aproxima de 6 .

Tabela 5: Inclinação de $I$ para alguns valores de $h$

\begin{tabular}{|c|c|c|c|}
\hline $\mathrm{h}$ & $I=[3,3+h]$ & Desenvolvimento & Inclinação \\
\hline \hline 0,6 & {$[3 ; 3,6]$} & $m_{I}=\frac{f(3,6)-f(3)}{3,6-3}=\frac{3,6^{2}-3^{2}}{3,6-3}$ & 6,6 \\
0,4 & {$[3 ; 3,4]$} & $m_{I}=\frac{f(3,4)-f(3)}{3,4-3}=\frac{3,4^{2}-3^{2}}{3,4-3}$ & 6,4 \\
0,2 & {$[3 ; 3,2]$} & $m_{I}=\frac{f(3,2)-f(3)}{3,2-3}=\frac{3,2^{2}-3^{2}}{3,2-3}$ & 6,2 \\
0,1 & {$[3 ; 3,1]$} & $m_{I}=\frac{f(3,1)-f(3)}{3,1-3}=\frac{3,1^{2}-3^{2}}{3,1-3}$ & 6,1 \\
\hline
\end{tabular}

Portanto, à medida que $h \rightarrow 0$, intuitivamente observamos que $m_{I} \rightarrow 6$, fato confirmado pela definição de derivada

$$
f^{\prime}(3)=\lim _{h \rightarrow 0} \frac{f(3+h)-f(3)}{h}=\lim _{h \rightarrow 0} \frac{9+6 h+h^{2}-9}{h}=\lim _{h \rightarrow 0}(6+h)=6
$$


A seguir, é proposta atividade a ser desenvolvida no Geogebra para confirmar o resultado acima obtido, seguindo construções e definições associadas à versão geométrica do conceito de derivada, cuja implementação utiliza a ferramenta Controle deslizante pertencente à barra de ferramentas do Geogebra. Para tal, devem ser desenvolvidos as seguintes instruções:

1. Clicar com o botão direito do mouse sobre a Janela de Visualização e escolher a opção Malha para exibir a malha quadriculada;

2. Na Barra de Ferramentas, clicar sobre a ferramenta Controle deslizante para criar controle deslizante denominado $h$, iniciando em 0 , terminando em 1 e com incrementos de 0.01;

3. Em Entrada digitar $f(x)=x \wedge 2$ e pressionar Enter para construir o gráfico de $f(x)=x^{2}$;

4. Em Entrada digitar $A=(3, f(3))$ e pressionar Enter para marcar, no plano, o ponto $A=(3,9)$ que servirá de base para cálculo de $f^{\prime}(3)$;

5. Em Entrada digitar $B=(3+h, f(3+h))$ e pressionar Enter;

Nesse momento da construção, ao alterar o valor da variável $h$, o ponto $B$ deslocase sobre o gráfico de $f(x)=x^{2}$.

6. Em Entrada digitar $\operatorname{Reta}[\mathbf{A}, \mathrm{B}]$ e pressionar Enter para construir a reta que contém os pontos $A$ e $B$;

7. Em Entrada digitar $\mathbf{m}=$ Inclinação[a] e pressionar Enter para explicitar a inclinação da reta que contém $A$ e $B$, associando-a à tangente do ângulo formado pela reta e o sentido positvo do eixo horizontal.

Ao selecionar a ferramenta Mover e clicar sobre o controle deslizante $h$ de forma a alterar seu valor, o Geogebra atualiza automaticamente os elementos dispostos na Janela de Visualização para os diferentes valores de $h$. Ajustando $h$ para valores próximos de 0 , observa-se que a taxa de variação de $f$ tende a ser igual a 6 , conforme está representado na figura 59. 


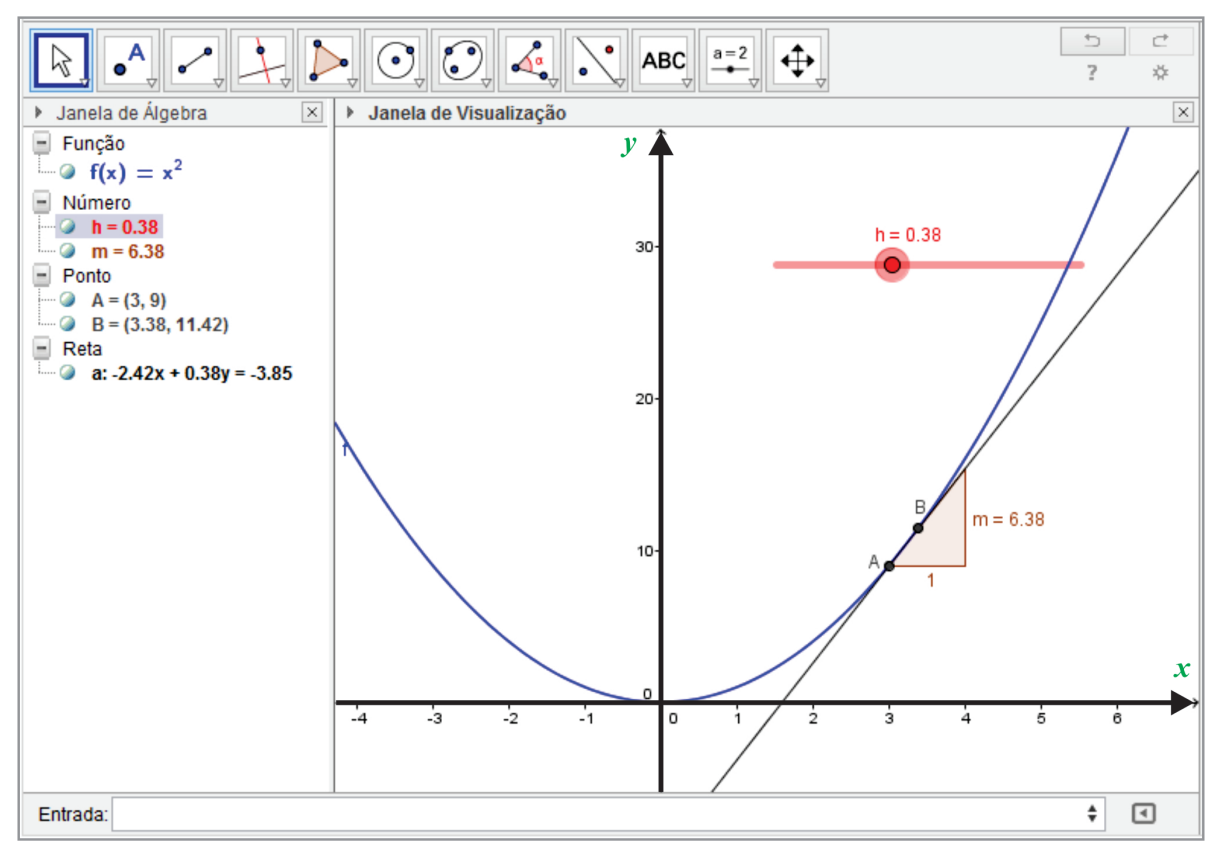

Figura 59: Taxa de variação de $f(x)=x^{2}$ no Geogebra

\subsection{Funções reais de duas variáveis reais}

Definição 9. Uma função real de duas variáveis reais $f: D \subset \mathbb{R}^{2} \rightarrow \mathbb{R}$ é uma relação que associa a cada par $(x, y) \in \mathbb{R}^{2}$ um único número $f(x, y) \in \mathbb{R}$. Nesse caso, $D$ é o dominio de $f$.

Na figura 60, tem-se a representação gráfica da definição 9 .

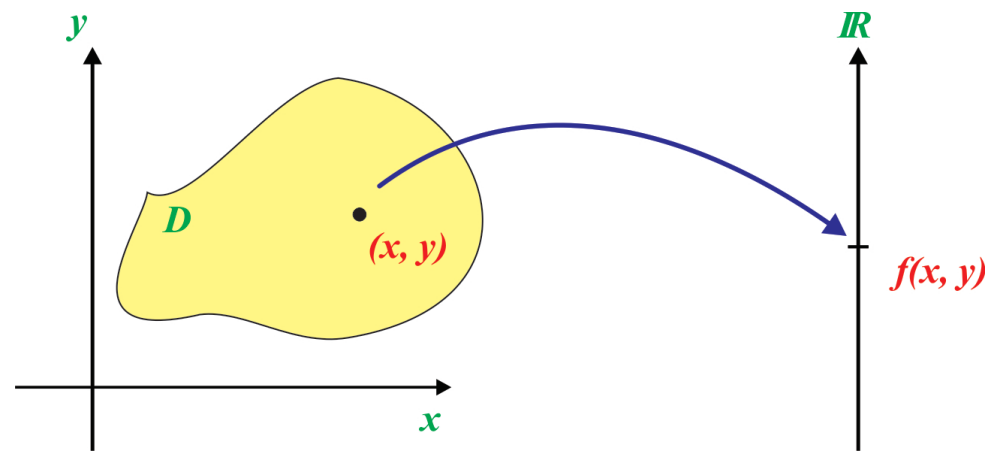

Figura 60: Função real de duas variáveis reais 
Funções de duas ou mais variáveis são observadas em diferentes situações do quotidiano e em diferentes ocasiões da educação básica como, por exemplo, no cálculo da força necessária para deslocar uma massa $m$ sob aceleração $a, F(m, a)=m \cdot a$ ou para determinar a pressão exercida por um gás confinado em um recipiente de volume $V$ e temperatura $T, p(T, V)=\frac{n \cdot R \cdot T}{V}$ ou ainda na própria matemática, no cálculo do volume de um cilindro, $V(r, h)=\pi \cdot r^{2} \cdot h$.

Definição 10. Seja $f: D \subset \mathbb{R}^{2} \rightarrow \mathbb{R}$ uma função real de duas variáveis reais. $O$ gráfico de $f$ é o conjunto

$$
\operatorname{Graf}(f)=\left\{(x, y, f(x, y)) \in \mathbb{R}^{3}:(x, y) \in D\right\}
$$

A figura 61 mostra o gráfico de $f(x, y)=x^{2}+y^{2}$.

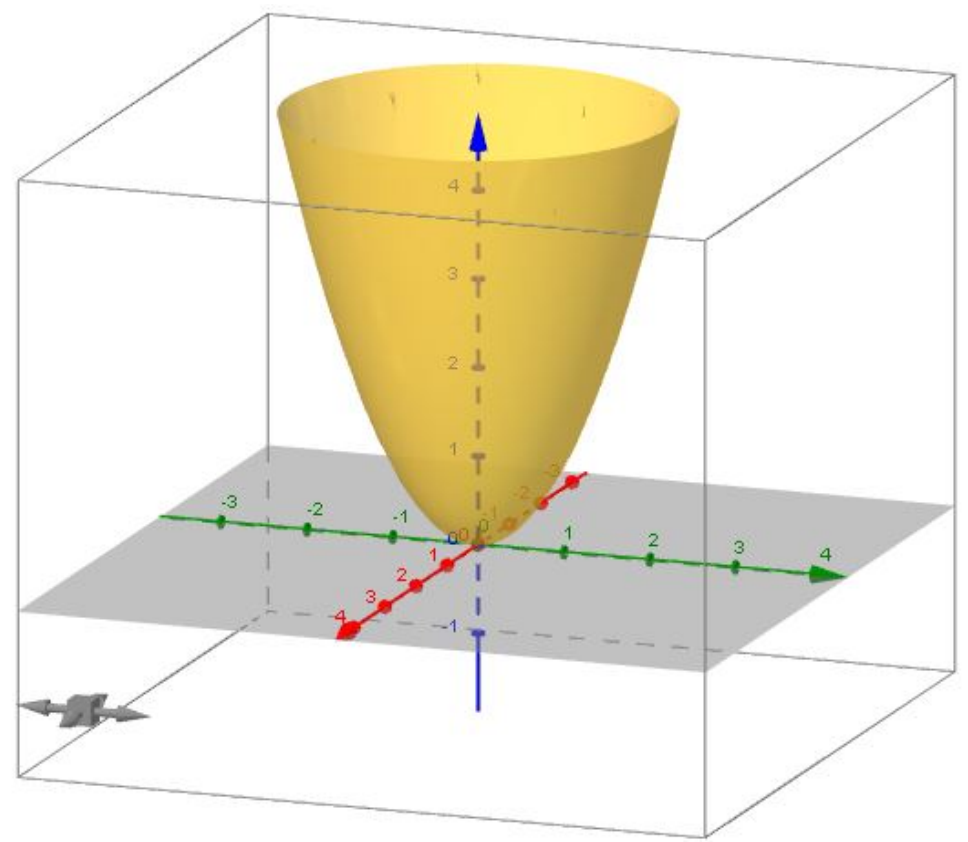

Figura 61: Gráfico de $f(x, y)=x^{2}+y^{2}$

Muitas funções $z=f(x, y)$, mesmo que definidas por expressões algébricas relativamente simples, podem apresentar gráficos difíceis de se esboçar e, para se ter noção do comportamento geométrico dessas funções, é comum o uso de curvas de nível, cuja idéia básica remete à cartografia, onde se faz a representação, no plano, de superfícies 
tridimensionais. Quando essas curvas são colocadas num mapa e designadas apropriadamente, o mapa topográfico resultante permite obter um panorama dos contornos do terreno no espaço tridimennsionail a partir de representação bidimensional.

Definição 11. Seja $f: D \subset \mathbb{R}^{2} \rightarrow \mathbb{R}$ uma função real de duas variáveis reais. Uma curva de nível de $f$ é uma região constituída por todos os pontos de $D$ nos quais $f$ tem a mesma imagem $k$, ou seja,

$$
C(k)=\left\{(x, y) \in D \subset \mathbb{R}^{2}: f(x, y)=k\right\}
$$

Para $f(x, y)=x^{2}+y^{2}$, as curvas de nível, por apresentarem equações do tipo $x^{2}+y^{2}=k$, determinam um conjunto de circunferências de centro $(0,0)$ e raio $\sqrt{k}$, como estão representados na figura 62 .

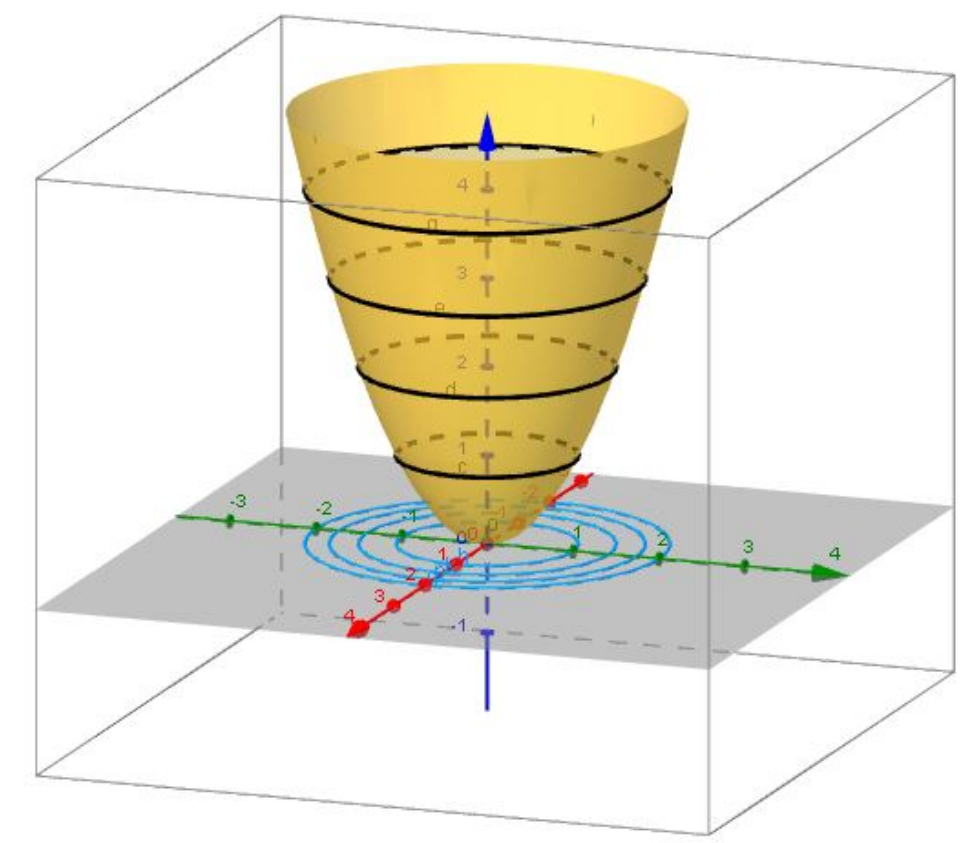

Figura 62: Curvas de nível de $f(x, y)=x^{2}+y^{2}$

Uma aplicação relevante do uso de funções de duas (ou mais) variáveis está em otimizar funções lineares como $f(x, y)=a x+b y$ definidas em um conjunto compacto e poligonal $D \subset \mathbb{R}^{2}$ para o qual o algoritmo Simplex se apresenta como ferramenta muito eficiente. 


\subsection{Derivadas parciais e gradiente de uma função}

Definição 12. Seja $D \subset \mathbb{R}^{2}$ um conjunto aberto e $f: D \rightarrow \mathbb{R}$ uma função real de duas variáveis reais. A derivada parcial de $f$ em relação a $x$ em um ponto $(a, b) \in D$ é definida por

$$
f_{x}(a, b)=\frac{\partial f}{\partial x}(a, b)=\lim _{t \rightarrow 0} \frac{f(a+t, b)-f(a, b)}{t}
$$

caso o limite exista. Analogamente, nas mesmas condições, a derivada parcial de $f$ em relação a y é definida por

$$
f_{y}(a, b)=\frac{\partial f}{\partial y}(a, b)=\lim _{t \rightarrow 0} \frac{f(a, b+t)-f(a, b)}{t}
$$

As derivadas parciais $f_{x}(a, b)$ e $f_{y}(a, b)$ representam as taxas de variação de $f(x, y)$ no ponto $(a, b)$ em relação aos eixos cartesianos $x$ e $y$, respectivamente.

Definição 13. Seja $f: D \subset \mathbb{R}^{2} \longrightarrow \mathbb{R}$ função definida no aberto $D e(x, y) \in D$. $O$ gradiente de $f$, denotado por $\nabla f$ ou grad $f$, é o vetor cujas componentes são as derivadas parciais, isto é,

$$
\nabla f=\left(\frac{\partial f}{\partial x}, \frac{\partial f}{\partial y}\right)=\frac{\partial f}{\partial x}(x, y) \cdot \vec{i}+\frac{\partial f}{\partial y}(x, y) \cdot \vec{j}
$$

onde $\vec{i}=(1,0)$ e $\vec{j}=(0,1)$ são os vetores uniitários de $\mathbb{R}^{2}$.

Exemplo 18. Seja $f: \mathbb{R}^{2} \rightarrow \mathbb{R}$ uma função real de duas variéveis reais definida por $f(x, y)=x^{2}+y^{2}$. Como as derivadas parciais de $f$ em relação a $x$ e a y são, respectivamente,

$$
\begin{aligned}
f_{x}(x, y)=\frac{\partial f}{\partial x}(x, y) & =\lim _{t \rightarrow 0} \frac{f(x+t, y)-f(x, y)}{t} \\
& =\lim _{t \rightarrow 0} \frac{(x+t)^{2}+y^{2}-x^{2}-y^{2}}{t} \\
& =\lim _{t \rightarrow 0} \frac{x^{2}+2 t x+t^{2}-x^{2}}{t} \\
& =\lim _{t \rightarrow 0} \frac{2 t x+t^{2}}{t}=\lim _{t \rightarrow 0} 2 x+t=2 x
\end{aligned}
$$




$$
\begin{aligned}
f_{y}(x, y)=\frac{\partial f}{\partial y}(x, y) & =\lim _{t \rightarrow 0} \frac{f(x, y+t)-f(x, y)}{t} \\
& =\lim _{t \rightarrow 0} \frac{x^{2}+(y+t)^{2}-x^{2}-y^{2}}{t} \\
& =\lim _{t \rightarrow 0} \frac{y^{2}+2 t y+t^{2}-y^{2}}{t} \\
& =\lim _{t \rightarrow 0} \frac{2 t y+t^{2}}{t}=\lim _{t \rightarrow 0} 2 y+t=2 y
\end{aligned}
$$

conclui-se que o gradiente de $f(x, y)=x^{2}+y^{2}$ é $\nabla f=(2 x, 2 y)=2 x \vec{i}+2 y \vec{j}$.

Definição 14. A derivada direcional de $f$ no ponto $(x, y)$, na direção do vetor unitário $\vec{u}=\left(x_{0}, y_{0}\right)$, denotada por $\frac{\partial f}{\partial \vec{u}}(x, y)$ é definida por

$$
\begin{aligned}
\frac{\partial f}{\partial \vec{u}}(x, y) & =\lim _{t \rightarrow 0} \frac{f(p(t))-f(p(0))}{t} \\
& =\lim _{t \rightarrow 0} \frac{f\left(x+t x_{0}, y+t y_{0}\right)-f(x, y)}{t}
\end{aligned}
$$

A derivada direcional de $f$ no ponto $(x, y)$ na direção $\vec{u}=\left(x_{0}, y_{0}\right)$ exprime a taxa de variação $f$ ao longo da reta $p(t)=(x, y)+t \cdot\left(x_{0}, y_{0}\right)$.

Exemplo 19. A derivada de $f(x, y)=5 x+3 y$, no ponto $(1,1)$, na direção de $\left(\frac{3}{5}, \frac{4}{5}\right)$ é

$$
\begin{aligned}
\frac{\partial f}{\partial \vec{u}}(1,1) & =\lim _{t \rightarrow 0} \frac{f(p(t))-f(p(0))}{t} \\
& =\lim _{t \rightarrow 0} \frac{f\left(1+t \frac{3}{5}, 1+t \frac{4}{5}\right)-f(1,1)}{t} \\
& =\lim _{t \rightarrow 0} \frac{5+3 t+3+\frac{4}{5} t-8}{t} \\
& =\lim _{t \rightarrow 0} \frac{\frac{19}{5} t}{t} \\
& =\frac{19}{5}
\end{aligned}
$$

Definição 15. A função $f: D \subset \mathbb{R}^{2} \longrightarrow \mathbb{R}$ é diferenciável no ponto $u=(x, y) \in D$ quando existirem as derivadas parciais $\frac{\partial f}{\partial x}(u)$ e $\frac{\partial f}{\partial y}(u)$ e, além disso, para todo vetor 
$v=(a, b) \in \mathbb{R}^{2}$, com $u+v \in D$, se tenh $a$

$$
f(u+v)=f(u)+\frac{\partial f}{\partial x}(u) \cdot a+\frac{\partial f}{\partial y}(u) \cdot b+r(v)
$$

onde $\lim _{v \rightarrow 0} \frac{r(v)}{|v|}=0$.

Quando $f$ é diferenciável em todos os pontos de $D$, dizemos simplesmente que $f$ é diferenciável. De $\lim _{v \rightarrow 0} \frac{r(v)}{|v|}=0$, concluímos que $\lim _{v \rightarrow 0} r(v)=0$ e, desse fato, resulta que toda função diferenciável num ponto é contínua nesse ponto.

Definição 16. Sejam $\overrightarrow{v_{1}}=\left(x_{1}, y_{1}\right)$ e $\overrightarrow{v_{2}}=\left(x_{2}, y_{2}\right)$ vetores em $\mathbb{R}^{2}$. O produto interno ou escalar entre $\overrightarrow{v_{1}}$ e $\overrightarrow{v_{2}}$, denotado por $\left\langle\overrightarrow{v_{1}}, \overrightarrow{v_{2}}\right\rangle$, é definido por

$$
\left\langle\overrightarrow{v_{1}}, \overrightarrow{v_{2}}\right\rangle=\overrightarrow{v_{1}} \cdot \overrightarrow{v_{2}}=x_{1} x_{2}+y_{1} y_{2}
$$

A partir do conceito de produto escalar, podemos definir a norma de um vetor $\vec{v}=(x, y)$ como $\|\vec{v}\|=\sqrt{\vec{v} \cdot \vec{v}}=\sqrt{x^{2}+y^{2}}$. Geometricamente, a norma do vetor $\vec{v}$ representa a distância da origem de $\mathbb{R}^{2}$ ao ponto de coordenadas $(x, y)$, ou seja, é igual ao módulo do vetor $\vec{v}$.

A seguir mostraremos como a noção de produto interno permite determinar o ângulo entre dois vetores de $\mathbb{R}^{2}$ conforme indicado por $\theta$ na figura 63 .

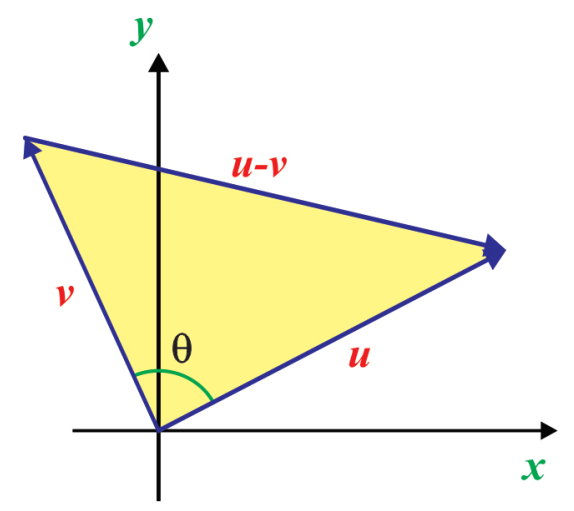

Figura 63: Ângulo entre os vetores $\vec{u}$ e $\vec{v}$

Aplicando a Lei dos Cossenos para o triângulo da Figura 63, obtemos

$$
\|\vec{u}-\vec{v}\|^{2}=\|\vec{u}\|^{2}+\|\vec{v}\|^{2}-2 \cdot\|\vec{u}\| \cdot\|\vec{v}\| \cdot \cos \theta
$$


Por outro lado, da definição de produto interno, segue que

$$
\begin{aligned}
\|u-v\|^{2} & =(\vec{u}-\vec{v}) \cdot(\vec{u}-\vec{v}) \\
& =\vec{u} \cdot \vec{u}-\vec{u} \cdot \vec{v}-\vec{v} \cdot \vec{u}+\vec{v} \cdot \vec{v} \\
& =\|\vec{u}\|^{2}-2 \cdot \vec{u} \cdot \vec{v}+\|\vec{v}\|^{2}
\end{aligned}
$$

Portanto,

$$
\begin{aligned}
\|\vec{u}\|^{2}+\|\vec{v}\|^{2}-2 \cdot\|\vec{u}\| \cdot\|\vec{v}\| \cdot \cos \theta & =\|\vec{u}\|^{2}-2 \cdot \vec{u} \cdot \vec{v}+\|\vec{v}\|^{2} \\
& \Rightarrow-2 \cdot\|\vec{u}\| \cdot\|\vec{v}\| \cdot \cos \theta=-2 \cdot \vec{u} \cdot \vec{v} \\
& \Rightarrow\|\vec{u}\| \cdot\|\vec{v}\| \cdot \cos \theta=\vec{u} \cdot \vec{v} \\
& \Rightarrow \cos \theta=\frac{\vec{u} \cdot \vec{v}}{\|\vec{u}\| \cdot\|\vec{v}\|}
\end{aligned}
$$

Exemplo 20. O cosseno do ângulo entre os vetores $\vec{u}=(1,2)$ e $\vec{v}=(2,1)$ é

$$
\cos \theta=\frac{1 \cdot 2+2 \cdot 1}{\sqrt{1^{2}+2^{2}} \cdot \sqrt{2^{2}+1^{2}}}=\frac{4}{5}
$$

Teorema 5. Seja $D \subset \mathbb{R}^{2}$ um aberto de $\mathbb{R}^{2},(a, b) \in D$ e $f: D \rightarrow \mathbb{R}$ uma função diferenciável em $(a, b)$. Para qualquer vetor unitário $\vec{u}$, tem-se

$$
\frac{\partial f}{\partial \vec{u}}(a, b)=\nabla f(a, b) \cdot \vec{u}
$$

Ou seja, caso $f$ seja diferenciável, as derivadas direcionais serão dadas pelo produto interno do vetor gradiente pelo vetor unitário na direção indicada. Além disso, o teorema garante que, sendo $f$ diferenciável, ela admite derivada direcional $\frac{\partial f}{\partial \vec{u}}$ para todo vetor unitário $\vec{u}$.

Demonstração. Observando que a reta paralela ao vetor $\vec{u}$ que contém o ponto $(a, b)$ tem equação $\alpha(t)=(a, b)+t \cdot \vec{u}$, obtemos

$$
\begin{aligned}
\frac{\partial f}{\partial \vec{u}}(a, b) & =\lim _{t \rightarrow 0} \frac{f(\alpha(t))-f(\alpha(0))}{t} \\
& =\lim _{t \rightarrow 0} \frac{(f \circ \alpha)(t)-(f \circ \alpha)(0)}{t} \\
& =(f \circ \alpha)^{\prime}(0) .
\end{aligned}
$$


Aplicando a Regra da Cadeia e usando os fatos de que $\alpha(0)=(a, b)$ e $f$ é diferenciável em $(a, b)$, temos

$$
\begin{aligned}
\frac{\partial f}{\partial \vec{u}}(a, b) & =(f \circ \alpha)^{\prime}(0) \\
& =\nabla f(\alpha(0)) \cdot \alpha^{\prime}(0) \\
& =\nabla f(a, b) \cdot \vec{u}
\end{aligned}
$$

Suponha que $f$ seja diferenciável em $(a, b)$ e $\nabla f(a, b) \neq \overrightarrow{0}$, então

$$
\frac{\partial f}{\partial \vec{u}}(a, b)=\|\nabla f(a, b)\| \cdot\|\vec{u}\| \cdot \cos \theta=\|\nabla f(a, b)\| \cdot \cos \theta
$$

onde $\theta$ é o ângulo entre $\nabla f(a, b)$ e $\vec{u}$. Essa fórmula nos permite concluir que $\frac{\partial f}{\partial \vec{u}}(a, b)$ é máximo quando $\cos \theta=1$ ( ou $\theta=0$ ), isto é, o gradiente aponta na direção de maior crescimento da função $f$, no ponto $(a, b)$.

Exemplo 21. O gradiente de $g(x, y)=2 x+3 y$ é $\nabla g=(2,3)=2 \vec{i}+3 \vec{j}$ e esse é $o$ sentido no qual $g$ cresce mais rapidamente. 


\section{$7 \quad$ O Método Simplex}

A fundamentação teórica deste capítulo segue a referência [11].

\subsection{Introdução}

O Simplex é um algoritmo desenvolvido em 1947 por George B. Dantzing para resolver problemas de programação linear e consiste em um procedimento iterativo que percorre os pontos extremos do conjunto de soluções possíveis do problema, determinado pelas restrições levantadas na modelagem. O algoritmo apresenta critérios para escolha de soluções básicas que melhoram o desempenho do método, de forma que não seja necessária a verificação de todos os pontos extremos do conjunto de soluções viáveis do problema, e um teste de otimalidade, que verifica se o algoritmo alcançou seu ponto ótimo, quando é encerrado. Esses elementos são apresentados na figura 64 .

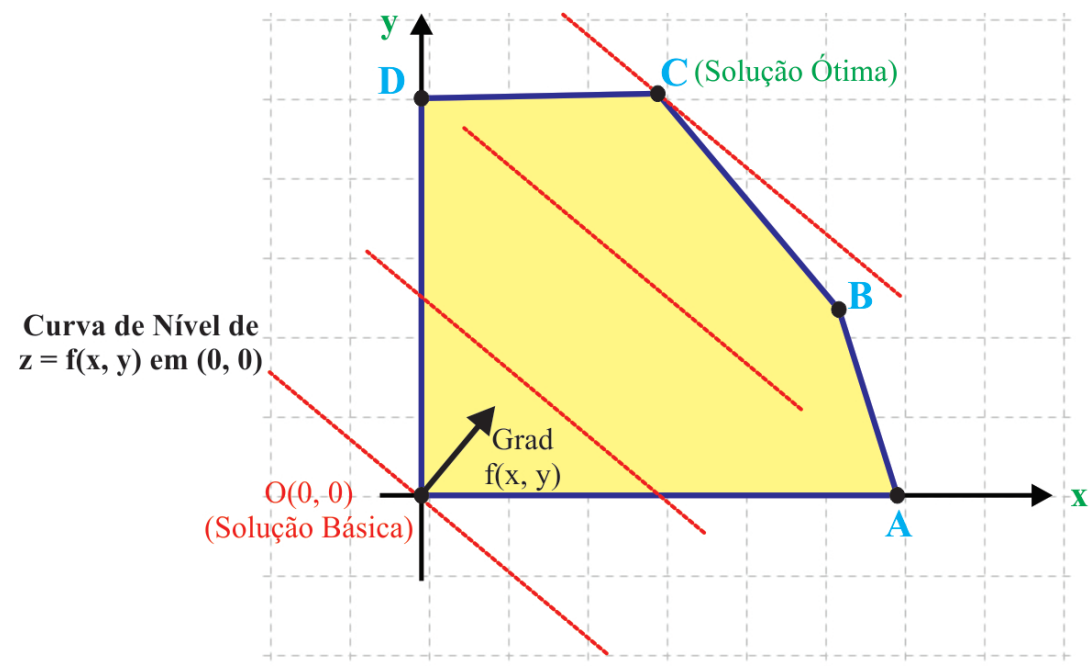

Figura 64: Algoritmo simplex

Para que o algoritmo seja iniciado, faz-se necessário o conhecimento de uma solução compatível básica ou solução inicial do problema proposto. Essa solução pode ser associada a qualquer um dos pontos extremos da região determinada pelas restrições. Em seguida, é avaliado o valor da função objetivo nesse ponto e é feito o teste de otimalidade. Caso seja uma solução ótima, o processo está encerrado. Caso contrário, é verificado se um dos pontos extremos adjacentes ao ponto extremo inicialmente adotado fornece para a função objetivo um valor melhor do que o atual. 
O método faz então a mudança do ponto inicial para o ponto extremo adjacente que melhore o valor da função objetivo. O procedimento adotado para o ponto extremo inicial é repetido para este segundo ponto extremo. O processo finaliza quando, estando num ponto extremo, todos os pontos extremos a ele adjacentes, fornecem valores piores para a função objetivo.

\subsection{Conceitos}

A modelagem matemática e sua resolução segundo métodos e diretrizes da programação linear está fundamentada em três grandes grupos conceituais: variáveis de decisão, restrições e função objetivo. As variáveis de decisão constituem as incógnitas a serem determinadas pela resolução do modelo, as restrições são condições que limitam os valores que podem ser atribuídos às variáveis enquanto a função objetivo é uma sentença matemática cuja otimalidade é buscada.

A construção de um modelo envolve a identificação de inequações e equações, das quais uma é utilizada para mensurar a eficiência do sistema para cada solução apresentada, sendo denominada função objetivo ou função de eficiência.

Definição 17. Sejam $c_{1}, c_{2}, \ldots, c_{n}$ números reais e $\left(x_{1}, x_{2}, \ldots, x_{n}\right) \in \mathbb{R}^{n}$. Em um modelo de programação linear, a função objetivo é a função linear definida por

$$
f(x)=\sum_{i=1}^{n} c_{i} x_{i}=c_{1} x_{1}+c_{2} x_{2}+\ldots+c_{n} x_{n}
$$

em $\mathbb{R}^{n}$ cujo valor se deseja otimizar, isto é, maximizar ou minimizar.

O simplex se propõe a otimizar funções lineares definida em subconjunto compacto do $\mathbb{R}^{n}$ determinado pelas desigualdades levantadas na fase de modelagem e tem seu funcionamento justificado pelo significado geométrico associado ao gradiente da função que mostra o sentido de seu maior crescimento.

Exemplo 22. O sentido de maior crescimento de $f(x, y)=3 x+4 y$ é $\nabla f=(3,4)$ e ocorre de forma mais efetiva na direção Oy do que na direção Ox uma vez que, para todo $(a, b) \in \mathbb{R}^{2}$, tem-se

$$
\frac{\partial f}{\partial y}(a, b)>\frac{\partial f}{\partial x}(a, b)
$$


Definição 18. Um problema de programação linear está na forma canônica se suas restrições são desigualdades, ou seja, se possui a forma

$$
\begin{gathered}
\text { Maximizar } f\left(x_{1}, \ldots, x_{n}\right)=c_{1} x_{1}+\ldots+c_{n} x_{n} \\
\text { Sujeito a }\left\{\begin{array}{l}
a_{11} x_{1}+\ldots+a_{1 n} x_{n} \leq b_{1} \\
a_{21} x_{1}+\ldots+a_{2 n} x_{n} \leq b_{2} \\
a_{31} x_{1}+\ldots+a_{3 n} x_{n} \leq b_{3} \\
\vdots \\
a_{m 1} x_{1}+\ldots+a_{m n} x_{n} \leq b_{m}
\end{array}\right.
\end{gathered}
$$

A forma canônica será util na resolução de problemas pela versão geométrica do Simplex que associa o ponto ótimo da função objetivo a um dos pontos pertercentes ao polígono construído a partir das desigualdades determinadas pelas restrições.

Definição 19. Um problema de programação linear está na forma padrão quando sua restrições são igualdades. Logo, está na forma padrão um problema cuja formulação é

$$
\begin{array}{cl}
\text { Maximizar } & f\left(x_{1}, \ldots, x_{n}\right)=c_{1} x_{1}+\ldots+c_{n} x_{n} \\
\text { Sujeito a }\left\{\begin{array}{l}
a_{11} x_{1}+\ldots+a_{1 k} x_{k}=b_{1} \\
a_{21} x_{1}+\ldots+a_{2 k} x_{k}=b_{2} \\
a_{31} x_{1}+\ldots+a_{3 k} x_{k}=b_{3} \\
\vdots \\
a_{m 1} x_{1}+\ldots+a_{m k} x_{k}=b_{m}
\end{array}\right.
\end{array}
$$

onde $k=m+n, x_{1}, x_{2}, \cdots, x_{n}$ são as variáveis inicialmente observadas no PPL $e$ $x_{n+1}, x_{n+2}, \cdots, x_{k}$ são denominadas variáveis de sobra e são utilizadas com o objetivo de transformar cada uma das desigualdades presentes ma forma canônica em uma igualdade.

Na forma padrão, associa-se o ponto ótimo da função objetivo à solução do sistema cujas equações são restrições observadas no problema e é obtida a partir de escalonamento combinado com testes de otimalidade. No desenvolvimento do processo, as soluções intermediárias são obtidas e são classificadas em básicas e não-básicas, conforme algumas de suas incógnitas tenham valores igualados a zero. 
Algebricamente, a transformação da forma canônica de um problema para sua forma padrão é possível a partir do acréscimo de uma variável de folga para cada desigualdade. A desigualdade $x_{1}+2 x_{2} \leq 15$ é transformada na igualdade $x_{1}+2 x_{2}+s=15$ em função da insersão da variável de folga $s \geq 0$.

Definição 20. Sejam $m$ e $n(n \geq m)$, respectivamente, o número de equações linearmente independentes e o número de incógnitas de um sistema linear. Define-se por solução básica a solução do sistema obtido atribuindo-se 0 a $n-m$ dessas incógnitas.

Exemplo 23. Determinar as soluções básicas do sistema determinado pelas equações $x_{1}+2 x_{2}+3 x_{3}=14$ e $x_{1}+3 x_{2}+2 x_{3}=17$

\section{Solução}

Como o sistema apresentado é formado por 3 incógnitas em 2 equações linearmente independentes, cada uma de suas soluções básicas é obtida atribuindo-se 0 a $3-2=1$ de suas variáveis. Então:

I. Fazendo $x_{1}=0$, o sistema resume-se a

$$
\left\{\begin{array}{l}
2 x_{2}+3 x_{3}=14 \\
3 x_{2}+2 x_{3}=17
\end{array}\right.
$$

cuja equações tornam-se verdadeiras para $x_{2}=\frac{23}{5}$ e $x_{3}=\frac{8}{5}$. Portanto, a solução básica obtida foi $\left(x_{1}, x_{2}, x_{3}\right)=\left(0, \frac{23}{5}, \frac{8}{5}\right)$.

II. Para $x_{2}=0$, o sistema obtido é

$$
\left\{\begin{array}{l}
x_{1}+3 x_{3}=14 \\
x_{1}+2 x_{3}=17
\end{array}\right.
$$

onde $x_{3}=-3$ e $x_{1}=23$ gera como solução básica $\left(x_{1}, x_{2}, x_{3}\right)=(23,0,-3)$.

III. A terceira e última solução básica ocorre quando $x_{3}=0$, ao resolver o sistema

$$
\left\{\begin{array}{l}
x_{1}+2 x_{2}=14 \\
x_{1}+3 x_{2}=17
\end{array}\right.
$$

e gera a solução básica $\left(x_{1}, x_{2}, x_{3}\right)=(8,3,0)$. 


\subsection{Teoremas fundamentais}

O algoritmo Simplex tem funcionamento estruturado em quatro teoremas que utilizam de conceitos elementares da análise e da álgebra matemática como conjunto convexo e ponto extremo de um conjunto convexo.

Definição 21. Um conjunto $C \subset \mathbb{R}^{n}$ é dito convexo se, e somente se, para todos os vetores $x_{1}, x_{2} \in C$, com $x_{1} \neq x_{2}$ e $0 \leq \lambda \leq 1$, tem-se que $x=\lambda x_{1}+(1-\lambda) x_{2} \in C$.

Definição 22. Dado um conjunto convexo $C, x \in C$ 'e um ponto extremo de $C$ quando não pode ser escrito como combinação linear não trivial de pontos de C. Em outras palavras, $x=x_{1} \lambda_{1}+x_{2} \lambda_{2}+\cdots+x_{n} \lambda_{n} \Rightarrow x=x_{i}$ para algum $i$.

Teorema 6. O conjunto de todas as soluções do modelo de programação linear é um conjunto convexo.

Demonstração. Seja $C$ o conjunto de todos os pontos $x$ tais que $A x=b, x \leq 0$. Considerando duas soluções $x_{1}$ e $x_{2}$ e distintas pertencentes a $C$, temos $A x_{1}=b$ e $A x_{2}=b$. Fazendo $x=\lambda x_{1}+(1-\lambda) x_{2}$, temos:

$$
\begin{aligned}
A x & =A \cdot\left(\lambda x_{1}+(1-\lambda) x_{2}\right) \\
& =A \cdot \lambda x_{1}+A \cdot(1-\lambda) x_{2} \\
& =\lambda \cdot A x_{1}+(1-\lambda) \cdot A x_{2} \\
& =\lambda b+(1-\lambda) b=b
\end{aligned}
$$

Teorema 7. Toda solução básica do sistema $A x=b$ é um ponto extremo do conjunto de soluçôes viáveis, ou seja, um extremo do conjunto $C$.

Demonstração. Seja $C$ o conjunto de todos os pontos $x$ tais que $A x=b, x \geq 0$, onde $x \geq 0$ significa afirmar que todas as coordenadas de $x$ são maiores ou iguais a zero. Seja ainda uma solução viável qualquer $x \in \mathbb{R}^{n}$ na qual, sem perda de generalidade, as $m$ primeiras variáveis são básicas, ou seja, $x=\left(x_{1}, x_{2}, \ldots, x_{m}, 0,0, \ldots, 0\right)^{T}$.

Supondo, por absurdo, que $x$ não seja ponto interno do $C$, definido anteriormente, então $x$ pertence a qualquer segmento de reta cujas extremidades também são pontos 
de $C$, e pode ser expresso como combinação linear de quaisquer dois pontos distintos de $C$, aos quais chamaremos u e v, isto é, $x=\alpha u+(1-\alpha) v, 0 \leq \alpha \leq 1$, como se vê na figura 65.

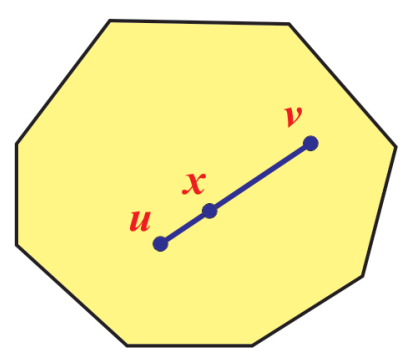

Figura 65: Região convexa

No entanto, como $u, v \in C$, escrevemos $A u=b, u \geq 0, A v=b$ e $v \geq 0$ e expressamos $x=\alpha u+(1-\alpha) v$ em termos de suas coordenadas:

$$
\begin{aligned}
x_{1} & =\alpha u_{1}+(1-\alpha) v_{1} \\
x_{2} & =\alpha u_{2}+(1-\alpha) v_{2} \\
& \vdots \\
x_{m} & =\alpha u_{m}+(1-\alpha) v_{m} \\
0 & =\alpha u_{m+1}+(1-\alpha) v_{m+1} \\
& \vdots \\
0 & =\alpha u_{n}+(1-\alpha) v_{n}
\end{aligned}
$$

Como $0 \leq \alpha \leq 1$ e as coordenadas de $u$ e $v$ não são negativas, as últimas $n-m$ equações só seriam atendidas nos seguintes casos:

1. $x$ pertence ao segmento de reta limitado por $u$ e $v$, ou seja, $0<\alpha<1$. Então $u_{m+i}=0$ e $v_{m+i}=0$ para $i \in 1,2, \ldots, n-m$. Logo, tanto $u$ quanto $v$ são soluções básicas do sistema.

2. $\alpha=0$ e $u$ seja uma solução básica do sistema. Então $x=\left(x_{1}, x_{2}, \cdots, x_{m}, 0, \cdots, 0\right)=$ $\left(v_{1}, v_{2}, \cdots, v_{m}, v_{m+1}, \cdots, v_{n}\right)=v$.

3. Analogamente ao item anterior, considerando $\alpha=1$ e $v$ uma solução básica do sistema, concluimos que $x=u$ e $x=\left(x_{i}\right)_{i \in\{1,2,3, \cdots\}}=\left(u_{i}\right)_{i \in\{1,2,3, \cdots\}}=u$. 
Concluimos então que não existem soluções viáveis $u$ e $v$, distintas de $x$ para que se tenha $x=\alpha u+(1-\alpha) v$. Por contradição, demonstra-se que $x$ é um ponto extremo de $C$.

Teorema 8. Todo ponto extremo $x$ de um conjunto de soluções viáveis de um sistema $A x=b$ é uma solução básica viável.

Por fim, o último elemento teórico necessário para justificar a estratégia adotada pelo simplex diz respeito ao valor ótimo alcançado pela função objetivo. O próximo teorema estabelece a conexão entre pontos extremos e valor da função objetivo, bem como a garantia de que o valor ótimo é obtido nos pontos extremos de C.

Teorema 9. Se a função objetivo possui um máximo (minimo) finito, então pelo menos uma solução ótima é um ponto extremo do conjunto convexo no qual a função objetivo está definida. Se a função objetivo assume o máximo (mínimo) em mais de um ponto extremo, então ela toma o mesmo valor para qualquer combinação convexa desses pontos extremos.

Em [11], o leitor encontra as demonstrações dos teoremas 8 e 9.

\subsection{O algoritmo simplex}

O detalhamento do Método Simplex utilizará a notação matricial onde será adotada a matriz $A_{m \times n}$ e os vetores colunas $b \in \mathbb{R}^{n}$ e $c \in \mathbb{R}^{m}$ para que a modelagem de um problema de programação linear possa ser expressa como $\max f(x)=c^{T} \cdot x$ sujeito a $A \cdot x=b$, onde $x \in \mathbb{R}^{n}$ e $x \geq 0$, isto é, todas as coordenadas de $x$ são não negativas. Portanto, para a forma padrão de um problema de programação linear,

$$
\begin{gathered}
\text { Maximizar } f\left(x_{1}, \ldots, x_{n}\right)=c_{1} x_{1}+\ldots+c_{n} x_{n} \\
\text { Sujeito a }\left\{\begin{array}{l}
a_{11} x_{1}+\ldots+a_{1 k} x_{k}=b_{1} \\
a_{21} x_{1}+\ldots+a_{2 k} x_{k}=b_{2} \\
a_{31} x_{1}+\ldots+a_{3 k} x_{k}=b_{3} \\
\vdots \\
a_{m 1} x_{1}+\ldots+a_{m k} x_{k}=b_{m}
\end{array}\right.
\end{gathered}
$$


onde, para $k=m+n$, temos

$$
A=\left[\begin{array}{cccc}
a_{11} & a_{12} & \cdots & a_{1 k} \\
a_{21} & a_{22} & \cdots & a_{2 k} \\
\vdots & \vdots & \ddots & \vdots \\
a_{m 1} & a_{m 2} & \cdots & a_{m k}
\end{array}\right]
$$

como matriz dos coeficientes do sistema linear $A \cdot x=b, b=\left[b_{1}, b_{2}, \cdots, b_{m}\right]$ o vetor dos termos independentes, $c^{T}=\left[c_{1}, c_{2}, \cdots, c_{n}\right]$ o vetor dos coeficientes da função objetivo e $x=\left[x_{1}, x_{2}, \cdots, x_{n}, \cdots, x_{n+m}\right]$ o vetor formado pelas variáveis de decisão e de sobra.

Com intuito de simplificar a notação, dividiremos a matriz $A$ e os vetores $c$ e $x$ em dois grupos cada: o primeiro referente a elementos que formam a base, $\left(A_{B}, c_{B}, x_{B}\right)$, e o segundo referente a variáveis que não estão na base, $\left(A_{N}, c_{N}, x_{N}\right)$. Sem prejuízo para a generalidade, consideraremos que as colunas de $A$ e os elementos de $c^{T}$ e $x^{T}$ estejam ordenados e que as variáveis da base estejam à esquerda das demais, ou seja, $A=\left(A_{B}, A_{N}\right), c^{T}=\left(c_{B}^{T}, c_{N}^{T}\right)$ e $x=\left(x_{B}, x_{N}\right)$ e geram as matrizes

$$
A_{B}=\left[\begin{array}{cccc}
a_{11} & a_{12} & \cdots & a_{1 n} \\
a_{21} & a_{22} & \cdots & a_{2 n} \\
\vdots & \vdots & \ddots & \vdots \\
a_{m 1} & a_{m 2} & \cdots & a_{m n}
\end{array}\right] \text { e } A_{N}=\left[\begin{array}{cccc}
a_{1 n+1} & a_{1 n+2} & \cdots & a_{1 k} \\
a_{2 n+1} & a_{2 n+2} & \cdots & a_{2 k} \\
\vdots & \vdots & \ddots & \vdots \\
a_{m n+1} & a_{m n+2} & \cdots & a_{m k}
\end{array}\right]
$$

e os vetores $c_{B}^{T}=\left[c_{1}, c_{2}, \cdots, c_{n}\right], c_{N}^{T}=\left[c_{n+1}, \cdots, c_{k}\right], x_{B}=\left[x_{1}, x_{2}, \cdots, x_{n}\right]$ e $x_{N}=$ $\left[x_{n+1}, \cdots, x_{k}\right]$.

\subsubsection{Coeficiente de custo}

O coeficiente reduzido de custo é definido como a derivada parcial da função objetivo na direção de cada variável não básica, com o intuito de determinar aquela(s) que otimizarão a função se a incluirmos na base. Considerando apenas variáveis básicas, determinamos o valor da função objetivo $f_{0}(x)=c_{B}^{T} x_{B}$.

Do sistema $A x=b$, infere-se que $A_{B} x_{B}+A_{N} x_{N}=b$, e que, tomando $A_{B}=I$ (Identidade), obtemos

$$
\begin{aligned}
x_{B} & =b-A_{N} x_{N} \\
c_{B}^{T} x_{B} & =c_{B}^{T} b-c_{B}^{T} A_{N} x_{N}
\end{aligned}
$$


Sendo $f(x)=c_{B}^{T} A_{N}$, observamos que $c_{B}^{T} x_{B}=f_{0}(x)-f(x) x_{N}$ pois $f(x) x_{N}=0$. Assim,

$$
\sum_{j \leq m} c_{i} x_{i}=f_{0}(x)-\sum_{j>m} f_{i}(x) x_{i}
$$

cujo lado esquerdo é formado somente por variáveis básicas. Somando-se as não-básicas, encontramos $c^{T} x$ :

$$
c^{T} x=f_{0}(x)+\sum_{i>m} c_{i} x_{i}-\sum_{i>m} f_{i}(x) x_{i}=f_{0}(x)+\sum_{i>m}\left(c_{i}-f_{i}(x)\right) x_{i}
$$

Esse resultado mostra o quanto o valor da função objetivo aumenta à medida que aumentamos o valor das variáveis não-básicas e será útil para determinar que variáveis devem ter seu valor aumentado pelo Simplex. Derivando-a, termo a termo, em relação a $x_{i}$, temos que

$$
\frac{\partial c^{T} x}{\partial x_{i}}=c_{i}-f_{i}(x)
$$

ou seja, os valores de $c_{i}-f_{i}(x)$ indicam as direções para as quais a função objetivo é otimizada e são chamados de coeficientes reduzidos (ou relativos) de custo.

\subsubsection{O tableau}

O tableau é uma das formas de implementação do Simplex e consiste em representar todas as informações, devidamente organizadas, em uma tabela com objetivo de melhor compreender as etapas do processo. Sua construção é iniciada pela inclusão da função obtivo ao sistema $A x=b$ considerando o problema de programação linear na forma padrão.

$$
\left\{\begin{array}{ccccccccc}
a_{11} x_{1} & + & a_{12} x_{2} & + & \cdots & + & a_{1 k} x_{k} & = & b_{1} \\
a_{21} x_{1} & + & a_{22} x_{2} & + & \cdots & + & a_{2 k} x_{k} & = & b_{2} \\
& \vdots & & & & & & \vdots & \\
a_{m 1} x_{1} & + & a_{m 2} x_{2} & + & \cdots & + & a_{m k} x_{k} & = & b_{m} \\
c_{1} x_{1} & + & c_{2} x_{2} & + & \cdots & + & c_{k} x_{k} & = & -f_{0}(x)
\end{array}\right.
$$


Esquematicamente, o tableau pode ser visualizado como

$$
\left(\begin{array}{ccc}
A_{B} & A_{N} & b \\
c_{B}^{T} & c_{N}^{T} & -f_{0}(x)
\end{array}\right)
$$

onde $A_{B}, A_{N}, c_{B}^{T}, c_{N}^{T}$ e $b$ foram definidos na seção 7.4.

Os coeficientes reduzidos de custo indicam quanto cada unidade de cada variável não-básica $x_{j}$ contribui para a otimização da função objetivo. Assim, para compor a nova base, basta escolher aquela variável não básica que apresentou o melhor $r_{j}=$ $c_{j}-f_{j}(x)$, segundo o critério de otimização adotado. Existem diferentes critérios de escolha como o de maior coeficiente reduzido de custo, aresta mais íngreme, regra de Bland ou escolha aleatória, onde algumas levam à convergência mais lenta do que outras, sem que se obtenha resultados divergentes. Determinada a variável que entrará na base pelo teste da derivada parcial, passaremos à definição da variável que sairá da base em teste que se resume a determinar o índice que minimiza $x_{i} / a_{i q}$ :

$$
p=\min _{i \leq m}\left\{\frac{x_{i}}{a_{i q}}: a_{i q}>0\right\}
$$

O comportamento adotado pelo Simplex consiste em percorrer diferentes bases do problema de programação linear na busca de otimizar a função objetivo. As colunas da base serão mantidas de forma a compor uma (sub)matriz identidade de ordem $m$.

Para incluir a variável $x_{q}$ na base, no lugar de $x_{p}$, escreveremos a primeira em função das variáveis não básicas. Para tal, utilizamos operações elementares sobre as linhas do tableau, de forma que a coluna $a_{q}$ fique igual a $a_{p}$. Assim, para cada elemento $a_{i j}$, faremos:

$$
\begin{aligned}
a_{p j}^{*} & =\frac{a_{p j}}{a_{p q}} \\
a_{i j}^{*} & =a_{i j}-\frac{a_{p j} a_{i q}}{a_{p q}}
\end{aligned}
$$

Resumidamente, todas os estágios indicados sobre a execução do Simplex foi consolidado na figura 66 e utilizam, como parâmetros de entrada, respectivamente, a matriz de coeficientes, o vetor de termos independentes e o vetor de coeficientes da função objetivo. 


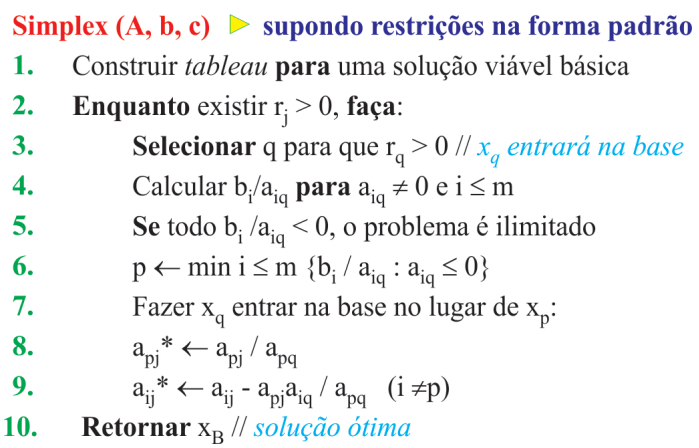

Figura 66: Algoritmo simplex

Exemplo 24. Maximizar a função $f(x, y)=5 x+2 y$ sujeito a $x \leq 3, y \leq 4, x+2 y \leq 9$, $x \geq 0$ e $y \geq 0$, problema cujas restrições são expressas na figura $6 \%$.

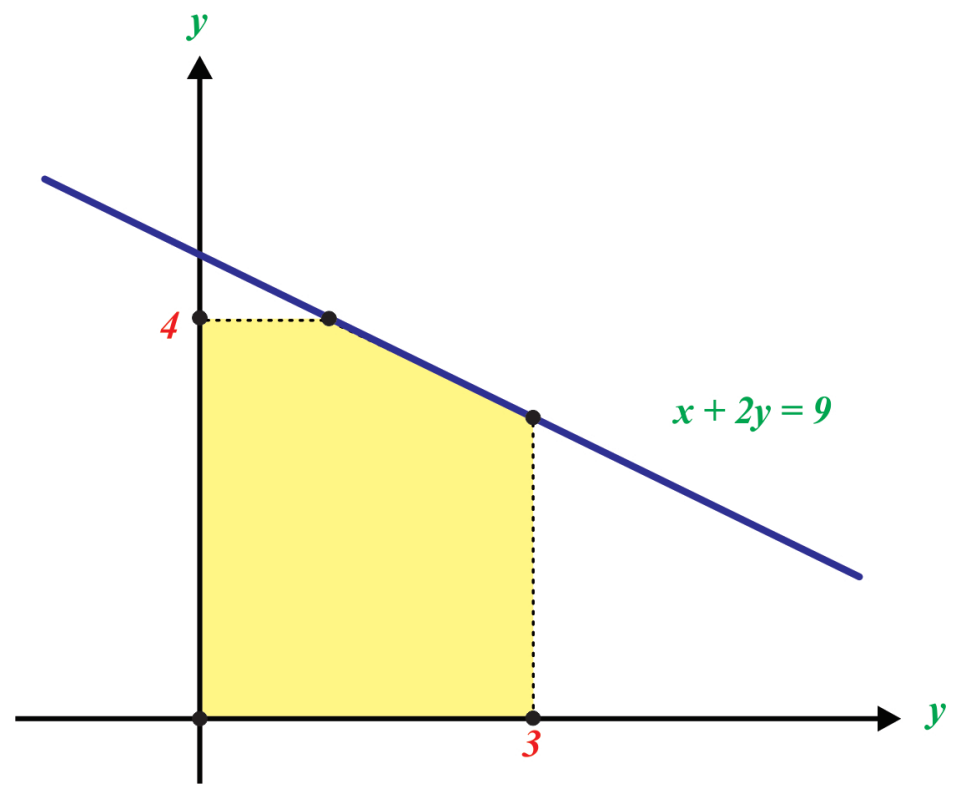

Figura 67: Restrições

\section{Solução}

Os estágios da resolução do problema de programação linear segundo método algébrico são:

1. Reversão do modelo para a forma padrão mediante transformação das desigualdades em igualdades a partir do acréscimo das variáveis de sobra : 


$$
\begin{array}{cl}
\text { Maximizar } & f(x, y)=5 x+2 y+0 s_{1}+0 s_{2}+0 s_{3} \\
\text { Sujeito a } & \left\{\begin{array}{l}
1 x+0 y+1 s_{1}+0 s_{2}+0 s_{3}=3 \\
0 x+1 y+0 s_{1}+1 s_{2}+0 s_{3}=4 \\
1 x+2 y+0 s_{1}+0 s_{2}+1 s_{3}=9
\end{array}\right.
\end{array}
$$

2. Construção do Tableau inicial, no qual as variáveis de folga determinam uma base canônica e a última linha da tabela contém os coeficientes da função objetivo.

Tabela 6: Tableau inicial do exemplo 67

\begin{tabular}{|c|c|c|c|c|c|c|c|}
\hline Base & $\boldsymbol{x}$ & $\boldsymbol{y}$ & $\boldsymbol{s}_{1}$ & $\boldsymbol{s}_{\mathbf{2}}$ & $\boldsymbol{s}_{3}$ & $\boldsymbol{b}$ & Linha \\
\hline $\boldsymbol{s}_{\boldsymbol{1}}$ & 1 & 0 & 1 & 0 & 0 & 3 & $\boldsymbol{e}_{1}$ \\
\hline $\boldsymbol{s}_{2}$ & 0 & 1 & 0 & 1 & 0 & 4 & $e_{2}$ \\
\hline $\boldsymbol{s}_{3}$ & 1 & 2 & 0 & 0 & 1 & 9 & $e_{3}$ \\
\hline $\boldsymbol{f}(\boldsymbol{x}, \boldsymbol{y})$ & 5 & 2 & 0 & 0 & 0 & 0 & $e_{4}$ \\
\hline
\end{tabular}

3. Por gerar maior colaboração para o crescimento de $f$, a variável a ser escolhida para entrar na base é $x$. Para sair da base, deve ser escolhida a variável $s_{1}$ pois terá menor razão $\frac{b}{x}$. Em seguida, usa-se o Método da Eliminação de Gauss para cancelar coeficientes de $x$ para as linhas $e_{3}$ e $e_{4}$ :

Tabela 7: Tableau após $1^{a}$ iteração

\begin{tabular}{|c|c|c|c|c|c|c|c|}
\hline Base & $\boldsymbol{x}$ & $\boldsymbol{y}$ & $\boldsymbol{s}_{\mathbf{1}}$ & $\boldsymbol{s}_{\mathbf{2}}$ & $\boldsymbol{s}_{\mathbf{3}}$ & $\boldsymbol{b}$ & Linha \\
\hline $\boldsymbol{x}$ & 1 & 0 & 1 & 0 & 0 & 3 & $e_{5}$ \\
\hline $\boldsymbol{s}_{\mathbf{2}}$ & 0 & 1 & 0 & 1 & 0 & 4 & $e_{6}$ \\
\hline $\boldsymbol{s}_{3}$ & 0 & 2 & -1 & 0 & 1 & 6 & $e_{7}$ \\
\hline $\boldsymbol{f}(\boldsymbol{x}, \boldsymbol{y})$ & 0 & 2 & -5 & 0 & 0 & -15 & $e_{8}$ \\
\hline
\end{tabular}

4. O único coeficiente positivo da função objetivo e, portanto, colabora para seu crescimento está na coluna dos $y^{\prime} s$ e entrará na base no lugar de $s_{3}$, em função da menor razão $\frac{b}{s_{3}}$. Tomando o elemento da coluna $y$ e linha $s_{3}$ como pivô para eliminar os demais coeficientes de $y$, é obtida a 
Tabela 8: Tableau após $2^{a}$ iteração

\begin{tabular}{|c|c|c|c|c|c|c|c|}
\hline Base & $\boldsymbol{x}$ & $\boldsymbol{y}$ & $\boldsymbol{s}_{\mathbf{1}}$ & $\boldsymbol{s}_{\mathbf{2}}$ & $\boldsymbol{s}_{\mathbf{3}}$ & $\boldsymbol{b}$ & Linha \\
\hline $\boldsymbol{x}$ & 1 & 0 & 1 & 0 & 0 & 3 & $\boldsymbol{e}_{9}$ \\
\hline $\boldsymbol{s}_{2}$ & 0 & 0 & -1 & -2 & 1 & -2 & $e_{10}$ \\
\hline $\boldsymbol{y}$ & 0 & 2 & -1 & 0 & 1 & 6 & $e_{11}$ \\
\hline $\boldsymbol{f}(\boldsymbol{x}, \boldsymbol{y})$ & 0 & 0 & -4 & 0 & -1 & -21 & $e_{12}$ \\
\hline
\end{tabular}

A linha $e_{12}$ está associada à equação $f(x, y)=-4 s_{1}-s_{3}=-21$ na qual aumento no valor das variáveis $s_{1}$ e $s_{3}$ ocasionariam redução no valor de $f$ e, portanto, indicam condição para finalização do algoritmo. Nesse instante, as variáveis não-básicas são $s_{1}$ e $s_{3}$ e apresentam valores iguais a zero. A linha $e_{9}$, traduzida em $1 x+1 s_{1}=3$ permite que se conclua que $x=3$ enquanto a linha $e_{11}$ gera a equação $2 y-s_{1}+s_{3}=6$ permite que se obtenha $y=3$. Da linha $e_{10}$, vem que $-1 s_{1}-2 s_{2}+s_{3}=-2$, ou seja $s_{2}=1$. O valor máximo para $f$, dadas as condições apresentadas, é portanto, $f(3,3)=5 \cdot 3+2 \cdot 3=21$.

A partir da forma padrão para do problema de programação linear,

$$
\begin{cases}x+s_{1}=3 & : e_{1} \\ y+s_{2}=4 & : e_{2} \\ x+2 y+s_{3}=9 & : e_{3}\end{cases}
$$

outra possível implementação do Simplex está em, resolver o sistema linear gerado pelas restrições segundo valores dos coeficientes de custo da função objetivo. Em $f(x)=5 x+2 y$, como $5=\frac{\partial f}{\partial x}<\frac{\partial f}{\partial y}=2$, por apresentar maior colaboração para o crescimento de $f$, infere-se que a $x$ deve ser substituída utilizando equação $e_{1}$ por apresentar maior capacidade restritiva quanto ao valor de $x$.

Explicitando $x$ em $e_{1}$ e substituindo-o nas demais equações do sistema, obtém-se:

$$
\begin{cases}x=3-s_{1} & : e_{1} \\ y+s_{2}=4 & : e_{2} \\ x+2 y+s_{3}=9 \Rightarrow 2 y-s_{1}+s_{3}=6 & : e_{4}\end{cases}
$$

A função objetivo passará a ser $f\left(s_{1}, y\right)=5\left(3-s_{1}\right)+2 y \Rightarrow f\left(s_{1}, y\right)=15+2 y-5 s_{1}$, 
onde o único coeficiente que colabora para o crescimento de $f$ é determinado por $\frac{\partial f}{\partial y}=2>0$ apontando $y$ como variável a ser substituída utilizando $e_{4}$. Explicitando $y$ em $e_{4}$ e substituindo-o em $e_{2}$, o sistema passará a ser:

$$
\begin{cases}x=3-s_{1} & : e_{1} \\ \frac{6+s_{1}-s_{3}}{2}+s_{2}=4 \Rightarrow s_{1}+2 s_{2}-s_{3}=2 & : e_{5} \\ y=\frac{6+s_{1}-s_{3}}{2} & : e_{4}\end{cases}
$$

Escreve-se, em termos e $s_{1}$ e $s_{3}$, a função objetivo como

$$
f\left(s_{1}, s_{3}\right)=15+2 \frac{6+s_{1}-s_{3}}{2}-5 s_{1} \Rightarrow f\left(s_{1}, s_{3}\right)=21-4 s_{1}-s_{3}
$$

Na forma obtida para $f$, não existe variável que colabora para seu crescimento, fato esse que confirma o final da execução do Simplex e o máximo para $f$ ocorre ao fazer $s_{1}=s_{3}=0$. Para esses valores, o máximo para $f$ é 21 e as demais variáveis, determinadas a partir das retro-substituições, são $f(x, y)=21, x=3, y=3$ e $s_{2}=1$.

\subsection{Método gráfico}

O método gráfico pode ser utilizado na resolução de problemas de programação linear definidos no $\mathbb{R}^{2}$ em função de caracteríticas geométricas apresentadas pelas restrições (conjunto compacto) e pela função objetivo (conjunto de curvas de nível). Para ilustrálo, utilizaremos o Geogebra na resolução do seguinte problema:

Exemplo 25. Max $f(x, y)=6 x+7 y$ sujeito a $\left\{\begin{array}{r}x+y \leq 10 \\ 3 x+7 y \leq 42 \\ x, y \geq 0\end{array}\right.$

\section{Solução}

A seguir, estão listadas todas as etapas a serem desenvolvidas:

1. Exibir malha;

2. Escrever, em Entrada, $p: x+y<=10$ e pressionar Enter; 
3. Escrever, em Entrada, $q: 3 x+7 y<=42$ e pressionar Enter;

As instruções executadas nas etapas 2 e 3 possibilitam a construção dos semiplanos $p$ e $q$ definidos, respectivamente, por $x+y \leq 10$ e $3 x+7 y \leq 42$. Para não sobrecarregar a Janela de Visualização, as restrições de não negatividade são observadas ao considerar somente a região determinada pelas inequações presentes no primeiro quadrante do plano cartesiano.

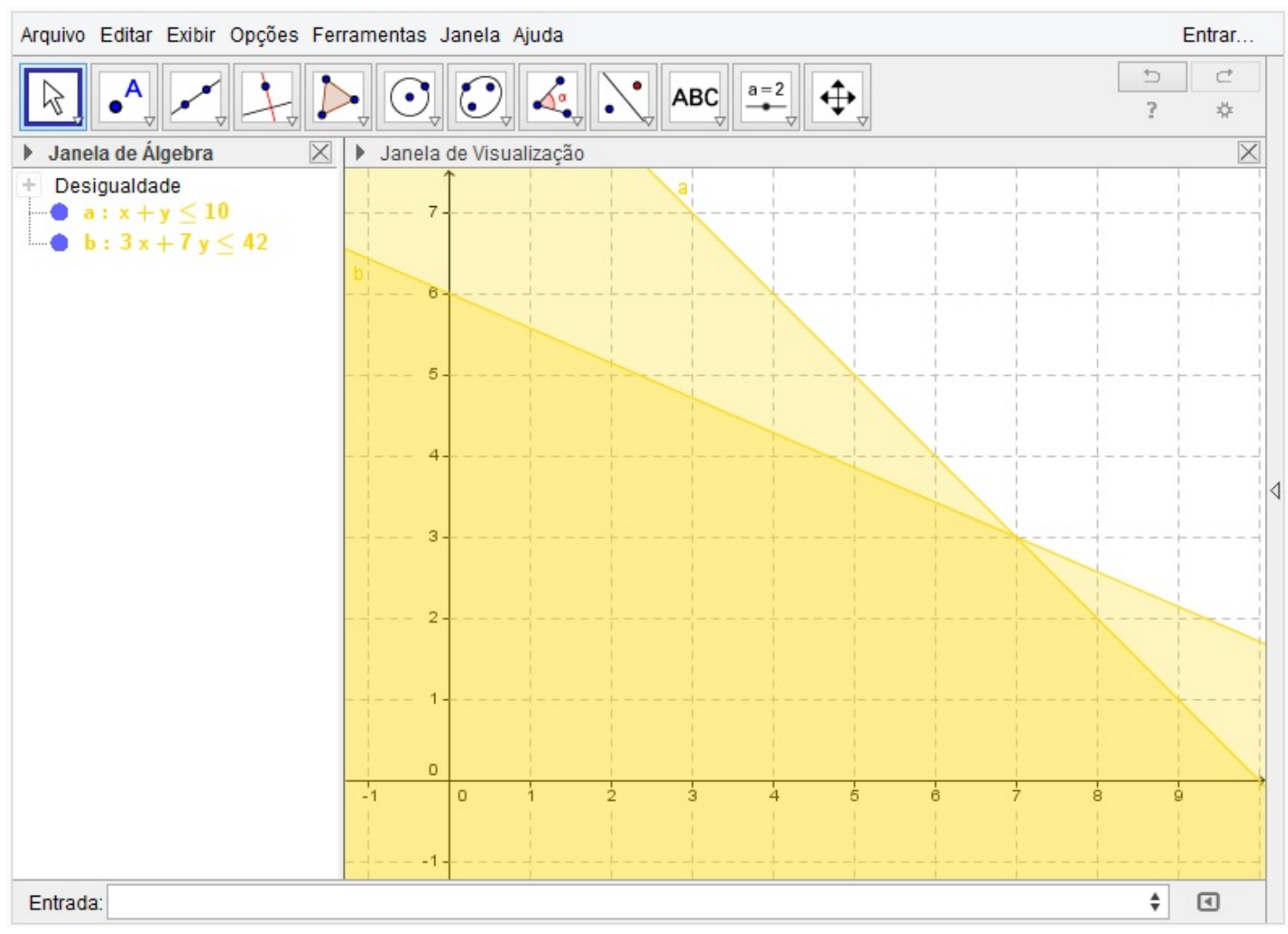

Figura 68: Interseção dos semiplanos

4. Determinar todos os pontos extremos do conjunto viável a partir do comando Geogebra Interseção, cuja sintaxe é Interseção[ $<$ Objeto $>$, $<$ Objeto $>$ ], onde $<$ Objeto $>$ é a equação da reta origem do semiplano. Esses pontos serão denominados $A, B, C$ e $D$ e determinados segundo os seguintes comandos, digitados em Entrada:

- $\mathrm{A}=$ Interseção $[\mathrm{x}+\mathrm{y}=10,3 \mathrm{x}+7 \mathrm{y}=42]$;

- $\mathrm{B}=$ Interseção $[3 \mathrm{x}+7 \mathrm{y}=42, \mathrm{x}=0]$; 
- $\mathrm{C}=$ Interseção $[\mathrm{x}+\mathrm{y}=10, \mathrm{y}=0]$; e

- $\mathrm{D}=$ Interseção $[\mathrm{x}=0, \mathrm{y}=0]$;

Para destacar o conjunto viável, duas instruções serão realizads:

5. Na Janela de Álgebra, clicar sobre cada inequação com o botão direito do mouse e desmarcar a opção Exibir Objeto;

6. Escolher a ferramenta Polígono presente na barra de ferramentas e marcar os vértices da região no sentido horário;

Após esses passos, a Janela de Visualização do Geogebra apresenta aspecto similar ao da figura 69.

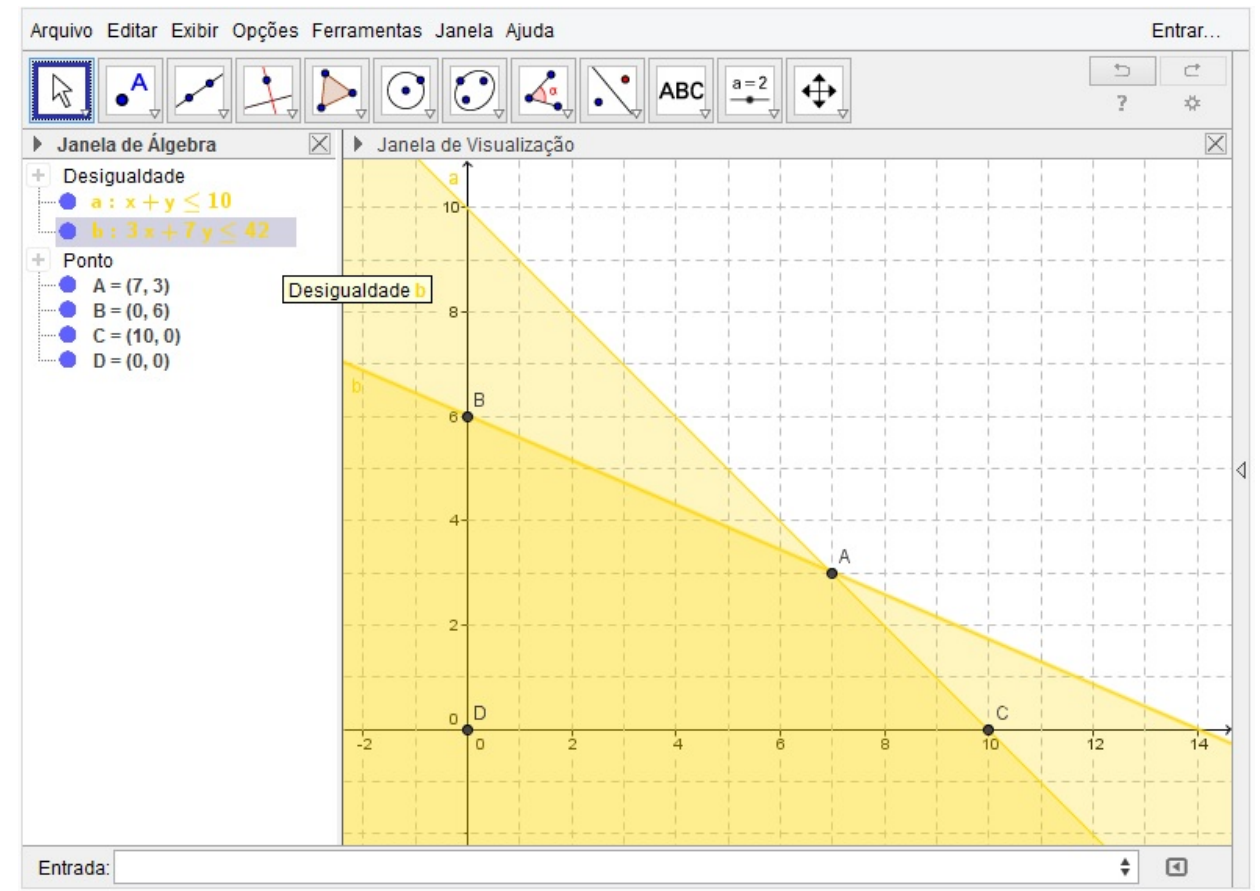

Figura 69: Solução do sistema de inequações determinadas pelas restrições do PPL

O polígono $D B A C$, mostrado na figura 70, é a região viável do PPL proposto e, na Janela de Álgebra estão seu perímetro (pol1) e as medidas de seus lados $\left(a_{1}, a_{2}, c\right.$ e $\left.d\right)$;

7. Em Entrada, digitar a equação da curva de nível no ponto $(0,0)$, ou seja, $e$ : $6 x+7 y=0 ;$ 


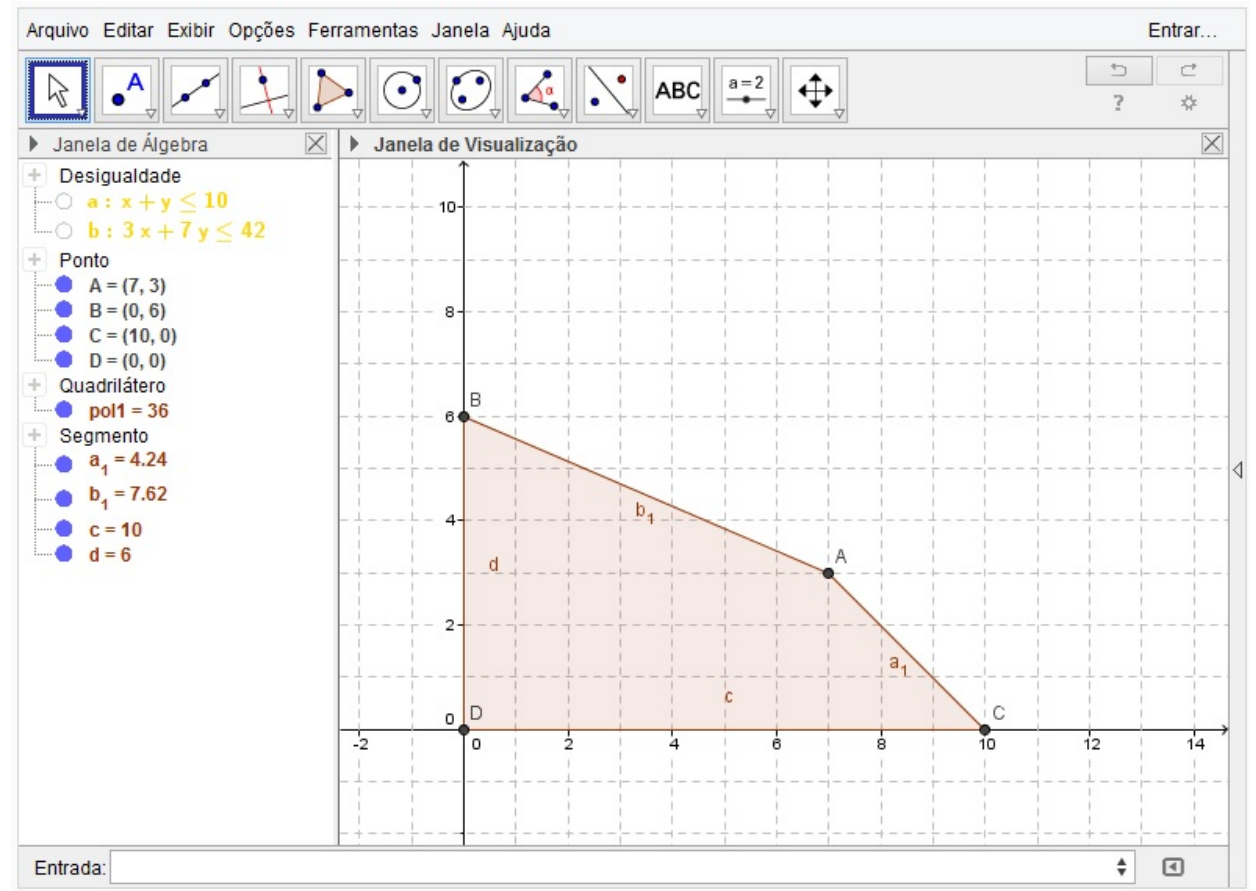

Figura 70: Polígono $D A B C$

8. Construir as curvas de nível de $f(x, y)=6 x+7 y$ nos demais vértices (pontos extremos) do polígono DBAC (região viável). Para tal, usa-se o comando Reta[ $<$ Ponto $>$, $<$ Reta Paralela $>$ ], onde $<$ Ponto $>$ e $<$ Reta Paralela $>$ são, respectivamente, um ponto e uma reta paralela à reta que se deseja construir. As retas $e, f, g$ e $h$ foram determinadas com os seguintes comandos:

- f: Reta[B, e];

- g: Reta[A, e];

- h: Reta[C, e];

9. O ponto máximo para $f(x, y)=6 x+7 y$ é determinado pelo maior valor de $6 x+7 y$ pertencente à Janela de Álgebra, no campo Reta. Portanto, o máximo de $f$ é 63 e ocorre em $A$, quando as variáveis de decisão $x$ e $y$ valem, respectivamente, 7 e 3. Tais conclusões podem ser confirmadas na figura 71 . 


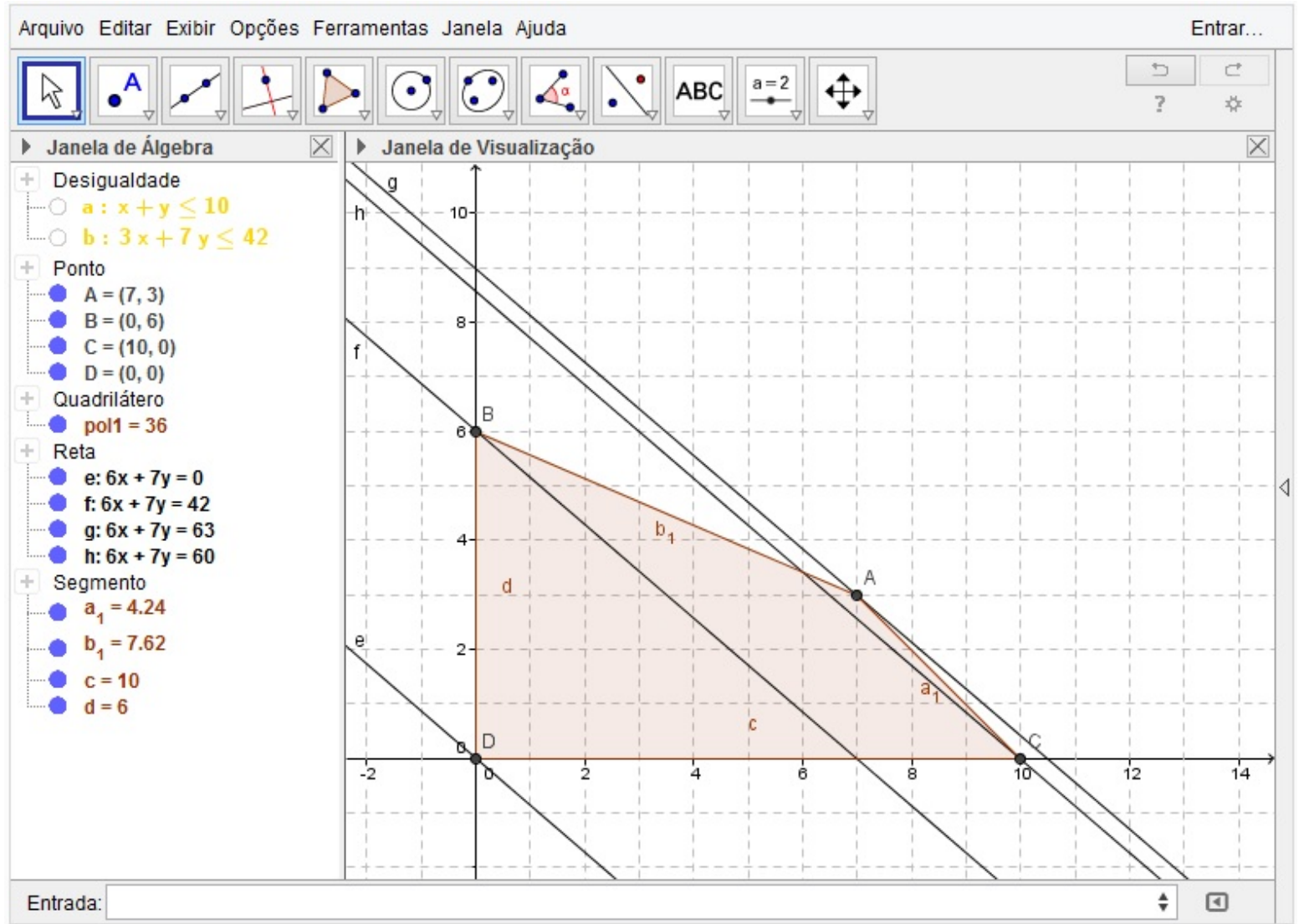

Figura 71: $A$ gera o valor máximo de $f(x, y)=6 x+7 y$

\subsection{Casos excepcionais}

Embora apresente convergência em função do procedimento de troca de variáveis em cada iteração do algoritmo, existem algumas situações particulares em relação às decisões a serem tomadas em seu processo de execução. Tais situações refletem ão denominadas "Empate na entrada", "Degeneração"e "Múltiplas soluções".

\subsubsection{Empate na entrada}

Ocorre empate na escolha da variável que entra na base quando as variáveis que compõem a função objetivo contribuem quantitativamente de forma equivalente para o crescimento da função objetivo. A escolha a ser adotada é arbitrária e não gera solução errada: a única implicação envolvida está em escolher um caminho mais longo (ou mais curto) para se chegar à solução ótima. 
Exemplo 26. No $\mathbb{R}^{2}$, ocorrerá empate na entrada quando os coeficientes de $x$ e y de $f$ forem iguais, como pode ser observado no problema

$$
\begin{array}{cl}
\text { Maximizar } & f(x, y)=2 x+2 y \\
\text { Sujeito a } & \left\{\begin{array}{l}
x+2 y \leq 12 \\
2 x+y \leq 12 \\
x, y \geq 0
\end{array}\right.
\end{array}
$$

A escolha da variável para entrar na base deve ser arbitrária e a única consequência desse fato está em adotar caminho mais longo para se obter a solução ótima. O ponto ótimo para o problema proposto, $Q=(4,4)$, pode ser obtido partindo da origem $O=(0,0)$ e seguindo em direção a $P=(0,6)$ ou $Q=(6,0)$, como se vê na figura 72.

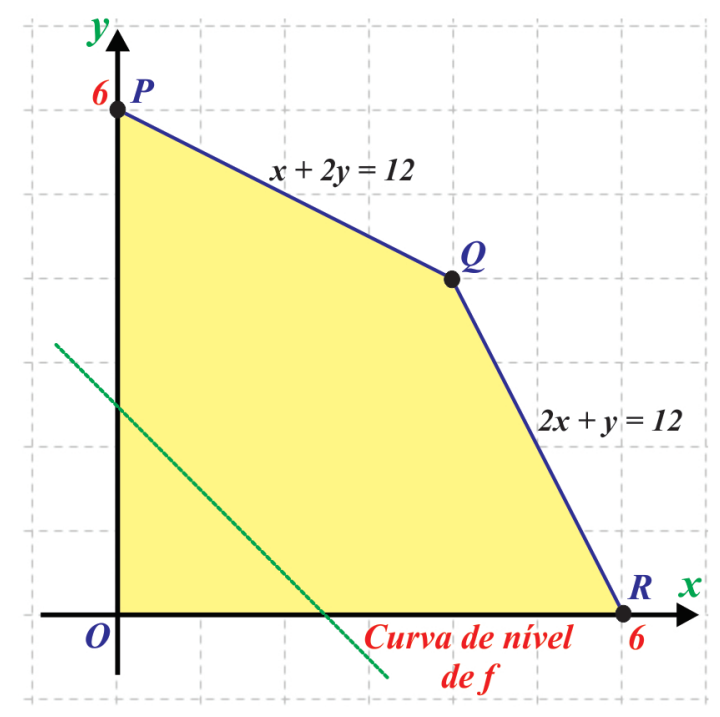

Figura 72: Empate na entrada de variáveis na base

\subsubsection{Degeneração}

A degeneração ou ciclagem ocorrerá quando, após mudanças da base, o algoritmo retorna ao mesmo ponto do espaço viável, representado por vetores lineamente dependentes. Tal fato decorre de empates na saída da base, normalmente em função de alguma variável básica apresentar valor nulo. 


$$
\begin{array}{cl}
\text { Maximizar } & f(x, y)=5 x+2 y \\
\text { Sujeito a } & \left\{\begin{array}{l}
x \leq 3 \\
y \leq 4 \\
4 x+3 y \leq 12 \\
x, y \geq 0
\end{array}\right.
\end{array}
$$

Exemplo 27. Ocorrerá degeneração no problema de programação linear Geometricamente, a região plana representada pela restrição $\left\{(x, y) \in \mathbb{R}^{2}: 4 x+3 y \leq 12\right\}$ está contida na região determinada por $\left\{(x, y) \in \mathbb{R}^{2}: x \leq 3\right.$ e $\left.y \leq 4\right\}$. A figura 73 mostra essa situação.

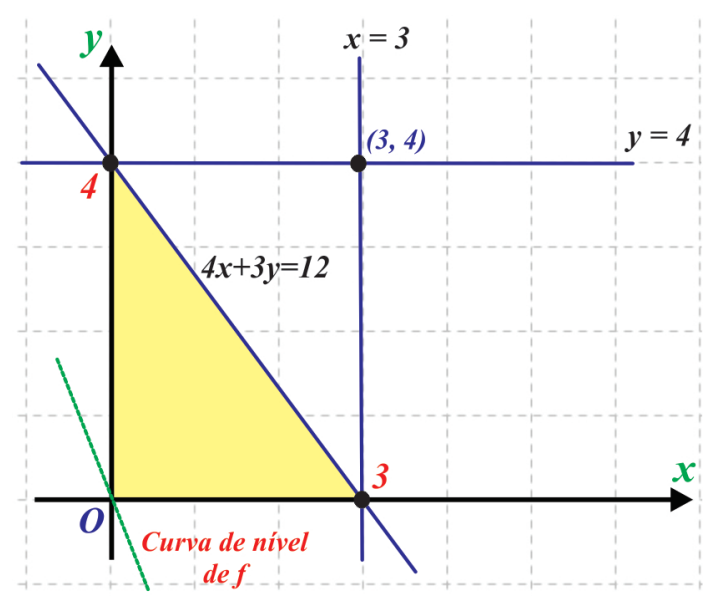

Figura 73: Degeneração

No tableau, ocorre degeneração quando é observado o empate no valor de $\frac{x_{i}}{a_{i q}}$ de duas ou mais linhas da tabela onde q indica a coluna da variável que entrará na base. $N a$ tabela 9, o empate na saída ocorre entre $s_{1}$ e $s_{3}$ nas linhas $e_{1}$ e $e_{3}$, respectivamente e a escolha da variável que, defato, entrará na base, se dá de forma aleatória.

\subsubsection{Múltiplas soluções}

Se, na solução ótima o coeficiente de um variável não é básica, esta variável poderá ser escolhida para entrar na base sem que se modifique o valor da função objetivo, gerando outra solução ótima, distinta da primeira. Por ser o espaço viável convexo, qualquer combinação linear dessas 2 soluções também será ótima. 
Tabela 9: Tableau do problema 27

\begin{tabular}{|c|c|c|c|c|c|c|c|c|}
\multicolumn{1}{l}{$\downarrow$} \\
\hline Base & $\mathbf{x}$ & $\mathbf{y}$ & s1 & s2 & s3 & b & Linha & Razão \\
\hline s1 & 1 & 0 & 1 & 0 & 0 & 3 & e1 & $3 / 1=3$ \\
\hline s2 & 0 & 1 & 0 & 1 & 0 & 4 & e. & \\
\hline s3 & 4 & 3 & 0 & 0 & 1 & 12 & es & $12 / 4=3$ \\
\hline f & 5 & 2 & 0 & 0 & 0 & 0 & e4 & \\
\hline
\end{tabular}

Exemplo 28. Ocorrerão múltiplas soluções em

$$
\begin{array}{cl}
\text { Maximizar } & f(x, y)=4 x+10 y \\
\text { Sujeito a } & \left\{\begin{array}{l}
4 x+3 y \leq 12 \\
2 x+5 y \leq 10 \\
x, y \geq 0
\end{array}\right.
\end{array}
$$

No tableau, tal fato é observado quando, após mudança da base, o valor verificado para a função objetivo não se altera. Geometricamente, no $\mathbb{R}^{2}$, tal fato pode ser verificado na figura 74, que mostra curva de nivel de $f$ paralela à reta $2 x+5 y=10$.

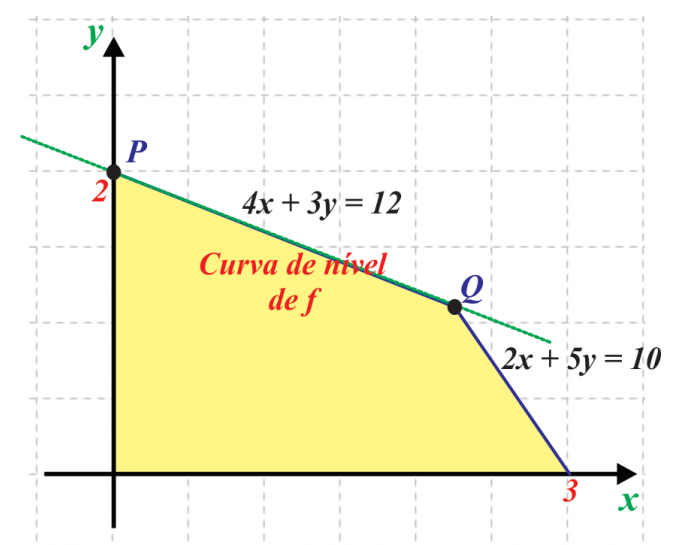

Figura 74: Múltiplas soluções

Portanto, sendo $P$ e $Q$ pontos ótimos de $f$, qualquer ponto interno ao segmento $\overline{P Q}$ também geram o mesmo valor ótimo para a função objetivo, será solução para o problema proposto e causarão o encerramento da execução do algoritmmo. 


\subsection{Complexidade computacional}

A análise de algoritmos é a área da Ciência da Computação que busca determinar a complexidade ou o custo de execução de um algoritmo, o que torna possível comparar diferentes algoritmos que realizam as mesmas tarefas e, por consequência, determinar se existe um algoritmo ótimo para uma dada situação.

Nos sistemas computacionais modernos, as principais métricas usadas no estudo da complexidade de algoritmos são o tempo de execução e a quantidade de memória necessários, e podem ser revertidos em elementos como esforço para sua execução. Mesmo com os avanços tecnológicos das últimas décadas, escolhas erradas de algoritmos para situações específicas, podem causar gasto de tempo demasiadamente grande.

\subsubsection{Custo de execução do simplex}

No $\mathbb{R}^{2}$, cada desigualdade determina um semiplano e a interseção de todas as restrições de um problema de programação linear gera uma região poligonal convexa. Nesse contexto, uma estratégia para se determinar a ordem de complexidade do simplex consiste em determinar o número de vértices que esse polígono possui. Geometricamente, cada vértice é determinado pela interseção de pelo menos duas retas. Portanto, em um problema de programação linear formado por $m$ restrições lineares acrescido dos dois eixos coordenados, o número de vértices, no $\mathbb{R}^{2}$, será

$$
p(m)=C_{m+2,2}=\frac{(m+2) !}{2 ! \cdot m !}=\frac{(m+2) \cdot(m+1)}{2}=\frac{m^{2}+3 m+2}{2}
$$

Dizemos que a ordem de complexidade do simplex no $\mathbb{R}^{2}$ é quadrática e usaremos a notação $O\left(m^{2}\right)$ uma vez que para $m$ suficientemente grande, existe uma constante positiva $k$ para a qual $k \cdot m^{2} \geq p(m)$, ou seja, existe $k \in \mathbb{R}$ para que se tenha

$$
k \cdot m^{2} \geq \frac{1}{2}\left(m^{2}+3 m+2\right)
$$

Analogamente, no espaço tridimensional $\mathbb{R}^{3}$, cada vértice é determinado pela interseção de pelo menos 3 semiplanos. O número máximo de vértices que $m$ restrições podem gerar é

$$
p(m)=C_{m+3,3}=\frac{(m+3) !}{3 ! \cdot m !}=\frac{m^{3}+6 m^{2}+3 m+2}{6}=O\left(m^{3}\right)
$$


Indutivamente, para o $\mathbb{R}^{n}$, a quantidade máxima de vétrices que o algoritmo deveria percorrer para determinar o valor ótimo da função objetivo é dado pela escolha de $n$ restrições de um conjunto de $m+n$ restrições:

$$
p(m)=C_{m+n, n}=\frac{(m+n) !}{n ! \cdot m !}=O\left(m^{n}\right)
$$

Enfim, afirmamos que a complexidade do simplex é exponencial e utilizamos a notação $O\left(m^{n}\right)$ onde $m$ é o número de restrições no espaço $n$-dimensional.

\subsection{Excel}

O Microsoft Excel é um software editor de planilhas eletrônicas pertencente ao pacote de softwares Microsoft Office e possui diferentes recursos que abrangem desde cálculos aritméticos simples a elaboradas ferramentas estatíticas e financeiras, além de elementos de banco de dados. Muitas organizações tem funcionamento graças ao auxílio de planílhas eletrônicas que possibilitam gerenciar, dentre outros elementos, folha de pagamentos, fluxo de caixa e controle de estoque.

O software apresenta recursos para construção de tabelas, gráficos, classificação e análise de dados, além de funções que permitem automatizar tarefas que muito podem contribuir para a formação acadêmica e profissional do aluno do ensino médio.

\subsubsection{Requisitos de hardware e software}

Para pleno funcionamento, o Microsoft Office e, por consequência o Microsoft Excel, devem ser instalados em computador com processador x86 ou x64 bits de 1 gigahertz $(\mathrm{GHz})$, memória RAM de pelo menos 1 gigabyte e disco rígido com no mínimo 3 gigabytes disponíveis. O requisito de software envolve sistema operacional da família Windows 7 ou posterior, em versões de 32 bits ou 64 bits [19].

\subsubsection{Solver}

O Solver é um suplemento do Microsoft Excel desenvolvido para testar hipóteses e determinar um valor ótimo (máximo ou mínimo) para uma função objetivo definida em uma célula, conforme restrições ou limites definidas sobre as variáveis presentes em outras células. O Solver trabalha com um grupo de células, denominadas variáveis de 
decisão, usadas no cálculo das fórmulas nas células de objetivo e de restrição. Para otimização, seu funcionamento consiste no ajuste de valores nas células variáveis de decisão para satisfazer aos limites sobre células de restrição e produzir o resultado desejado para a função objetiva.

\subsubsection{Instalação do Solver}

Se o comando Solver ou o grupo Análise não estiver disponível, será necessário ativá-lo conforme procedimento descrito a seguir:

1. Clicar na guia Arquivo, a seguir em Opções e selecionar Suplementos. A figura 75 mostra a janela Opções do Solver.

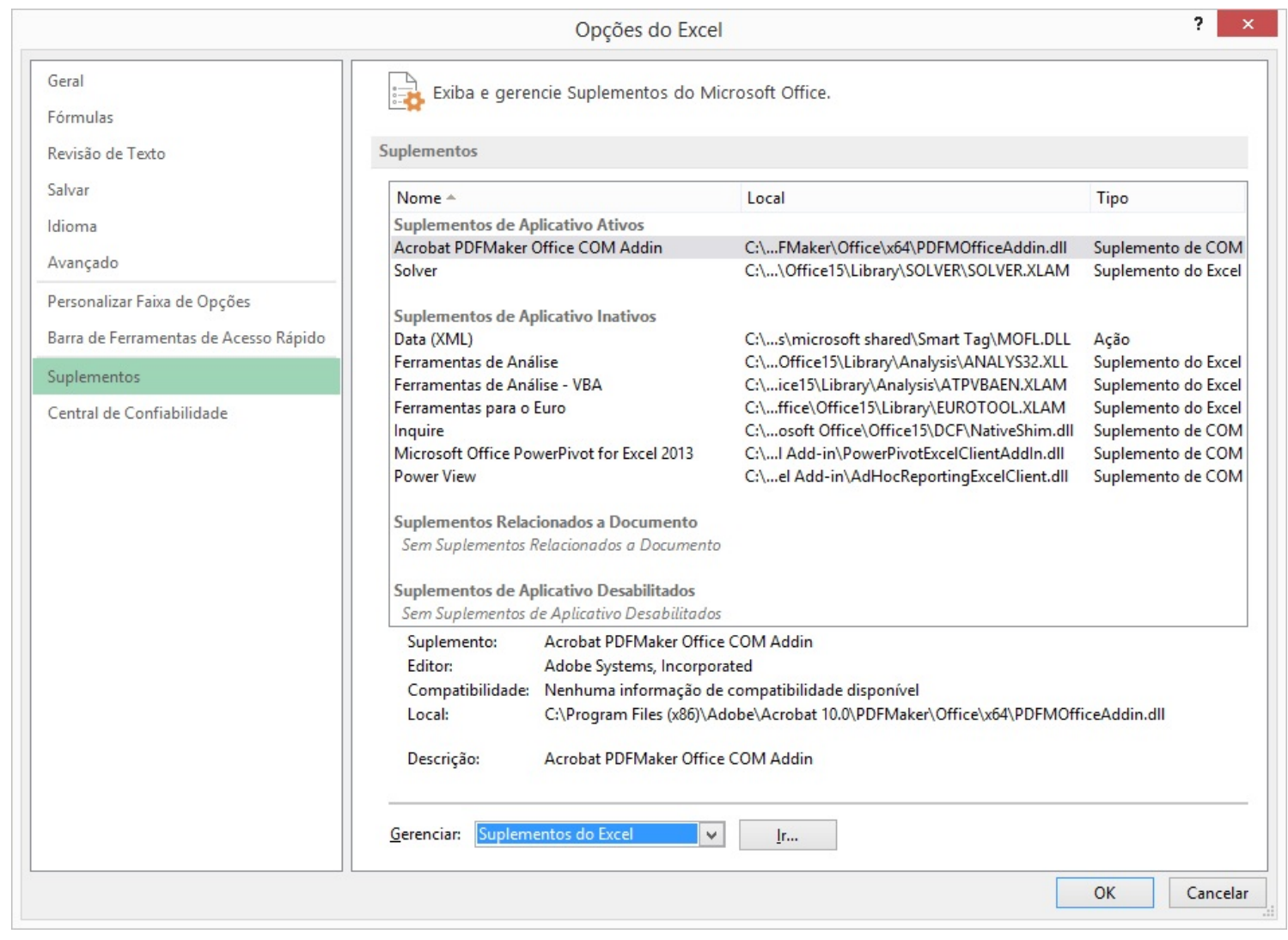

Figura 75: Opções do Solver

2. Na caixa Gerenciar, clicar em Suplementos do Excel e, em seguida, clicar em Ir. 
3. Na caixa Suplementos disponíveis, marcar a caixa de seleção Solver Add-in e clicar em $\mathbf{O K}$, como pode ser observado na figura 76 .

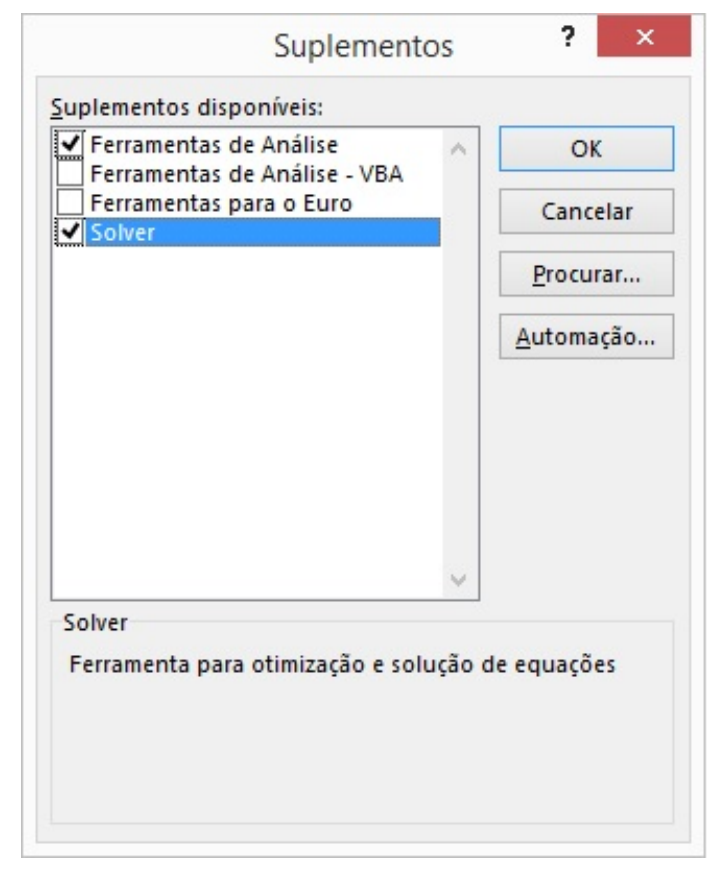

Figura 76: Suplementos

4. Após execução dos passos 1, 2 e 3, o comando Solver será acrescentado no grupo Análise da guia menu Dados da pasta de trabalho do Microsoft Excel.

\subsubsection{Definindo e resolvendo um problema}

1. Em Definir Objetivo, deve ser digitada a referência a uma célula ou um nome para a célula objetivo, a qual deve conter a fórmula que define a função objetivo do PPL.

2. Nas opções de Para, deve ser marcado o tipo de otimização a ser buscado: caso o problema seja de maximização marca-se Máx. e, caso seja de minimização, marca-se Mín.. A otimização pode ser definida para um valor específio da função objetivo quando for marcada a opção Valor de e digitado o valor indicado na caixa correspondente. 
3. Na caixa Alterando Células Variáveis deve ser inserida a referência para as células que contém as variáveis de decisão e que compõem a função objetivo e as restrições do PPL.

4. Em Sujeito às Restrições, cada restrição será acrescentada a partir do seguinte procedimento:

a) Na caixa de diálogo Parâmetros do Solver, clicar em Adicionar.

b) Na caixa Referência de Célula, clicar em Adicionar, insirir a referência a célula cujo valor deseja restringir.

c) Clicar na relação $(<=,=,>=$, int, bin ou dif) desejada entre a célula referenciada e a restrição escolhida.

d) Ao escolher $<=$, = ou $>=$ para a relação na caixa Restrição, deve ser digitado um número, uma referência ou um nome de célula ou uma fórmula.

e) A seguir, um dos procedimentos deve ser adotado:

- Para aceitar a restrição e adicionar uma outra, clicar em Adicionar.

- Para aceitar a restrição e retornar à caixa de diálogo Parâmetros do Solver, clicar em OK.

f) Na caixa de diálogo Parâmetros do Solver, clicar na restrição que deseja alterar ou excluir.

g) Clicar em Alterar e, em seguida, realizar as alterações ou clicar em Excluir.

5. Clicar em Solucionar e sequir um destes procedimentos:

- Para que os valores das soluções sejam mantidos na planilha, na caixa de diálogo Resultados do Solver, clicar em Manter Solução do Solver.

- Para restaurar os valores originais antes de ter clicado em Resolver, clicar em Restaurar Valores Originais.

6. O processo pode ser interrompido pressionando a tecla Esc. Nesse caso, o Excel recalculará a planilha com os últimos valores obtidos para as células das variáveis de decisão. 
Exemplo 29. Para ilustrar o uso da ferramenta Solver, será resolvido o problema de programação linear:

$$
\operatorname{Max} f(x, y)=6 x+7 y \quad \text { sujeito a }\left\{\begin{array}{r}
x+y \leq 10 \\
3 x+7 y \leq 42 \\
x, y \geq 0
\end{array}\right.
$$

\section{Solução}

O problema consiste em maximizar uma função real de duas variáveis reais e contínuas $x$ e $y$, definida em uma região do eixo xOy determinada pelas inequações $x+y \leq 10$ e $3 x+7 y \leq 42$. Assim, faz-se necessária a escolha de uma célula para o armazenamento de cada um desses elementos.

As variáveis $x$ e $y$ serão armazenadas, respectivamente, nas células $C 4$ e $C 5$. Assim, para se fazer referência ao valor da variavel $x$ utilizar-se-á C4 e, para $y$, utiliza-se $C 5$. A função objetivo, $f(x, y)=6 x+7 y$ será armazenada em $C 7$, observando referências adotadas para $x$ e $y$. Assim, em $C 7$, digita-se a fórmula $=6 * C 4+7 * C 5$.

A figura 77 apresenta a planilha após definição das células para as variáveis do problema proposto.

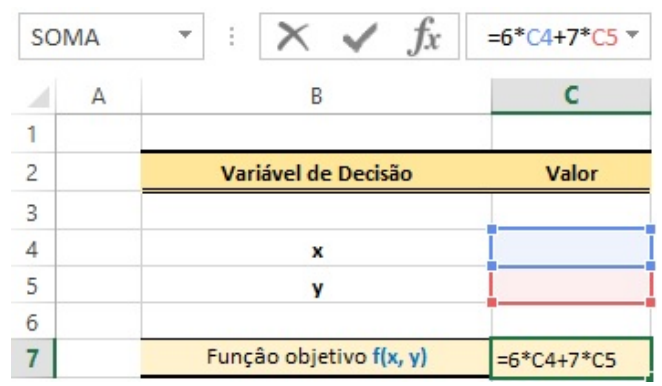

Figura 77: Definindo células

Os primeiros membros das inequações serão armazenados em $C 10$ e $C 11$ utilizando procedimento similar ao que fora utilizado na definição da função objetivo. Para a primeira restrição, $x+y \leq 10$, digita-se, em $C 10,=C 4+C 5$ e, para $3 x+7 y \leq 42$, digita-se, em $C 11,=3 * C 4+7 * C 5$. Após inserções, a planilha apresentará aspecto seguinte com valores nulos ocorrendo em virtude da não inicialização das variáveis de decisão definidas no problema, como se vê na figura 78 . 


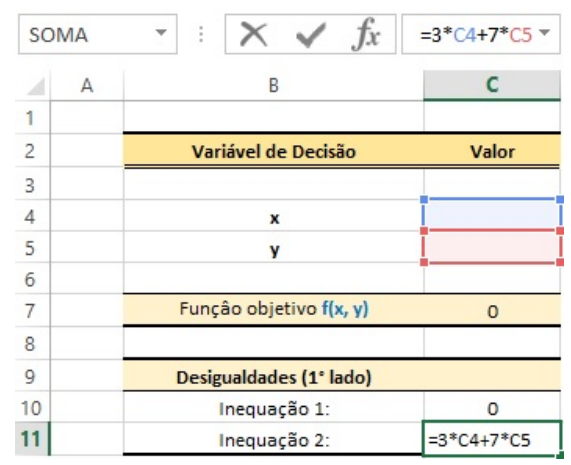

Figura 78: Definindo restrições

Definidas as células que conterão variáveis de decisão, função objetivo e restrições do problema de programação, seleciona-se a ferramenta Solver presente no grupo Análise da guia Dados. Será apresentada a janela da figura 79, onde serão assinaladas células e valores com elementos para resolução do problema.

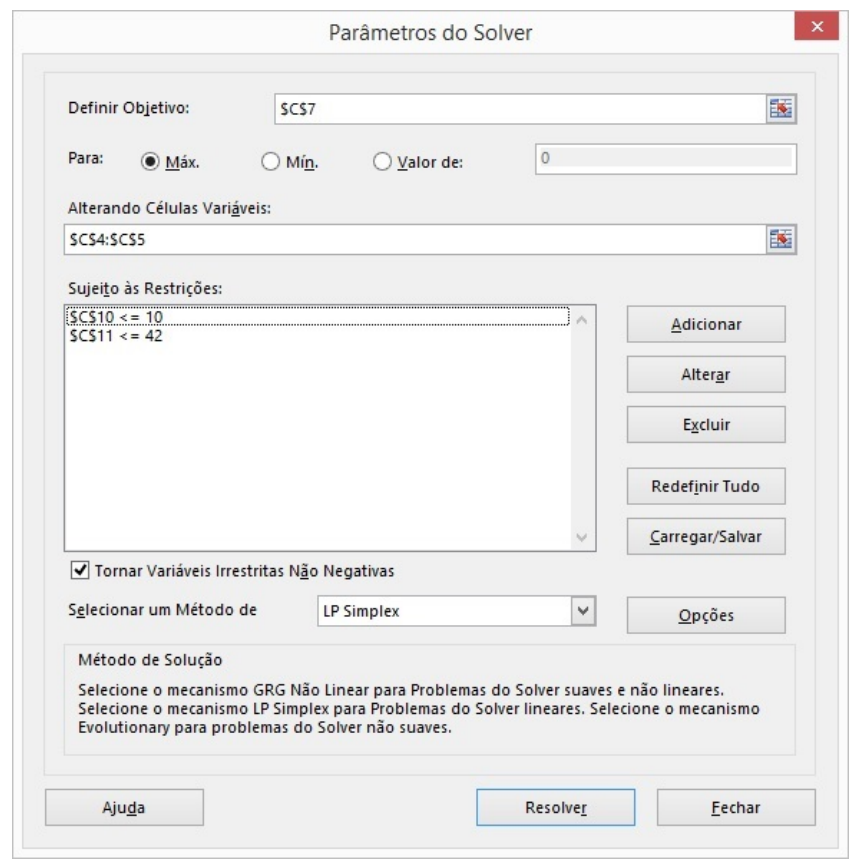

Figura 79: Parâmetros do solver

Para cada restrição a ser acrescentada, clica-se em Adicionar e, na janela mostrada na figura 80, escolhe-se a célula que contém o primeiro lado da desigualdade, o tipo e o valor numérico que complementa a restrição do problema. 


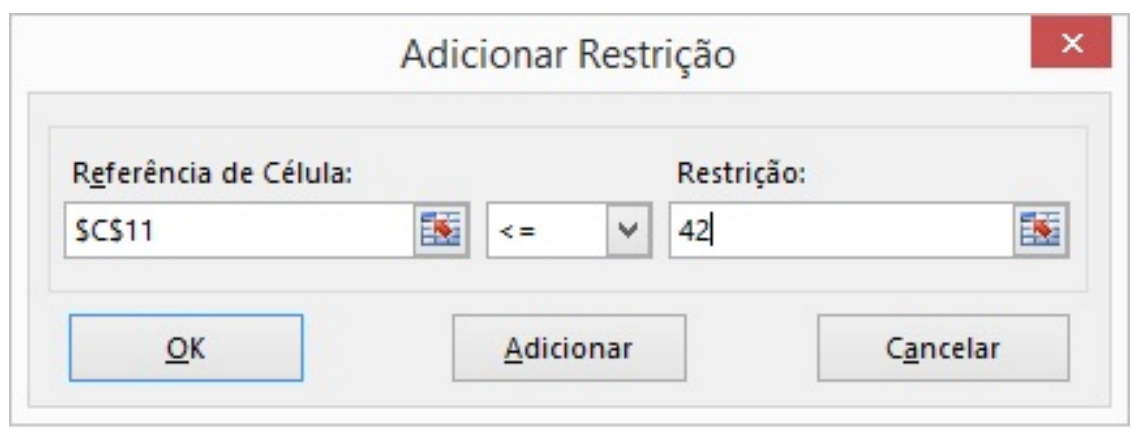

Figura 80: Adicionar Restrição

Clicando em Resolver e, em seguinda, na janela Resultados do Solver, mantendo soluções e pressionando em $\mathbf{O k}$, os dados serão nas células definidas como variáveis de decisão. O valor ótimo para $f$ é 63 para $x$ e $y$ valendo, respectivamente, 7 e 3 , como se vê na figura 81.

\begin{tabular}{|c|c|c|c|c|}
\hline \multicolumn{2}{|c|}{ E14 } & 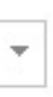 & $\therefore \vee f_{x}$ & 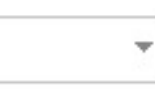 \\
\hline$\Delta$ & $\mathrm{A}$ & & B & C \\
\hline 1 & & & & \\
\hline 2 & & & Variável de Decisão & Valor \\
\hline 3 & & & & \\
\hline 4 & & & $\mathrm{x}$ & 7 \\
\hline 5 & & & $\mathrm{y}$ & 3 \\
\hline 6 & & & & \\
\hline 7 & & & Funçâo objetivo $f(x, y)$ & 63 \\
\hline 8 & & & & \\
\hline 9 & & & Desigualdades ( $1^{\circ}$ lado) & \\
\hline 10 & & & Inequação 1: & 10 \\
\hline 11 & & & Inequação 2: & 42 \\
\hline
\end{tabular}

Figura 81: Resultado

\subsection{O problema da dieta}

A seguir, apresentaremos a resolução do problema proposto em 2.4.2, cujo objetivo consiste em determinar, em uma dieta para redução calórica, as quantidades de certos 
alimentos que deverão ser ingeridos diariamente, de modo que determinados requisitos nutricionais sejam satisfeitos a custo mínimo. O modelo

$$
\begin{array}{cl}
\text { Minimizar } & C\left(x_{1}, x_{2}, x_{3}, x_{4}\right)=2 x_{1}+4 x_{2}+1,5 x_{3}+3 x_{4} \\
\text { Sujeito a } & \left\{\begin{array}{l}
2 x_{1}+2 x_{2}+10 x_{3}+20 x_{4} \geq 11 \\
50 x_{1}+20 x_{2}+10 x_{3}+30 x_{4} \geq 70 \\
80 x_{1}+70 x_{2}+10 x_{3}+80 x_{4} \geq 250 \\
x_{1}, x_{2}, x_{3}, x_{4} \geq 0
\end{array}\right.
\end{array}
$$

Na tabela 10, são apresentados os elementos necessários para resolução do problema proposto utilizando o Solver do Microsoft Excel. Para tal, foram delimitadas as células para armazenar cada das variáveis de decisão $x_{1}, x_{2}, x_{3}$ e $x_{4}$, e restrições $R_{1}, R_{2}$ e $R_{3}$. O modelo elaborado é formado pelas variáveis e desigualdades conforme se vê em

\begin{tabular}{|c|c|c|c|c|c|}
\hline \multicolumn{6}{|c|}{ Variáveis de decisão: } \\
\hline$x_{1}$ & 2,861 & & & & \\
\hline$x_{2}$ & 0,000 & & & & \\
\hline$x_{3}$ & 0,000 & & & & \\
\hline$x_{4}$ & 0,264 & & & & \\
\hline \multicolumn{6}{|c|}{ Coeficientes } \\
\hline & $x_{1}$ & $x_{2}$ & $x_{3}$ & $x_{4}$ & \\
\hline $\mathrm{R}_{1}$ & 2 & 2 & 10 & 20 & 11,0 \\
\hline $\mathrm{R}_{2}$ & 50 & 20 & 10 & 30 & 151,0 \\
\hline $\mathrm{R}_{3}$ & 80 & 70 & 10 & 80 & 250,0 \\
\hline Função & 2,0 & 4,0 & 1,5 & 3,0 & 6,514 \\
\hline
\end{tabular}

Tabela 10: Solução do problema usando o Solver

O valor ótimo da função objetivo, $R \$ 6,514$, ocorre para $x_{1}=2,861, x_{2}=0, x_{3}=0$ e $x_{4}=0,264$ e é obtido depois de 4 iterações do algoritmo simplex. Na tabela 11, é apresentado o valor de cada uma das variáveis do problema, bem como o valor da função objetivo no final de cada uma das iterações executadas. 
Tabela 11: Valor das variáveis e da função objetivo em cada iteração

\begin{tabular}{|c|c|c|c|c|}
\hline \multicolumn{5}{|c|}{ Iterações } \\
\hline & 1 & 2 & 3 & 4 \\
\hline$x_{1}$ & 1,400 & 3,152 & 3,064 & 2,861 \\
\hline$x_{2}$ & 0,000 & 0,000 & 0,000 & 0,000 \\
\hline$x_{3}$ & 0,000 & 0,000 & 0,487 & 0,000 \\
\hline$x_{4}$ & 0,000 & 0,000 & 0,000 & 0,264 \\
\hline Objetivo & 2,800 & 6,304 & 6,859 & 6,514 \\
\hline
\end{tabular}

Os resultados presentes nas tabelas 10 e 11 permitem a realização de inferências sobre valores finais das variáveis, como os nulos obtidos para $x_{2}$ e $x_{3}$ que, provavelmente, decorrem, respectivamente, do alto preço da carne frente aos demais itens e da baixa quantidade das vitaminas $\mathrm{C}$ e $\mathrm{D}$ do peixo, quando comparado com os outros itens. 


\section{Teoria do Consumidor}

\subsection{Introdução}

Considera-se como Teoria do Consumidor a área das ciências econômicas que estuda o comportamento do consumidor durante as suas decisões de consumo e, para sua formalização, é considerada a premissa de que os consumidores escolhem as melhores coisas dentro daquilo que eles podem adquirir. Ao leitor interessado em mais detalhes recomenda-se a obra de Mankiw [17].

Definição 23. Uma cesta de consumo ou cesta de mercadorias é uma combinação de diferentes mercadorias e cada uma em uma quantidade. Matematicamente, uma cesta de $n$ produtos é um vetor de $n$ coordenadas

$$
Q=\left\{q_{1}, q_{2}, q_{3}, \ldots, q_{n}\right\}
$$

onde $q_{i}$ corresponde à quantidade do item $i$ que compõem a cesta.

Admitindo a existência de somente dois bem para cada cesta, torma-se possível sua representação no plano de coordenadas cartesianas $x O y$, onde os eixos coordenados indicam as quantidades dos bens 1 e 2 . As cestas $A(1,1), B(2,5), C(4,3), D(7,0)$ e $E(0,4)$ estão representados na figura 82.

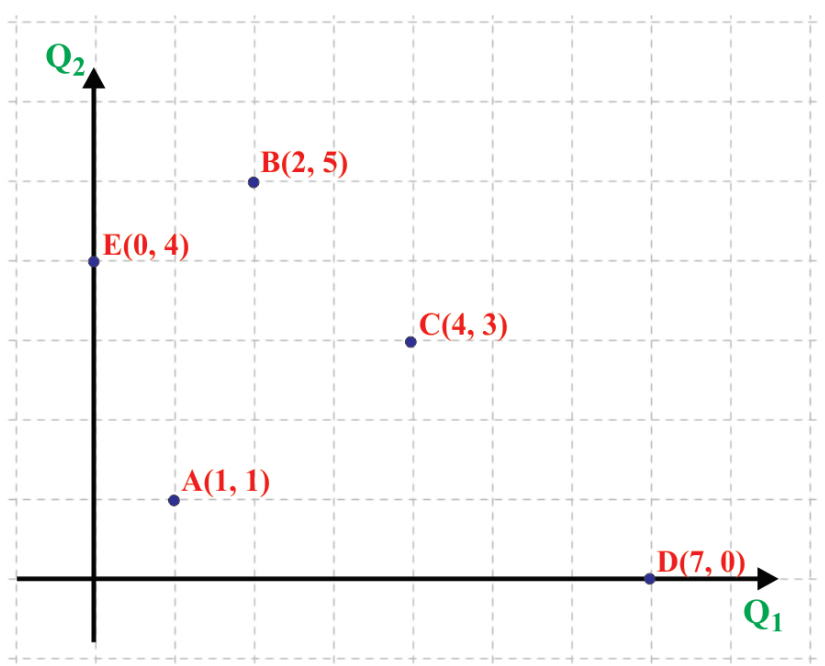

Figura 82: Exemplos de cestas de consumo 
Embora pareça uma simplificação que não seja aplicada à prática, essa hipótese de dois bens pode ser bem factível ao tomar como um dos bens todos os outros bens que o consumidor deseja adquirir. Por exemplo, se quisermos estudar a demanda de laranjas do consumidor, podemos fazer com que $Q_{1}$ represente o consumo de laranjas ao passo que $Q_{2}$ represente todos os outros itens que o consumidor gostaria de consumir.

\subsection{Restrição Orçamentária}

Todo consumidor só consegue adquirir o que seu orçamento pessoal lhe permite. Essa limitação imposta é chamada de restrição orcamentária e basicamente informa que o consumidor não pode gastar mais do que possui.

Definição 24. Sejam $p_{1}, p_{2}, \ldots, p_{n}$ preços unitários dos bens $1,2, \ldots, n$ e $q_{1}, q_{2}, \ldots, q_{n}$ as respectivas quantidades. A renda minima $R$ necessária para a aquisição da cesta $Q=\left\{q_{1}, q_{2}, q_{3}, \ldots, q_{n}\right\}$ é dada por

$$
\sum_{i=1}^{n} p_{i} q_{i}=p_{1} q_{1}+p_{2} q_{2}+\ldots+p_{n} q_{n} \leq R
$$

No espaço bidimensional, essa restrição se resume a $p_{1} q_{1}+p_{2} q_{2} \leq R$, cuja representação gráfica determina o triângulo retângulo de vértices $(0,0),\left(0, \frac{R}{p_{2}}\right)$ e $\left(\frac{R}{p_{1}}, 0\right)$, como está representado na figura 83.

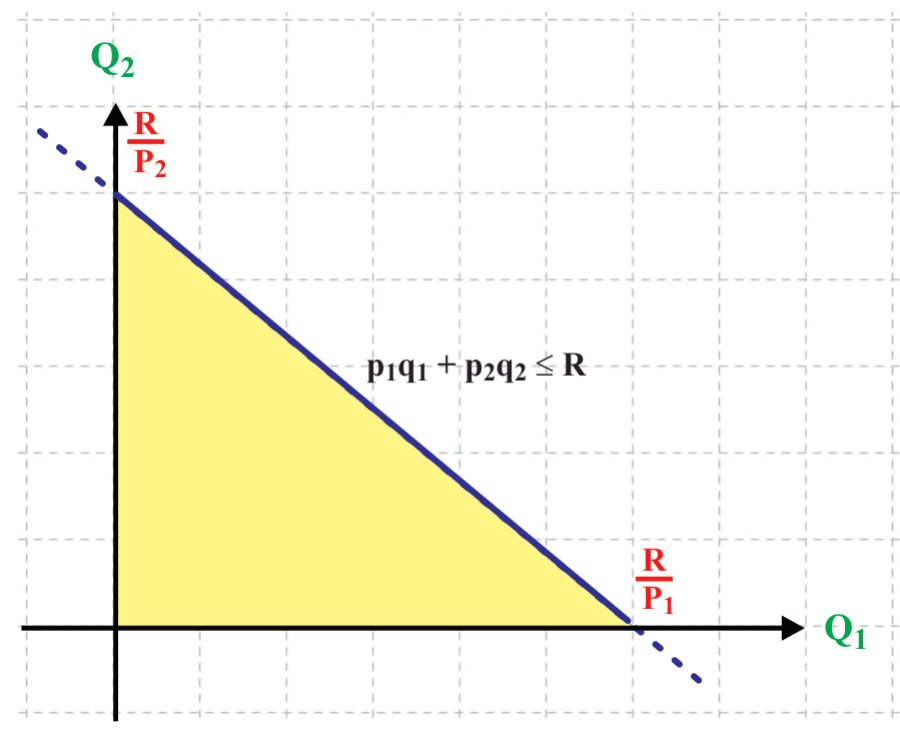

Figura 83: Restrição Orçamentária 
A hipotenusa desse triângulo está contida na reta de equação $p_{1} q_{1}+p_{2} q_{2}=R$, é chamada de reta orçamentária e contém todas as cestas que exaurem a renda do consumidor. Na forma reduzida, a equação apresenta elementos geométricos importantes como a inclinação da reta e o intercepto com o eixo das ordenadas.

$$
p_{1} q_{1}+p_{2} q_{2}=R \Rightarrow p_{2} q_{2}=-p_{1} q_{1}+R \Rightarrow q_{2}=-\frac{p_{1}}{p_{2}} q_{1}+\frac{R}{p_{2}}
$$

A incliação da reta orçamentária, $-p_{1} / p_{2}$, contém um dado importante do consummidor: ela mede a taxa com a qual o consumidor está disposto a substituir o bem 1 pelo bem 2. Assim, se a inclinção da reta orçamentária for -3 , o consumidor troca uma unidade do bem 1 por três unidades do bem 2 .

\subsection{Mudanças na reta orçamentária}

A reta orçamentária pode variar em função de dois fatores: a primeira decorrente da mudança na renda do consumidor e segunda decorrente da mudança dos preços dos bens e serão abordadas geometricamente a partir de seus interceptos com os eixos coordenados.

\subsubsection{Mudanças na renda}

Os interceptos da reta orçamentária com os eixos coordenados são $\left(\frac{R}{p_{1}}, 0\right)$ e $\left(0, \frac{R}{p_{2}}\right)$ e indicam quantas unidades dos itens 2 e 1 que o consumidor, dadas suas limitações orçamentárias, consegue adquirir. Aumentando (ou reduzindo) a renda do consumidor para $R^{\prime}, R^{\prime} \neq R$, os interceptos passam a ser $\left(\frac{R^{\prime}}{p_{1}}, 0\right)$ e $\left(0, \frac{R^{\prime}}{p_{2}}\right)$. A figura 84 ilustra esta situação.

Dados os novos interceptos da reta orçamentária, é possível determinar sua equação

$$
\frac{q_{1}}{\frac{R^{\prime}}{p_{1}}}+\frac{q_{2}}{\frac{R^{\prime}}{p_{2}}}=1 \Rightarrow \frac{p_{1} q_{1}}{R^{\prime}}+\frac{p_{2} q_{2}}{R^{\prime}}=1 \Rightarrow p_{1} q_{1}+p_{2} q_{2}=R^{\prime}
$$

Portanto, o aumento da renda do consumidor de $\mathrm{R}$ para $\mathrm{R}$ ' gera deslocamento da reta orçamentária no sentido de seu gradiente, paralelamente à reta original. Analogamente, a reta $p_{1} q_{1}+p_{2} q_{2}=R^{\prime}, R^{\prime}<R$, é o resultado do deslocamento da reta orçamentária no sentido contrário ao sentido de seu gradiente. 


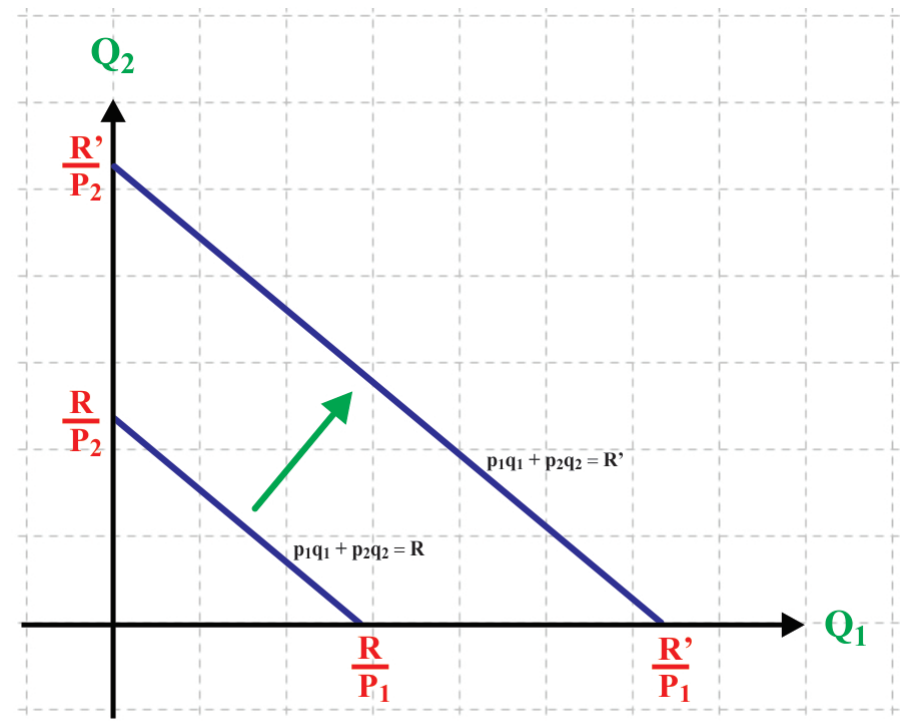

Figura 84: Aumento na renda do consumidor

\subsubsection{Mudanças nos preços}

O impacto gerando pela alteração no preço de um bem da cesta está associado à quantidade de itens desse bem que o consumidor poderá adquirir. Sem perda de generalidade, caso o preço do bem 1 varie de $p_{1}$ para $p_{1^{\prime}}$, o intercepto com o eixo $Q_{1}$ passaria de $\left(\frac{R}{p_{1}}, 0\right)$ para $\left(\frac{R}{p_{1}^{\prime}}, 0\right)$, conforme se vê na figura 85 .

A reta orçamentária é passará a ser:

$$
\frac{q_{1}}{\frac{R}{p_{1^{\prime}}}}+\frac{q_{2}}{\frac{R}{p_{2}}}=1 \Rightarrow \frac{q_{1} p_{1^{\prime}}}{R}+\frac{q_{2} p_{2}}{R}=1 \Rightarrow q_{1} p_{1^{\prime}}+q_{2} p_{2}=R
$$

Portanto, a modificação do preço de um bem desloca o intercepto da reta orçamentária com o eixo que representa a quantidade desse bem. No caso de redução no preço de um item na cesta gera uma rotação da reta orçamentária, em torno de $\left(0, \frac{R}{p_{2}}\right)$, no sentido anti-horário.

\subsection{Uma situação problema}

Exemplo 30. Um investidor dispõe de $R \$ 6.000,00$ para compra de ações dos tipos $A$ e $B$, com preços unitários pra aquisição de $R \$ 5,00$ e $R \$ 3,00$ e rentabilidade anual esperada de 30\% e 35\%, respectivamente. Supondo que o investidor não deseje adquirir 


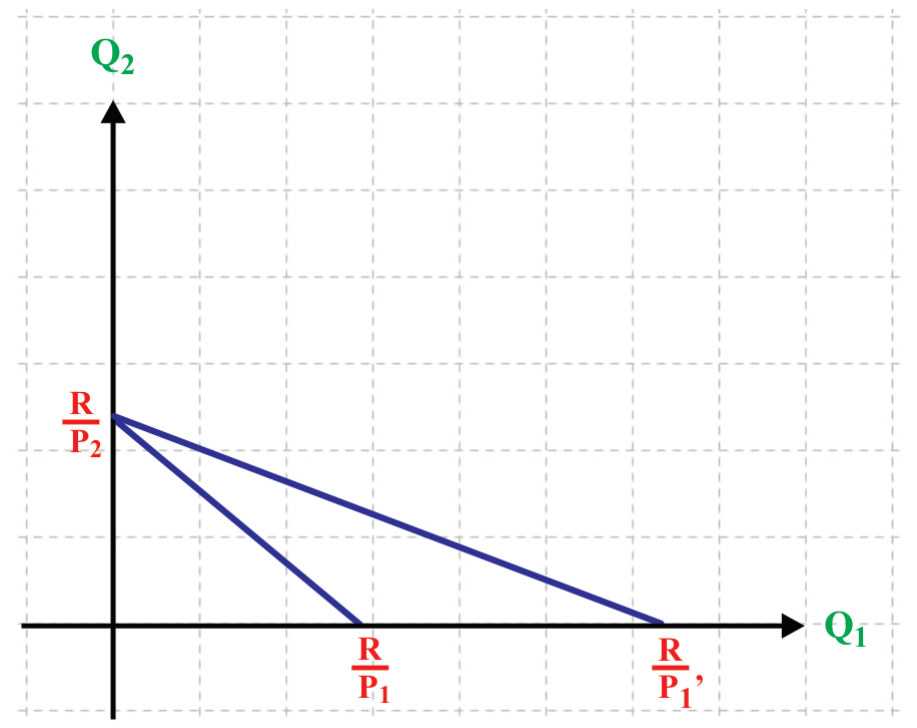

Figura 85: Mudança nos preços

mais do que 1750 ações e que lhe sejam disponíveis, para compra, 1000 ações do tipo $A$ e 1500 ações do tipo B, que quantidades deve comprar de cada tipo de ação, na hipótese de que seja seu objetivo maximizar o total de capital no fim de um ano?

\section{Solução:}

Sejam $x$ e $y$, respectivamente, as quantidades de ações dos tipos A e B que serão adquiridas. As informações apresentadas possibilitam a elaboração das restrições:

1. limitação quando à quantidade de ações do tipo A: $x \leq 1000$;

2. limitação quando à quantidade de ações do tipo B: $y \leq 1500$;

3. quantidade máxima a ser adquirida: $x+y \leq 1750$;

4. limitação orçamentária: $5 x+3 y \leq 6000$;

Como A e B apresentam expectativa de rentabilidade anual da ordem de $30 \%$ e $35 \%$, respectivamente, espera-se que as unidades das mesmas sejam vendidas, após um ano, por $(1+0,30) \cdot R \$ 5,00=R \$ 6,50$ e $(1+0,35) \cdot R \$ 3,00=R \$ 4,05$, a função objetivo será $f(x, y)=6,50 x+4,05 y$. O modelo proposto é 


$$
\begin{aligned}
\text { Maximizar } & f(x, y)=6,50 x+4,05 y \\
\text { Sujeito a } & \left\{\begin{array}{l}
x \leq 1000 \\
y \leq 1500 \\
x+y \leq 1750 \\
5 x+3 y \leq 6000
\end{array}\right.
\end{aligned}
$$

\subsubsection{Solução pelo método geométrico}

Por ser um problema de programação linear definido no $\mathbb{R}^{2}$, uma alternativa de resolução consiste na utilização da interpretação geométrica do Algoritmo Simplex. Para tal, inicializa-se o Geogebra e desenvolvem-se os seguintes passos:

1. Clicar com o botão direito do mouse sobre a Janela de Visualização e marcar a opção Malha para exibir a malha quadriculada. A seguir, será construído espaço viável, formado por todo $(x, y) \in \mathbb{R}^{2}$ que atendem a todas as restrições.

2. Em Entrada, digitar $a: x<=1000$ e pressionar Enter;

3. Em Entrada, digitar $b: y<=1500$ e pressionar Enter;

4. Em Entrada, digitar $c: x+y<=1750$ e pressionar Enter;

5. Em Entrada, digitar $d: 5 x+3 y<=6000$ e pressionar Enter;

A figura 86 mostra a janela de visualização do Geogebra com as restrições observadas no exemplo 30 .

A região viável, formada pela interseção das quatro restrições observadas, é constituída pela região mais escura cujos vértices são determinados com o uso do comando Interseção[ $<$ objeto $>,<$ objeto $>$ do Geogebra.

6. Em Entrada, digitar $\mathbf{P} \mathbf{1}=$ Interseção[5x $+3 \mathbf{y}=\mathbf{6 0 0 0}, \mathrm{x}+\mathbf{y}=\mathbf{1 7 5 0}] \mathrm{e}$ pressionar Enter;

7. Em Entrada, digitar $\mathbf{P} 2=$ Interseção[5x $+3 \mathrm{y}=6000, \mathrm{x}=\mathbf{1 0 0 0}]$ e pressionar Enter;

8. Em Entrada, digitar $\mathbf{P 3}=$ Interseção $[\mathbf{x}=\mathbf{1 0 0 0}, \mathbf{y}=\mathbf{0}]$ e pressionar Enter; 


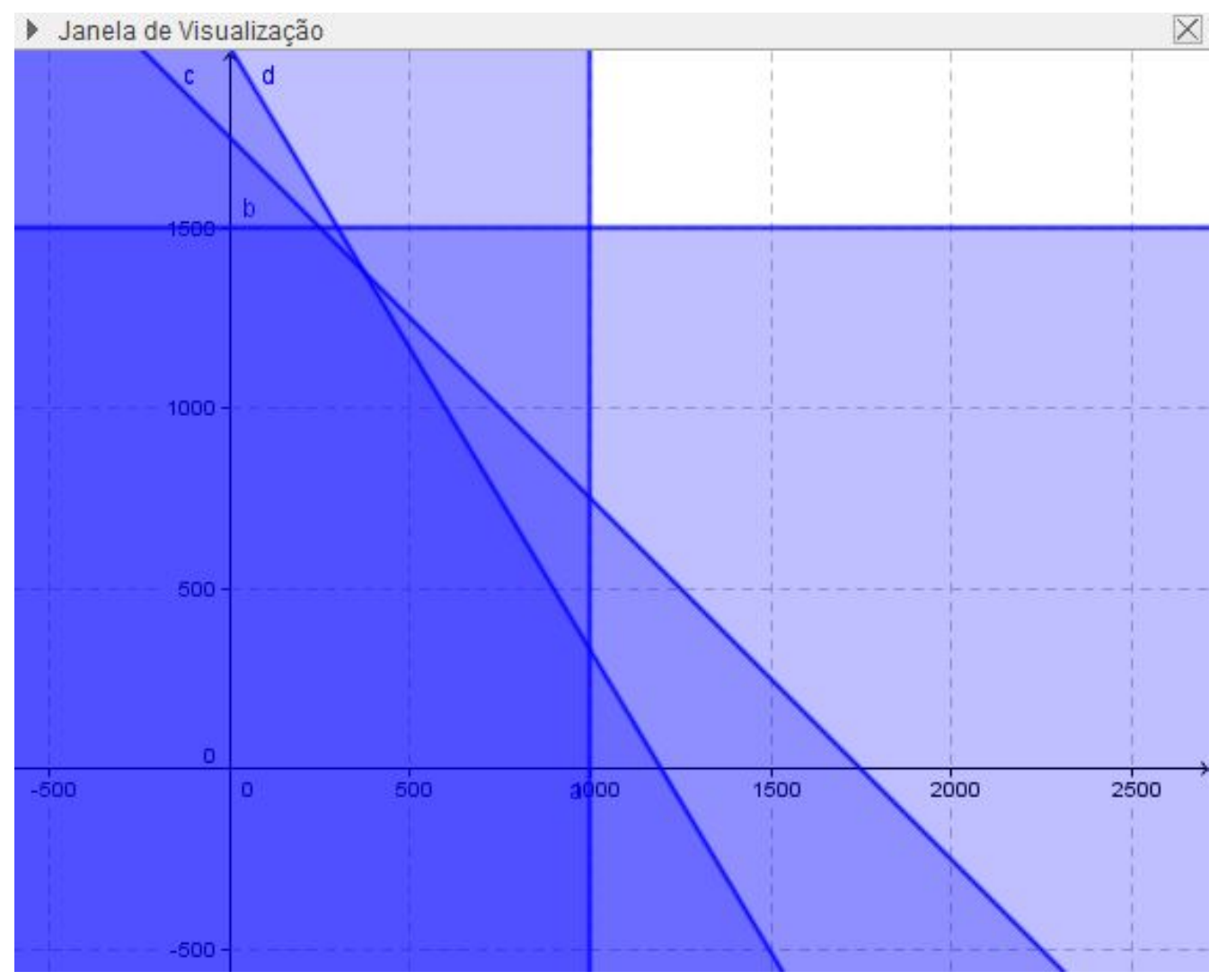

Figura 86: Representação gráfica das restrições do exemplo 30

9. Em Entrada, digitar $\mathbf{P} \mathbf{4}=(\mathbf{0}, \mathbf{0})$ e pressionar Enter;

10. Em Entrada, digitar P5 $=$ Interseção $[\mathbf{x}=\mathbf{0}, \mathbf{y}=\mathbf{1 5 0 0}]$ e pressionar Enter;

11. Em Entrada, digitar $\mathbf{P 6}=$ Interseção $[\mathbf{y}=\mathbf{1 5 0 0}, \mathbf{x}+\mathbf{y}=\mathbf{1 7 5 0}]$ e pressionar Enter;

12. Na Janela de Álgebra, clicar com o botão direito do mouse sobre cada uma das desigualdades e desmarcar a opção Exibir Objeto

13. Em entrada, digitar Polígono[P1, P2, P3, P4, P5, P6] e pressionar Enter para destacar a região viável do modelo proposto.

14. Em Entrada, digitar $r: 6.5 x+4.05 y=0$ e pressionar Enter;

O valor máximo ocorre em um ponto extremo da região viável determinado pela reta paralela a $r$ que não contém ponto interior da região viável. Esse fato ocorre em $P 1=(375,1375)$, quando $f(375,1375)=8006,25$. 


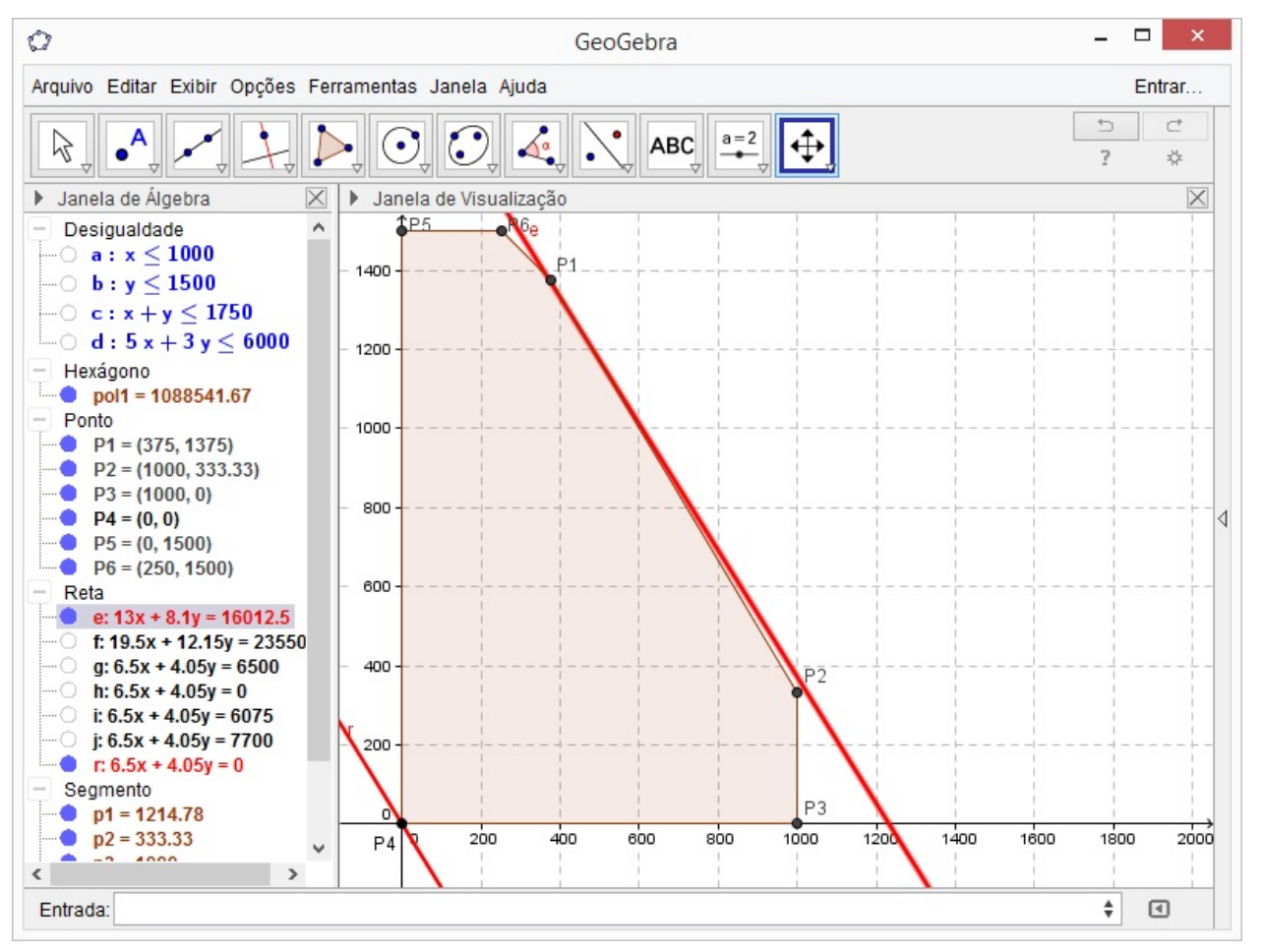

Figura 87: Polígono viável do exemplo 30

\subsubsection{Solução do problema proposto no exemplo 30 utilizando o Solver}

A resolução de um problema de programação a partir da ferramenta Solver do Microsoft Excel envolve processo formado por três etapas:

1. O processo é inicializado pela definição de células para armazenar as variáveis, a função objetivo e as restrições. Os valores das variáveis $x$ e $y$ serão armazenados em $C 4$ e $C 5$, respectivamente e, em $C 6$, digita-se a fórmula $=6,5 * C 4+4,05 * C 5$. A seguir, nas células $C 8, C 9, C 10$ e $C 11$ escrevem-se os primeiros lados das restrições, ou seja, $=C 4,=C 5,=C 4+C 5 \mathrm{e}=5 * C 4+3 * C 5$.

Os valores nulos observados na figura 88 ocorrem em virtude da não inicialização das células $C 4$ e $C 5$.

2. Na guia Dados, no conjunto Solver, clicar na opção Solver. Na janela apresentada, define-se como objetivo a célula $\$ C \$ 6$, o campo células variáveis com $\$ C \$ 4$ : $\$ C \$ 5$ e completa-se as restrições associando cada uma das células do intervalo $C 8$ : $C 11$ aos respectivos limites observado para cada uma. Na figura 89, tem-se preenchimento dos campos da janela Parâmetros do Solver. 


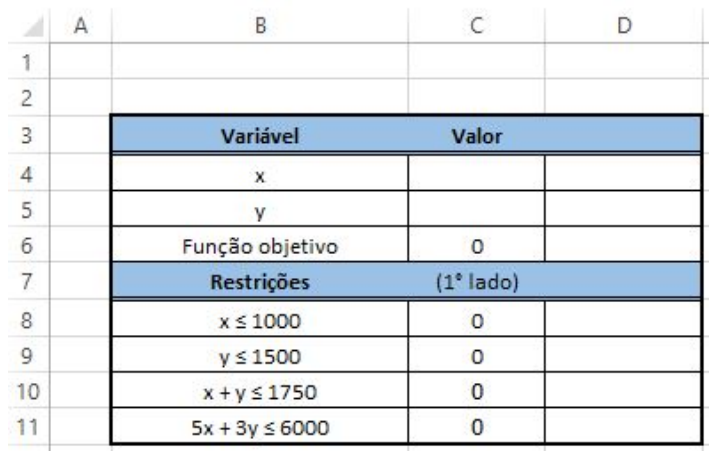

Figura 88: Planilha do Excel com definição de variáveis e restrições

3. Clicar em Resolver e, na janela seguinte, clicar em Ok para consolidar a solução encontrada na planilha. Os valores de $x$ e $y$ obtidos pelo Excel serão armazenados em $C 4$ e $C 5$, e será determinado o valor ótimo da função objetivo, conforme é mostrado na figura 90 .

\subsubsection{Solução envolvendo método algébrico}

A resolução envolvendo procedimento algébrico envolve resolução do sistema linear gerado pela transformação da forma canônica,

$$
\begin{aligned}
\text { Maximizar } & f(x, y)=6,50 x+4,05 y \\
\text { Sujeito a } & \left\{\begin{array}{l}
x \leq 1000 \\
y \leq 1500 \\
x+y \leq 1750 \\
5 x+3 y \leq 6000
\end{array}\right.
\end{aligned}
$$

para a respectiva forma padrão acrescentando variáveis de sobra a cada uma das restrições observadas na fase de modelagem. Obtem-se então o sistema linear:

$$
\begin{cases}x+s_{1}=1000 & : e_{1} \\ y+s_{2}=1500 & : e_{2} \\ x+y+s_{3}=1750 & : e_{3} \\ 5 x+3 y+s_{4}=6000 & : e_{4}\end{cases}
$$

$\operatorname{Em} f(x, y)=6,5 x+4,05 y$, como $6,5=\frac{\partial f}{\partial x}>\frac{\partial f}{\partial y}=4,05$, infere-se que $x$ deve ser substituída utilizando equação $e_{1}$. Explicitando $x$ em $e_{1}$ e substituindo-o nas demais 


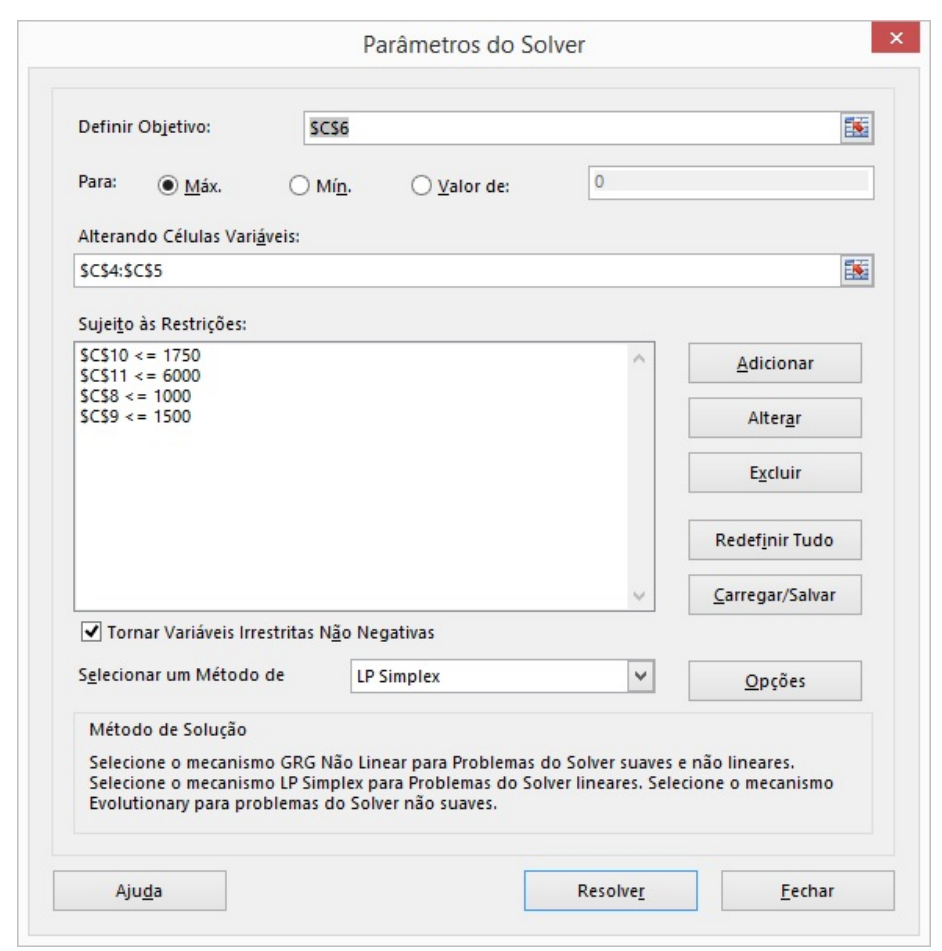

Figura 89: Parâmetros do Solver

equações do sistema, obtém-se:

$$
\begin{cases}x=1000-s_{1} & : e_{1} \\ y+s_{2}=1500 & : e_{2} \\ y-s_{1}+s_{3}=750 & : e_{5} \\ 3 y-5 s_{1}+s_{4}=1000 & : e_{6}\end{cases}
$$

A função objetivo passará a ser $f\left(s_{1}, y\right)=6500-6,5 s_{1}+4,05 y$, onde o único coeficiente que colabora para o crescimento de $f$ é determinado por $\frac{\partial f}{\partial y}=4,05>0$ apontando $y$ como variável a ser substituída, o que será feito utilizando $e_{6}$. Então

$$
\begin{cases}x=1000-s_{1} & : e_{1} \\ 5 s_{1}-s_{4}+3 s_{2}=3500 & : e_{7} \\ 2 s_{1}+3 s_{3}-s_{4}=1250 & : e_{8} \\ y=\frac{1000+5 s_{1}-s_{4}}{3} & : e_{6}\end{cases}
$$

No atual estágio, a função objetivo, em função de $e_{6}$, passa a ser $f\left(s_{1}, s_{4}\right)=7850+$ $0,25 s_{1}-1,35 s_{4}$ que será otimizada ao substituir a variável $s_{1}$ utilizando $e_{8}$. Explicitando 


\begin{tabular}{|c|c|c|c|c|}
\hline 4 & A & B & C & D \\
\hline \multicolumn{5}{|l|}{1} \\
\hline \multicolumn{5}{|l|}{2} \\
\hline 3 & & Variável & Valor & \\
\hline 4 & & $\mathrm{x}$ & 375 & \\
\hline 5 & & $\mathrm{y}$ & 1375 & \\
\hline 6 & & $f(x, y)=6,5 x+4,05 y$ & 8006,25 & função objetivo \\
\hline 7 & & Restrições & ( $1^{\circ}$ lado) & \\
\hline 8 & & $x \leq 1000$ & 375 & \\
\hline 9 & & $y \leq 1500$ & 1375 & \\
\hline 10 & & $x+y \leq 1750$ & 1750 & \\
\hline 11 & & $5 x+3 y \leq 6000$ & 6000 & \\
\hline
\end{tabular}

Figura 90: O valor máximo de $f$ é indicado na célula $D 6$

$s_{1}$ em $e_{8}$ e substituindo-a na função objetivo, obtemos $f\left(s_{3}, s_{4}\right)=8006,25-0,375 s_{3}-$ $0,16875 s_{4}$ cujo máximo ocorre para $s_{3}=s_{4}=0$. Para esses valores, conlui-se que $x=375, y=1375, s_{1}=675, s_{2}=125$ e $f(x, y)=8006,25$. 


\section{Considerações finais}

Em sua obra "Projeto de Pesquisa", publicada no ano de 2007, John W. Creswell, [8], afirma que:

"... os problemas surgem a partir de questões, dificuldades e práticas correntes. O problema de pesquisa em um estudo começa a tornar-se claro quando o pesquisador pergunta "Qual é a necessidade deste estudo?"ou "Que problema influenciou a necessidade de fazer este estudo?"

Muitos avanços tecnológicos ocorridos nas últimas décadas, principalmente no período após a segunda Guerra Mundial, decorrem das dificuldades e necessidades apresentadas pelo ser humano. As redes de computadores e, por consequência a internet, originaram-se em função da necessidade de se transmitir informações, com segurança, no período que hoje conhecemos com o nome de Guerra Fria. Na mesma dinâmica, desenvolveram-se diferentes áreas do conhecimento humano como a engenharia, a economia, a medicina, a física, a logística, dentre várias outras. Muito desse desenvolvimento foi impulsionado em função da grande capacidade de processamento dos supercomputadores atuais.

A criação de algoritmos eficientes auxiliou no mapeamento do genoma humano, no planejamento da produção de grandes empresas e trouxe para a realidade termos como inteligência artificial e realidade virtual. Assim, relacionamos a resolução de problemas ao planejamento necessário para sua realização, materializando a aplicação de algoritmos, uma das essências do saber matemático. As conquistas advindas do desenvolvimento do raciocínio algoritmico devem ser elementos presentes na educação básica, como afirma Jurkiewicz [14]:

O pensamento algorítmico pode e deve ser introduzido de forma educacionalmente pertinente de maneira a fornecer às sociedades do século $X X I$, não programadores (embora também), mas cidadãos aptos a viver num mundo onde a cultura dos procedimentos sequenciais se torna rapidamente um padrão.

Neste trabalho, apresentamos noção de algoritmo bem como fatores a serem observados em sua formulação como notações comumente adotadas e eficiência computacional durante sua execução. Propusemos diversas atividades com resolução rápida, 
para serem desenvolvidas no Geogebra ou no Excel e apresentamos sequencialização de ações que compõem o processo de resolução do problema a ela associado, o que caracteriza um algoritmo e apresenta elementos comuns com conceitos abordados em disciplinas como Algoritmos e Estruturas de Dados, presentes em cursos como Ciência da Computação ou Sistemas de Informação. A proposta aqui apresentada não se materializa no ensino de linguagens de programação como Java ou C para o ensino médio mas sim utilizar elementos presentes na própria estrutura curricular da educação básica para desenvolver habilidades de encadeamento de estruturas e fatos lógicamente dependentes.

Enquanto ferramenta auxiliar no processo de ensino, o estudo de algoritmos consolidase com a apresentação do Simplex, principal algoritmo desenvolvido para resolução de problemas de programação linear e apresenta duas versões distintas aos quais denominamos geométrica e algébrica. A versão geométrica consiste em determinar o ponto de uma região do plano que maximiza ou minimia uma função linear, envolve conceitos da geometria analítica e se configura como importante circunstância para uso do Geogebra. Paralelamente, a versão algébrica deve ser vista como forma complementar da versão algébrica e justifica seu correto funcionamento, além de possibilitar o uso da planilha eletrônica, ferramenta empregada como mecanismo de planejamento e suporte a decisão em muitas instituições da sociedade contemporânea.

Enfim, consideramos que o ensino de programação linear, construção de algoritmos e modelagem matemática oferecem importante contribuição para um ensino que evidencie a articulação do saber matemático com assuntos relacionados à ciência e à tecnologia, além de permitir abordar problemas de planejamento gerencial presentes em situações concretas. Assim sendo, observamos que no ensino de programação linear, existe uma grande oportunidade de contribuir para o ensino de Matemática que seja experimental e contextualizado e esperamos que a abordagem aqui proposta possa contribuir para a confirmação de uma filosofia de ensino vinculada ao quotidiano, na qual conceitos são devidamente fundamentados, justificados e nunca apresentados sem o devido sentido. 


\section{Referências}

[1] ANDRADE, E., Introducão a Pesquisa Operacional: Métodos e Modelos para Análise de Decisões (3 ed), LTC, 2004, Rio de Janeiro, RJ.

[2] BASSANEZI, R. Ensino-aprendizagem com modelagem matemática: uma nova estratégia, Contexto, 2002, São Paulo, SP

[3] BRASIL, RECEITA FEDERAL DO. Disponível em $<$ <ttp://www.receita.fazenda.gov.br>. Acesso em: 01 julho 2015.

[4] EFetiva, Simulador DE Alíquota. Disponivel em $<h t t p: / / w w w . r e c e i t a . f a z e n d a . g o v . b r / a p l i c a c o e s / a t r j o / s i m u l a d o r / s i m u l a d o r . a s p>$. Acesso em: 01 julho 2015.

[5] CHIAVEnATO, I., Introdução à Teoria Geral da Administração, (7 ed), Elsevier, 2004, Rio de Janeiro, RJ.

[6] Cormen, Thomas H., Algoritmos - Teoria e Prática, Elsevier, 2002, Rio de Janeiro, RJ.

[7] Coutinho, Luciano., A Terceira Revolução Industrial e Tecnológica: As Grandes Tendências da Mudança. Disponível em: $<$ http://www.eco.unicamo.br/docprod/downarq.php?id=398\&tp=a>. Acesso em: 09 janeiro 2015.

[8] CRESWell, John W., Projetos de Pesquisa: Métodos Qualitativo, Quantitativo e Misto (tradução da 3 edição), ARTMED, 2010, Porto Alegra, RS.

[9] DAnte, Luiz Roberto., Matemática, Atica, 2008, Sao Paulo, SP.

[10] DANTE, Luiz Roberto., Didática na Resolução de Problemas, Atlas, 2003, São Paulo, SP

[11] GoldBARG, M. C. e LUnA, Henrique Pacca., Otimização Combinatória e Programação Linear, Elsevier, 2005, Rio de Janeiro, RJ.

[12] HefeZ, Abramo e FERnAndeZ, Cecília de Souza, Introdução à Álgebra Linear, SBM, (procuar ano) 
[13] IEZZI, Gelson., Matemática: ciência e aplicações (4 ed), Atual, 2005, São Paulo, SP.

[14] JURKIEWICZ, S., Grafos: Uma introdução. Disponivel em $<$ http://www.obmep.org.br/docs/apostila5.pdf> Acesso em: 13 de junho de 2015.

[15] LiMA, Elon L., Curso de análise - Volume 1, IMPA, 2011, Rio de Janeiro, RJ.

[16] LiMA, Elon L., Curso de análise - Volume 2, IMPA, 2011, Rio de Janeiro, RJ.

[17] MANKIW, Gregory, Introdução à Economia - Princípios de Micro e Macroeconomia (2 ed), Campus, 2005, Rio de Janeiro, RJ

[18] Maximiano, Antônio C. A., Teoria Geral da Administração - Da Revolução Urbana à Revolução Digital (3 ed), Atlas, 2002, São Paulo, SP.

[19] Microsoft, TechNet: Ferramenta de suporte on-line da Microsoft. Disponivel em <https://technet.microsoft.com/pt-br/library/ee624351.aspx>Acesso em: 17 de julho de 2015.

[20] Paiva, Manoel Rodrigues., Matemtica Paiva, Vol. 1, 2 e 3, Moderna, 2010, São Paulo, SP.

[21] POLYA, GeORGe., A arte de resolver problemas, Inferências, 2006, Rio de Janeiro, RJ.

[22] Simmons, George F., Cálculo com geometria analítica, Volume I, Makron Books, 1987, São Paulo, SP. 